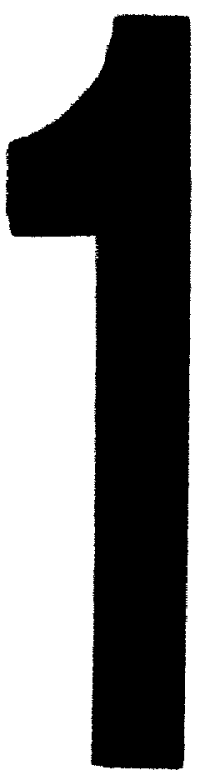

PM-1 3\%" $\times 4$ " PHOTOGRAPHIC MICROCOPY TAAGET NBS 1010a ANSI/ISO \#2 EOUIVALENT

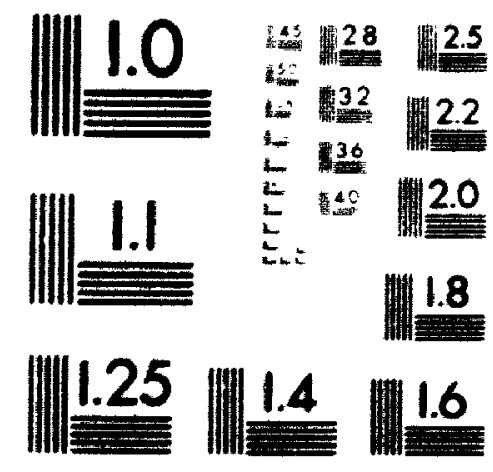


Acquisitions and

Bibliographic Services Branch

395 Weltington Street

Ottawa. Ontaro

KIA ONA

\section{du Canada}

Direction des acquisitions et

des services bibliographiques

395. rue Wellington

Otlawa (Ontarto)

KIA ONA

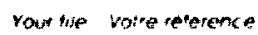

Our the Nowe reterence
NOTICE

The quality of this microform is heavily dependent upon the quality of the original thesis submitted for microfilming. Every effort has been made to ensure the highest quality of reproduction possible.

If pages are missing, contact the university which granted the degree.

Some pages may have indistinct print especially if the original pages were typed with a poor typewriter ribbon or if the university sent us an inferior photocopy.
La qualité de cette microforme dépend grandement de la qualité de la thèse soumise au microfilmage. Nous avons tout fait pour assurer une qualité supérieure de reproduction.

S'il manque des pages, veuillez communiquer avec l'université qui a conféré le grade.

La qualité d'impression de certaines pages peut laisser à désirer, surtout si les pages originales ont été dactylographicées à l'aide d'un ruban usé oll si l'université nous a fait parveni- une photocopie de qualité inférieure.

La reproduction, même partielle, de cette microforme est soumise à la Loi canadienne sur le droit d'auteur, SRC 1970, c. C-30, et ses amendements subséquents.
Reproduction in full or in part of thi . microform is governed by the Canadian Copyright Act, R.S.C. 1970, c. C-30, and subsequent amendments.

AVIS 


\title{
Interactive Design of Flexural Steel Members SuBJECTEd TO BENDING, AND Combined Bending And TORSION
}

\author{
by \\ Yuxiang He
}

\begin{abstract}
A thesis submitted to
the Faculty of Graduate Studies and Research

in the partial fulfillment of the requirements

for the degree of

Master of Engineering*
\end{abstract}
Department of Civil and Environmental Engineering Carleton Iniversity Ottawa, Canada
(C) Yuxiang He, April. 199:3

* The Civil Engineering Program is a joint program with University of Ottawa, administered by the Ottana-Carleton Institute for ("ivil Engineering. 
National Library

of Canada

Acquisitions and

Bibliographic Services Branch

395 Wellington Street

Ottawa, Ontano

K1A ON4
Bibliothdque nationale

du Canada

Direction des acquisitions et

des services bibliographiques

395. ne Wellington

Ottawa (Ontano)

KIA ONA
The author has granted an irrevocable non-exclusive licence allowing the National Library of Canada to reproduce, loan, distribute or sell copies of his/her thesis by any means and in any form or format, making this thesis available to interested persons.
L'auteur a accordé une licence irrévocable et non exclusive permettant à la Bibliotheque nationale du Canada de reproduire, prêter, distribuer ou vendre des copies de sa thèse de quelque manière of sous quelque forme que ce soit pour mettre des exemplaires de cette these à la disposition des personnes intéressées.

L'auteur conserve la propriété du droit d'auteur qui protège sa these. Ni la these ni des extraits substantiels de celle-ci ne doivent être imprimés ou autrement reproduits sans son autorisation.

ISBN $\quad 0-315-84131-1$ 
Nome Yuxiang He

Dissertation Abstracts International is arranged by broad, general subject categories. Please select the one subject which most nearly describes the content of your dissertation. Enter the corresponding four-digit cade in the spaces provided.

Civil

SUBECT TEM

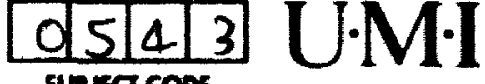
SUBEeC COOE
Subject Cologories

\section{THE MUMANITIS AND Social seitincts}

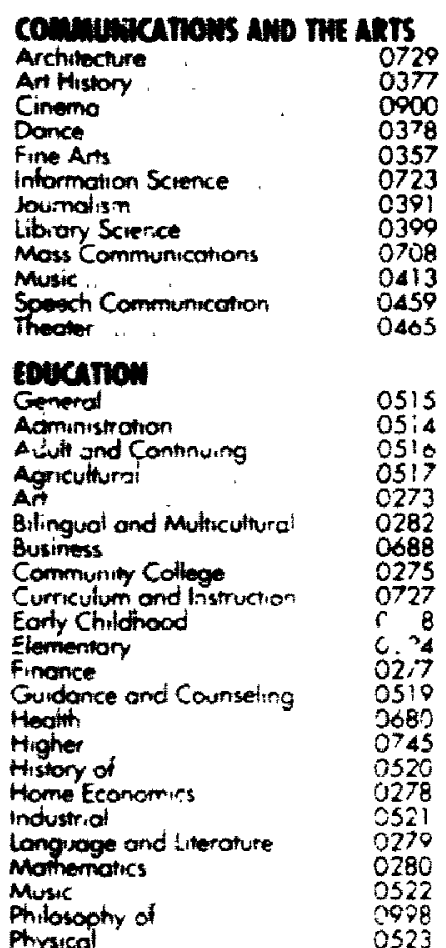

$\begin{array}{ll}\text { Psychology } & 0525 \\ \text { Reoding } & 0535 \\ \text { Relugrous } & 0527 \\ \text { Sciences } & 0714 \\ \text { Secondary } & 0533 \\ \text { Sociol Sciences } & 0534 \\ \text { Sociology of } & 0340 \\ \text { Speciol } & 0529 \\ \text { Tecther Troining } & 0530 \\ \text { Technotogy } & 0710 \\ \text { Tests ond Meosurements } & 0298 \\ \text { Vocational } & 0747\end{array}$

\section{UMCEACE, UTERATURE AMO} UNeustics

longuage

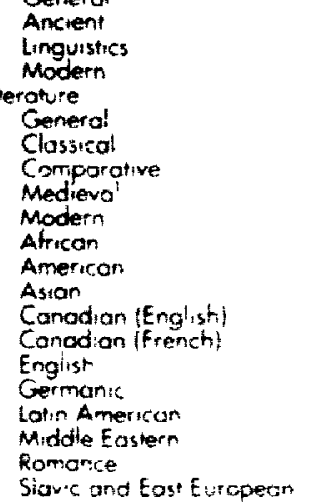

0679

0289

02901

0401

029

0295

0297

3298

C581

0,15

0.355

$035:$

0593

$03 \mathrm{i}$

03:5

$03: 3$

Physical

0523 milosomy, RelLeion ano

\section{miecloor}

Philosophy

Retigion

Bublical Studies

Clergy

History of

Philosophy of

Theotogy

soan somins

Americon Studies

Anthropology

Archoeglogy

Cutura:

Business Adminsstration

Generol

Accounting

Banking

Manogemen

Conodian Snudies

Fconomiss

General

Agricuhurol

Commerce Business

Finance

History

Labor

Fniklore

Geography

Gerontology

Geret
0422

0318

0319

0322

0468

0323

0324

0326
0327

0310

0272

0770

0454

0338
0385

0501

0503

0505

0508

0509

0510

0358

0366

035

0578

\section{min SeInMCES AND ENGINIZRING}

\section{molokel scances}

Agricuiture

Agronomy

Animal Cuture and

Nutrition

Animol fathology

Food Science ond

Fechnology

Piont Culture

Plont Pothology

Plont Physiotagy

Ronge Management

biotogr

Ely

Anotomy

Bopony

Cell

Ecology,

Entomology

Genetres

Lmmology

Molecular

Neviroscience

Oeconogrophy

Prytiogy

Podiation

Zoology

Biophrsucs

Genora:

0473

0285

0475

0476

0355

0478
0.79

0430

0017

0777

0746

0306

0287

0304

0379

0324

0353

0369

0793

0410

0317

0317

Dale

0433

0821

0778
0472

0,786

6760

cinis serinas

Brogeochemisty

0.25

0796
Geodesy

Goolugy

Mineralog

Poleobotony

Poleoecology

Poleontology

Patynoicay

Prysica! Geography

Physiral Oceonogrophy

HETT An Emmonnenta

\section{sctinas}

Environmental sciences $\quad 570 \hat{8}$

Heoint Scrences

General

Audiology

Chemotheropy

Dentistry

Hospital Monogement

Humun Developmen"

immunotogy

M56

Nursing 056

Nutrition

Obstetrics and Gynecology 0380

Occupotional Heolth and

Theropy 0354

Ophitholmology

Pothology

Pharmoxology

Pharmacy

Ptysical theropy

Pubik Mool

Recreation

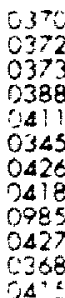

$A^{4}$

0506

5300

0567

0350

0769

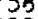

347

0570

0381

05719

0419
0572

0572
0382

0573

0574

0575
Hydrotogy

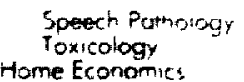

\section{Pursken satuces}

\section{Pure Scionces}

Cnemistiny

Generol

Anricultiva

Biochemsistry

Inorganic

Orgonic

Phormoceunical

Physteal

Podrotion

Mathenatics

Physics

General

Astronomy and

Astrophysics

Amospheric Sctence

Alomic

Electronics and $E_{1}$ - meristy

Elementory Part

Flud

Molecular

Nucleor

Optics

Rodiotion

Sictisties

Applind Sciences

Applied Macrianics

Computer Science
0460
0383

0380

0485

0748

0486

048

0488

0490

049

0494

0495

0754
0405

0.05

0986

0606

$(1608$

0748

$060 \%$

0798

$075 \%$

0609

0610

0752

0756

0611

0463

0346

0984

Ancient 0579

Medieval 0581

Modern 0582

Btock $\quad 0328$ 
Department of Civil and Environmental Engineering

The Undersigncd recommend to the Faculty of Graduate Studies and Research acceptance of the thesis

"Interactive Design of Steel Members Subjected to Bending, and Combined Bending and Torsion"

Submitted by Yuxiang He

in partial fulfilment of the requiements for the degree of Master of Engineering
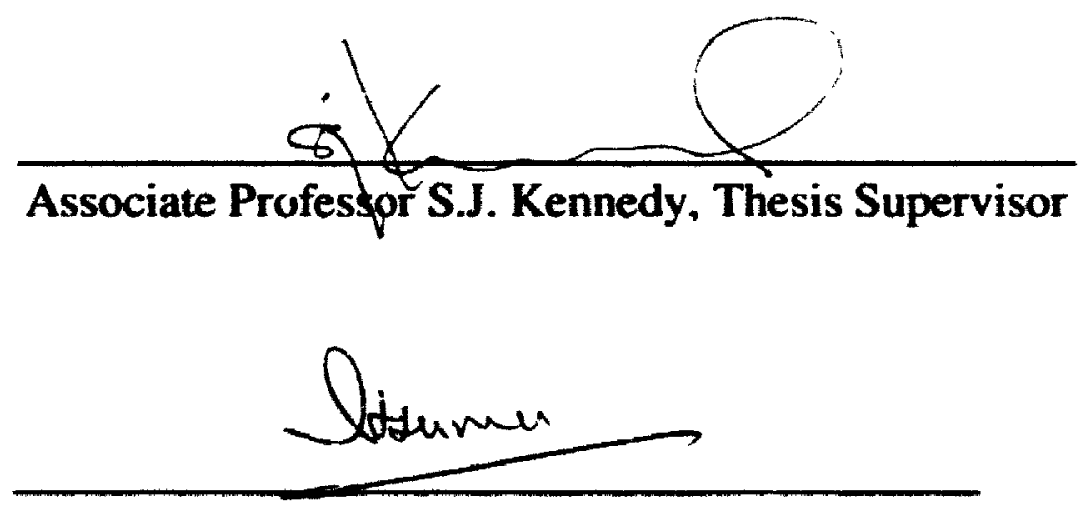

Professor J.L. Humar, Chair

Department of Civil and Environmental Engineering

Carleton University

April 28, 1993 


\section{Abstract}

This thesis describes a state-of-the-art graphics-oriented computer program IDFSM for Interactive Design of Flexural Steei Members Subjected to Bending, and Combined Bending and Torsion. Unlike existing computer software, which provide limited design rules with respect to lateral stability, IDFSM includes analytical and design procedures that take into account the effect of the type of lateral support, the type and point of application of the load, copes and the influence of interactive buckling on the lateral-torsional buckling capacity. Bearing stiffeners are automatically designed when required. IDFSM provides the structural engineer with solution strategies of different levels of sophistication to handle simple well defined problems and the most complex lateral stability problems as well. IDFSM has the capacity to analyze and design steel beams subjectéd to both flexural and torsional loads. IDFSM will either perform comprehensive design checks for a user specified beam, or an automatic design to obtain the least weight section that meets all the design constraints. An all mouse-driven menu and fully graphical input screen enable the structural engineer to produce, with little effort, 3D configurations of real members with realistic boundary conditions, lateral bracing and connections for systems like the Gerber system. These configurations, along with the loading conditions may be edited graphically as further refinements are required. High quality moment, shear and torque diagrams and deflection shapes along the member will be displayed graphically for each load combination. An inquiry system allows the user to obtain different levels of report, including intermediate calculations, design criterion and design strategies. IDFSM currently runs on Sun workstation and $\mathrm{X}$-Window systems and has been designed to work on PC's and other system evironments. IDFSM is programmed in $\mathrm{C}++, \mathrm{C}$ and FORTRAN programming languages along with HOOPS graphics user interface package. 


\section{Acknowledgements}

I would like to express my gratitude to the thesis supervisor, Dr. S.J. Kennedy for his invaluable guidance and generous suggestions throughout the course of this work. Ilis effort of enhancing computer environment within the Department of Civil and Environmental Engineering at Carleton University by providing more workstations is highly appreciated.

Special thanks go to the following persons who contributed to the development of the program IDFSM: Dr. N. Holtz who provided the routines to access the CISC section data base, D.B. Marshall who provided the user interface routines for CISC section tables, Dr. D.W. Mirray who provided the program PLFRAM and X. Zeng who provided the basic routine for calculations of torsional properties.

I wish to thank the individuals at Carleton University who through their help, have given me a good understanding of the application of computers.

Finally the author takes this opportunity to express his deepest appreciation to his wife June for her encouragement and understanding throughout my studies. This thesis is dedicated to her. 


\section{Contents}

$\begin{array}{ll}\text { Abstract } & \text { ii }\end{array}$

Acknowledgements

Contents $\quad$ iv

$\begin{array}{ll}\text { List of Figures } & \text { ix }\end{array}$

List of Tables $\quad$ xiv

List of Symbols $\quad$ xvi

1 INTRODUCTION 1

1.1 General Background . . . . . . . . . . . . . . . 1

1.2 Steel Beam Design: Still A Challenge . . . . . . . . . . . 2

1.3 An Innovative Approach in CAD Systems $\ldots \ldots \ldots \ldots$

1.4 Objectives and Scope of Present Work $\ldots \ldots \ldots \ldots$

2 COMPUTER AIDED MEMBER DESIGN PROCESS AND A DESCRIPTION OF THE CORRESPONDING USER INTERFACE 7

2.1 General . . . . . . . . . . . . . . . . 8

2.2 Selection of An Existing Job or Creation of A New Job . . . . . 10

2.3 Structural System . . . . . . . . . . . . . . . 13 
2.4 Definition of Member Length, and Section Type and Size . . . . . . 15

2.5 Support, Stiffeners and End Coping Definition . . . . . . . . . 18

2.5.1 In-plane support ................... 18

2.5 Lateral support . . . . . . . . . . . . . . . 20

2.5.3 Definition of end coping details and bearing stiffeners . . . . . 23

2.6 Applied Load Description . . . . . . . . . . . . . 26

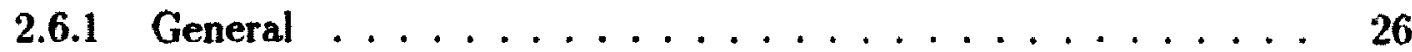

2.6.2 Semi-automatic load definition for lateral supported points . . 27

2.6.3 Additional transverse/torsional load definition . . . . . . . 28

2.6.4 Load combinations ................. 34

2.6.5 Return to main menu .................. 35

2.7 Determination of Internal Forces and Deflections . . . . . . . . . 36

2.8 Design Constraints and Solution Strategies . . . . . . . . . . . 37

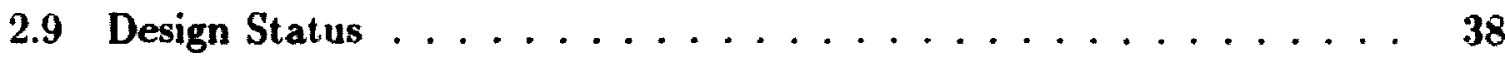

2.10 Representation of Design Results . . . . . . . . . . . . . 39

2.10.1 On screen display . . . . . . . . . . . . . . . . 39

2.10 .2 Output files . . . . . . . . . . . . . . 40

3 ANALYSIS MODELLING 42

3.1 Module PLFRAM . . . . . . . . . . . . . . . . 42

3.2 Analysis for Torsion and Bending . . . . . . . . . . . 45

3.2.1 General procedure .................. 45

3.2.2 Torsional solution .....................45

3.2.3 Program implementation . . . . . . . . . . . . . 48

4 MEMBER DESIGN

4.1 Introduction . . . . . . . . . . . . . . . . 53

4.2 Classification of Sections . . . . . . . . . . . . . 53 
4.3 Cross-Section Strength $\ldots \ldots \ldots \ldots \ldots \ldots$

4.4 Shear Capacity for Beam . . . . . . . . . . . . . 55

4.5 Lateral-Torsional Buckling Strength . . . . . . . . . . 56

4.5 .1 General . . . . . . . . . . . . . . . 56

4.5 .2 Assumptions . . . . . . . . . . . . 57

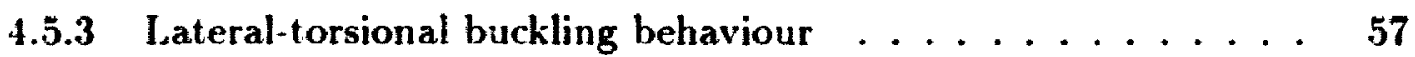

4.5.4 Review of different solution strategies . . . . . . . . 60

4.5.5 Lateral support types . . . . . . . . . . . . . 67

4.5.6 Laterally unsupported length determination . . . . . . . 69

4.5.7 Special treatment for cantilever beams and the cantilever portion of overhanging beams $\ldots \ldots \ldots \ldots \ldots \ldots$

4.5 .8 Effect of end coping . . . . . . . . . . . . 74

4.5.9 Applications of different solution strategies . . . . . . 77

4.6 Limit States Design for Beams Subjected to Combined Bending and Torsion . . . . . . . . . . . . . . . . 80

4.6.1 Description of moment-torque interaction diagrams -ultimate limit state .................... 80

4.6.2 Serviceability limit state . . . . . . . . . . 85

4.6.3 Application of the Driver and Kennedy approach ..... 86

4.6.4 Implementation of torsion evaluation into IDFSM $\ldots . . .95$

4.7 Bearing Stiffeners . . . . . . . . . . . . . . 96

4.7 .1 Local web stability . . . . . . . . . . . . 96

4.7 .2 Automatic design for bearing stiffeners $\ldots \ldots \ldots . \ldots 98$

4.8 Deflection and Camber Requirements . . . . . . . . . 100

4.8.1 Vertical deflections . . . . . . . . . . . . 100

4.8 .2 Lateral deflections $\ldots \ldots \ldots \ldots \ldots \ldots$

4.9 Determination of the Optimum Section Size $\ldots \ldots \ldots 101$ 
4.10 Design Module Structure . . . . . . . . . . . . . . 107

5 INTERACTIVE CAD SYSTEM FOR FLEXURAL MEMBER DESIGN $\quad 110$

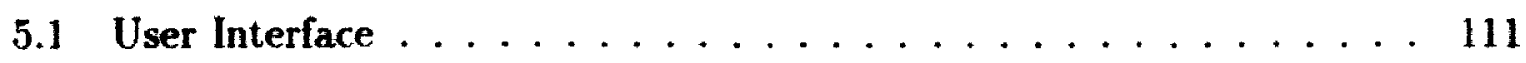

5.2 Integration . . . . . . . . . . . . . . . . 114

5.2.1 Design of stand alone program for an integrated system . . . 114

5.2.2 Flexural member design program as an integrated application 116

5.3 Portability ...................... 116

6 PROGRAM STRUCTURE 118

6.1 General Information . . . . . . . . . . . . . 118

6.2 System Requirements . . . . . . . . . . . . . . . . . . 119

6.3 Program Installation and File Structure . . . . . . . . . 120

6.4 Program Execution . . . . . . . . . . . . . . . . . 122

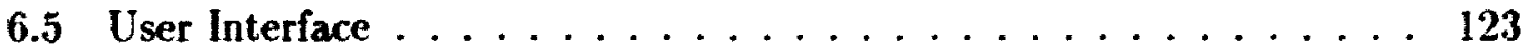

6.6 Updating IDFSM $\ldots \ldots \ldots \ldots \ldots \ldots \ldots \ldots \ldots \ldots$

6.7 Program Modules . . . . . . . . . . . . . . . . 126

6.7 .1 Major modules . . . . . . . . . . . . 126

6.7.2 Corresponding programming routines for modules . . . . . 126

6.7 .3 Structure of graphic data . . . . . . . . . . 126

7 ILLUSTRATED EXAMPLE PROBLEMS 134

7.1 Moment Capacity for Laterally Supported Bearn . . . . . . . . . 134

7.2 Moment Capacity for Laterally Unsupported Beam . . . . . . . . 137

7.3 Laterally Unsupported Beam Using Different Solution Strategies for Evaluation of Moment Resistance . . . . . . . . . . . . 139

7.4 Laterally Unsupported Coped Beam . . . . . . . . . . . . . 143 
7.5 Cantilever Beam $\ldots \ldots \ldots \ldots \ldots \ldots \ldots \ldots \ldots$

7.6 Beam Laterally Supported Along Entire length of the Top Flange . . 150

7.7 Laterally Insupported Overhang Beam with Various Load Combinations 155

7.8 Laterally Unsupported Beam with Combined Bending and Torsional

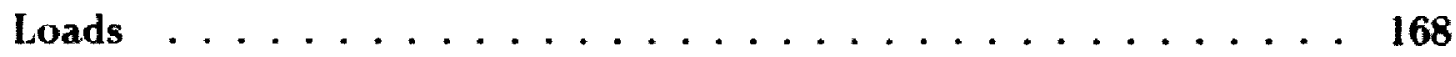

7.9 Laterally Unsupported Beam with Combined Bending and Torsional Load of Different Patterns . . . . . . . . . . . . . 171

7.10 Combined Bending and Torsional Loading within a Laterally Unsupported Segment . . . . . . . . . . . . . . . 175

8 CONCLUSIONS, RECOMMENDATIONS AND FUTURE WORK179 8.1 Conclusions . . . . . . . . . . . . . . . 179

8.2 Recommendations and Future Work . . . . . . . . . 180

g REFERENCES 182 


\section{List of Figures}

1.1 Screen of design parameter definition, Beam and Column Design (ECOM

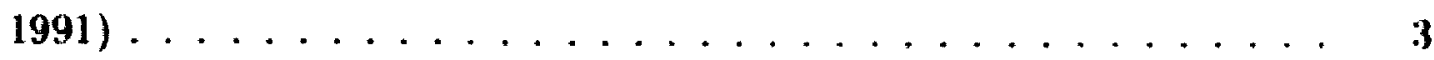

1.2 A typical IDFSM screen of interactive user interface . . . . . . . j

2.1 Main menu screen of the program IDFSM $\ldots \ldots \ldots$

2.2 Front page of the program IDFSM $\ldots \ldots \ldots \ldots$

2.3 New job definition screen . . . . . . . . . . . . . . 11

2.4 Job catalog listing . . . . . . . . . . . . . . . . 12

2.5 Structural system selection screen: Gerber Girder $\ldots \ldots \ldots \ldots$

2.6 Structural system selection screen: Beam to Girder/Column . . . . 14

2.7 Member length, section type and size definition screen . . . . . 15

2.8 Member length definition screen $\ldots \ldots \ldots \ldots \ldots \ldots$

2.9 In-plane support definition screen $\ldots \ldots \ldots \ldots \ldots \ldots$

2.10 Lateral support definition screen $1 \ldots \ldots \ldots 20$

2.11 Lateral support definition screen $2 \ldots \ldots \ldots \ldots$

2.12 Lateral support definition screen $3 \ldots \ldots \ldots . \ldots . \ldots 2$

2.13 Cope(s) and bearing stiffener(s) definition screen . . . . . . . 23

2.14 Load definition screen $1 \ldots \ldots \ldots \ldots \ldots$

2.15 Load definition screen $2 \ldots \ldots \ldots \ldots \ldots . \ldots \ldots$

2.16 Load definition screen 3: Load type definition . . . . . . . . 28 
2.17 Load definition screen 4 : Location of load $\ldots \ldots \ldots \ldots$

2.18 Load definition screen 5: Load eccent ricity . . . . . . . . . . 31

2.19 Load definition screen 6: Load value . . . . . . . . . . 32

2.20 Load definition screen 7 : Dead load summary $\ldots \ldots \ldots \ldots$

2.21 Load definition screen 8: Load factors . . . . . . . . . . . . 34

2.22 Screen for displaying of internal force diagrams and deflected shapes 36

2.23 Screcn for "Member Evaluation and Results" . . . . . . . . . 39

3.1 Block diagram for incorporating PLFRA.II module . . . . . . . 44

3.2 General orientation of member in to:sion, AISC (1983), p.6 . . . 46

3.3 Torsional boundary conditions and schematic representation of the corresponding structural connertion, AISC (1983), p.10 . . . . . 49

3.4 Various torsional loadings and end conditions. AISC (1983), p.26 . . 50

3.5 Solutions for different torsional loadings and boundary conditions. AISC

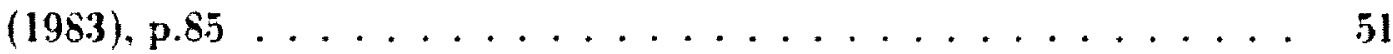

3.5 Solutions for different torsional loadings and boundary conditions (Con-

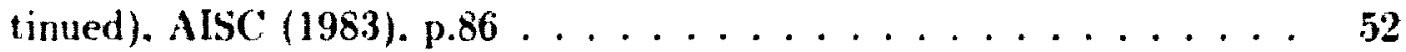

4.1 Lateral buckling of an I-section under uniform moment . . . . . . 58

4.2 Mement diagram between two laterally $\mathrm{su}_{\mathrm{r}-\mathrm{-}}$-rted points for determi-

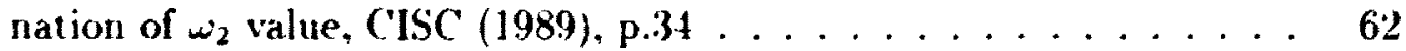

4.3 Beam with discrete lateral supports . . . . . . . . . 66

1.‡ Lateral support types . . . . . . . . . . . . . . . . . 68

4.5 Laterally unsupported length and load configurations . . . . . . 70

4.6 Laterally unsupported cantilever beam with different load combinations 72

4.7 Copes and stiffeners definition menu $\ldots \ldots \ldots \ldots \ldots$

4.8 Moment-torque interaction diagram for (lass 1.2 sections, Fig. 17, Driver and kennedy (1989) $\ldots \ldots \ldots \ldots \ldots$ 
4.9 Moment-torque interaction diagram for Class 3 sections, Fig. 18, Driver and Kennedy (1989) . . . . . . . . . . . . . . 82

4.10 Beam to beam configuration . . . . . . . . . . . . . . . 90

4.11 OWSJ's to beam configuration . . . . . . . . . . . . . . . . 92

4.12 Examples illustrating design limitations and boundary conditions for beams with lateral unsupported segments . . . . . . . . . . . . 94

4.13 Program block diagram for design of beams subjected to combined bending and torsion . . . . . . . . . . . . . . 95

4.14 Definitions of bearing lengths and types . . . . . . . . . . . 97

4.15 Shape and section groupings for the optimization procedure . . . . 103

4.16 Illustration of logic of direct search method . . . . . . . . . . . . . 105

4.16 Illustration of logic of direct search method (Continued) . . . . . . 106

4.17 Block diagram for the module TORSTEEL . . . . . . . . . . 108

4.18 Block diagram for the module BEAM_DESIGN . . . . . . . . . 109

5.1 Graphics-assisted entry ................... 112

5.2 Instant response to the data entry . . . . . . . . . . . . 113

6.1 Typical IDFSM screen regions and the corresponding HOOPS segments 124

6.3 Module related routines . . . . . . . . . . . . . 129

6.3 Module related routines (Continued) . . . . . . . . . . . 130

6.3 Module related routines (Continued) . . . . . . . . . . . 131

6.3 Module related routines (Continued) . . . . . . . . . . . . 132

6.4 HOOPS segment tre within IDFSM ............. 133

7.1 Loads and geometry: Example provlem 1 . . . . . . . . . 135

7.2 Design result screen: Example problem 1 . . . . . . . . . 136

7.3 Loads and geometry: Example problem 2 . . . . . . . . . . . 137 
7.t Design result screen: $\mathbf{b}$-ample problem $2 \ldots \ldots \ldots$

7.5 Loads and geometry: Example problem 3 ... Illustration of different solution strategy options for evaluating the moment capacity . . . . 139

7.6 Different solution strategy options for evaluating moment capacity (extracted from the main menu screen) $\ldots \ldots \ldots \ldots$

7.7 Design result: User specified solution $\ldots \ldots \ldots \ldots$

T.8 Loads and geometry: Example problem 4 . . . . . . . . . . 144

7.9 Coping definition screen $\ldots \ldots \ldots \ldots \ldots \ldots \ldots$

7.10 Design results: Laterally unsupported coped beam . . . . . . . . 145

7.11 Loads and basic geometry: Cantilever beam . . . . . . . . . 14i

7.12 Lateral support provided to the top flange at the load point $\ldots . .148$

7.13 Lateral support provided to both the top and bottom flanges at the load point (OWSJ's with a bottom chord extension) . . . . . . 148

T.14 Lateral support provided along the beam length (both top and bottom flanges $\ldots \ldots \ldots \ldots \ldots \ldots \ldots \ldots \ldots \ldots$

7.15 Load and geometry: Beam laterally supported along top flange only . 151

7.16 Design result: V'ser specified solution . . . . . . . . . 153

7.17 Moment diagram showing points of moment inflections $\ldots \ldots \ldots 154$

7.18 General design conditions, CISC (1989), p.8 $\ldots \ldots \ldots \ldots$

7.19 Load combinations . . . . . . . . . . . . . . 157

7.20 Specified dead loads (Load Case 1) . . . . . . . . 157

7.21 Specified wind and snow load (Load Case 2 and 3) $\ldots \ldots 158$

7.22 Load Case 4: Full snow load on cantilevers and half load on main span Load Case 5: Half snow load on cantilevers and full load on main $\operatorname{span} \ldots \ldots \ldots \ldots \ldots \ldots \ldots \ldots \ldots \ldots$

7.23 Design option screen $\ldots \ldots \ldots \ldots \ldots$

7.24 Bending moment diagrams, for load combinations 1 and $2 \ldots 160$ 
7.25 Bending moment diagrams, for load combinations 3 and $4 \ldots \ldots$

7.26 Shear force diagrams, for load combinations 1 and $2 \ldots \ldots 161$

7.27 Shear force diagrams, for load combinations 3 and $4 \ldots \ldots 161$

7.28 Deflected shapes, for the specified dead and live loads from load com-

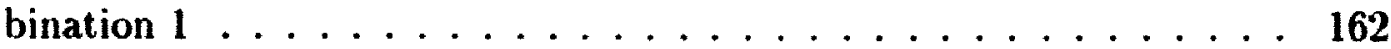

7.29 Deflected shapes, for the specified live loads from load combinations 2

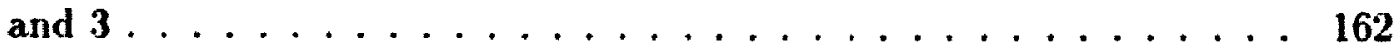

7.30 Deflected shapes, for the specified live ioads from load combination $4 \quad 163$

7.31 Design check: W410x74 section $\ldots \ldots \ldots \ldots$

7.32 Automatic redesign . . . . . . . . . . . . . . 164

7.33 Loads and geometry: Combined bending and torsion $\ldots \ldots \ldots 168$

7.34 Torque dia jram . . . . . . . . . . . . . . . . . 169

7.35 Design results: Combined bending and torsion . . . . . . . . 169

7.36 Moment-torque diagram for class 1 sections $\ldots \ldots \ldots \ldots$

7.37 Load and geometry: Combined bending and torsion with different load patterns ........................... 171

7.38 Torque diagrams $\ldots \ldots \ldots \ldots \ldots \ldots \ldots \ldots \ldots$

7.39 Design result: Combined bending and torsion with different load patterns172

7.40 Loads and geometry: Combined bending and torsion on a laterally unsupported segments $\ldots \ldots \ldots \ldots \ldots \ldots \ldots$

7.41 Torque diagram . . . . . . . . . . . . . . 177

7.42 Design result: Combined bending and torsion on a laterally unsupported segment $\ldots \ldots \ldots \ldots \ldots \ldots \ldots \ldots \ldots \ldots$ 


\section{List of Tables}

2.1 Output file formats $\ldots \ldots \ldots \ldots \ldots \ldots \ldots$

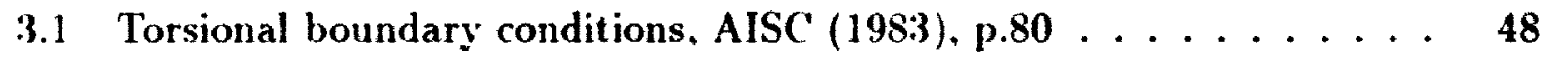

4.1 Width-thickness ratios for section classification . . . . . . . 54

4.2 Effective length factors $K$ for cantilevers. Galambos(1988), p.168 . . 64

4.3 Determination of lateral restraints and effective lengths for cantilever beam with more than one lateral support $\ldots \ldots \ldots \ldots \ldots$

4.4 Design options. . . . . . . . . . . . . . . . 78

4.5 Solution strategies available in the program IDFSM . . . . . . 79

4.6 Bases for determining limiting values of moments and torques, Table 4, Driter and Kennedy (1989) . . . . . . . . . . . . . 81

4.7 Warping facter, $K$, Table 3 , Driver and hennedy $(1989) \ldots \ldots$

7.1 Solution comparison: Example problem $1 \ldots \ldots \ldots \ldots$

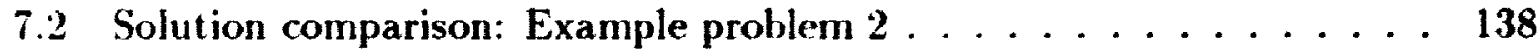

7.3 Solution comparison: Different solution strategy options $\ldots \ldots \ldots$

7.4 Solution comparison: Effect of end coping conditions with a cope length of $150 \mathrm{~mm} \ldots \ldots \ldots \ldots \ldots \ldots \ldots \ldots$

7.5 Solution comparison: Effect of end coping conditions with a cope length of $300 \mathrm{~mm} \ldots \ldots \ldots \ldots \ldots \ldots \ldots \ldots$ 
7.6 Solution comparison: Different lateral support conditions . . . . . 150

7.7 Design results and applicable solution strategies . . . . . . . 154

7.8 Load combinations and the corresponding Load conditions . . . . 155

7.9 Summary of design results $\ldots \ldots \ldots \ldots \ldots \ldots$ 


\section{List of Symbols}

A Area

B Bearing force in a member or component under factored load

$B_{r} \quad$ Fartored bearing resistance of a member

b Width of a section flange

$C_{w}$ Warping torsional constant

D Dead load

d Depth of beam

E Elastic modulus of steel, $200000 \mathrm{MPa}$

e Eccentricity of a torsional load

$F_{s} \quad$ Cltimate shear stress

$F_{y} \quad$ Yield strength

$F_{u} \quad$ Specified minimum tensile strength

G Shear modulus of steel, $700000 \mathrm{MPa}$

$I_{x}$ Moment of inertia of strong axis (X-axis)

$I_{y} \quad$ Moment of inertia of weak axis ( $Y$-axis)

J St. Venant torsionAL constant

K Effective length factor

KL Effective length

k Distance from outer face of flange to web-toe of fillet of 1-shaped sections

L. Length; Live load

$M_{f}$ Bending moment in a member under factored load 
Mp Plastic moment

$M_{y} \quad$ Yield moment

$M_{u}$ Ultimate moment of a unbraced beam

R End reaction or concentrated transverse load applied to a flexural member

S Elastic section modulus of a steel section

$T_{f}$ Torque in a member under factored load

$T_{r} \quad$ Ultimate resistance torque of a member

$T_{y} \quad$ Limiting torsional moment that causes first yield

$T_{y p}$ Plastic limiting torsional moment based on fully inelastic behaviour, but with maximum stresses taken at the yield level

$T_{u}$ Torsional moment based on fully inelastic behaviour with maximum stresses taken at the ultimate tensile strength level

t Thickness of flange

$V_{f}$ Shear force in a member under factored load

$V_{r} \quad$ Factored shear resistance of a member

w Web thickness

Z Plastic section modulus of a ste el section

$z$ Distance from the left end of a member

a Load factor

$\lambda$ Nondimensional slenderness ratio in column formula

$\phi \quad$ Resistance factor of a member; angle of twist

$\omega_{2}$ Coefficient to account for increased moment resistance of a laterally unsupported beam segment when subject to a moment gradient

Note: The above symbols are general symbols used throughout this thesis. Additional nomenclature will be noted where they appear. 


\section{Chapter 1}

\section{INTRODUCTION}

\subsection{General Background}

In recent years the Civil Engineering profession has witnessed a broad acceptance of the concept of computer-aided structural engineering. Attractive advertisements describing the "state-of-the-art" programs claim to do wonderful things such as integrated analysis, design, detailing and shop drawing and are often illustrated in the professional magazines. Nevertheless, this is still a critical time for the software developers. As the evolution of hardware and underlying software is continuing, there is a need to develop better software on all platforms of operating systems and there is still a need to take advantages of continuing development of structural engineering knowledge to obtain correct estimates of member resistances and load effects by using a computer-aided approach.

This thesis addresses several important aspects of computer-aided structural engineering by presenting a comprehensive interactive computer program for the analysis and design of flexural steel members which demonstrates the trend of a new generation of software. 


\subsection{Steel Beam Design: Still A Challenge}

Beams and girders are one of the most commonly used members in structural steel buildings. The design of these members as programmed by commercial software is generally inadequate or incomplete.

In some cases, software developers oversimplify some of the design parameters in order to claim increased scope and number of attributes of their analysis and design programs. Figure 1.1 shows a screen of one of the major commercial member design software currently on market, Beam and Column Design, by ECOM Associates, USA, (1991). It can be seen that Braced Length is the only parameter defined directly associated with the evaluation of the lateral-torsional buckling capacity. In this thesis, it is demonstrated that certain parameters such as the type of the lateral support, the shape of the moment diagram, the end coping of the member and other factors have to be considered to obtain a good estimation of the capacity of the member concerned. In other cases, the commercial software can not always perform the the function as described in the documentation or indicated by their title. The "Advanced Integrated Beam Design Program" by Engineering Software Company, can only analyze continuous beams for one load case, Rahimian (1992). The design capability of the program are limited and not clearly described.

Generally, most commercial software programs use the rules explicitly given in the design standard. These are minimum requirements and in sol ce cases the standard refers to external references such as the Structural Stability Research Council's Guide to Stability Design Criteria for Metal Structures, Galambos (1988), for further guidance to solve more complex, often realistic problems. Such problems include Gerber system (Cantilever-link beam systems), see Clause 13.6 (c), CAN/CSA S16.1-M89; bending of monosymmetric shapes, see Clause 13.6(d), CAN/CSA S16.1-M89; and bending and torsion, see Clause 15.11, CAN/CSA S16.1-M89. The appropriate de- 


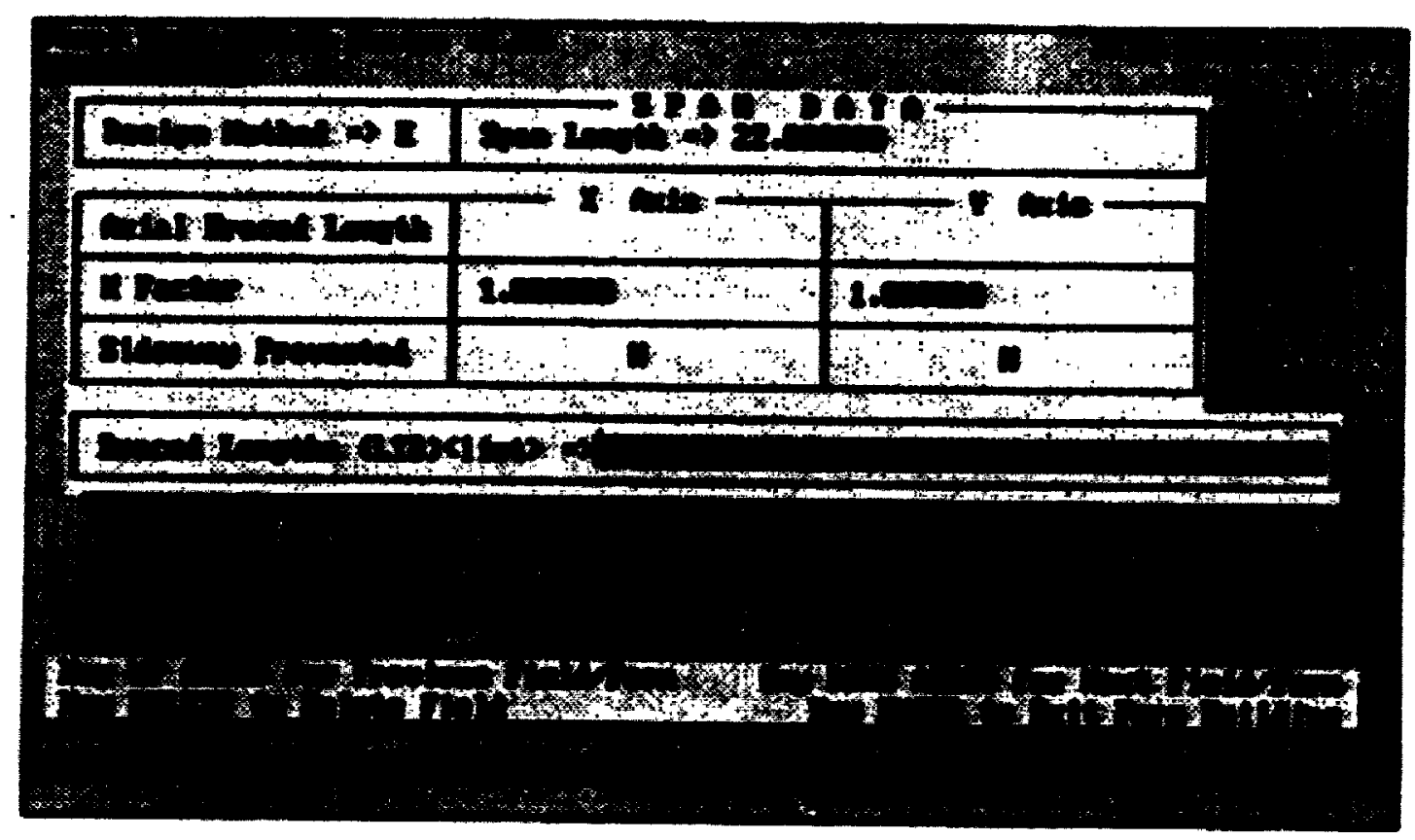

Figure 1.1: Screen of design parameter definition, Beam and Column Design (ECOM 1991)

sign rules described in these references have also to be incorporated in member design programs.

Furthermore, it is risky to use some commercial software in which only limited technical explanation is given and thus there is no way to verify if the design procedures adopted are appropriate or not, i.e. "black box". The authors of the structural analysis and design package, SODA, (Structural Optimization Design \& Analysis), W.E.S., (1992), claim that the design generated is satisfactory according to CAN/CSA-S16.1-M84 and that the members are selected to be of least weight. A technical explanation of the algorithm for the optimization process for the least weight criteria is not given. It is not possible, except through hand computations, for the user to verify if the optimum solution has been determined. For beam design, the 
program checks cross-sectional strength, lateral-torsional buckling capacity for one fixed braced length and live load deflection. Gerber system, beams subjected to load combinations that produce different unsupported lengths, beam with copes and/or different, lateral supports, and beams that are subjected to torsion can not be designed by using this program. This severely limits its use in practical cases.

Therefore, it is still a challenge to develop a reliable and technically complete program in this area that addresses all the concerns as described.

\subsection{An Innovative Approach in CAD Systems}

Many CAD systems provide the basic functionality required by designers with little consideration of the development of graphics-oriented data structure and user friendly interfaces that model the design process, Anumba and Watson (1992). These must be considered in the development of the system to achieve an effective program.

The increasing and aitimately dominant use of the computers for all analysis, design and drafting proress will demand radically new approaches to structural software design. One approach is to use interactive graphical methods for data input and output. The term "interactive graphics" is not clearly defined and often is used loosely when describing the attributes of a CAD systems. Some software described as interactive, actually consists of a graphics screen display for conventional numeric data input next to a representative figure (beam, column, structural frame or section) which does not respond to changes in the numbers. The reverse is more common, the program presents a figure with pertinent values noted, but does not have the capacity of changing the values on the screen, Brohn, (1992). An interactive graphics program is not just for ease of use, it should be designed to promote understanding of structural behaviour and it should feed back the information graphically required for verification and for checking the design, Brohn, (199?). Figure 1.2 shows a typical 


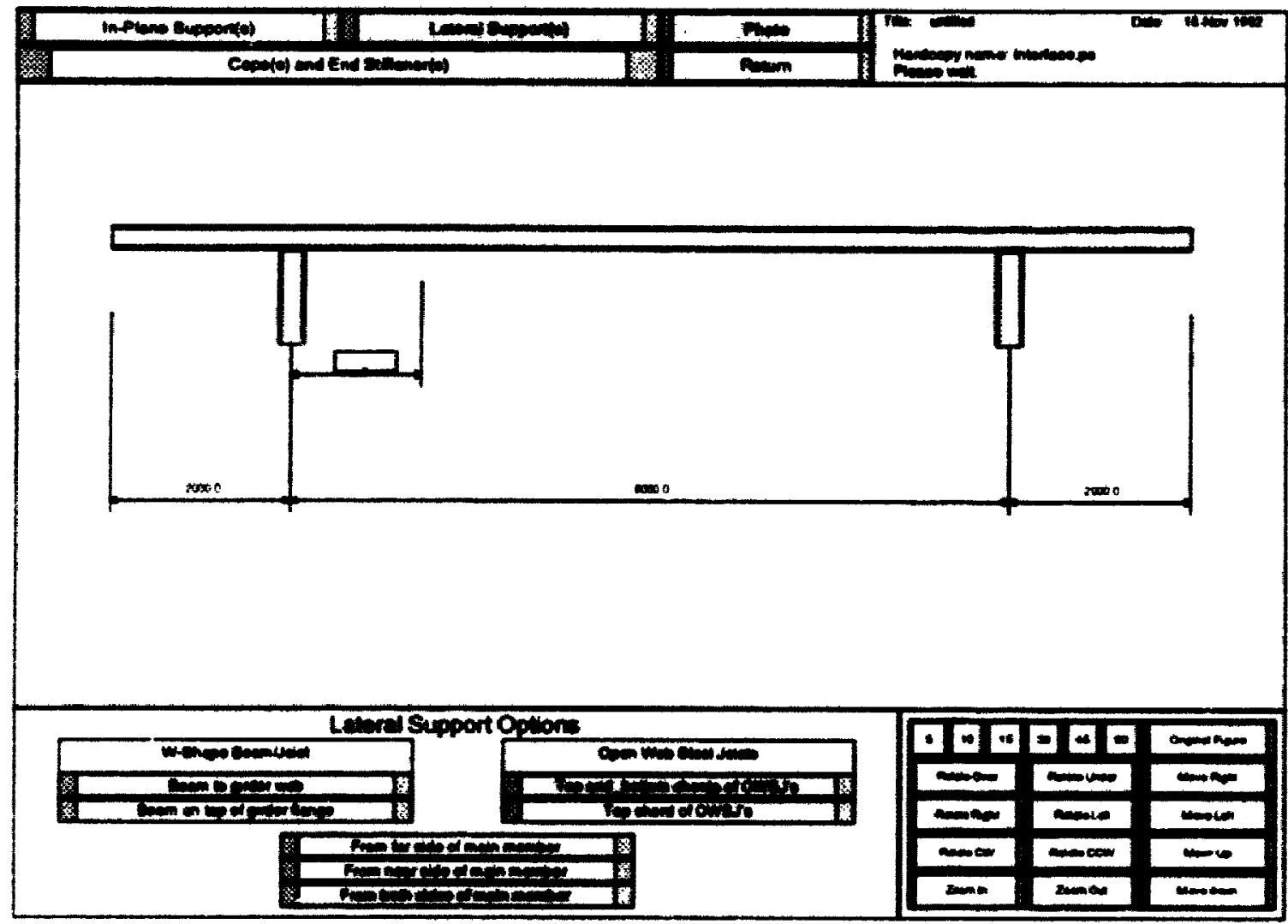

Figure 1.2: A typical IDFSM screen of interactive user interface

user interface of the program IDFSM, which meets the requirements of interactive graphic CAD systems.

\subsection{Objectives and Scope of Present Work}

The present work serves as part an of effort to develop a state-of-the-art integrated system of modelling, analysis, design and detailing for steel structures. The interactive graphic program module, IDFSM, for Interactive Design of Flexural Steel Members Subjected to Bending, and Combined Bending and Torsion, performs a first-order elastic analysis and designs of single span beams and overhanging beams with any prescribed boundary conditions for any combination of in-plane bending and torsional 
loadings. The beam is designed in accordance with CAN/CSA-S16.1-89 and the appropriate rules outlined in the Structural Stability Research Council's Guide to Stability Design Criteria for Metal Structures, Galambos (1988). Particular attention has been made to the detailed evaluation of lateral-torsional buckling capacity of the flexural members, taking account different in-plane and lateral supports, end coping, load patterns and torsional loadings. This has been coupled with a high lever graphical user interface for defining, editing, interpreting and illustrating the design data. Scaled three dimensional structural member images are illustrated throughout the entire design process. The program IDFSM has been developed to function as an independent module and has also been designed to be integrated with a larger system for the analysis, design and detailing of steel structures. The program IDFSM can also be used as a research and teaching aid in structural engineering. 


\section{Chapter 2}

\section{COMPUTER AIDED MEMBER DESIGN PROCESS AND A DESCRIPTION OF THE CORRESPONDING USER INTERFACE}

This chapter describes the member design process enployed by the program IDFSM, which molel that followed by structural onginers and gives the structural enginere Ho caparity io address strength. serviceability: architectural and economic limitations. Becature of the graphirs-oriented nature of the program IDPSM. each of these sepe in the denign process has its own reprement at ion in the form of a displayed screen or wincow. Which is cont rolked by the butlons (menu items) of the same or higher level. The design process. including limitations. will be described step by step along with the correnponding divplased sereeno or sindows. 


\subsection{General}

The member design process employed in program IDFSM consists of the following steps:

1. Selection of an existing job or creation of a new job.

The selection of an existing job implies that a file structure has been created to describe a tlexural problem and demonstrates the program potential to he integrated subsequently into a general program for the design of steel structures.

2. Definition of the type of flexural member (Structural system, i.e. Gerber system, Bram to Girder/Column. OW'S.'s, Plate Girder, Stub Girder or Floor).

3. Definition of section type and size, and member length.

4. Definition of in-plane and lateral supports, and stiffener and coping details.

5. Definition of loads and load combinations.

6. Selection of predefined design constraints (i.e. camber for dead load. deflection limitation, maximum member depth and minimum member width).

7. Selection of the appropriate solution strategy.

8. Flastic analysis and review of internal force distributions and deflected shapes.

9. Design check of an existing flexural member or an automatic design.

10. Review of design results and redesign with varied design parameters.

11. Production of engineering report (design notes and figures). 


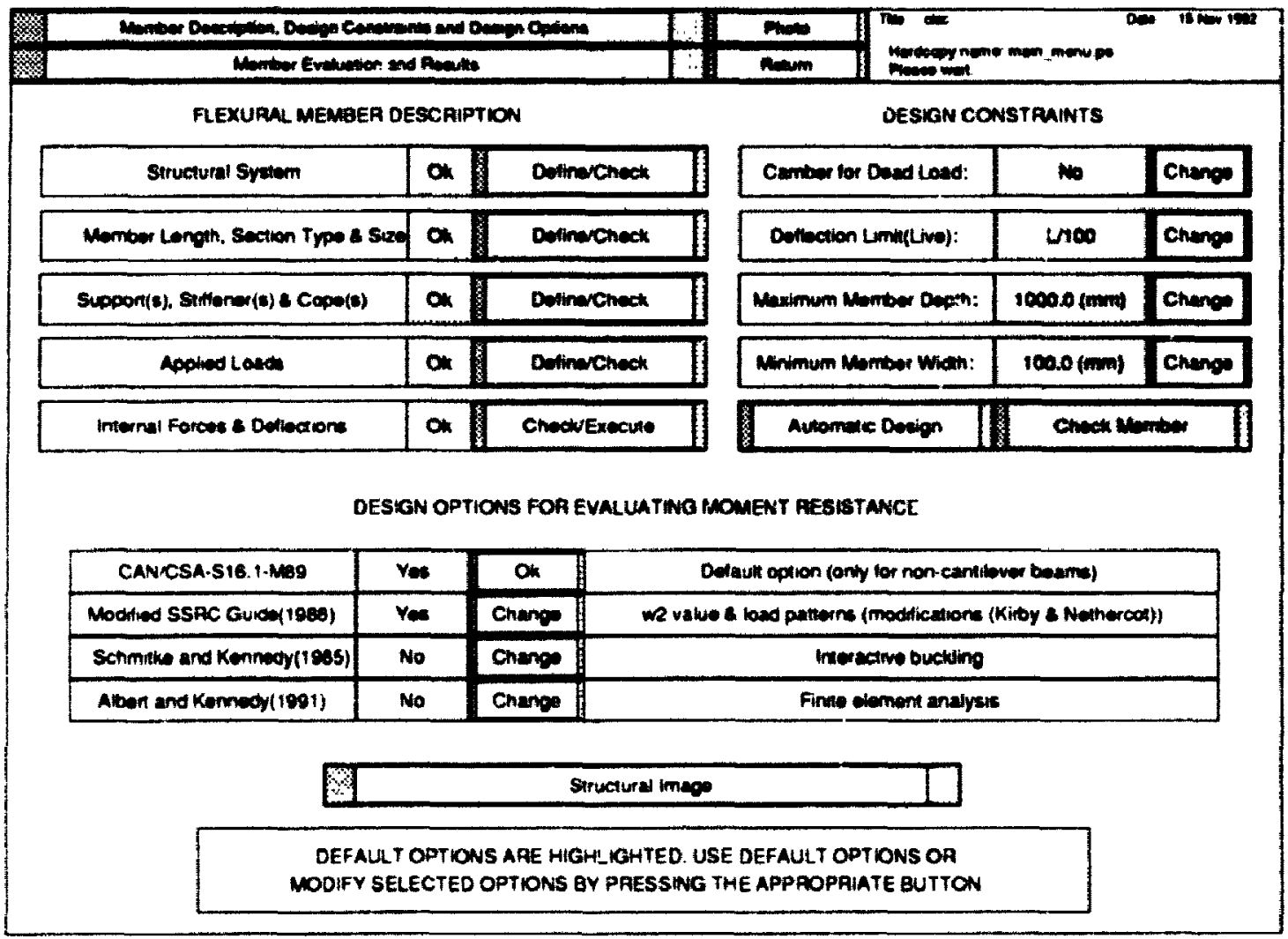

Figure 2.1: Main memu screen of the program IDFSM

The process is activated through buttons on the the program main menu, shown in Figure 2.1. A structural engineer should have no difficulty in using this program to design flexural members as each action results in instant. interactive and in most rases a graphical response. 


\subsection{Selection of An Existing Job or Creation of A New Job}

The computer aided-design process begins with the job definition. Upon execution of the program, the following front menu page screen will be displayed:

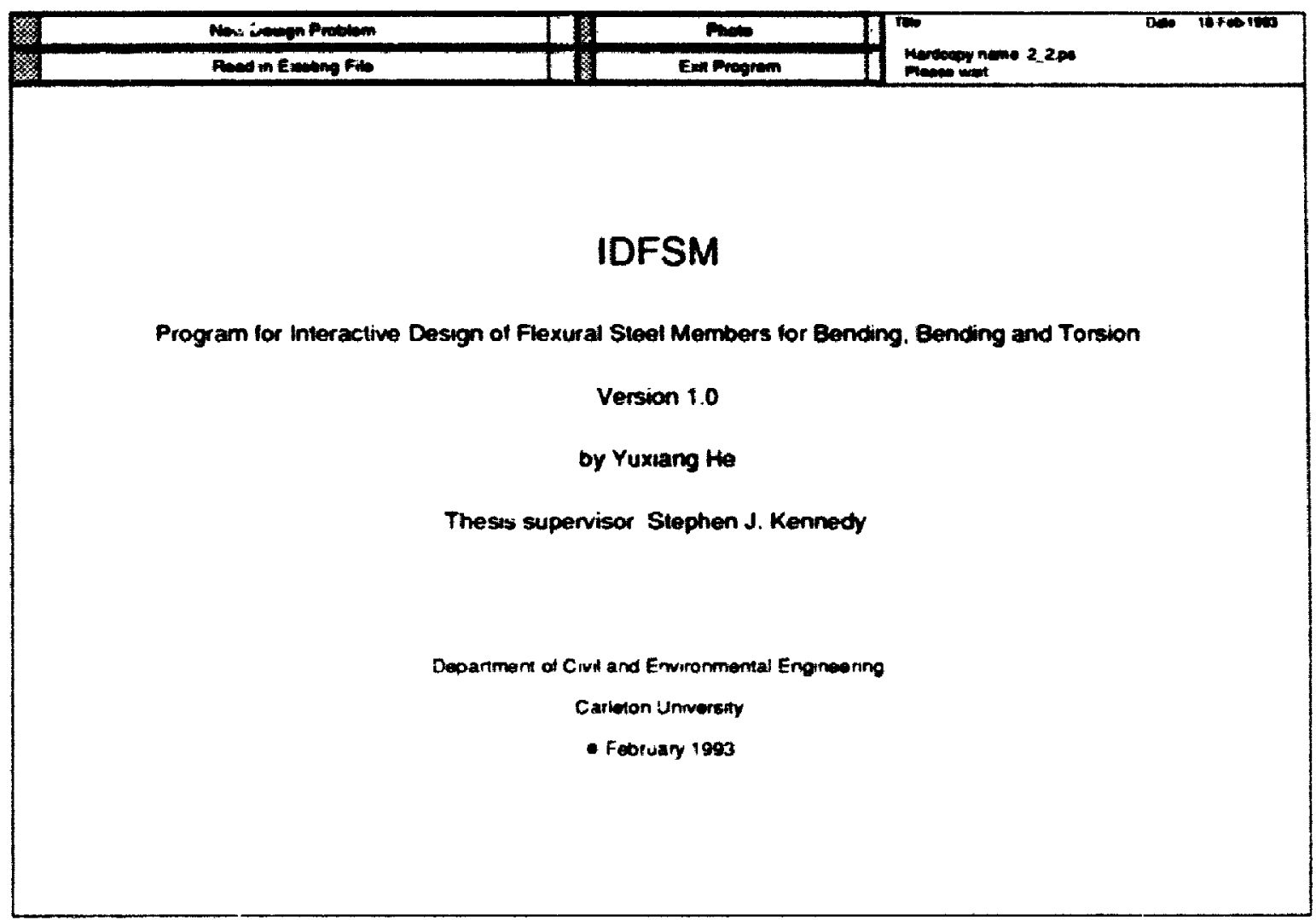

Figure 2.2: Front page of the program IDFSM 
For starting a new design job, the New Design Problem option has to be selected from the front page screen and the user will be prompted to type in the job title and job description as shown in Figure 2.3.

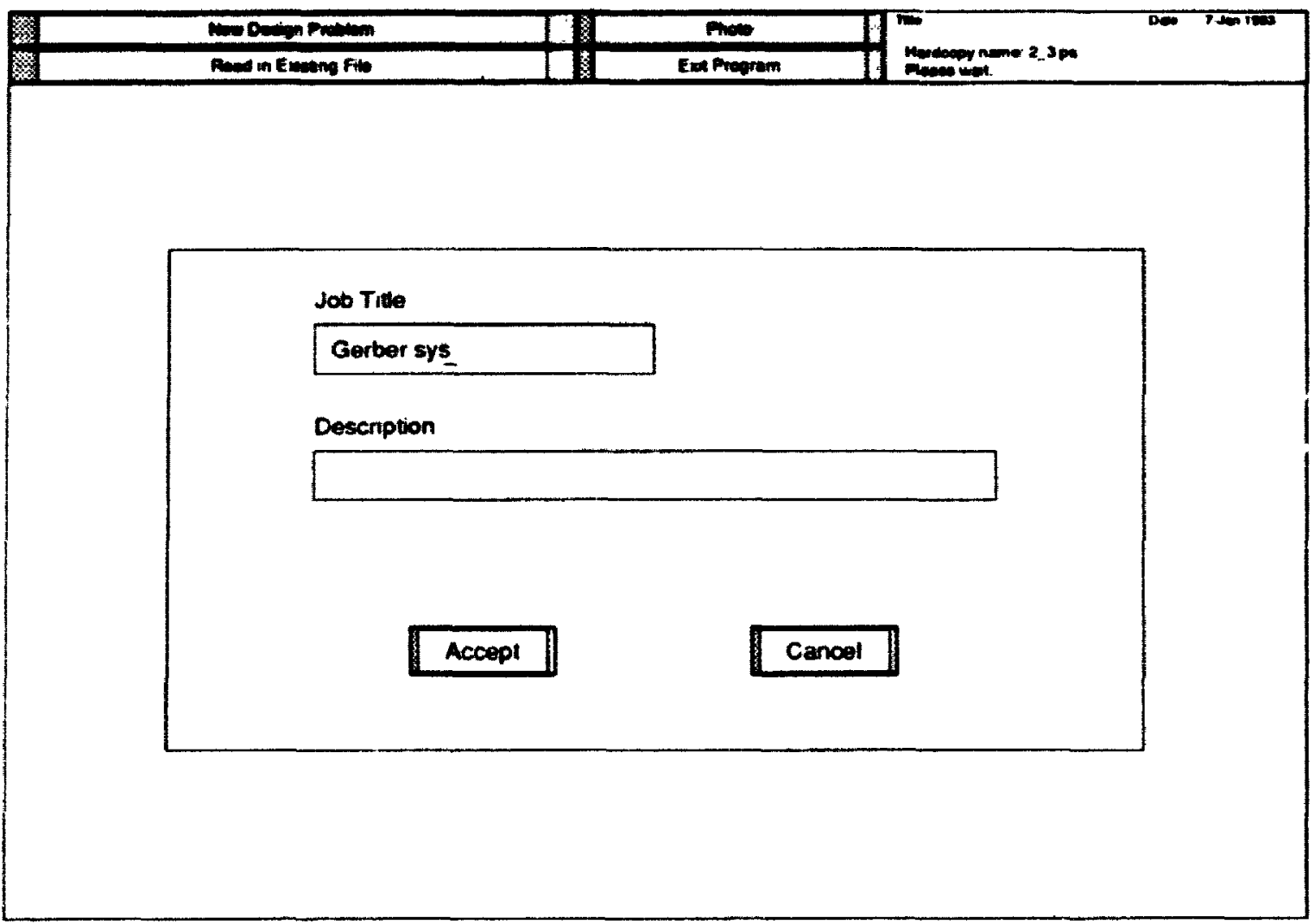

Figure 2.3: New job definition screen 
To access an existing job, select the Read in Existing File option from the front page screen. Figure 2.4 shows the corresponding screen in which the program will read in the job catalog from the data base.

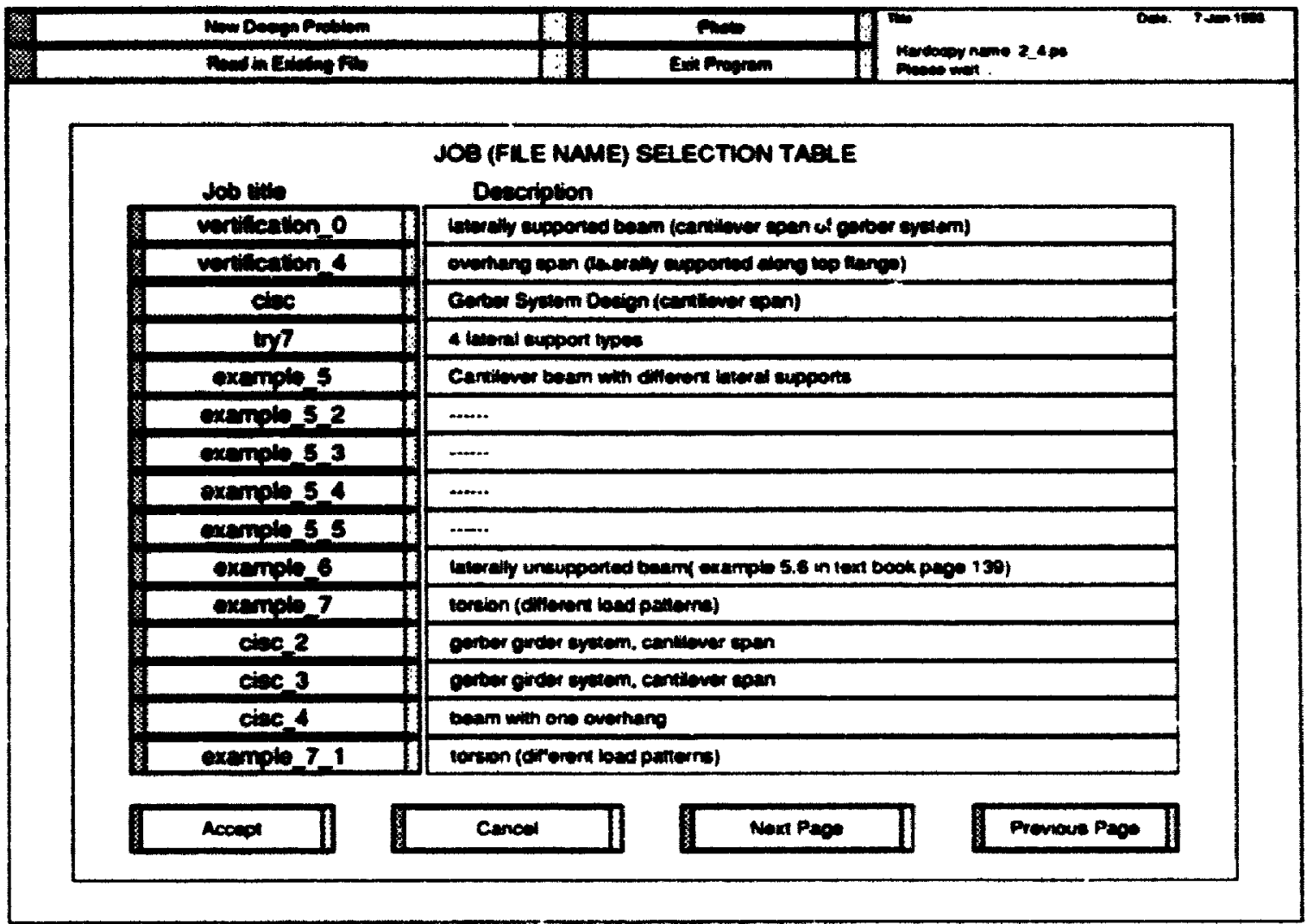

Figure 2.4: Job catalog listing

By selecting the Accept option. the existing file is read in or a new file is created and the program will return to the main menu as shown in Figure 2.1 . 


\subsection{Structural System}

Selecting the Check/Define button for Structural System from the main menu as shown in Figure 2.1, will activate the next step of the member design process and the screen shown in Figure 2.5 will be displayed.

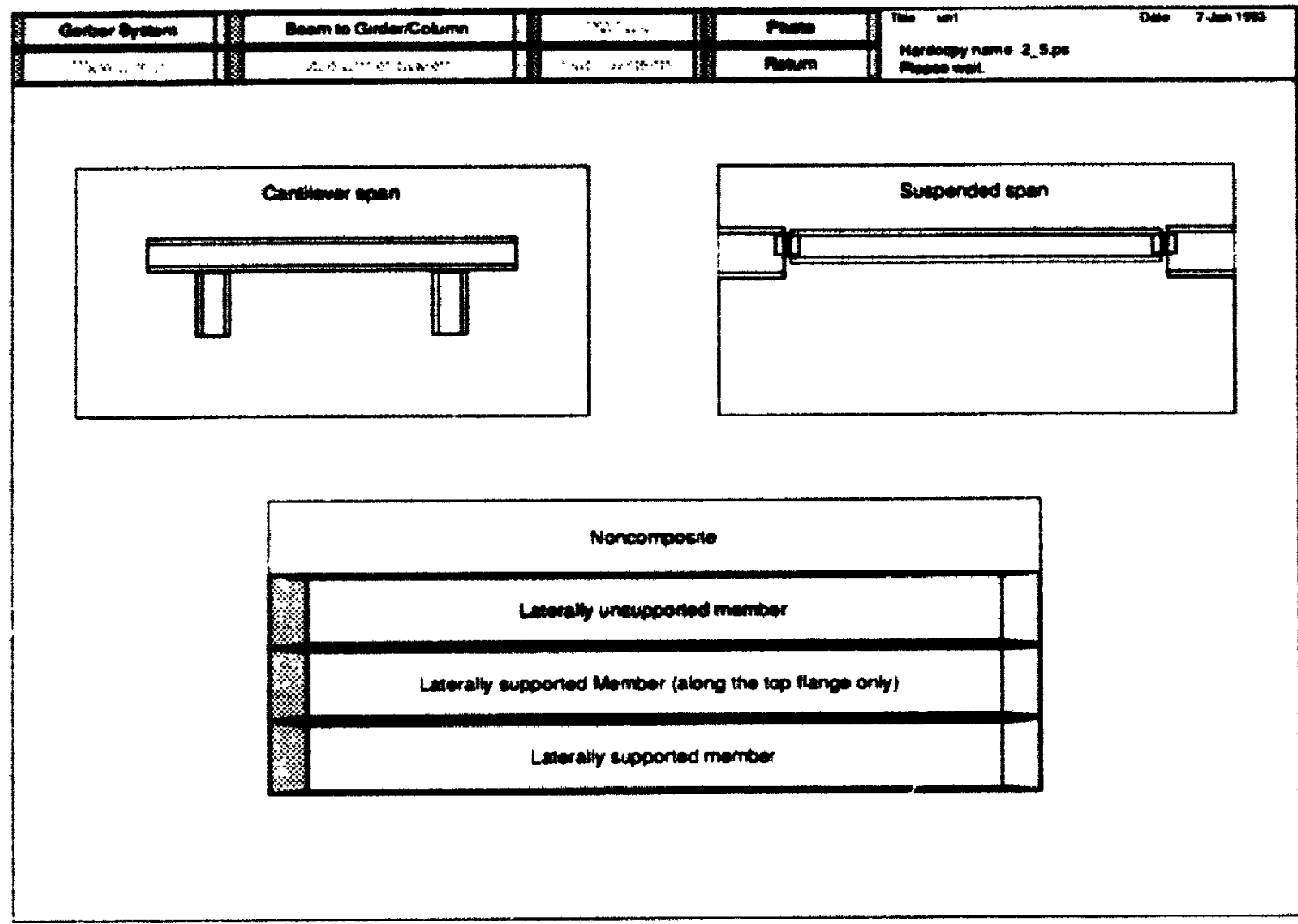

Figure 2.5: Structural system selection screen: Gerber Girder

The types of the flexural members that are designed by this program are clearly defined. The two options that are currenty active are: Gerber System and Beam to Girder/Column. Future modules will be written to design OWSJ's, plate girders, stub girders and various floor systems. The Gerber system selection shown in Figure 2.5 gives the option to the structural engineer to design either the cantilever or suspended span and to define basic lateral support(s). This sets up the graphics 
display for the remaining steps in the design process.

If the Beam to Girder/Column flexural member is selected then, various configuration of beams are displayed as shown in Figure 2.6. All possible framing patterns are illustrated. As before, the selection of any configuration sets up the graphics display for the remaining steps in the design process. Options under the Composite category are not currently active. The selection of the Return button returns to the main menu, displaying it on the computer screen. Once this design step is completed, the indicator on the main menu beside the structural system button will display Ok.

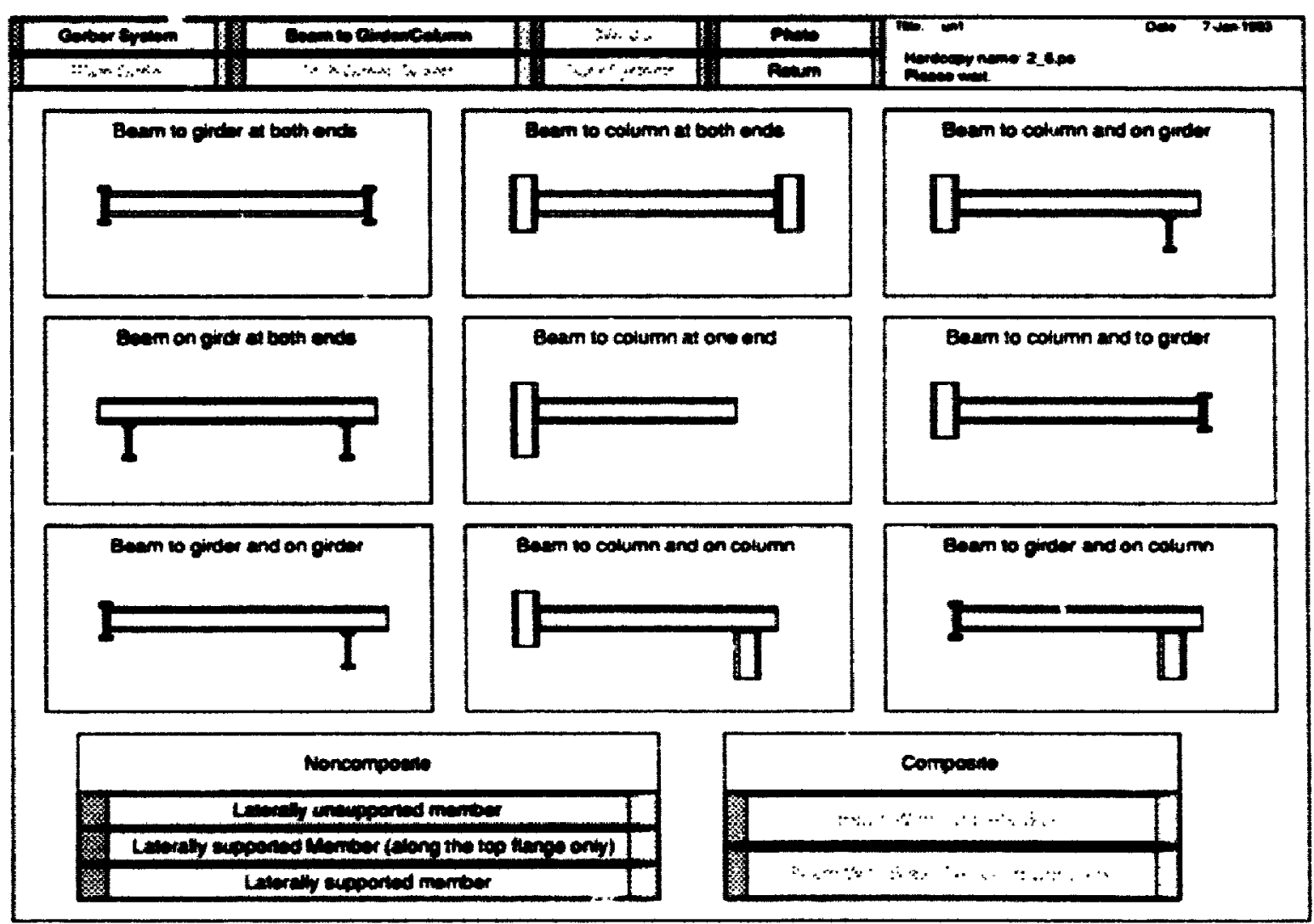

Figure 2.6: Structural system selection screen: Beam to Girder/Column 


\subsection{Definition of Member Length, and Section Type and Size}

The next step in the design process, is the definition of member length, and section type and size, which is achieved by selecting corresponding Check/Define button in the main menu as shown in Figure 2.1. The program will display the following menu and image:

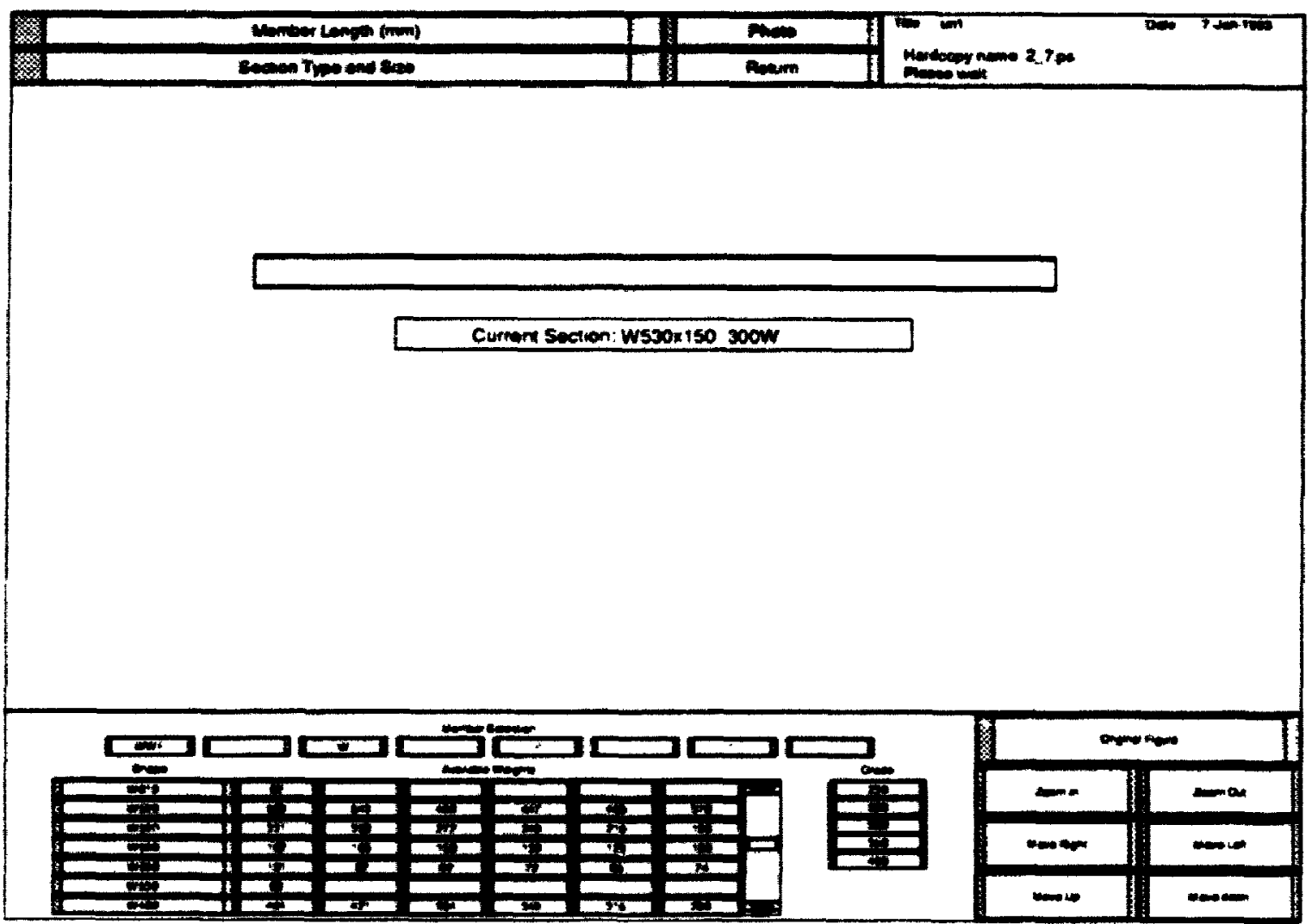

Figure 2.7: Member length, section type and size definition screen

With this sereen. the member length, and the section type and size can be defined interactively. 


\section{Section type and size}

Although all the standard shapes given in the CISC Handbook, CISC (1991) are tabulated in Member Selection subwindow, only the $W$ and WWF sections are currently active. The section type and size is selected by activating the appropriate buttons within the subwindow. The structural engineer may scroll through the table to find the appropriate section. The geometric data associated with the sections shown in the Member Section and Size subwindow are stored in a data base that is accessed during the design process when:

1. a section's capacity is checked, or when

2. a auto-designed shape and size is not available under user situation. In this case. similar size may be selected and checked.

The section and an image of the member are displayed inmediately after selertion is made. Activating the Return button returns to the main menu screen. 


\section{Member length}

The following screen will be displayed when the Member length (mm) button is selected:

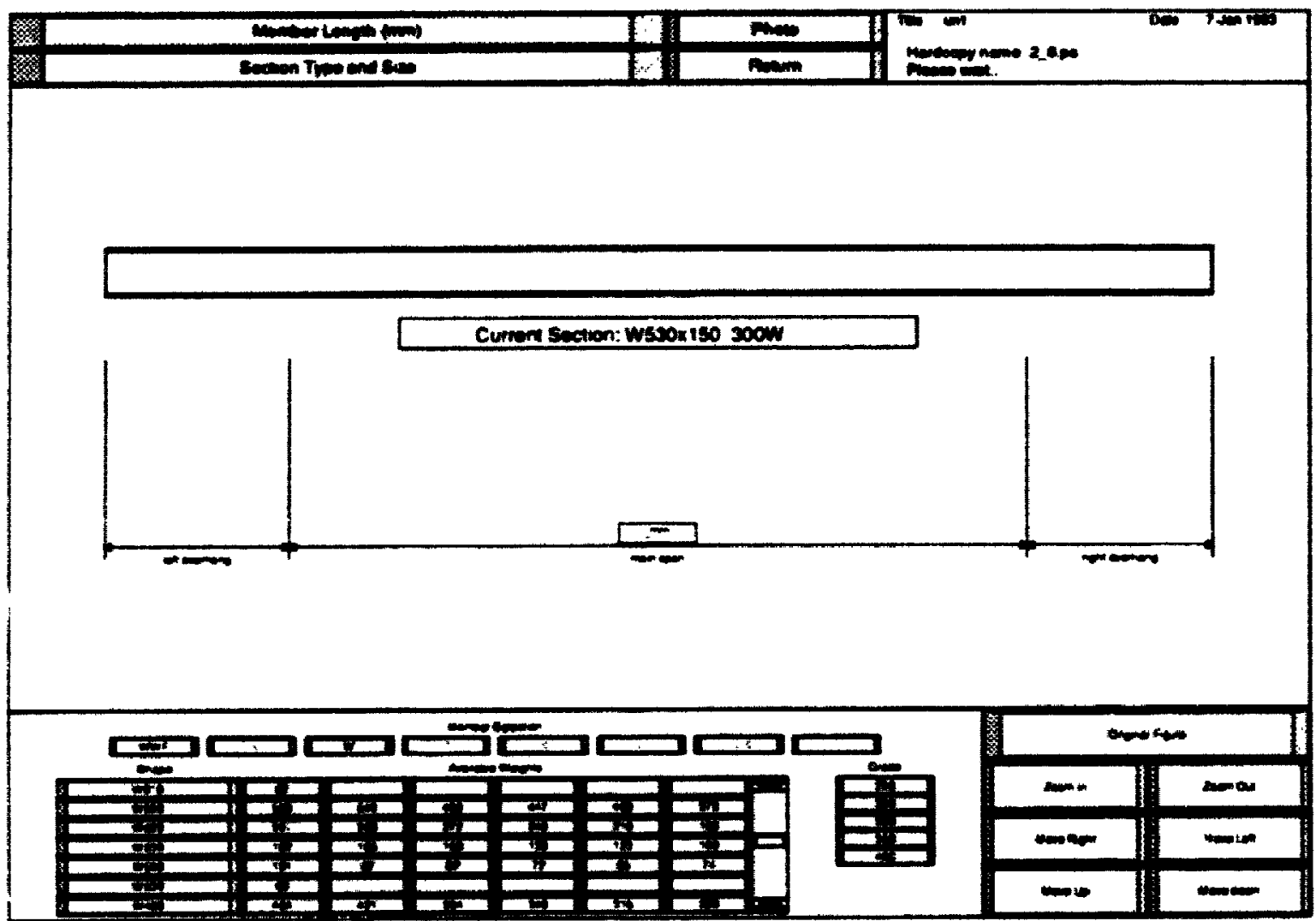

Figure 2.8: Member length definition screen

A non-zero positive numeric number in $\mathrm{mm}$ will be expreted as a length input for main span. A overhang length input of zero length is acceptable and simply indicates that there is no overhang. The displayed member image will respond to the length definition instantly by displaying the nember image to scale. As before. once all components of this design step have been complete and the structural engineer has ret urned to the main menu. then the indicator beside the Member Length, Section Type and Size button will display Ok. 


\subsection{Support, Stiffeners and End Coping Defini- tion}

\subsubsection{In-plane support}

Selecting the Support(s), Stiffeners \& Copes(s) option in main menu will display the following window:

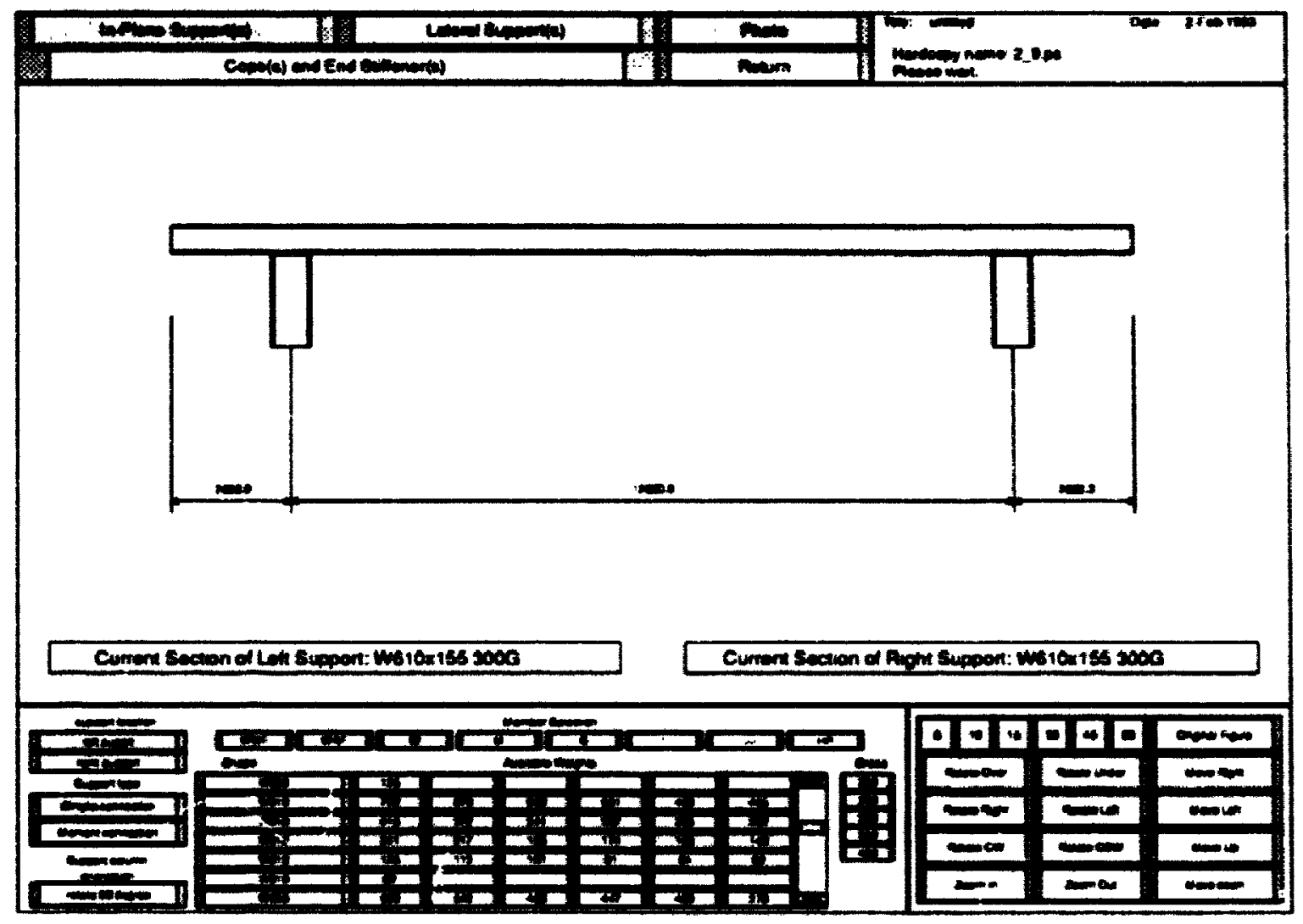

Figure 2.9: In-plane support definition screen

With this window, the supporting graphics for definition of in-plane support conditions is displayed automatically:

Definition of in-plane support includes a description of:

- the section (W or WWF) and size of in-plane support: 
- the orientation of support column ( column web parallel or perpendicular to the orientation of the member (screen). if applicable);

- the end conditions of support (simple or moment resistant connections, if applicable).

Note, no response will be given to selection of end conditions that are impossible for the structural system specified. For example, the selection of simple support condition for a cantilever will not be arcepted. For a suspended span of Gerber girder, a fixed support is not allowed. All default conditions are highlighted in the corresponding huttons. 


\subsubsection{Lateral support}

Selection the Lateral Support(s) option will result in either an image showing the lateral support conditions for a predefined problem, or for a new design problem, the following screen will be displayed. For predefined structural systems, the structural engineer may verify it visually and has the option to make modifirations. For new problems the structural enginerer must build the lateral support system according to the prompts given.

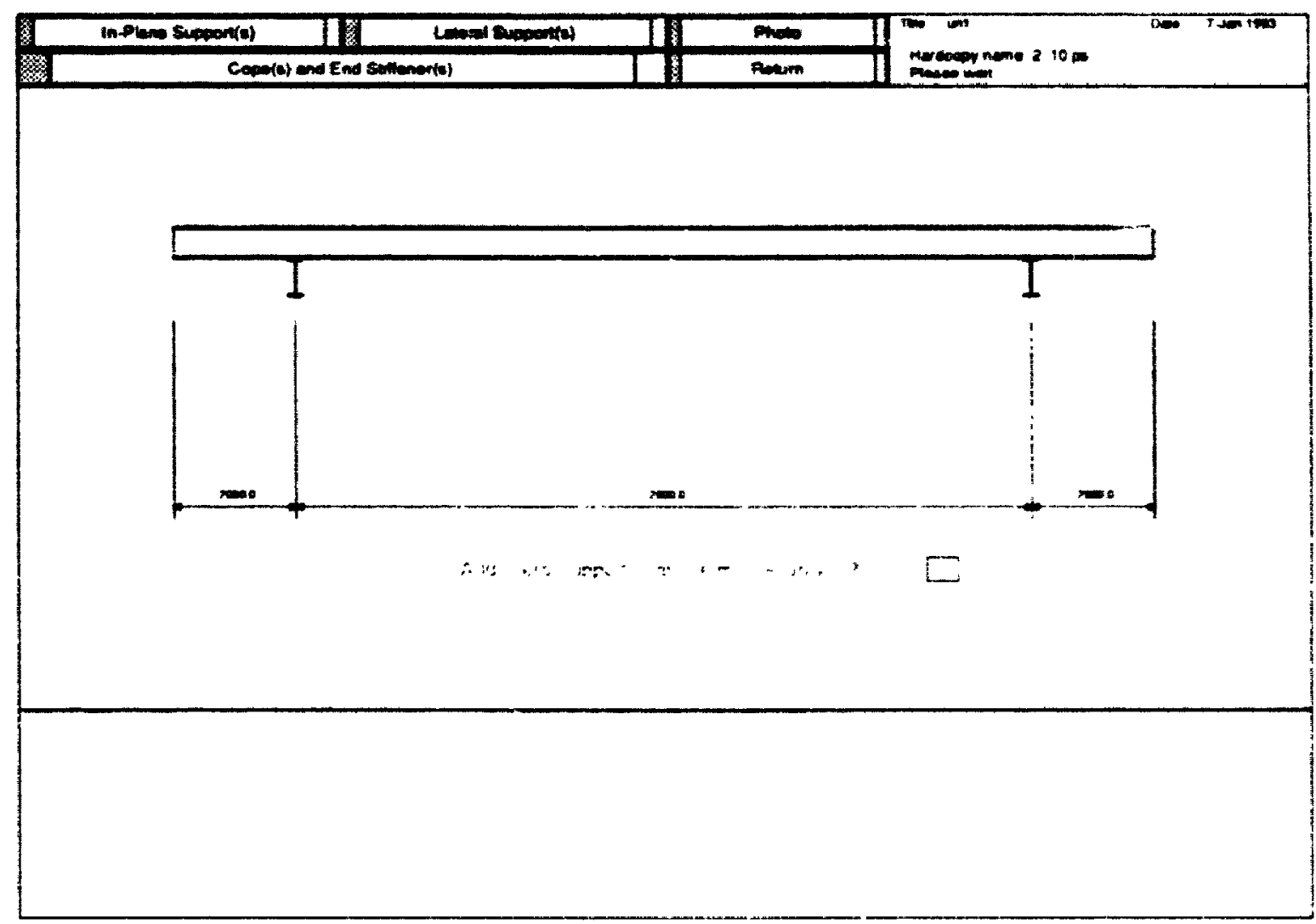

Figure 2.10: Lateral mpport definition sereren I

The st ructural engineer will be anked to sperify the lateral nuppert in the main span and then the left and right overhanging spans if applicable. If the answer to the question displayed is yes. "y" for example. then the screen shown in Figure 2.11 


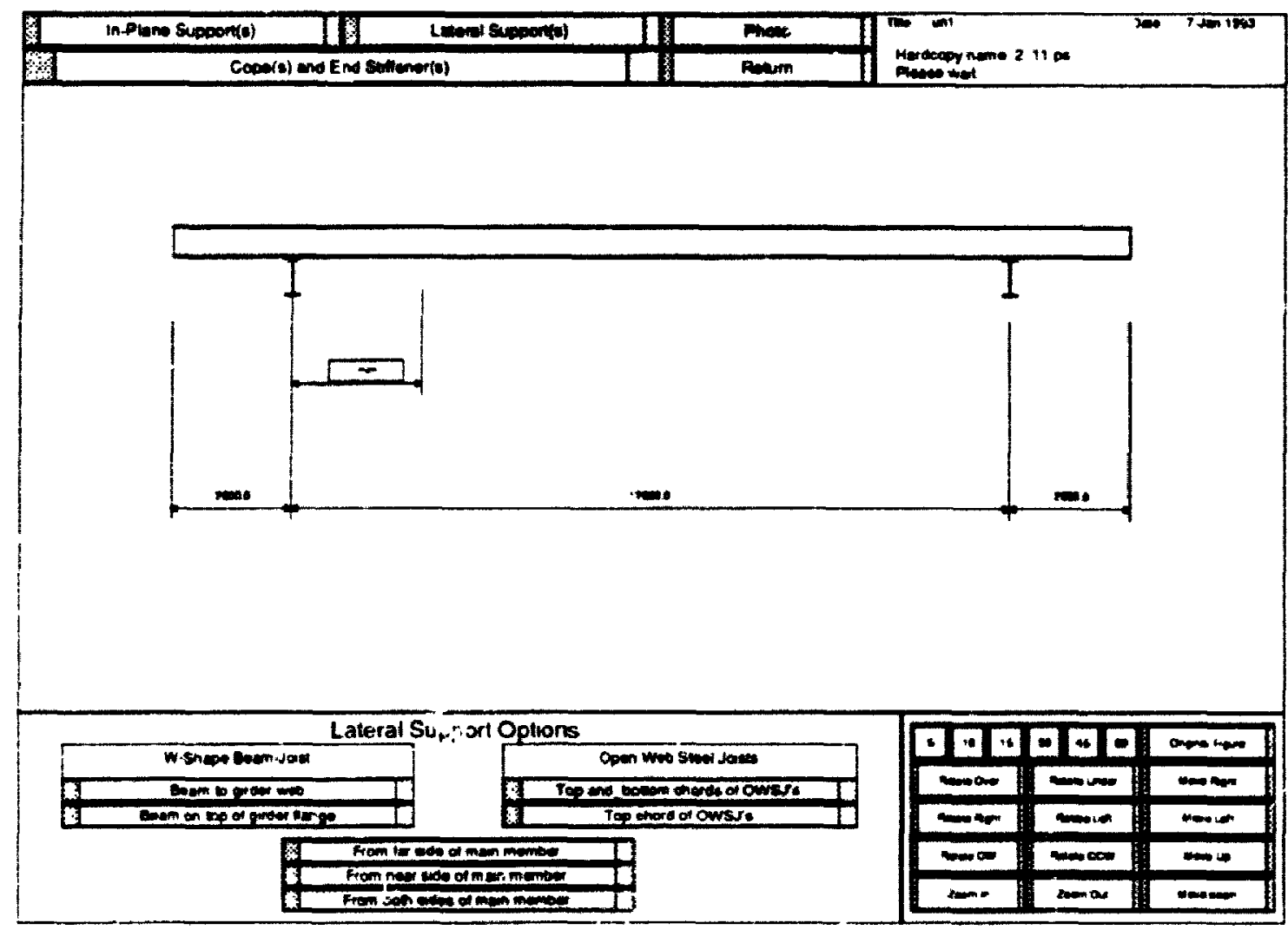

Figure 2.11: Lateral support definition screen ?

will appear. prompting for the location and then for the type as indicated in Figure 2.i2. In this progran. four typical lateral inpport types are identified (beam to girder web, beam on top of girder lange. top and bottom chord extension of OllS.l's. and top chord of OWS.l-1. earh of which lias a different effect on lateral-torsional buckling capacity of the Hexmal member being designed. The correct estimation of the corresponding moment rapacity for lateral segments with different bateral supports

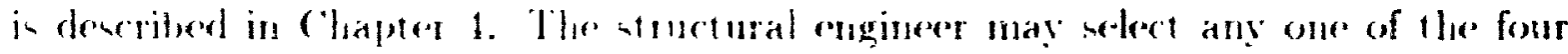
different latral support shown.

The lateral wppent definition proces deseribed above is repeated until all the

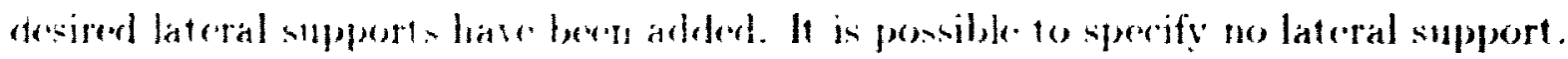

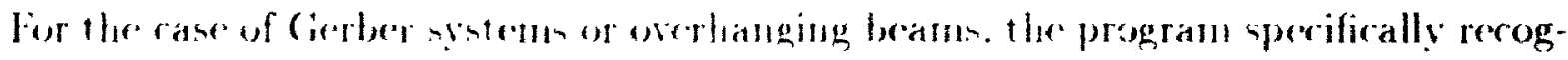




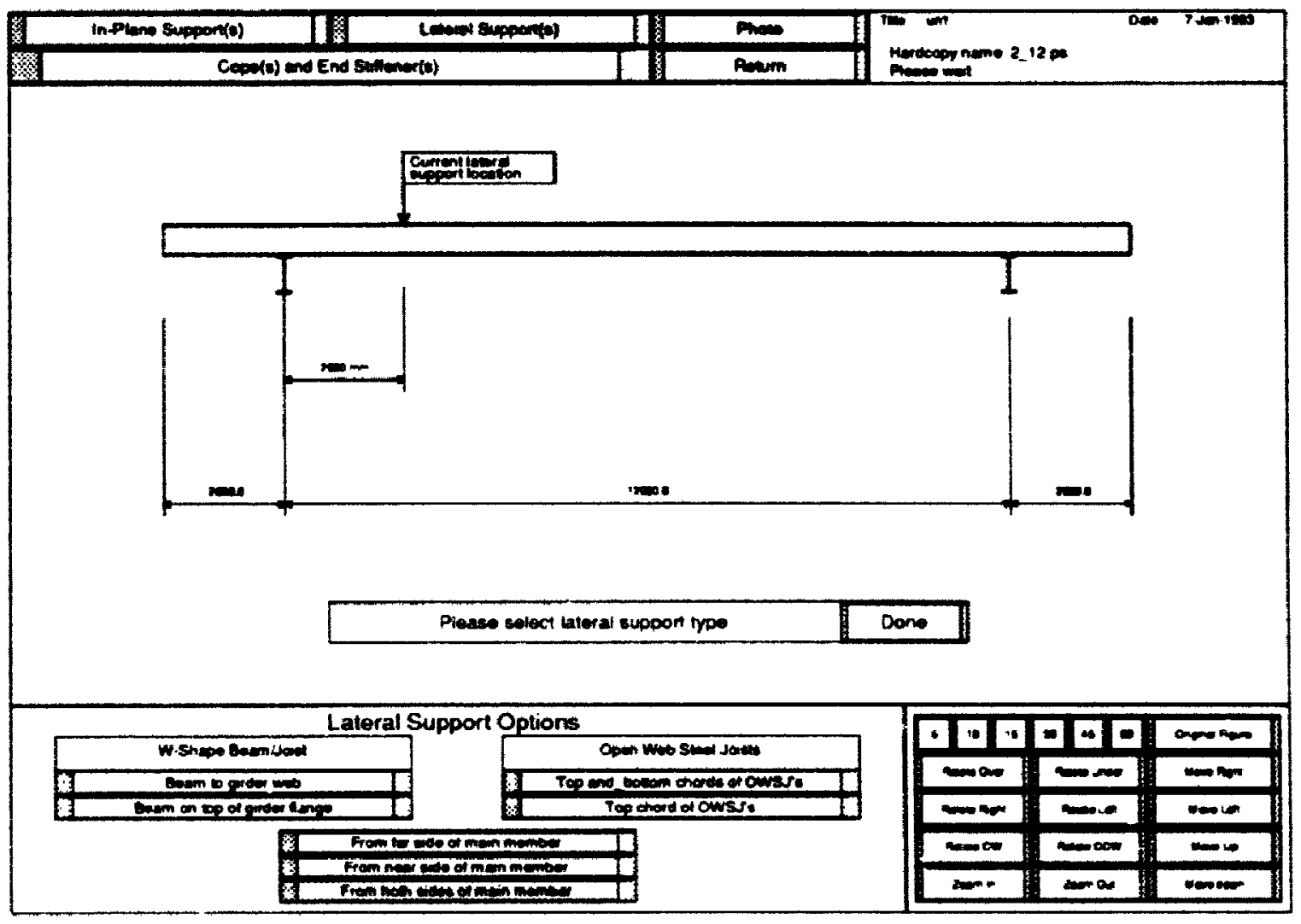

Figure 2.12: Lateral support definition scren:3

nizes that some form of lateral support should be provided at the in-plane supports to climinate potential stability problems. the minimum requirenent must be some form of lateral support or a pair of bearing stiffeners over the support s. If these are not specified, then the program will automatically provide a pair of bearing stiffeners. 


\subsubsection{Definition of end coping details and bearing stiffeners}

Selecting the Cope(s) and Bearing Stiffener(s) option generates the window for definition of coping and bearing stiffeners as shown below.

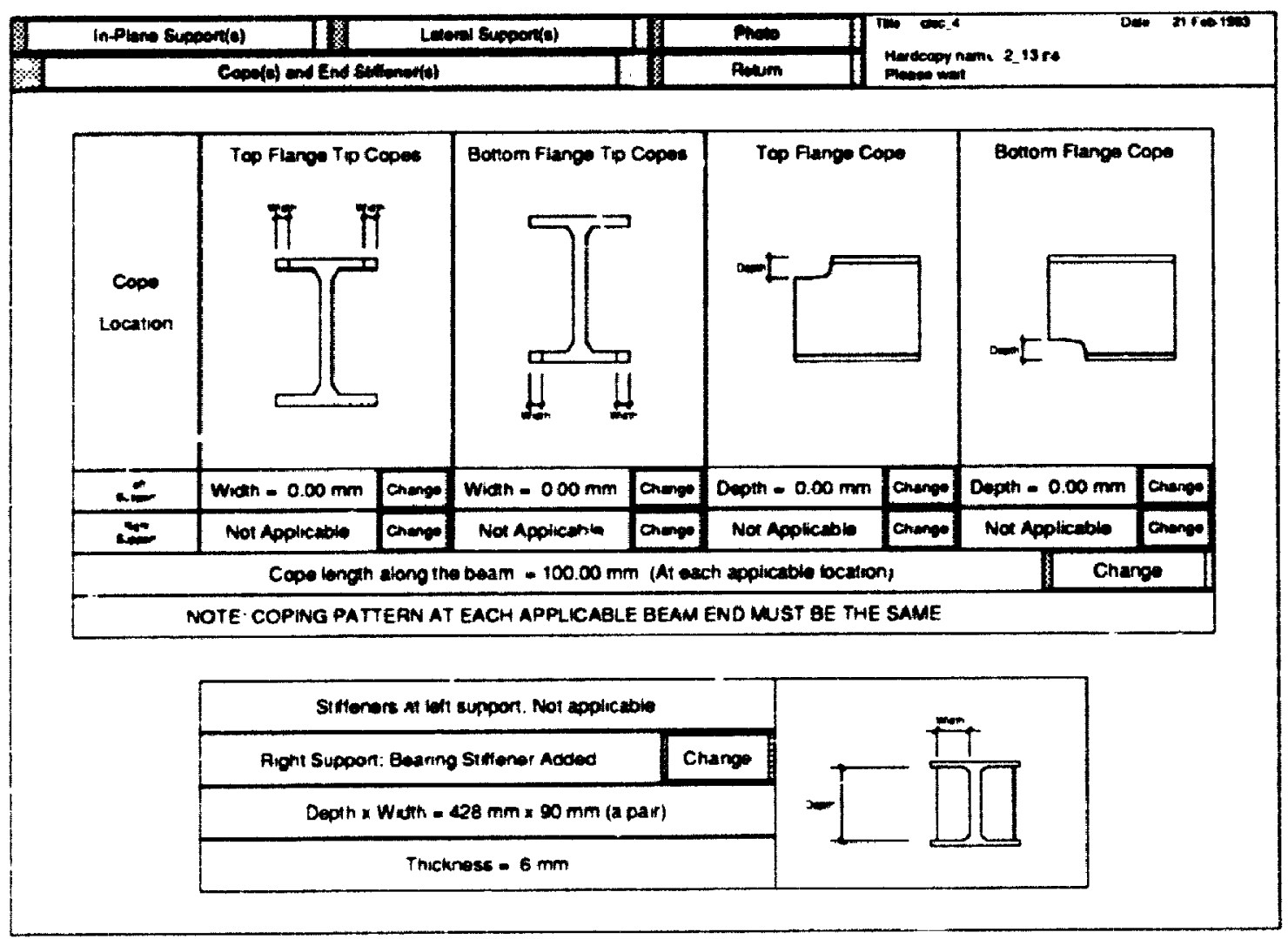

Figure 2.13: Copets! and bearing st iffencer(s) definition screen

\section{End coping details}

Copes in beams are made for fit and for case of erection. These reduce the crosssertion at the connections and reduce the lateral-torsional buckling capacity. Two types of coping details considered in the program. with the corresponding dimensions (width. length, and depth) are illustrated in Figure 2.13.

The defaul values for the cope dimetrions are $0.0 \mathrm{~mm}$. To change these values, 
simply select the corresponding Change buttons and enter the new value from the keyboard into the window provided. The following geometric restrictions are applied to the cope dimensions:

- for Flange Tip Copes, the

$$
\text { Width } \leq\left(\frac{b}{2}-k\right)
$$

- for Flange cope's, the

$$
\begin{aligned}
& \text { Depth } \leq \frac{1}{5} \times d \\
& \text { Length } \leq 2 \times d
\end{aligned}
$$

where, $d=$ section dept!. nm

$b=$ flange width, mm

$k=$ the distance the distance from outer face of flange to web-toe of fillet of the member (I-shape), mm

If copes are made in both the top and bottom flanges. then the dimensions specified must be the same. Only one type of cope, either flange tip copes or flange cope. can be made for a given location. i.e. top flange cope.

\section{Bearing stiffeners definition}

Bearing stiffeners may be required to resist the local bur'ling of the web or to provide lateral-torsional support in the case where lateral support at top of the flange is missing. The program will automatically check through these two requirements to determine whether or not bearing stiffencrs are necessary. The structural engineer may add stiffeners orer the supports by selecting the Change button(s) for the left or right in-plane support location. The pair of bearing stiffeners have a length equal to 
the full member web length and with a width not less than $10.0 \mathrm{~mm}$ and not beyond the tips of flanges. The program will determine the minimum thickness automatically ensuring Class 3 behaviour.

\section{Return to main menu}

lpon finishing up the definition of in-plane and lateral support. coping and stiffeners, select the Return button and the main menu screen shown in Figure 2.1 will be displayed. The indicator attached to the Support(s), Stiffener(s) \& Cope(s) option. will read Ok. 


\subsection{Applied Load Description}

\subsubsection{General}

The applied loads acting on a flexural member can be defined interactively and semiautomatically in the program IDFSM by selecting the Applied Loads option button in the main menu shown in Figure 2.1, displaying the following screen for new design problems:

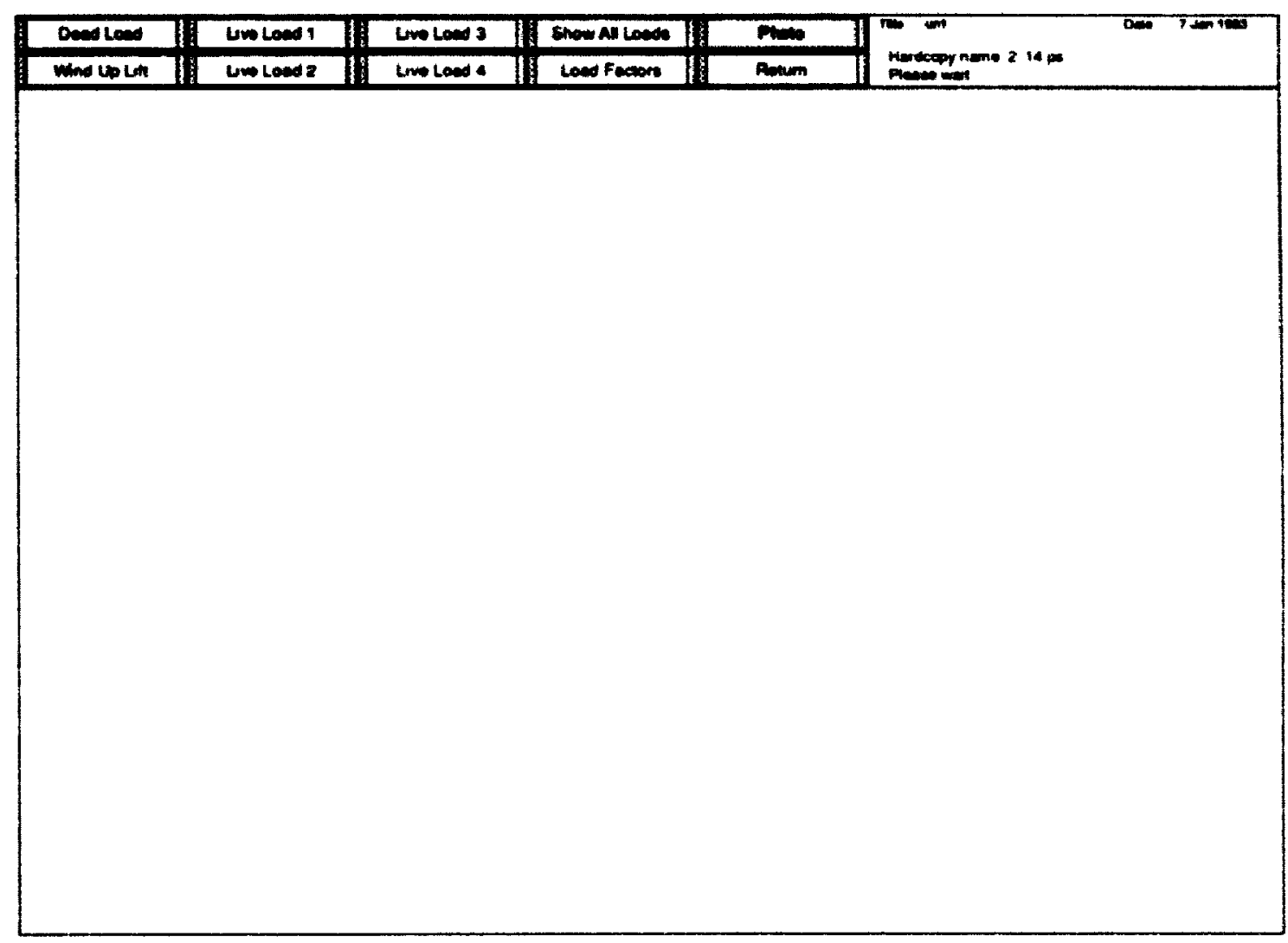

Figure 2.14: Load Jefinition screen 1

The program is capable of defining six load cases with a total of four load combinatıons. All load entries are defined as specified loads. Each load case may consist of any number of different load pattern types which include uniformly distributed loads. 
concentrated loads and linearly varying distributed loads. In addition, torsional loads may be applied on any lateral unsupported segments provided that no adjacent such segments are subjected to torsional loadings for same load combination.

\subsubsection{Semi-automatic load definition for lateral supported points}

Ipon selecting the load case from the menu as shown in Figure 2.14, the program will automatically show, one by one. the load types and locations. Where sub-members frame into the beam. the program will prompt for concentrated loads. as illustrated in Figure 2.15. and it will automatically apply a uniformly distributed dead load for self weight.

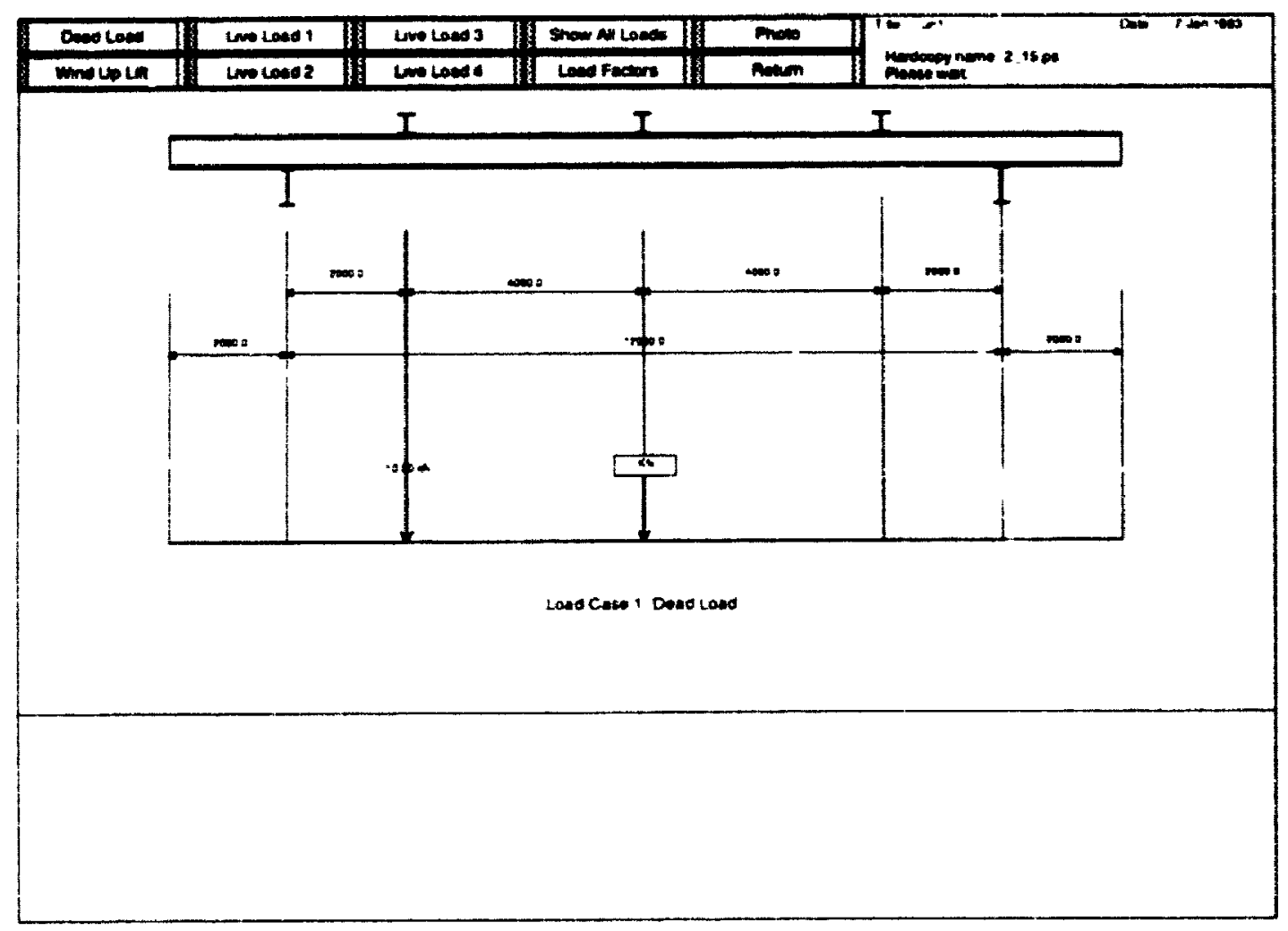

Figure 2.15: Load definition screen 2 


\subsubsection{Additional transverse/torsional load definition}

When the semi-automatic load definition process is over, the following messages will appear on the screen.

\section{Add additional transverse/torsional loads $(y / n) ?$ \\ Add load at main $\operatorname{span}(\mathrm{y} / \mathrm{n})$ ?}

If the answers to these questions are all yes, "y", then additional windows will be displayed on the screen.

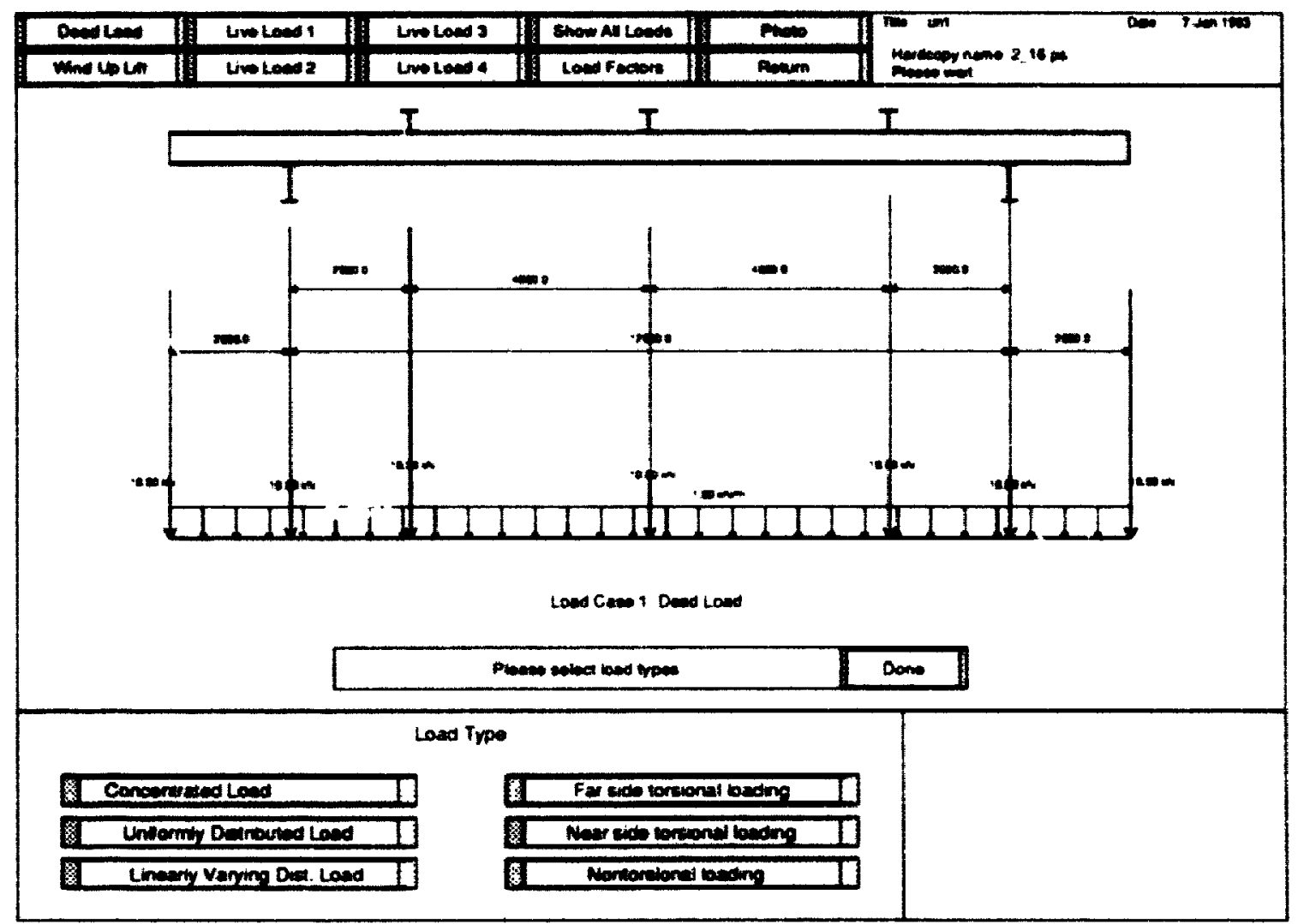

Figure 2.16: Load definition screen 3: Load type definition

At this stage, one set of loads of any type including torsional loads can be added. The following parameters must be defined to describe each load type: load type. location. eccmitricity of load (for torsional loads only) and the magnitude of the load. 
With the graphical interface, the structural engineer should have no difficulty at all to define complicated load cases. The program does not use any cryptic data input nor does it require any prescrilzed format. The response to input is automatic and is shown graphically on the screen making verification easier. Various stages of the load description process are illustrated in Figure 2.16 through 2.19. Each load case can be reviewed by selecting the corresponding load case button or the Show All Loads option. I'sing the view control buttons located in the lower right hand corner of the screen. the structural engineer can scroll through and verify all of the service loads acting on the beam. An example summary for a complex set of loads for a dead load case is illustrated in Figure 2.20.

A positive load value corresponds to a load acting in the same direction as shown on the load diagram. A negative load value implies that the direction of the load is opposite to that illustrated on the screen. Similar procedures can be followed to change the loads or make corrections. 


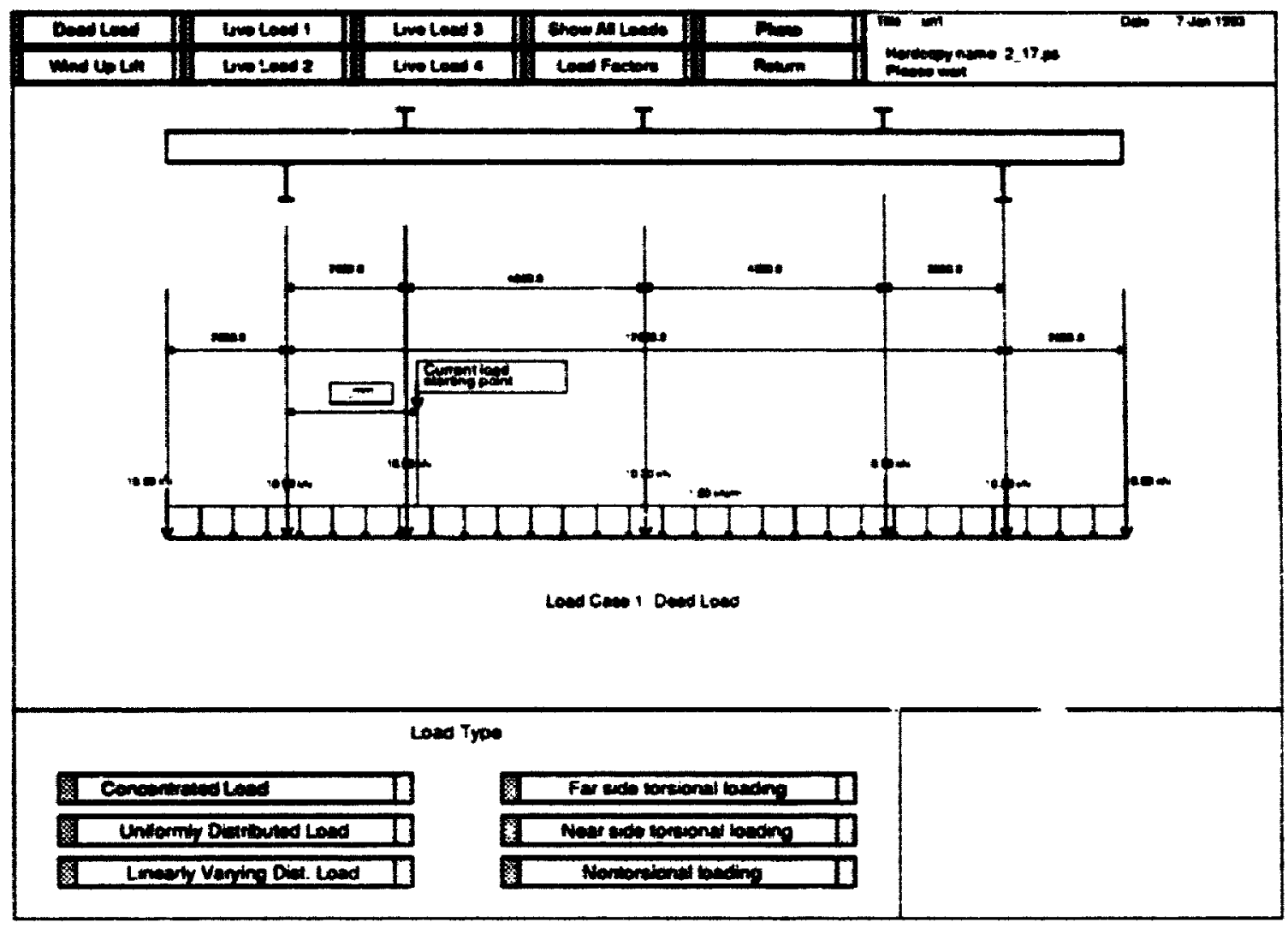

Figure 2.17: Load definition screen 4: Location of load 


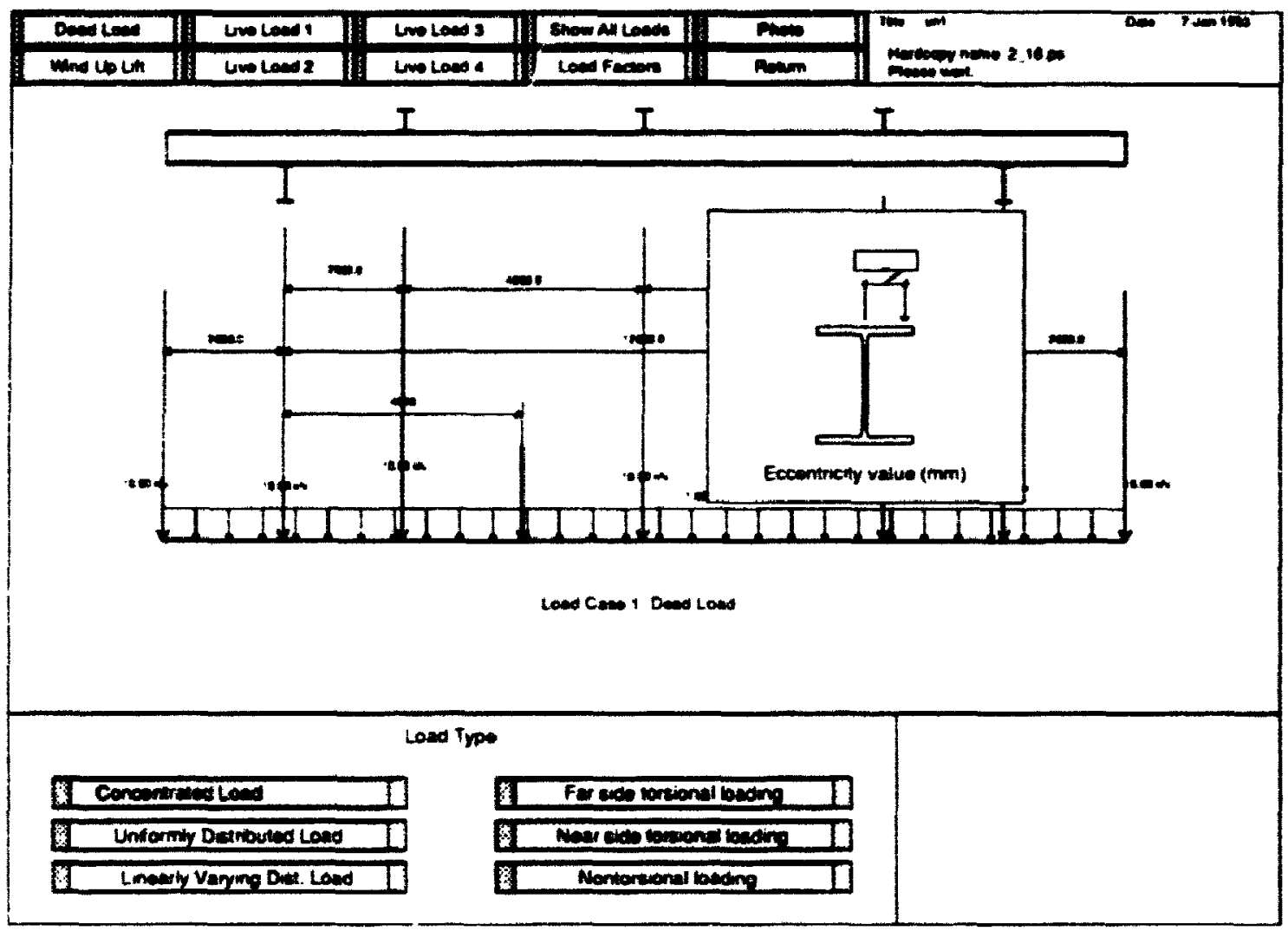

Figure 2.18: Load definition screen 5: Load eccent ricity 


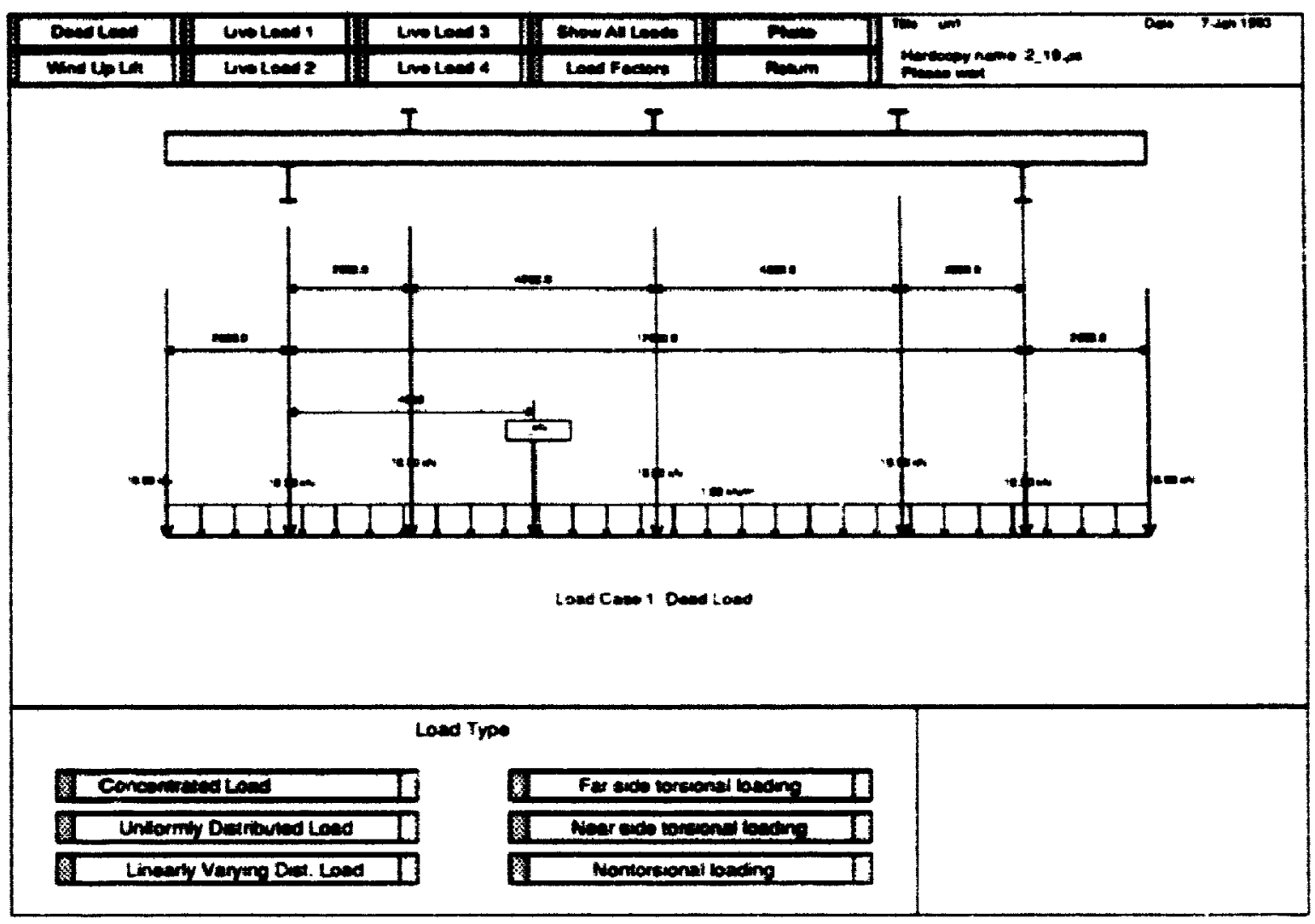

Figure 2.19: Load definition screen 6: Load value 


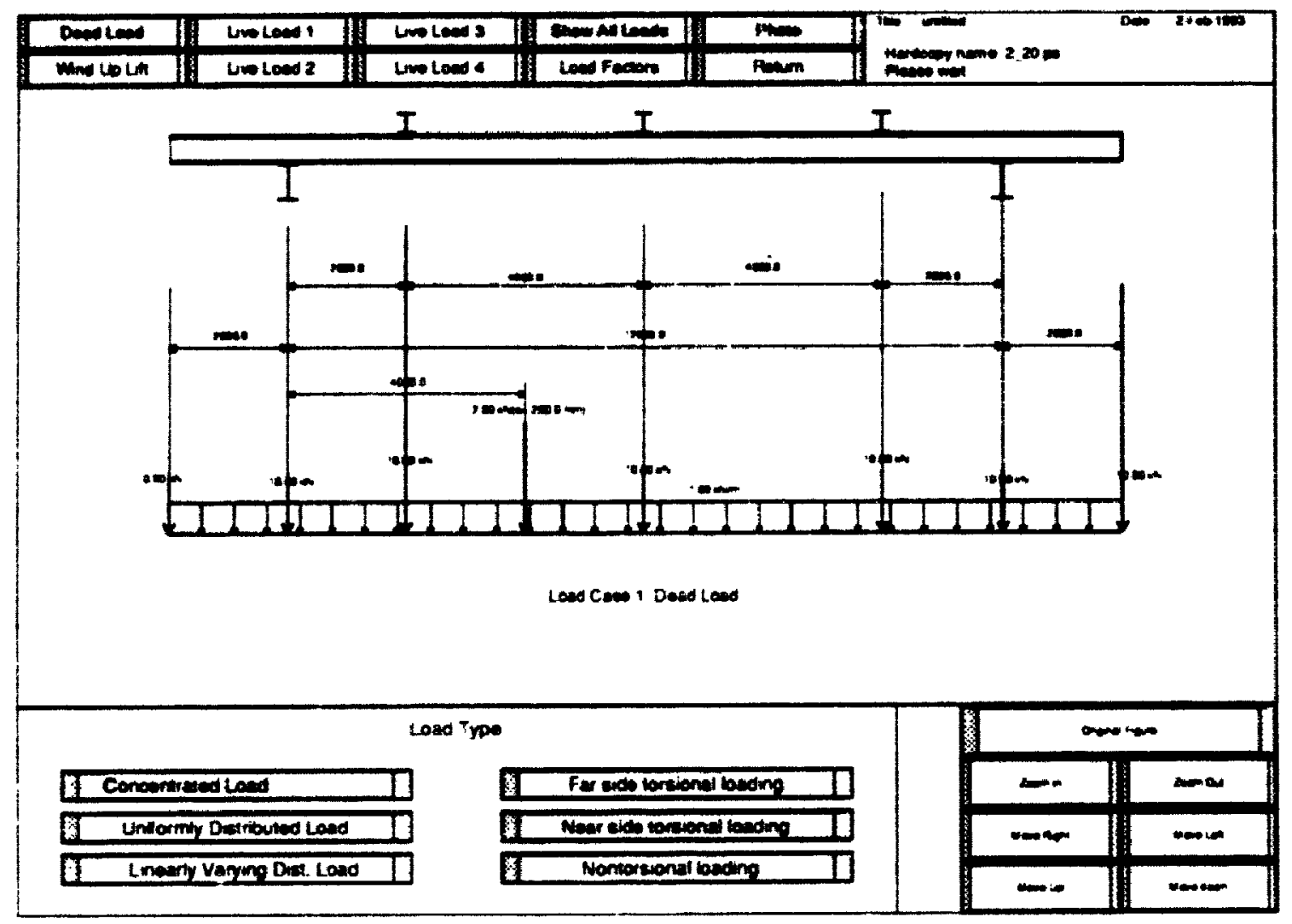

Figure 2.20: Load definition screen $\mathrm{i}$ : Dead load summary 


\subsubsection{Load combinations}

By selecting the Load Factor option in the load delinition screen. the structural engineer will be able to define up to funr different load combinations. Each load combination consists of a series of specified load sets which are multiplied by the appropriate load factor as defined in (lause 4.1 .4 of the National Building Code of Canada, NBCC: (1990). To change a load factor. the cursor is moved to the load factor to be changed and the mouse button is pressed. The program will then prompt with a small window as shown in Figure 2.21. for the new load factor value.

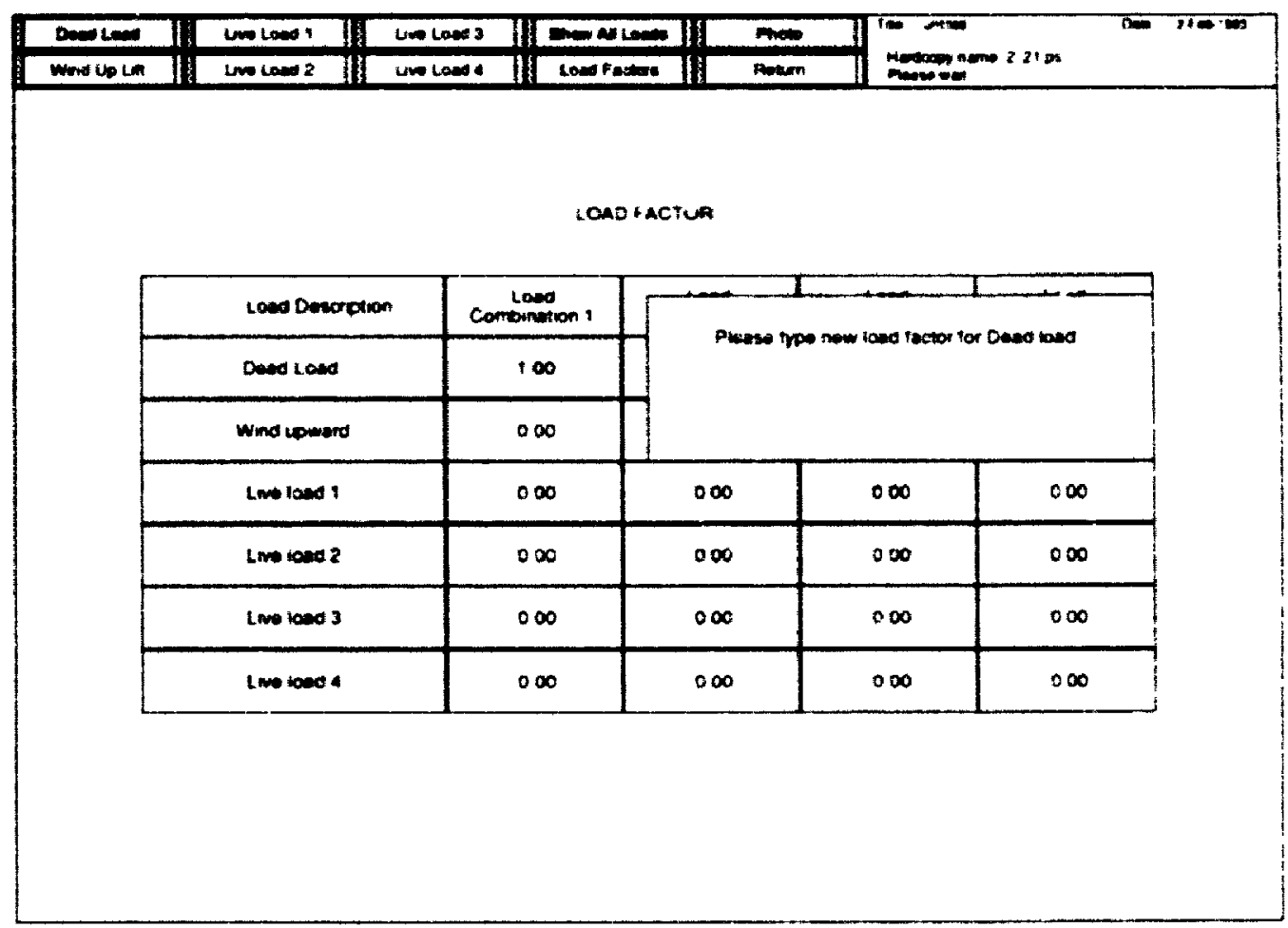

Figure 2.21: Load definition scresn s: Load factors 


\subsubsection{Return to main menu}

Once the definition of all loads aeting on the member are complete, select the Return option and the main ment. shown in Figure 2.1 will be displayed. The indicator atiached to the Applied Loads. will real Ok. 


\subsection{Determination of Internal Forces and Deflec- tions}

If the Internal Forces \& Deflections option on the main menu is selected. the program will execute the analysis modules and display the results with the bending moment diagrams being the default display, as shown in Figure 2.22. Selecting the options in the menu will display the corresponding internal force and deflection diagrams. By using the view control buttons lorated in the lower right hand corner of the screen, the structural engineer can review the diagrams for each load combination. The analysis modules incorporated into the program are described in Chapter 3. The selection of the Return stion any time during the review process will return to the main menu screen.

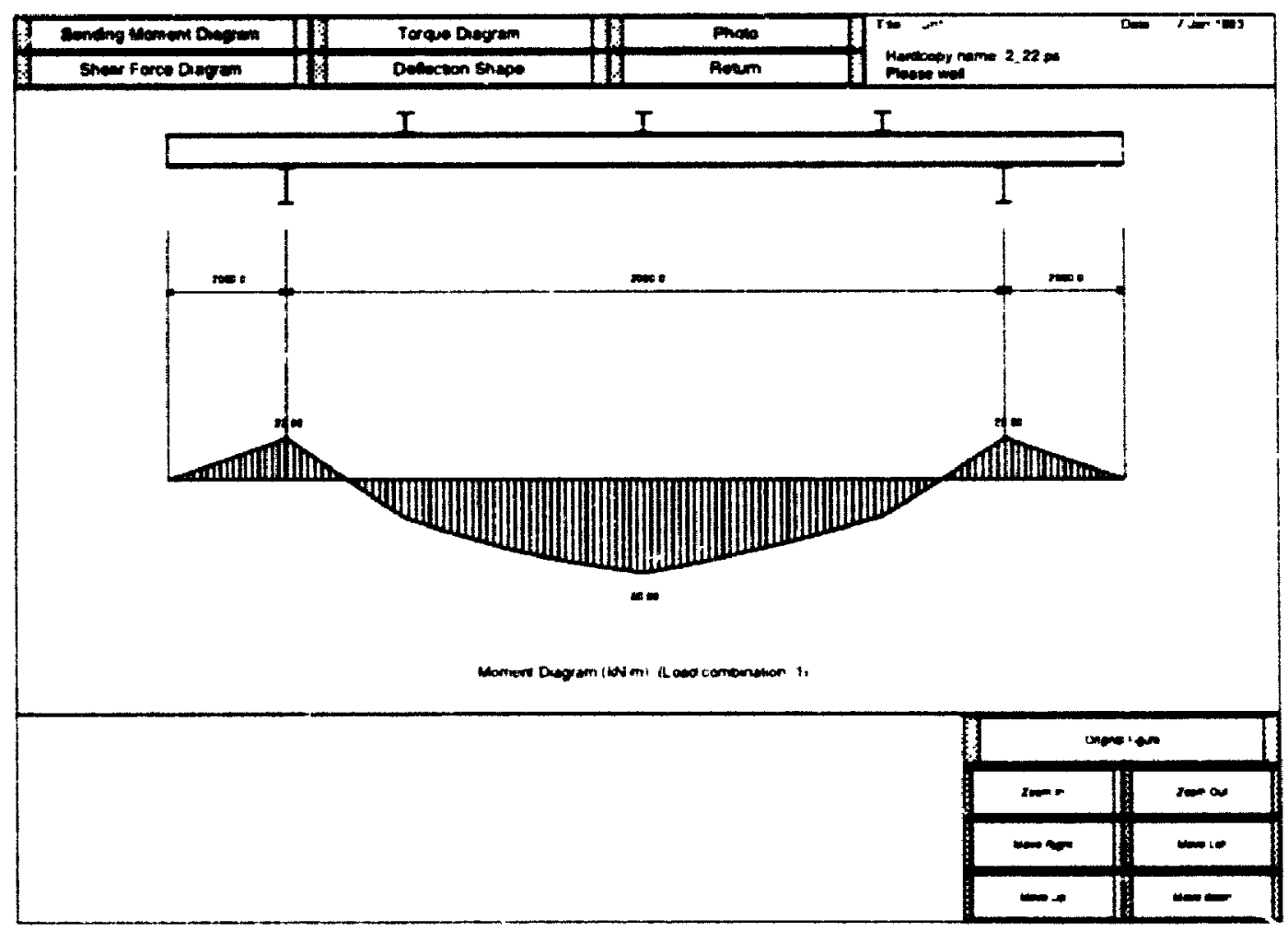

Figure 2.22: Screen for dimplaying of internal force diagrams and deflected shapes 


\subsection{Design Constraints and Solution Strategies}

The limitations or constraints imposed by the architect, fabricator and/or structural engineer. as well as the option of invoking different levels of sophistication of solutions should be explicitly incorporated into the design process. This is accomplished through two series of buttons in the programs main menu entitled, "DESIGN CONSTRAINTS" and "DESIGN OPTIONS FOR FVALLATING MOMENT RESISTA.NCFS" as shown in Figure 2.1.

Inder the category "DESICN CONSTR AINTS". the structural engineer is able to specify:

1. Camber for Dead Load where the deflection for the specified dead load and sustained live load will be calculated and reported as a prescribed camber.

2. Deffection Limit (Live) where the limit for specified live load deflections are specified in terms of the span length -L.". The term span refers to the length be tween in-plane supports or the length of the overhangs. Recommended values for the linits may be found in $\mathrm{Appes}_{\mathrm{p}}$. I in ('AX/C'SA S16.1-M89.

3. Maximum Member Depth sets the maximum depth allowable for the flexural member (generally an architertural constraint).

1. Miniumum Member Width sets the minimum flange width allowable for the flexural member (generally a fabricator comstraint).

A bige number of hean design problems can be handled adequately nsing the rules specified in ( AN/CSA S16.1-1189. However. for continuons beams and for special systems like the Gerber system. more sophisticated solution techniques are required to ohtain the best possible design. The ('AN/CSA S16.1-M89 option is always executed as a minimum requirement. The beam designed for this option can 
be compared directly to the beam designed for the user specified solution. The option is both functional and educational. A detailed descriptions of the different solution strategies available are given in ('hapter 4.

The structural engineer may ronduct a member check for existing members or Automatic Design. in which the nember will be designed to give a least weight section and to meet all design const raints by selecting the appropriate option. The results of the design can be obtained and viewed by selecting the Member Evaluation and Results option.

\subsection{Design Status}

Each step of the member design process has a small window which indicates whether or not the work within that step is complete with a corresponding Ok or NotOk response. If a design parameter or condition is changed in one step, others may be affected and their status might change if more work is required. For example. changing the applied loads would recuire the structural engineer to recompute the internal forces and deflertions. and then redesign the member. This sistem helps to provide a simple. casy to follow interface for designing beams. 


\subsection{Representation of Design Results}

\subsubsection{On screen display}

If all the design parameters under "Flexural Member Description" category have been defined. (with each of status indicator showing $\mathbf{O k}$ ) and other design criteria options decided. either by user actions or by default settings. the selection of the Member Evaluation and Results option in the upper part of screen for main monu will cause the program to execute member check or automatic design. Following the completion of this step. the screen illustrated in Figure 2.23 will be shown.

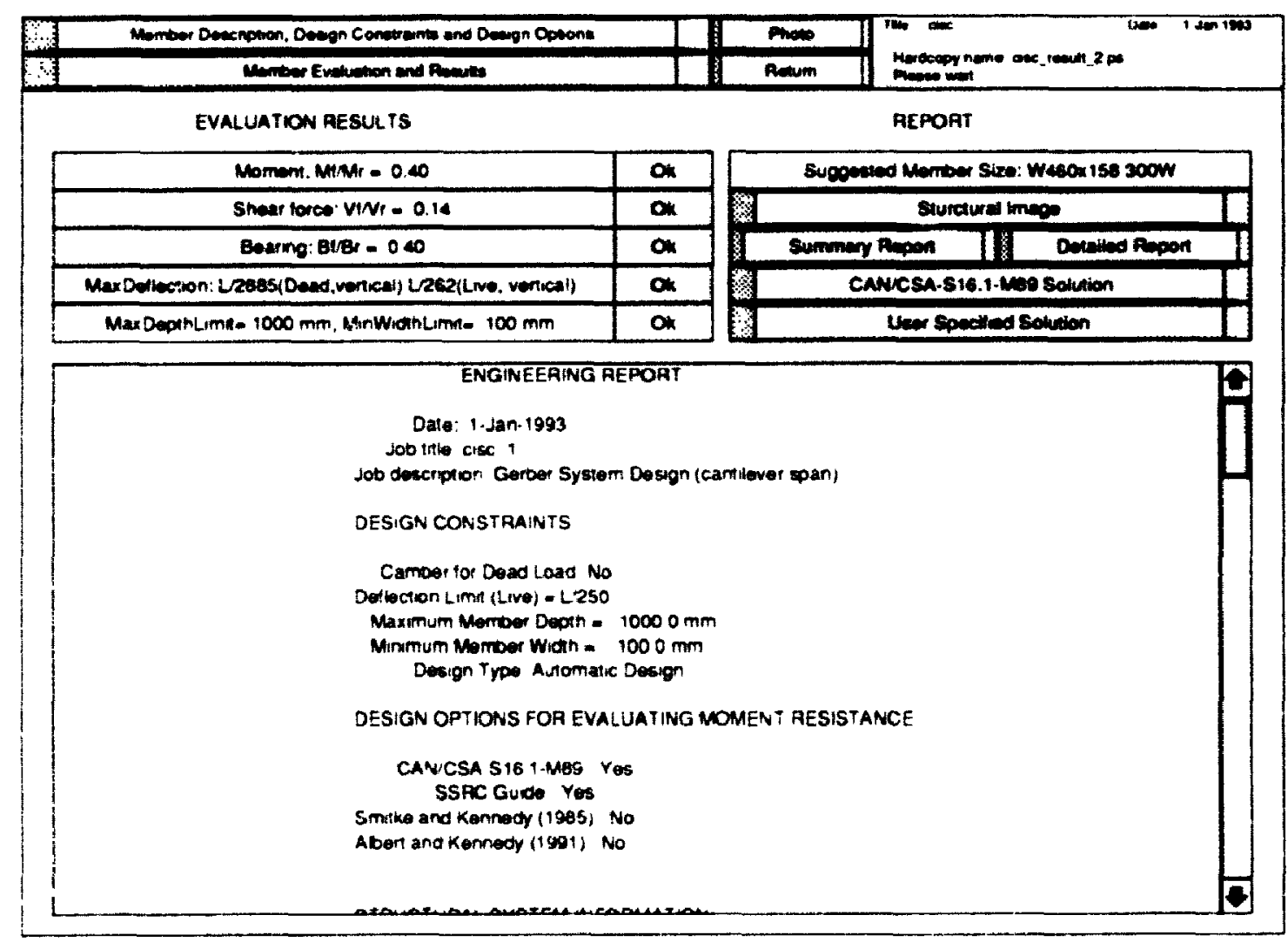

Figure 2.23: Soreen for "Mennber Evaluation and Results" 
This screen gives:

1. the section of the member checked or selected:

2. a very brief summary of the member capacity and whether or not it is satisfactory with respect to serviceability and geometric constraint criteria. The capacity of the member is expressed as a ratio of the maximum factored load to the factored resistance and has a value less than or equal to 1.0 if it is satisfactory. The corresponding indicator will read Ok:

3. a button entitled, Structural Image. which when activated will instruct the program to show the flexural member and in-plane and lateral supports in the window provided;

4. a button entitled, Summary Report, which when activated will display an engineering report in the window provided for review.

5. a button entitled. Detailed Report. which when activated will display a detailed enginecring report for review.

The buttons entitled. CAN/CSA-S16.1-M89, and. User Specified Solution. specify the solution to be shown on screen. A description of the contents of the summary and detailed reports is given in the next section.

\subsubsection{Output files}

The program IDFSM is capable of producing both the summary and detailed reports, in the form of computer files. Fach can be combined with optional graphic output specified by the user.

The summary report contains all user defined and/or default design parameters, with the exception of the applied loads which can be reported graphically: and gives 


\begin{tabular}{|c|c|c|c|c|}
\hline \hline File description & File directory & File type & File prefix & File suffix \\
\hline summary report & data2 & ascii text & (Job name) & .sum \\
\hline detailed report & data2 & ascii text & (Job name) & .det \\
\hline screen image & data2 & PostScript & (Job name) & .ps \\
\hline \hline
\end{tabular}

Table 2.1: Output file formats

the appropriate resistance values and the corresponding ratios, Example contents are given in Chapter 7 (Section 7.7 ). This report is available from the beginning of the design process. and it s contents may vary drpending upon the position of the user within the drsign process.

The detailed report provides all the intermediate design checks, for each load combination, as well as the results from the structural analysis. Example contents are given in Chapter 7 (Section 7.3 and 7.9$)$ ).

A Photo button is included in each scrern of the program IDFSM. The selection of this button at specific screen would generate a PostScript file of this window that may contain the non-menu part of the sereen or entire screen as specified by the user. The user must specify the prefix file name for each Post Script file. This facility enables the struct ural engineer to obtain a had copy of the st ructural image. load definitions. internal fore diagrams and any other displats of the screen. Ill user-related output file formats are described in Table 2.1 .

With these outpat fike avalahle. the design performed by the program IDFSM will not be a "black box". as in the ase with most existing design software. 


\section{Chapter 3}

\section{ANALYSIS MODELLING}

The two analysis modules in the program IDFSM are capable of analyzing the flexural members identified in the program for the internal forces. monents. shears. torques (where applicable), and for deffections. The first of the two modules. is based on PLFRAM, an independent plane frame analysis program developed by Murray (1988). Modifications have been made to this program for its use within the program IDFSM and are described in Section 3.1. The second module is for torsional analysis and consists of a number of subroutines from another independent program TORSTEEL. The analysis procedures. described in AISC (1983). are summarized in this chapter.

\subsection{Module PLFRAM}

The PLFRAM program module was developed for the analysis of plane frame structures and utilizes the stiffness method to perform first-order elastic analysis. The shear deformation of the flexural members are not included in the stiffness formulation. The analytical procedure is well document in the program code.

The program PLFRAM is integrated to main program by system calls from within the program IDFSM. The input and output data are exchanged between PLFRAM 
and IDFSM by file transmission. The modifications have been made in the input data processing portion of the program PLFRAM to antomate data input file generation from less cryptic graphical input and to automatically generate 100 submembers and the corresponding load definitions with any span. The second modification was required to obtain accuration descriptions of internal force distributions and of the deflected shape. as lhe original version of PI.FRAM only gives the interna: forces at member ends and the deflections at nodal points. The analy tical procedures followed, input and output modifications made for IDFSM (dished blocks) are shown in the block diagram in Figure 3.1.

The diagrams for shear force. bending moment and deflected shape can be viewed on the sereen as shown in a typical display in Figure 2.22. The bending moments are plotted on the tension side of the member. The maximum internal torce values and the maximum deflection. for each span. are shown on the diagrams. The deflected shape is proportional but not drawn to anle. The values associated with these diagrams are listed in the detailed report for each load combination. 


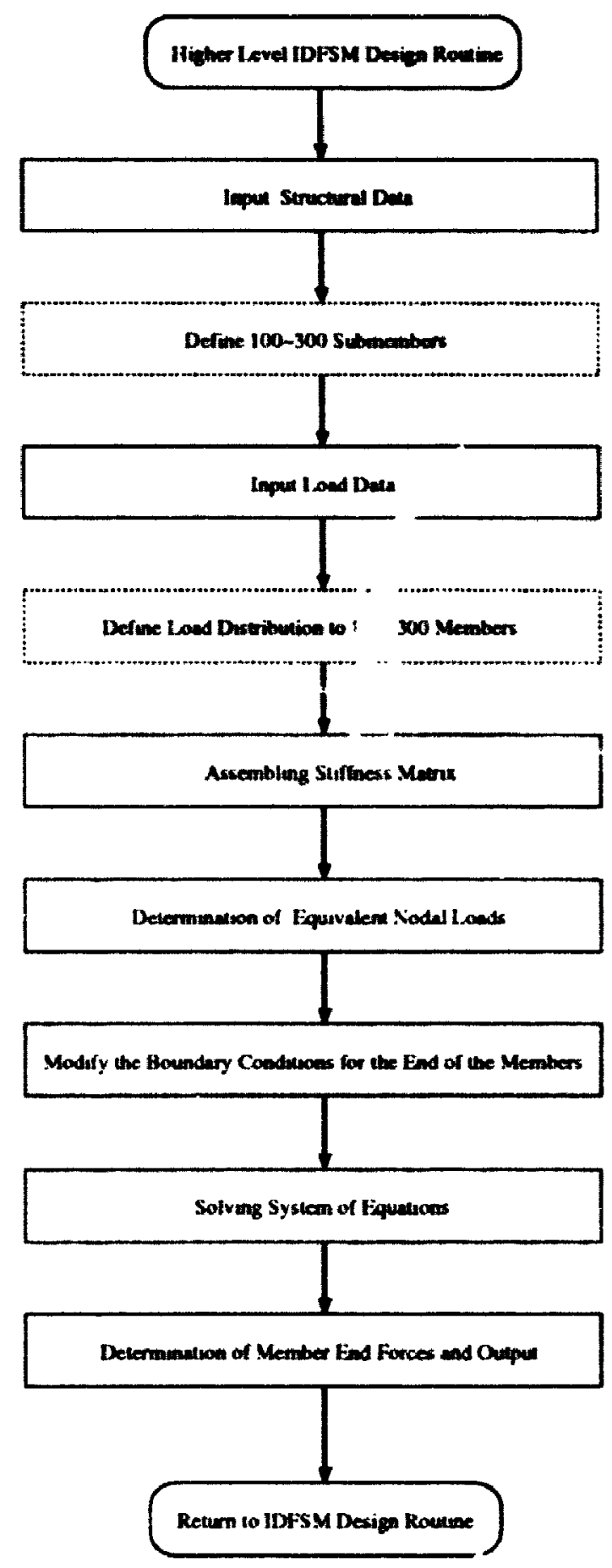

Figure 3.1: Block diagram for incorporating PLFRAll module 


\subsection{Analysis for Torsion and Bending}

\subsubsection{General procedure}

$A$ beam will be subjected to combined bending and torsion when the transverse forces pass through any point other than tice shear centre of the section. When the deformations caused by these loads are small (general structural engineering assumption and definition), then the bending and torsional loads can be evaluated separately. Bending moments and shear forces and the corresponding stresses due to the transverse load are calculated using the first order elastic analysis described in Section 3.1. The internal torque and the corresponding stresses are determined using a classic first order elastic analysis outlined in ASIC (1983) and summarized in Section 3.2.2. Once the internal forces due to transierse loads and torsional loads have been obtained, an evaluation of a beam and its redesign can be conducted using the method outlined in Driver and kennedy (1989) as described in Section 4.6.

\subsubsection{Torsional solution}

The resistance of a cross section to a torsional moment $T$ may be considered to be the sum of two components. Kollhrunner and Basler (1969). The first is the resistance to uniform torsion (St. Venant's torsion). $T_{1}$. while the second is the non-uniform torsion (llarping torsion), $\mathrm{T}_{2}$.

\section{Uniform torsion}

The general orientation of a l-shape beam in torsional loading is illust rated in Figure 3.2. The term "I-shaped" means any doubly-symmetric shape having two flanges and one web. Al any point along the length of the member subjected to torsional monent. the cross section will rotate through an angle of $\phi$. For noncircular cross 
sections, this rotation is accompanied by warping. Transverse sections do not remain plane after deformation. When the rate of change of the angle of twist is constant along the member, the longitudinal warping deflections are also constant along the member. It is in a state of uniform ' ion or St. Venant torsion. The torsional moment, $T_{1}$, resisted by the section is:

$$
T_{1}=G J \frac{d \phi}{d Z}
$$

where,

$$
\begin{aligned}
& G=\text { shear modulus of elasticity, (for sted. } G=\pi 7000 \mathrm{MPa} \text { ) } \\
& J=\text { torsional constant for the cross section. } \mathrm{mm}^{4}
\end{aligned}
$$

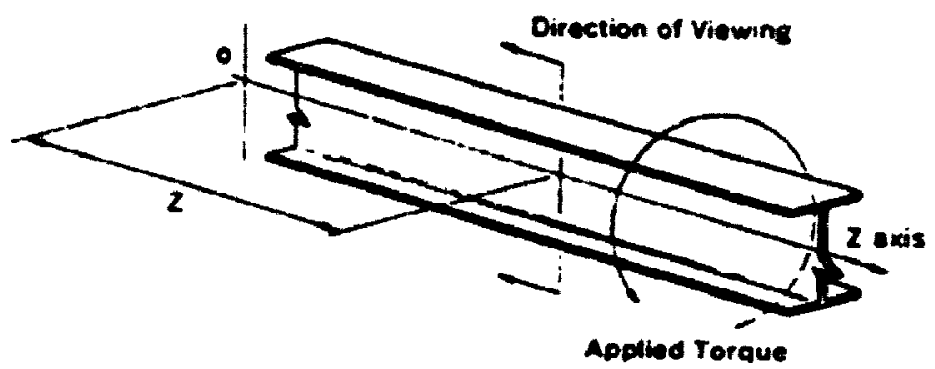

Apolied Torque

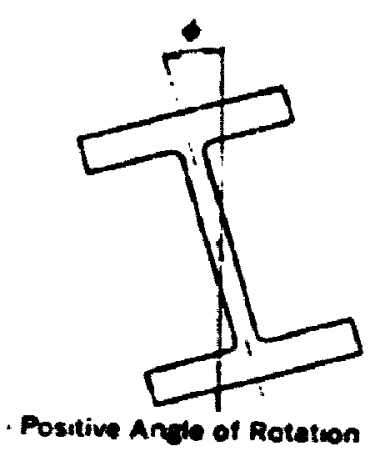

Positive Ande of Rotation

Figure 3.2: Gencra! orientation of member in torsion. AISC (198:3). p.6

Uniform torsion occurs when the iorque is constant and the ends of the member are free to warp. In this case, the torque acting at any cross-section is resisted by a set of shear stresses distributed around the cross-section.

\section{Non-uniform torsion}

When the tendency for a cross section to warp freely is prevented or restrained. then the angle of twist saries along the nember, causing a state of non-uniforn torsion. 
Kollbrunner and Basler (1969). In this case. the warping deflections vary along the member, and an additional set of shear stresses and warping normal stresses may be developed to form an additional torque $T_{2}$ for resisting the torque acted on the member in conjunction with $T_{1}$ due to uniform torsion. The $T_{2}$ and the angle of twist. have following relationship:

$$
T_{2}=-E C \cdot \frac{d^{3} o}{d^{3} Z}
$$

where

$$
\begin{aligned}
& E=\text { modulus of elasticit! } \text { ( for steel. } \mathbf{E}=200000 \mathrm{MPa} \text { ) } \\
& C_{u^{\prime}}=\text { warping torsional constant. } \mathrm{mm}^{6}
\end{aligned}
$$

The total torsional resisting monent $T$ for I-shaped beams is the sum of its St. Cenant corsional capacity. $T_{1}$ and warping torsional capacity: $T_{2}$ and is given as.

$$
T=T_{1}+T_{2}=(i) \frac{d O}{d Z}-H\left(\cdot \frac{d^{3} O}{d^{3} \%}\right.
$$

Equation 3.3 can be rewritten as.

$$
\frac{T}{E C_{n}}=\frac{1}{a^{2}} \frac{d o}{d \%}-\frac{d^{3} o}{d^{3} Z}
$$

where. $a^{2}=E C_{n} / \sigma_{i}, J$

\section{General solution}

The general differential expation for a beam subjected to a concent rated torque. $T_{f}$, is

$$
\frac{T_{j}}{E C^{*}}=\frac{1}{a^{2}} \frac{d o}{d Z}-\frac{d^{\prime} O}{d^{3} Z}
$$

The general whelion of which ran be writen as

$$
0=A+B \cosh \frac{Z}{a}+\left(\sinh \frac{Z}{a}+\frac{.11 \%}{(i)}\right.
$$


where, the terms $A, B$ and $C$ are constants of integration which can be determined by evalua ting the appropriate derivative of the general solution for the given boundary conditions. The torsional conditions and schernatic representation of connections rausing those conditions are illustrated in Figure 3.3. The corresponding physical and mathematical conditions are summarized in Table 3.1. where $\phi^{\prime}$ and $\phi^{\prime \prime}$ are the frst and second derivatives of angle of twist, $\phi$.

\begin{tabular}{ccc}
\hline $\begin{array}{c}\text { Mathematical } \\
\text { Condition }\end{array}$ & $\begin{array}{c}\text { Physical } \\
\text { Condition }\end{array}$ & $\begin{array}{c}\text { Torsional } \\
\text { End Condition }\end{array}$ \\
\hline$\phi=0$ & No rotation & Pinned or fixed end \\
$\phi^{\prime}=0$ & Section cannot warp & Fixed end \\
$\phi^{\prime \prime}=0$ & Section can warp freely & Pinned or free end \\
\hline \hline
\end{tabular}

Table 3.1: Torsional boundary conditions. Als(' (1983) p.80

For other torque dist ributions like uniformly and linearly varying torque moment distributions, similar solutions can be obtained by differentiating Equation 3.5 and analyzing the corresponding free body diagrans (see .ISC $19 \times 3$ for details). The twelve cases of different torsional boundary conditions and loading that have been incorperated into IIPFS.M are illustrated in Figure 3.1. 'Me correponding solutions. AISC (198:3). are liste Figure $3,5$.

\subsubsection{Program implementation}

Subroutine $\mathbf{r} 123$ (file: routines_torsteel.f) in the program IDFS.II calculates the angle of twist $\phi$, all its deriuatives $\phi^{\prime}$. $\phi^{\prime \prime}$. $\phi^{\prime \prime \prime}$ and the corresponding internal torques for all cases identified in Figure 3.4. The block diagram and complete description. with examples. for the torsional analysis and denign is given in section 1.6 . 

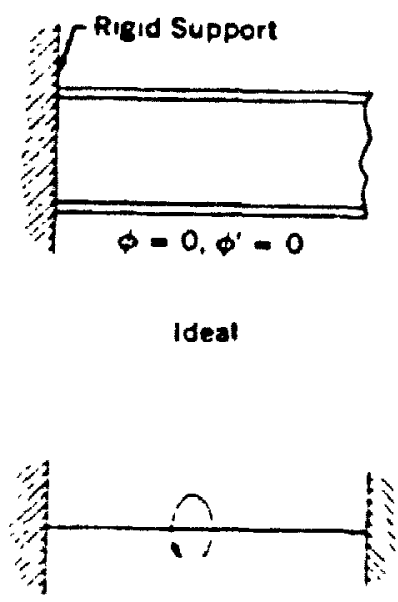

Schematic Representatirr:
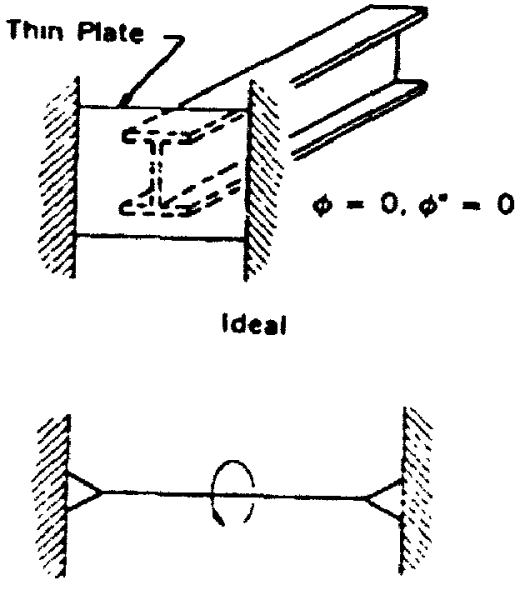

Schematic Representation

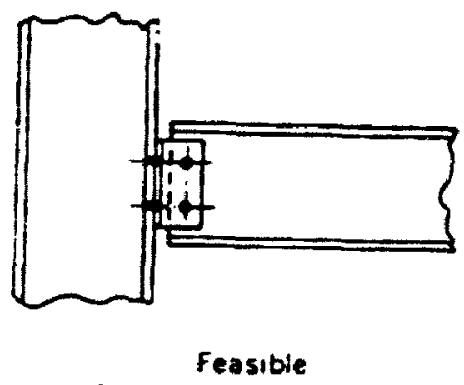

Structural Connection

(a) Fixed End

(b) Pinned End

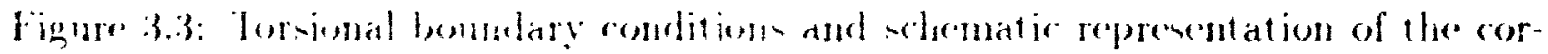

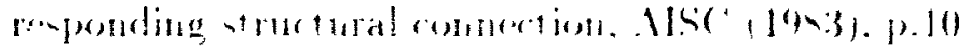




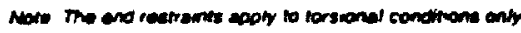

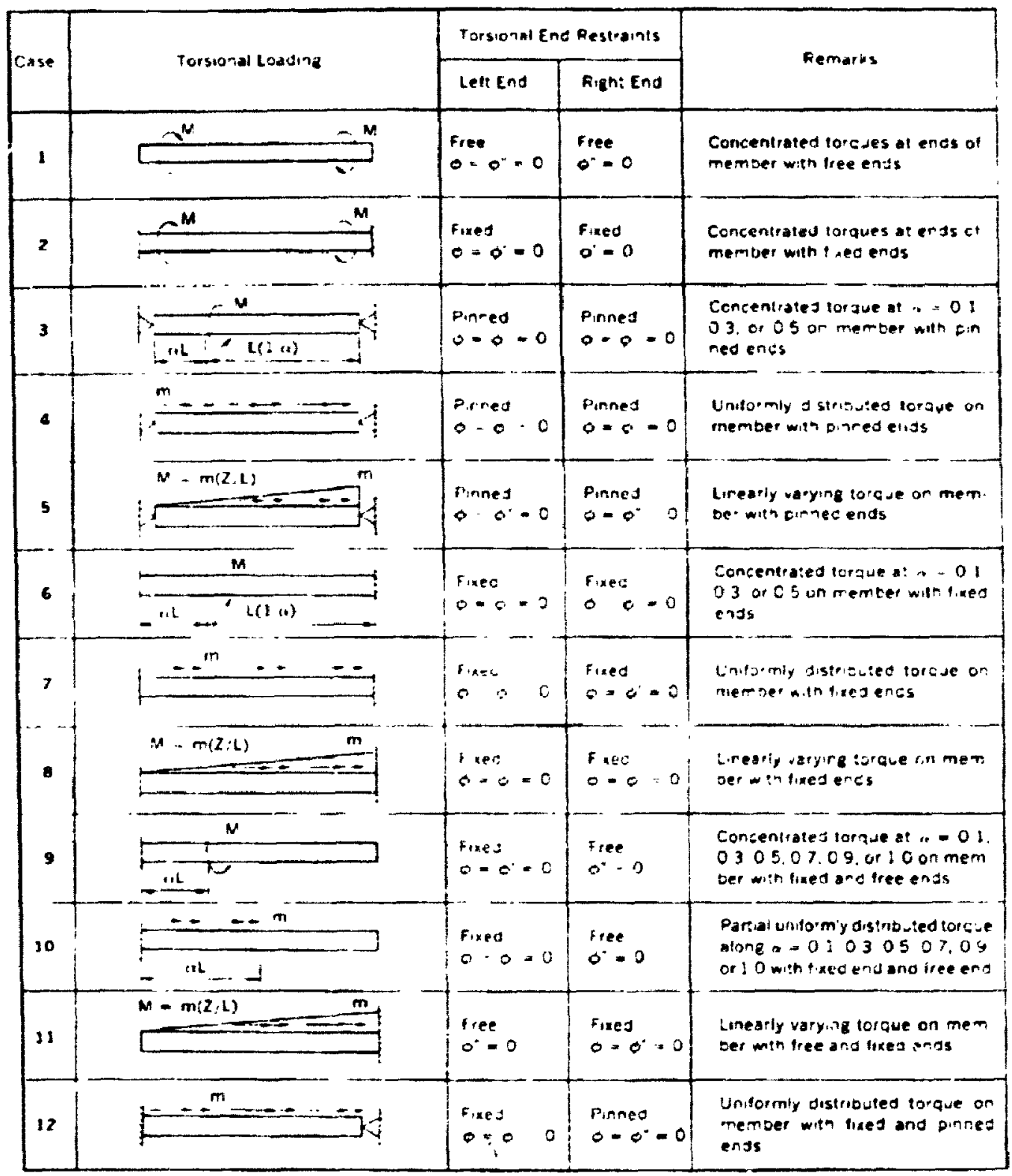

Figure 3.1: Vation torsional loading and and conditions. ALS (1953) p.26 


\section{SOLUTIONS TO DIFTERENTIAL EQUATIONS}

\section{FOR VAROUS LOADINES AND BOUNDARY CONDITIONS}

The following are the solutions of the difierential equations using the proper boundary conditions. Take derivative of $*$ equation to find $* * "$. and $* "$.

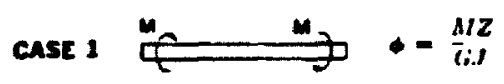

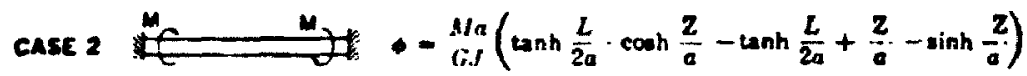

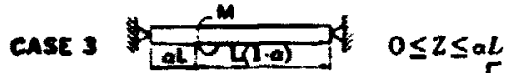

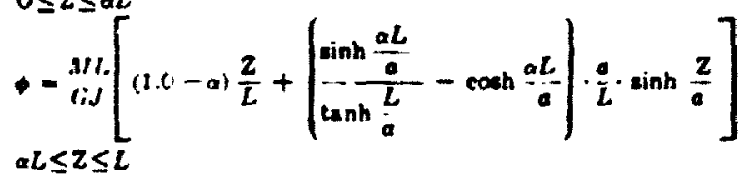

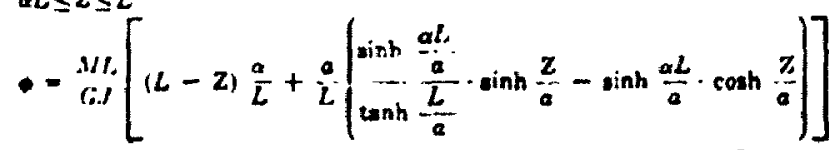

case 4 $\stackrel{m=0}{=}=-\frac{m a^{i}}{=}\left[\frac{L^{2}}{2 a^{i}}\left(\frac{z}{L}-\frac{Z}{i}\right)+\cosh \frac{z}{a}-\tanh \frac{L}{2 a} \cdot \sinh \frac{z}{a}-1.0\right]$

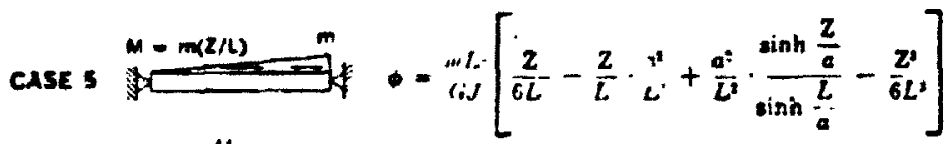

CASE 6

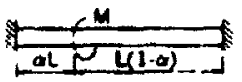

$$
\begin{aligned}
& -=\frac{M H a}{i H+1 i \sigma J}\left\{\left[H \cdot\left(\frac{1}{\sinh \frac{L}{a}}+\sinh \frac{\alpha L}{a}-\frac{\cosh \frac{a L}{a}}{\tanh \frac{L}{a}}\right)+\left(\sinh \frac{\alpha L}{a}-\right.\right.\right. \\
& \left.\left.\left.\left.\frac{\cosh \frac{a L}{a}}{\tanh \frac{L^{-}}{a}}+\frac{1}{\tanh \frac{L}{a}}\right]\right] \cdot \cosh \frac{z}{a}-1.0\right]-\sinh \frac{z}{a}+\frac{z}{a}\right\} \\
& a L \leq Z \leq L
\end{aligned}
$$

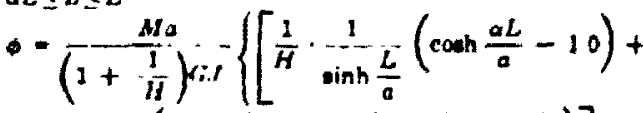

$$
\begin{aligned}
& \left(\cosh \frac{\left.\frac{a L}{a}-\cosh \frac{L}{a}+\frac{2}{a} \cdot \sinh \frac{L}{a}\right)}{\sinh \frac{L}{a}}\right]+
\end{aligned}
$$

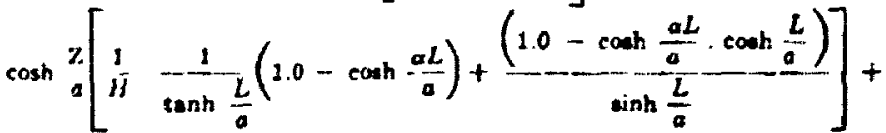

$$
\begin{aligned}
& \left.\sinh \frac{z}{a}\left[\frac{1}{H}\left(\cosh \frac{\alpha L}{a}-1.0\right)+\cosh \frac{\alpha L}{a}\right]-\frac{z}{a}\right\}
\end{aligned}
$$

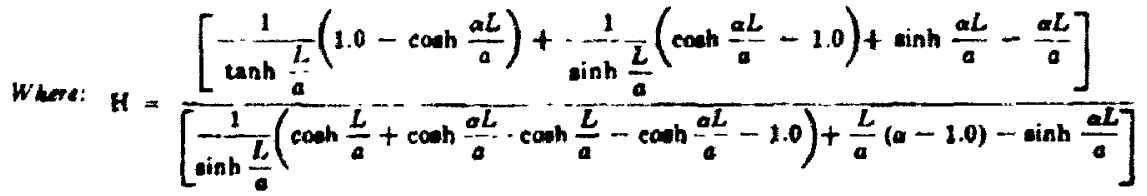

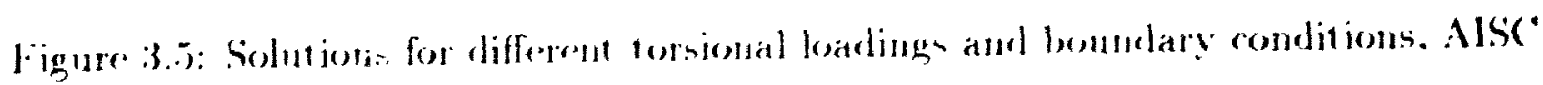
$\{19 \times 3\} ., 1 . x .5$ 


$$
\begin{aligned}
& \text { Case } 7=-m+\frac{m L a}{2 G \bar{J}}\left[\left(\frac{1+\cosh \frac{L}{a}}{\sinh \frac{L^{-}}{a}}\right)\left(\cosh \frac{z}{a}-1.0\right)+\frac{z}{a}\left(1-\frac{z}{L}\right)-\sinh \frac{z}{a}\right]
\end{aligned}
$$

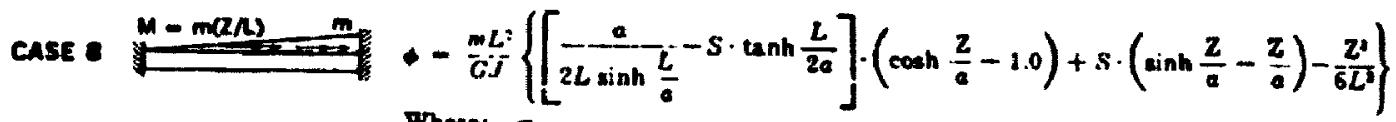

$$
\begin{aligned}
& \text { Where: }=\left[\begin{array}{l}
\left(\cosh \frac{b}{a}-1.0\right) \cdot \frac{a}{2 L}-\frac{\sinh \frac{L}{a}}{6.0} \\
\left(\frac{L}{a} \sinh \frac{L}{a}+2.0-2 \cosh \frac{L}{a}\right)
\end{array}\right] \\
& \text { case ? } 0 \leq \mathrm{C}
\end{aligned}
$$

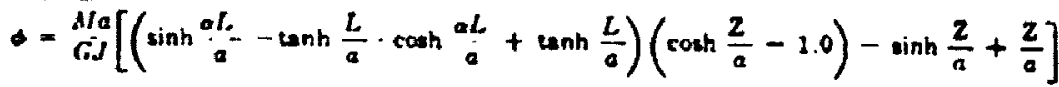

$$
\begin{aligned}
& a L \leq z \leq L \\
& \text { - }=\operatorname{MJ}_{\operatorname{CJ}}\left[\left(\operatorname{Lanh} \frac{L}{a} \cdot \cosh \frac{a L}{a}-\tanh \frac{L}{a}-\sinh \frac{a L}{a}\right)-\left(\cosh \frac{a L}{a}-10\right)\right. \\
& \left.\left(\tanh \frac{l}{a} \cdot \cosh \frac{z}{a}\right)+\left(\cosh \frac{a L}{a}-10\right) \cdot \sinh \frac{2}{a}+\frac{a L}{a}\right] \\
& \text { CAse } 10 \text { al } 0 \leq z \leq \alpha z
\end{aligned}
$$

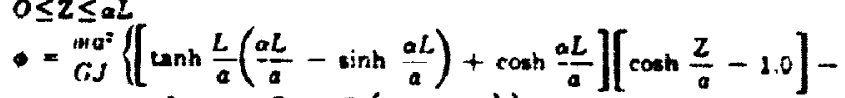

$$
\begin{aligned}
& \left.\frac{\alpha L}{a} \cdot \sinh \frac{2}{a}-\frac{2}{a}\left(\frac{a L}{a}-\frac{z}{2 a}\right)\right\} \\
& \alpha L \leq Z \leq L \\
& \text { - }=\frac{\operatorname{mat}}{G \bar{J}}\left[\tanh \frac{L}{a} \cdot \sinh \frac{a L}{a}-\cosh \frac{a L}{a}-\frac{a L}{a} \cdot \tanh \frac{L}{a}+20+\frac{a^{2} L^{2}}{2 a^{2}}-\right. \\
& \left.\left(\sinh \frac{a L}{a}-\frac{a L}{a}\right) \cdot \operatorname{conh} \frac{L}{a} \cdot \cosh \frac{2}{a}+\left(\sinh \frac{a L}{a}-\frac{a L}{a}\right) \cdot \sinh \frac{z}{a}\right]
\end{aligned}
$$

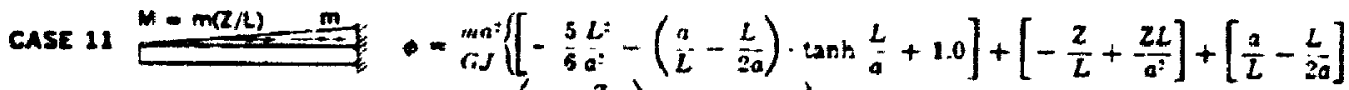

$$
\begin{aligned}
& \left.\left(\begin{array}{c}
\sinh \frac{2}{a} \\
\cosh \frac{L}{a}
\end{array}\right)-\frac{2:}{5 a^{2}} \cdot \frac{z}{L}\right\} \\
& \text { CAsE } 12+\frac{m}{\sigma o j}\left[H \cdot\left(\tanh \frac{L}{a}-\frac{z}{a}-\tanh \frac{L}{a} \cdot \cosh \frac{z}{a}+\sinh \frac{z}{a}\right)+\right. \\
& \left.\frac{\cosh \frac{z}{a}}{\cosh \frac{l}{a}}-\frac{1}{\cosh \frac{L}{a}}-\frac{z:}{2 a}\right] \\
& H=\left(-\frac{L^{2}}{2 a^{2}}-1.0+\frac{1}{\cosh \frac{b}{a}}\right) \cdot \frac{1}{\left(\tanh \frac{L^{2}}{a}-\frac{L}{a}\right)}
\end{aligned}
$$

Figure 3.5: Solutions for different torsional loadings and houndary conditions (Continued). Als(' (1983). p.86 


\section{Chapter 4}

\section{MEMBER DESIGN}

\subsection{Introduction}

Thi (hapter describes the structural design methodology adopted in the program IDFS.M. The focus is given to methods concerning the analysis and design of flexural sterl members that are referred in CAN/CSA-S16.1-.1LS9 in Clause 6, 11.1. 13.6.15.3.1 and 15.11. and to recent research yet to be incorporated into ( AN/CSA-S16.1-M89 and into existing structural soft ware.

\subsection{Classification of Sections}

Owerall menther behariour is a function of the local buckling behariour of the plate olement that make up the section and are categorized as Class 1. 2. 3 or 4 type sections. The linit between sach class are defined in terms of the slenderness of the plate elenerit and are a function of the boundary conditions, applied stress distribution, yirld strength and residual stresces. The limits given in CAN/CSA- 
\$16.1-.189 in Clause 11.1 for I-shapes subjert to bending have been incorporated into the program IDFS.II and are summarized in Table 4.1.

\begin{tabular}{ccc}
\hline \hline Section Class & Flange & Web \\
Class 1 & $b / t \leq 145 / \sqrt{F_{y}}$ & $h / u \leq 1100 / \sqrt{F_{y}}$ \\
('lass 2 & $b / t \leq 170 / \sqrt{F_{y}}$ & $h / u \leq 1700 / \sqrt{F_{y}}$ \\
('lass 3 & $h / t \leq 200 / \sqrt{F_{y}}$ & $h / u \leq 1900 / \sqrt{F_{y}}$ \\
\hline \hline
\end{tabular}

Table 1.1: Width-thickness ratios for section classification

Sections are defined as Class $t$ if they fail to met requirements listed in Table 1.1. Currently the program IDFSM does not design or check the capacity of Class 4 sections. it excludes only one section if grade 30011 sted is specified ( $11117500 \times 197$ ) and $x$ others if grade $350 \mathrm{~W}$ sterl is sperified.

\subsection{Cross-Section Strength}

The cross-section strength of members subjected to bending can be determined fiom ('lause J3.5 of CAN/(SA-S16.1-MR!) as:

- for Class 1 and ('lass 2 sections.

$$
M_{\mathrm{r}}=\phi Z F_{y}=\phi M_{p}
$$

- and for ('lass 3 sections.

$$
\boldsymbol{H}_{\tau}=0.5 F_{y}=0 . \boldsymbol{H}_{\mathrm{y}}
$$

where, $Z=$ plastic section modulus

$$
u_{r}=\text { plastic moment }
$$




$$
\begin{aligned}
& S=\text { clastic section modulus } \\
& \boldsymbol{M}_{y}=\text { yield moment }
\end{aligned}
$$

The noment capacity of flexural members with continuous lateral support along the compression flanges is given by its cross-section strength.

\subsection{Shear Capacity for Beam}

In arcordance with the clause 13.4 of CAN/CSA-S16.1-M89 standard. for a uncoped I-shaped beam or a coped beam with I-shape, the factored shear resistance, $V_{r}$, developed by the web of beam is.

$$
l_{r}=0.1, \%
$$

where.

$$
A=\text { shear area (dw for rolled shapes and hw for girders) }
$$

$F_{4}=$ the ultimate shear stress. depending upon the width-thickness ratio of web as defined in (lanse 13.1.1

For a coped heam, with 1 or Rectangular shape, it is assumed that the commection ascrmbly is capable of preventing the shear buckling of the web and that the factored -hear resistance can be taken as.

$$
i=0.1_{i}\left(0 .\left(i f i f_{y}\right)\right.
$$




\subsection{Lateral-Torsional Buckling Strength}

\subsubsection{General}

The determination of the lateral-torsional buckling capacity of a steel beam is relatively complex and is one of the prine concerns in the development of the program IDFSM. The complexity of evaluating and obtaining a good estimation of the latcraltorsional buckling capacity of a beam lies in the difficulty of assessing the influence on capacity due to the load distribution, the location of the load along the length of the tnember and with respect to the shear center and of the lateral restraint (restraint against lateral displacements, rotation, warping and shear distortions of the web) provided to the beams by OWSJ's, heam, columns and structural steel connections.

Extensive research in this field has been conducted by Johnston (1976). Trahair (1977), Kirby and Nethercot (1977,1983), Schmitke and hennedy (1984). Albert and Kennedy (1991) and others. Closed-form analytical solutions exist for most simple cases and are summarized in the "Gujde to Structural Stability Design Criteria for Met al Structures”, Galambos (1988). Since current design standards give only limited design rules with regard to the design of laterally unsupported members. there is a need to provide a comprehensive set of design guidelines to solve most common design problems and there is also a need to develop the corresponding computer soft ware to facilitate the process.

In this section, appropriate lateral-torsional buckling capacity solution strategies

are discussed, and the design approaches employed by program IDFSM in accordance with these strategies are presented. 


\subsubsection{Assumptions}

The following general assumptions have been made in the procedures employed by the program IDFSM for evaluating the lateral-torsional buckling problems.

1. The beam is geometrically perfect.

2. The applied loads act solely in the plane of the wrak axis.

3 The deflection of the member is small.

1. The shape of the cross section does not change during buckling.

5. The prebuckling deflection either in-plane or out-of-plane have no effect on the lateral-torsional buckling behaviour of the beam.

The first four above assumptions are common assumptions for beam stability probtems. The last assumption is considered to be valid when the ratios of the minor axis flexura! stiffness and torsional stiffness to the major axis flexural stiffness is small, Yong and Trahair (1992). The I-shaped members produced in Canadian mills and comsidered in this thesis fall into this category.

\subsubsection{Lateral-torsional buckling behaviour}

Members that are loaded in the plane of the weak axis and not continuously laterally supported along the compression flange may fail by lateral-torsional buckling. This type of failure is a bifurcation problem and occurs when the critical moment is reached.

\section{(a) Uniform bending case}

A perfectly straight elantic beam loaded by equal and opposite end moments applied abent the $x$-axis is shown in Figure 1.1 (p.322. (chen and Lui 1987). 
By equating the corresponding external and internal moments, the governing differential equations can be written as

$$
\begin{aligned}
& E I_{x} \frac{d^{2} v}{d z^{2}}+M_{0}=0 \\
& E I_{y} \frac{d^{2} u}{d z^{2}}+\gamma M_{0}=0 \\
& G J \frac{d \gamma}{d z}-E C_{u} \frac{d^{3} \gamma}{d z^{3}}-\frac{d u}{d z} M_{0}=0
\end{aligned}
$$

where,

$I_{x}, I_{y}$ moments of inertia atout the $\mathrm{X}$ and $\mathrm{Y}$ axis respectively

$u, v$ displacements in the $\mathrm{x}$ and $\mathrm{y}$ direction respectively

i $\quad \cdots$ angle of twist about the $Z$ axis

$M_{0} \quad$ - applied moment

J St. Venant torsional constant

$C_{y}$ - warping torsional constan!

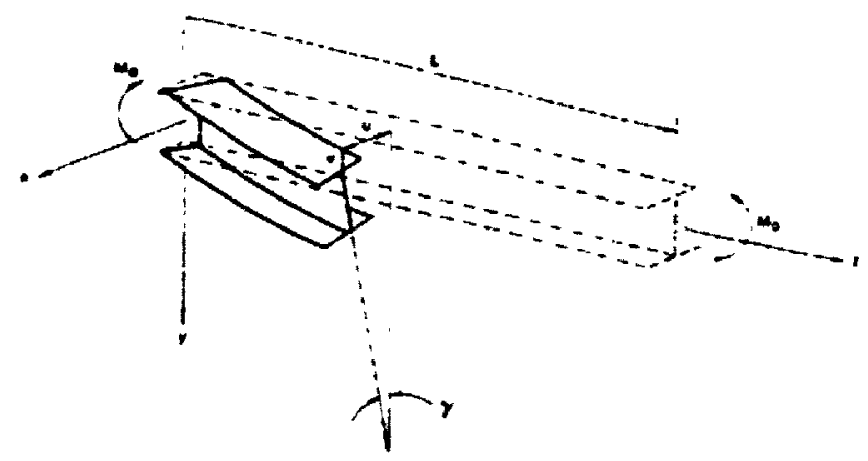

Figure 4.1: Lateral buckling of an I-section under uniform moment

The solution to ahove three equations given by Timoshenko (1961) is.

$$
M_{\mathrm{Ucr}}=(\pi / L) \sqrt{E I_{y} G J} \sqrt{1+\frac{\pi^{2} E C_{u}}{L^{2}(i J)}}
$$


where,

1. -..- length of the unbraced portion of the beam

$U_{r r}$ minimum (critical) moment at which lateral-torsional burk-

ling occurs

\section{(b) Nonuniform bending case}

In the case of a beam subjected to unequal moments at ends (i.e. a moment gradient), the general solution can be written as,

$$
M_{\cdot r}=\dot{\nu}_{2} \cdot M_{0 \cdot r}
$$

where $-_{2}$ is defined as equivalent uniform moment factor. Equation 4.9 is identical 10 the expression given in Clause 13.6 of CAN/CSA-S16.1-M89 for critical elastic moment capacity. $\mathbf{M r}_{\mathrm{cr}}$.

The maxinum moment resistance of a beam is its cross-sectional strength as defined in ('lause 13.5(a) in (AN/CSA-S16.1-M89 as the plastic moment capacity for ('lass 1 and Class 2 sections and in Clause 13.5 (b) as the elastic moment capacity for (lass 3 sections. The inelastic lateral-torsion buckling capacity is obtained from a st raight-line interaction equation given in Clause 13.6. The focus of this section on solntion strategies is in determining the correct values for $\omega_{2}$ and $L$ and hence $\mathbf{M}_{c r}$ or $M_{r}$ dirertly. The major factors influencing the elastic lateral-torsional buckling rapacity of a beam and its design are:

- member geometry. cross-sectional properties and length of laterally unsupported segment :

- Iype of in-plane support:

- type and location of lateral support and stiffness of lateral support; 
- load patterns and location of applied load;

- geometric imperfections (out-of-straightness);

- magnitude and distribution of the reidual stresses.

The latter two can only be incorporated into solutions using sophisticated finite element models such as the one presented by Albert and kennedy (1991).

\subsubsection{Review of different solution strategies}

As shown in Figure 2.1, the program IDFSM gives the user four options with respect to the evaluation of lateral-torsional buckling capacity of flexural members. At this time, only the first three are implemented. The strategies related to each of these options are described in the following sections.

\section{CAN/CSA-S16.1-M89 solution}

The equations and design rules in CAN/CSA-S16.1-M89 (lause 13.6. which is entitled "Bending-Laterally l'nsupported Members". form the core part of the design rules implemented in the program IDFSM as they embody the limit states design philosophy, describe probable failure modes. and by aw are the minimum design requirements. Hence all members are either checked or designed according to these rules. The general guidelines gi ien in CAN/CSA-S16.1-M89 make reference to and encompass other methods of evaluating the elastic critical moment capacity of flexural members that are not explicitly covered by the standard. such as cantilever beams and continuous beams with overhangs.

If the Modified SSRC Guide (1988) option is not activated. then ${ }_{-2}$ in Equa. tion 4.9 will be evaluated according to Clause 13.6.1. in CAN/CSA-S16.1-MS9.

$$
\dot{H}_{2}=1.75+1.05 \kappa+0.3 \kappa^{2} \leq 2.5
$$


where,

$n=$ ratio of the smaller factored moment to the larger factored moment at opposite ends of the unbraced length: the value is positive for double curvature and negative for single curvature

$\dot{\omega}_{2}=1.0$ when the bending moment at any point within the unbraced length is larger than the large end moment or when there is no effective lateral support for the compression flange at one of the ends of the unsupported length

The following rules for elastic and inelastic la'eral-torsional buckling capacity and cros:-sectional st rength as given in Clause 13.6 of CAN/C'SA-S16.1-M89 apply to all the lateral-torsional buckling solution st rategies implemented in the program IDFSM.

1. Elastic lateral-torsional buckling

$$
M_{r}=0 . M_{r}
$$

where. $M_{r}=$ Hic factored moment resistance

$$
O=0.9
$$

2. Inelastic lategal-torional buckling

- for donbly symmetric ('lass 1 and 2 sections, where

$$
\begin{aligned}
& U_{i,} \geq 0.67 . U_{p} \text {. then } \\
& U_{r}=1.150 . U_{p}\left(1-\frac{0.28+U_{p}}{. U_{r \mathrm{r}}}\right) \leq 0 . H_{z^{2}}
\end{aligned}
$$

- Cor dombly nimmetric (lass 3 sections, where

$$
\begin{aligned}
& H_{c r} \geq 0.67 \mathrm{H}_{y} \text {. Uhrn } \\
& U_{r}=1.150 . H_{y}\left(1-\frac{0.28 . M_{y}}{M_{r}}\right) \leq 0 . M_{y}
\end{aligned}
$$


3. cross-sectional strength

- for Class 1 and 2 sections,

$$
M_{r}=\phi M_{p}
$$

- for Class 3 sections,

$$
M_{r}=\phi M_{y}
$$

\section{Modified SSRC Guide}

If the Modified SSRC Guide (1988) option is activated. for beams without over hangings or the main spans of a continuous beam, the value in $_{2}$ is calculated using the formula proposed by hirby and Nethercot (1979).

$$
\omega_{2}=\frac{3 M_{2}+4 M_{3}+3 M_{4}+2 M_{\max }}{12 M_{\max }}
$$

where. $M_{2}, M_{3} ., I_{4}$, represent the moment values indicated in Figure $1.2 . M_{m a}$ is the maximum monent value on the span under consideration.

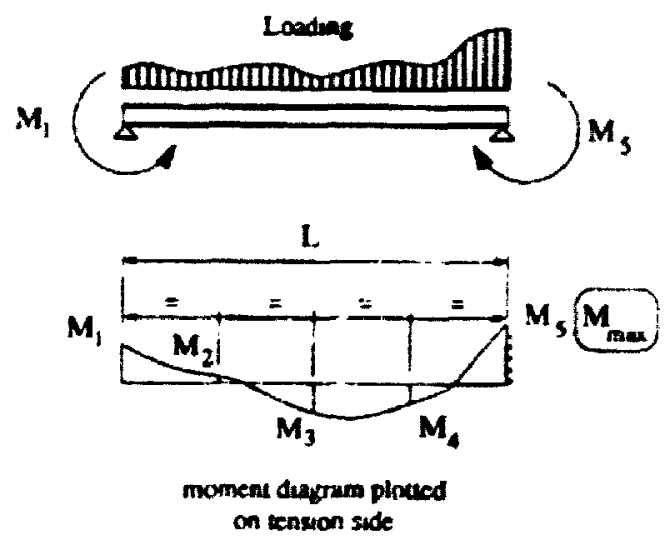

Figure 4.2: Moment diagram betwen two lat.ara!! sul ; orted points for determination of $\nu_{2}$ value. ('ls(' (1989). p.34 
All moment values are taken as absolute values. If the compression flange is laterally supported at the location where $M_{2}, M_{3}$ or $M_{4}$ is evaluated, use a moment value of zero in Equation 4.16.

In the situation in which continuous lateral support is provided to the ent ire length (main span) of the tension flange of a beam, the expression proposed by Roeder and Assadi (198:) is used to obtain the critical buckling moment.

$$
U_{r \mathrm{r}}=\omega_{2}\left[\frac{G J}{d^{\prime}}+\frac{\pi^{2} E I_{y} d^{\prime}}{2 L^{2}}\right]
$$

where $d^{\prime}=$ cott re to cent:e distance between flanges.

The basic erpuation for calculating the elastic lateral-torsional buckling caparity given $i_{1}$ ( $A N / C S A-\$ 16.1-11 S 9$ (Fquation 4.10). Kirby and Nethercot (1979) (Equation 4.16$)$ and Rorder and Issadi (1982) (Equation 4.17) rannot be applied to cantilexer beams. Galambos (19si) recommends the approach described in the SSRC: Giade. Cialambon (1985). proponed by Nethercot (1983). for a variety of luading condition: top flange loding. load applied through the shear centre or the bot tom flange) and bumdary conditiom (lateral support) at the root and tip of the cantilever. The 11. expression proposed is as follows:

$$
u_{r}=\frac{\pi}{K L} \sqrt{E I_{u}(i J} \sqrt{1+\frac{\pi^{2} E C_{u}}{(\pi L)^{2} C_{i} J}}
$$

where. $k$ in the effective length factor it ralue can be obtained by using Table 1.2

The rules mat aler be applied to the overhanging portion of a continuous beams. such as in a Cerber girder sytems.

For bigution 1.14. the following restrictions outlined in Nethereot (197:3) and

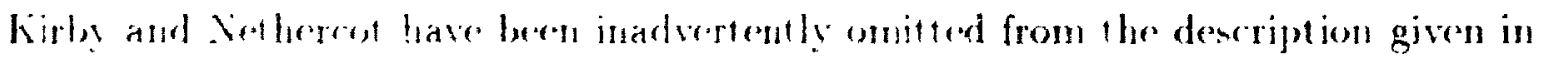

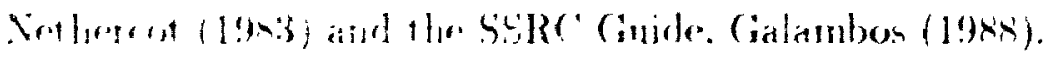




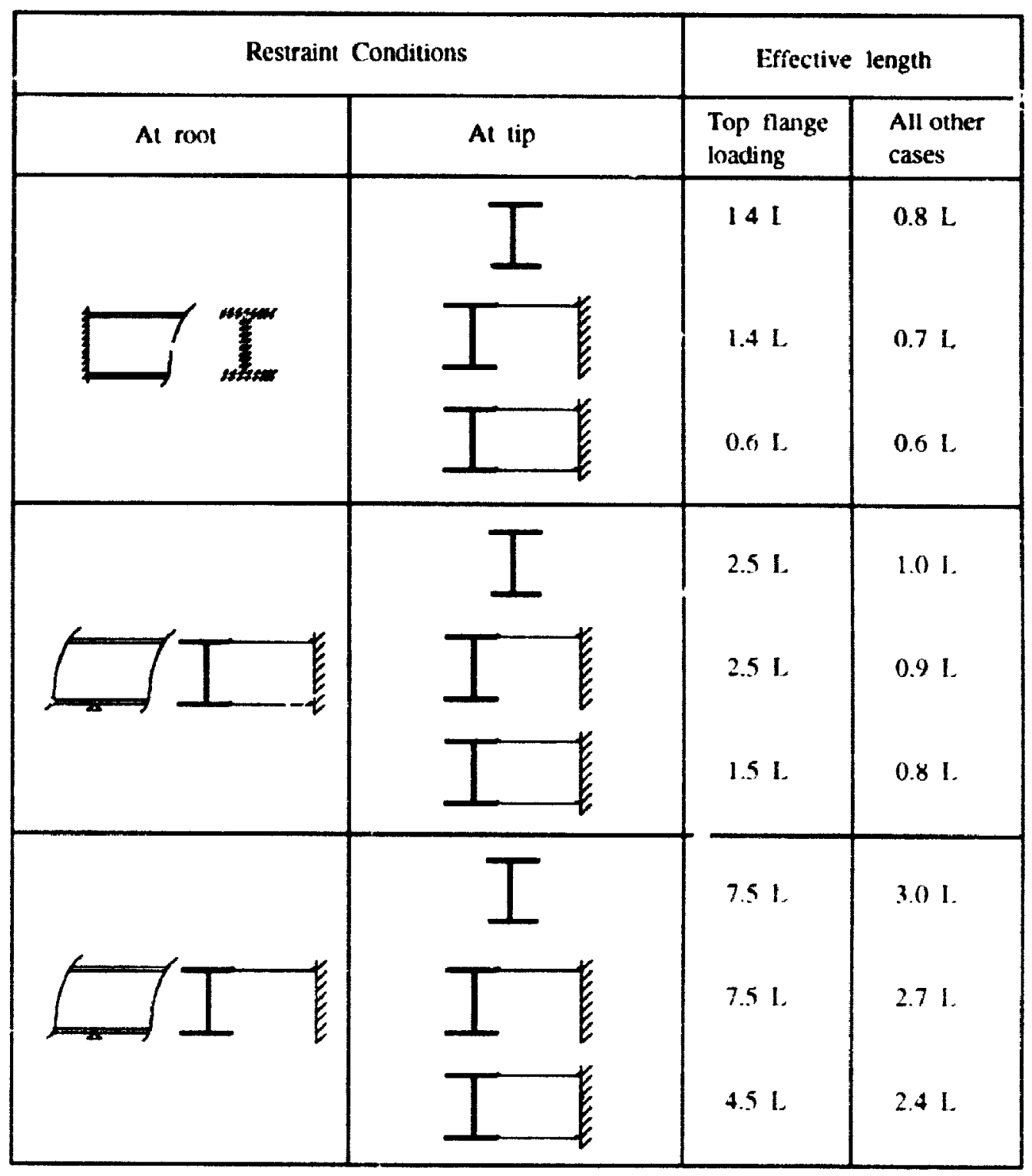

Table 4.2: Fffective length factor $K$ for cantilewers. Calambos(1988). p.168 
1. For the beam parameter. $X$

$$
0<x<1.57
$$

where.

$$
X=\sqrt{\frac{\pi^{2} E C_{u}}{\left(r . J L^{2}\right.}}
$$

2. For a overhanging beam, the effertive length of the overhanging span should not be less than the back pan.

These restriction have not wet ben incorporated into IDFSM as there is no recent literature that suggent w that the solut ions generated are incorrect. These may severely rentrict the application of the effective length factors. Future incorporation of the .llhert and kennedy (1991) finite element solution may render this portion of the pougran code obotete.

\section{Schmitke and Kennedy: interactive buckling of adjacent spans of a con- tinuous nember}

The laterally unsupported spans of a continuon beam with discrete lateral supports. an liown in Figure 4.3. do not buckle independently. Restricting the capacity of the berm whe lowe critical buckling monent rapacity of one of the lateral unsupported pan-alculated independently would be concervative. Schmitke and hennedy (198.1) lawe propened a method for determining the interactive buckling capacity of the entire feam and is ralled the eguivalent beam method. This methed has been incorporated

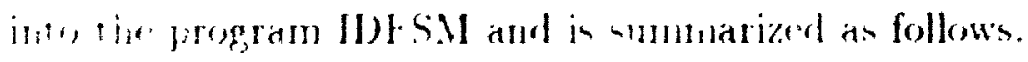

1. Compute. 14 , for the mon-miform moment on each segment. $L_{1}, L_{2} \ldots . L_{n}$ of

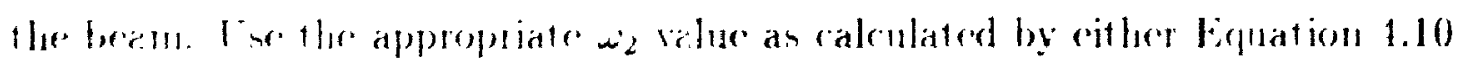
(1) 1.16i. 


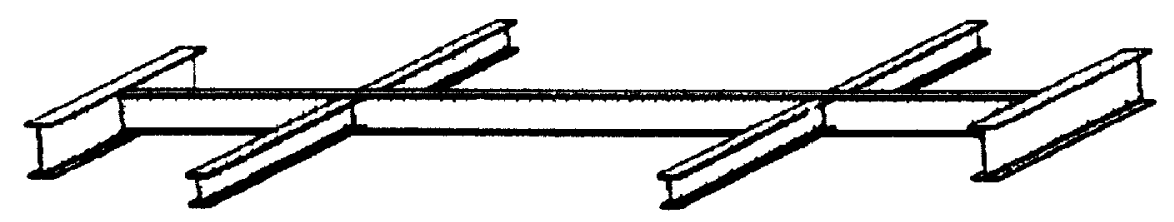

(a) Structural image

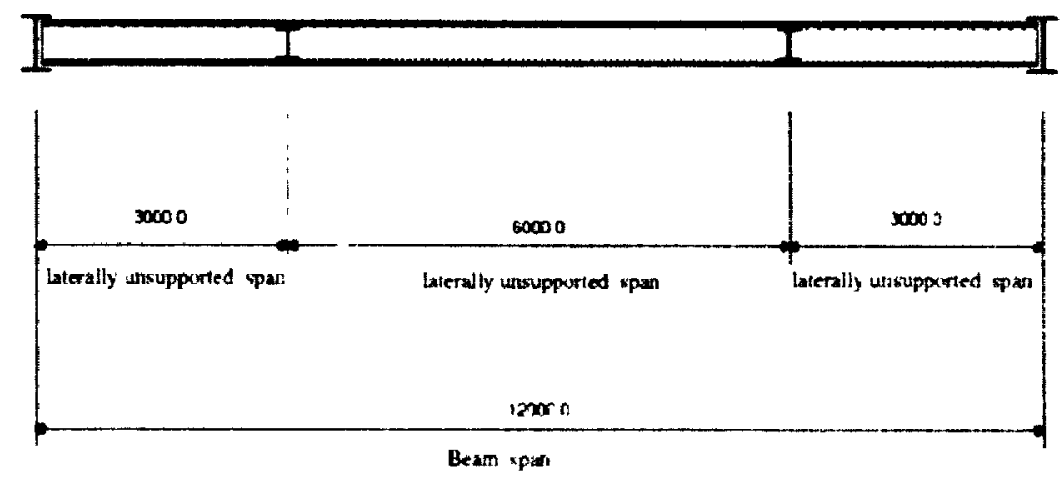

(b) I ateral span layout

Figure 4.3: Bean with discrete lateral supports

2. Compute the corresponding equivalent length of each segment for a beam with

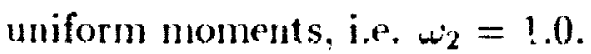

$$
L_{*}=\frac{\pi\left(E I_{y}(B J)^{1 / 2}\right.}{\sqrt{2} H_{c r}}\left\{1+\left[1+\frac{4 M_{c r}^{2} C_{u r}}{I_{y}(G J)^{2}}\right]^{1 / 2}\right\}^{1 / 2}
$$

3. Rrplace the beam by an equivalent beam (with uniform moment) of length $L$ $=\sum L_{\varepsilon}$.

1. ("alculate the effective length for each segment of the equivalent beam such that they have the same critical moment (beam buckles interactively).

$$
L^{\prime}=\sum L_{r} / n
$$


where. $n=$ number of segmont...

5. ( alculate the corresponding critical moment capacity of that segment $\left(\omega_{2}=1.0\right.$ miform moment).

6. Modify $M_{\text {er }}$ to reflect inelastic behaviour as required. refer to Equation 4.12 and 1.13.

\subsubsection{Lateral support types}

The trpe of lateral support has a pronounced effect on the lateral-torsicnal buckling remistance of beams, as to how and where the lateral supports are connected to the beams: and to the restraint they provide to the beam through their flexural and axial stiffues. Funr typica' types of lateral supports have been included for in the program II)FS.11. shown in Figure 4.1.

The evaluation of the effect of the lateral support on $M_{r r}$ is based on the following ansmmptions:

1. The lateral supports shown in Figure 4.1. are capable to provide adeculate supfmit to prevent lateral and torsional displacements of the beam at the locations at the support. Vote: (alculations for the recuired stiffures of late ral supports a!e not inchurled in II)ISM.

2. Discrete lateral support provided to the compression flange of a beam has caparity to rentain both lateral displacements and twisting of the cross section of the beam at the bo ation of the lateral support.

3. I.ateral suppent provided to the tension llange of a beam have little or no impart on the lateral-tomional buckling resistance, therefore their contribution in ignored. 


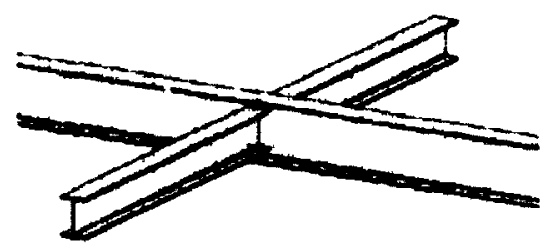

(a) Beam to hean web connection

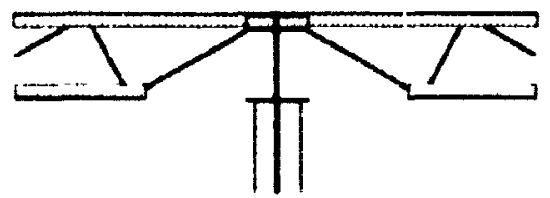

(c) OWSJ's connected to the top flange of a heam

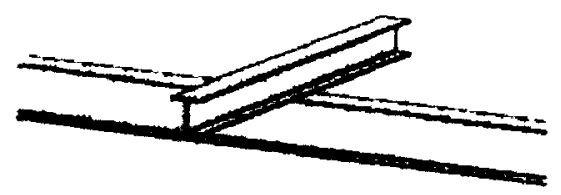

(b) Beam connected to the top flange of a heam

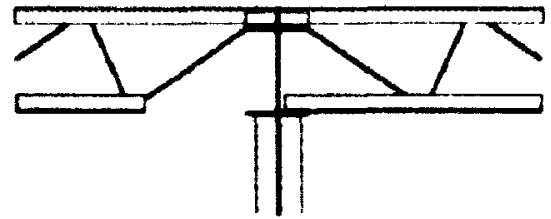

(d) OWSJ's connecied to hoth the top and hottom flanges of a beam

Figure 4.4: Lateral support types

Based on these and other assumptions stated previously, the effectiveness of the lateral restraints for cach lateral support type defired in IDFSM can be estimated.

Beam to beam web connections, as shown in Figure 4.4 (a). are generally made with standard end plates. back-to-back angles, or with single angles, bolted and/or welded depending on the construction. The shape of the cruse-sectivin at the point of lateral support will be maintained (no web distortion). The compression flange is effectively braced from lateral displacements and the member restrained from twisting. Similar restraint is provided by an OWS.J framing onto the top and bot tom the nge of a bean, Figure 4.4 (d).

Beams or OWSS's connected to the top flange of a beant, as shown in Figures 1.1 (b) and (c) respectively, prevents lateral displacement of that flange and provides limited restraint againht rotation of the beam at that location. The web may still distort. 
If the top flange is in compression then it is assumed that effective lateral support is provided for lateral displacements and twisting. If the top flange is in tension then the relative effectivencss of the lateral support is small, Trahair (1988), and is ignored in the calculation of $M_{r}$. The progran IDFSM gives a slightly conservative design for this latter case.

The effects of these lateral supports is more closely modelled with the finite element solution proposed by Albert and Kennedy (1991).

\subsubsection{Laterally unsupported length determination}

A major factor affecting the lateral-torsional buckling resistance of a beam is the distance between two effective lateral supports. Effective lateral supports are those that provide effective lateral rest raint to compresion flange at locations of lateral sapport (bracing points). For cases where lateral support is provided only to the top flange of a beam. it is crucial to determinc whether or not the flange is in compression or in teusion and hence whether or not the lateral support is effective.

The laterally unsupported length is a function of the bending moment diagram idefine which flange or where it is acting in compression ) and the type and location of $\mid$ atral -upport.

A. :lluntrated in Figure 4.5 for a typical gerber girder roof system with equally upared Oll $5 . J$ s. the lengths of unsupported segments may be different for different. load ambinations. The program II)FSM calculates the unsupported lengths for each load case and nsed these values along with the appropriate solution st rategy to determine the elatir lateral-torsional buckling trength. $\mathbf{M}_{c r}$. A serious shortcoming of most commercial software is that they use a predefined laterally unsupported length thronginent the design procesh. 


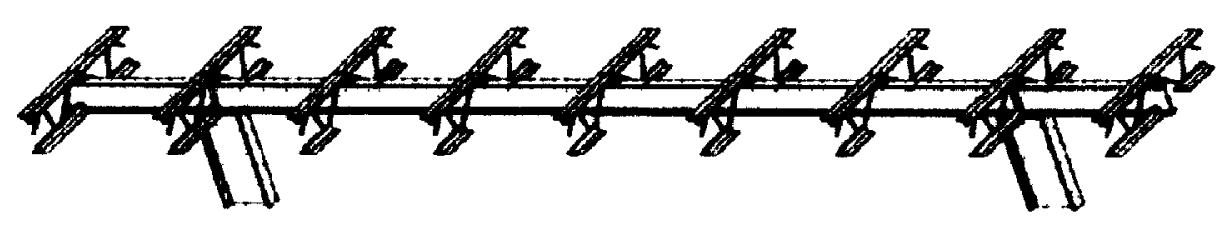

(a) Gerber gunder system image

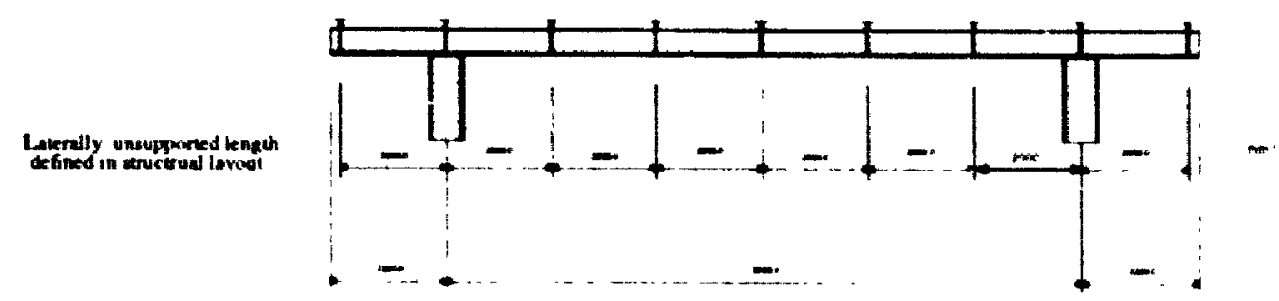

(b) Ongual length of lateral unsupponed segment
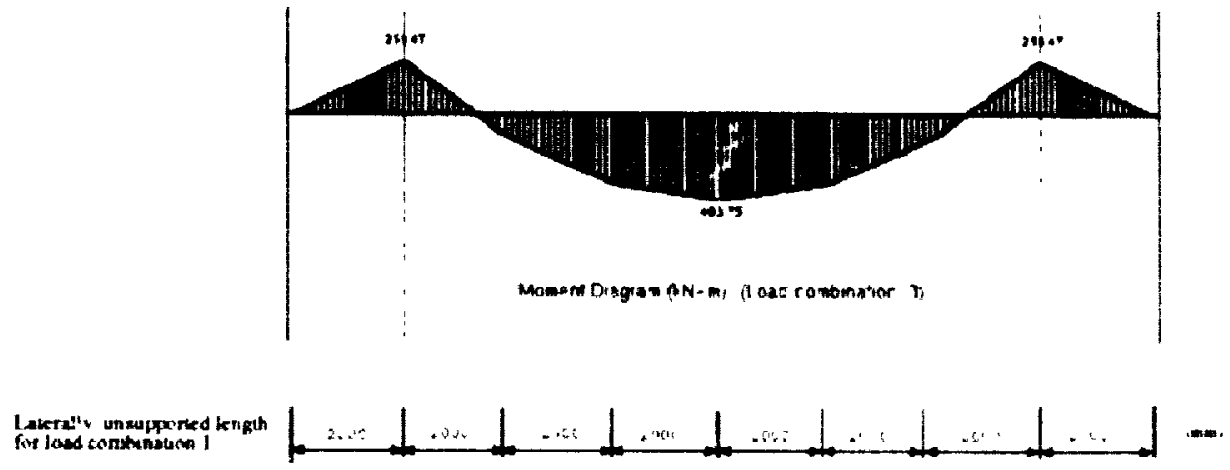

(c) Length of laicral unsupponed seginent unchanged

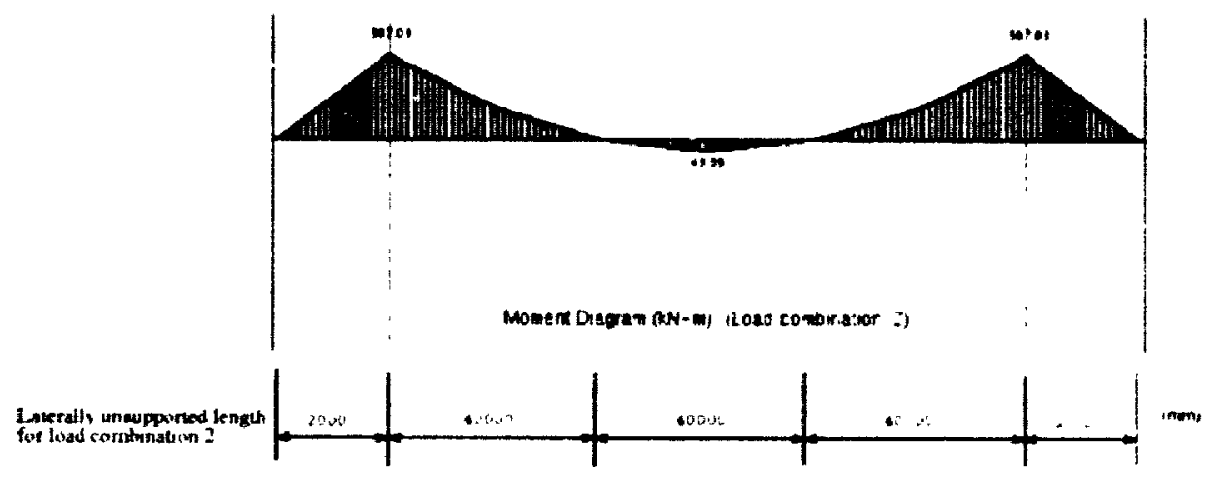

(d) Length of lateral unsupponed segment changed

Figure 1.5: Laterally unsupported length and load configurations 


\subsubsection{Special treatment for cantilever beams and the can- tilever portion of overhanging beams}

The design approarh for determining the effectiveness of a lateral support, presented in preceding section can only be applied to a beam between vertical supports (columns or beams)

The design approarh proposed by Nethercot (1983), as described in Section 4.5.4 has to be used for build-in cant ilever beams or for the cantilever portion of overhanging beams. The lethercot approach provides a good estimation of the lateral-torsional buckling capacity due to different types of lateral support at the root and tip of the cantilever engments. This approarh cannot be applied directly when more than one lateral support is present along a cantilever beam or along the cantilever portion of worhanging beans. The following design rules presented here are an extension of that approach.

- The length of all laterally unsupported segments within the cantilever are defined by the stantural confignration and are independent of the loads and the renting bending moment:

- Fach laterally unsupported segment is ireated as an independew cantilever with Bhe hracing point closer to the in-plane support taken as the rool point.

- Ihe wastic lateral-torsional buckling capacity of each segment is calculated independently uning Equation 1.1s, in which the effective length factor $k$ is determined fom the value given in Table 4.2 .

- Lateral injowen provided to the compreajon flange prevents lateral displace. nerlit and luisting of the beam at that location. 


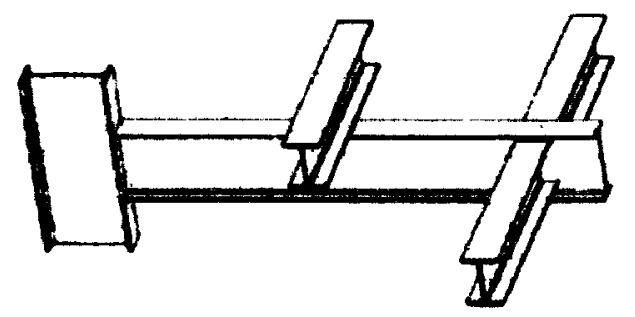

(a) Structural image

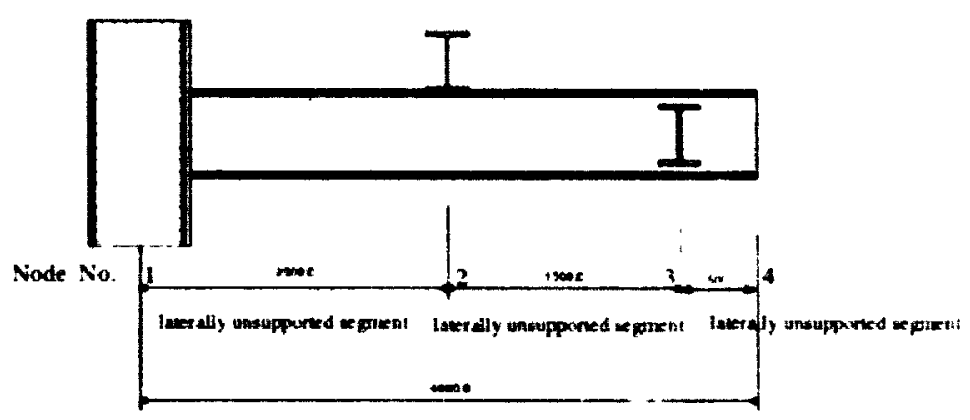

(b) Locations of lateral supports along the beain length

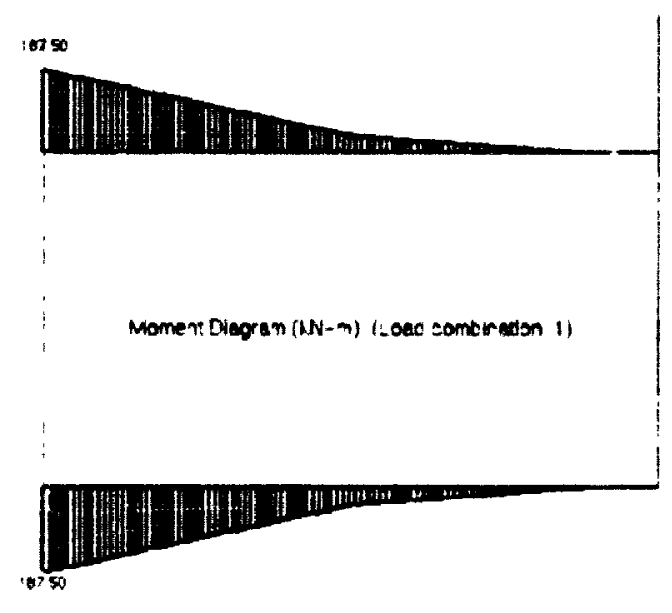

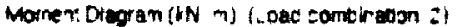

(c) Moment diagrasn for different load combunaisuns

Figure 4.6: Laterally unsupported cantilever beam with different load combinations 


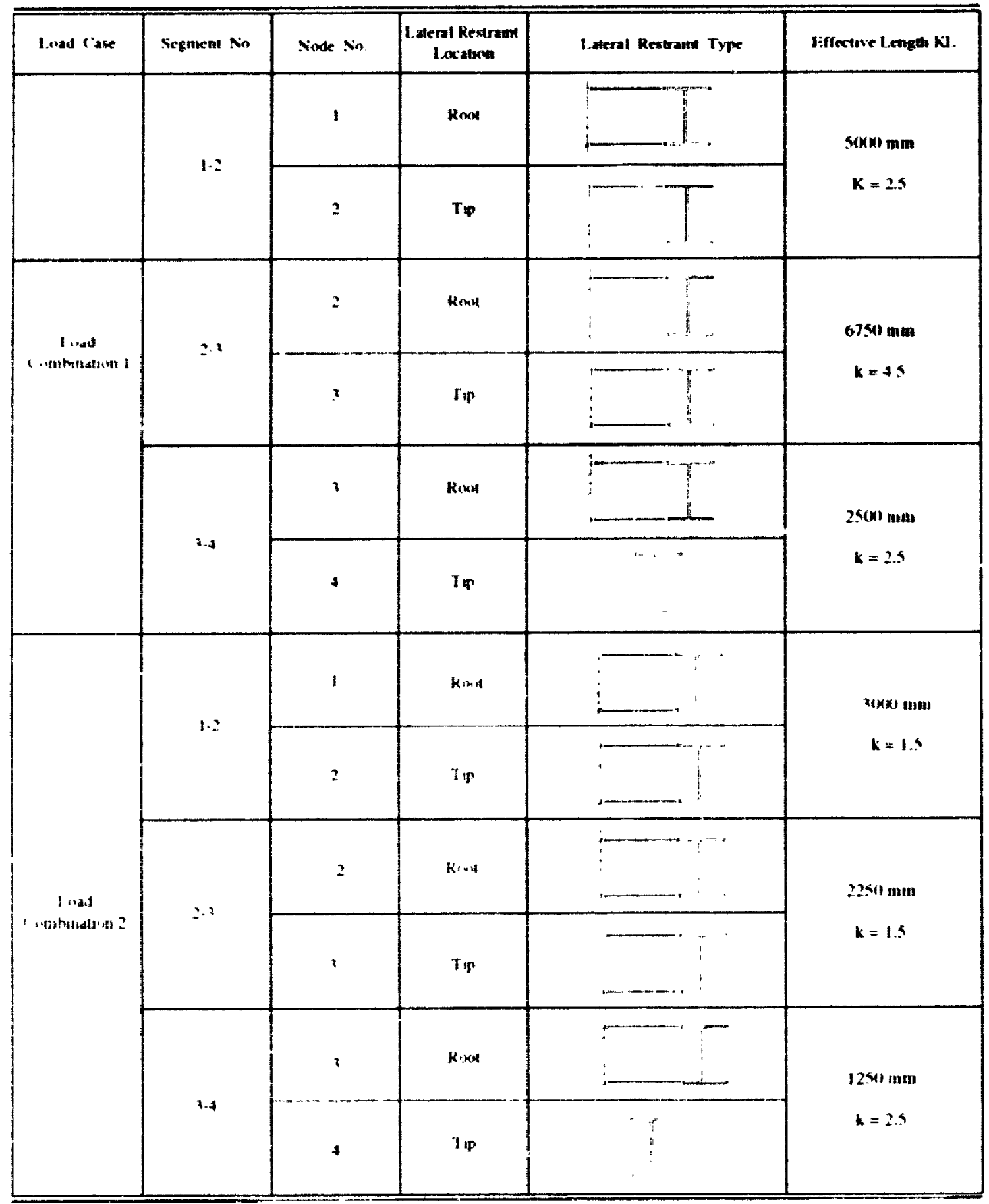

lable 4.3: Delermmatuon of lateral rewtraints and effective lengths for cantilever bean with inore than onc latcral supmort 
ligures $1.6(a)$. (b) and (c) show a cantilever bean with two different lateral support systems and the corresponding bending moment diagrams for load combinations: that produce compression in the bottom and top flanges respectively. The relative effectiveness of the lateral support on the moment resistance is dependent on which flange is being laterally supported and how it is being supported. This is illust rated by the figures and values in Table 4.3 for lateral rest raint types and effective lengths. The effective length for load combination I excerds that for load combination 2. As expected, the moment resist ance of the member was governed by load combinat ion 1 where the $M_{f} / M_{r}$ ratios for load combination 1 and 2 are 0.53 and 0.43 respectively. For this particular case the design was controlled by the deflection limit.

\subsubsection{Effect of end coping}

The ends of flexural nembers are frequenty coped for fit and for ease of contruction. The type, location and dimensions of these copes can be defined in II)fsil using the menu shown in Figure 1.7

The effect of coping at the end of the beam are:

1. to reduce the cromesection, he coped region of an l-haped bean mat become singly symmetric (gene, ally one plane of symmetry. about the weak axind and

2. to give rise to two possible local failure modes thear buckling of the weth and fatigne cracking ( not implemented into the program). and

3. To reduce the torsional and laterd stiffness of the beam reducine it - lateral. torsional buckling strength. ('heng. Vura and Johnson (i $9 \times 4)$.

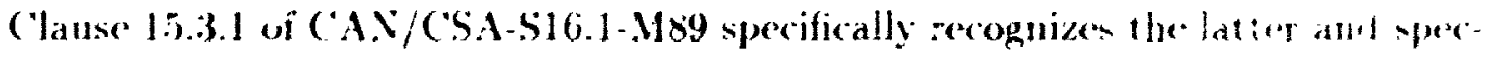
ifies that the effect of copes on the lateraltorsional buckling resintance of a leam an

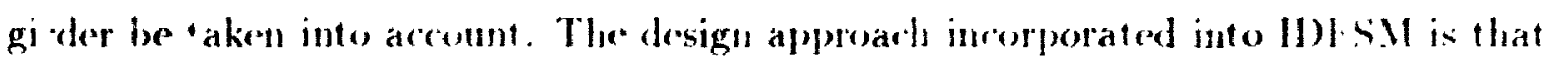




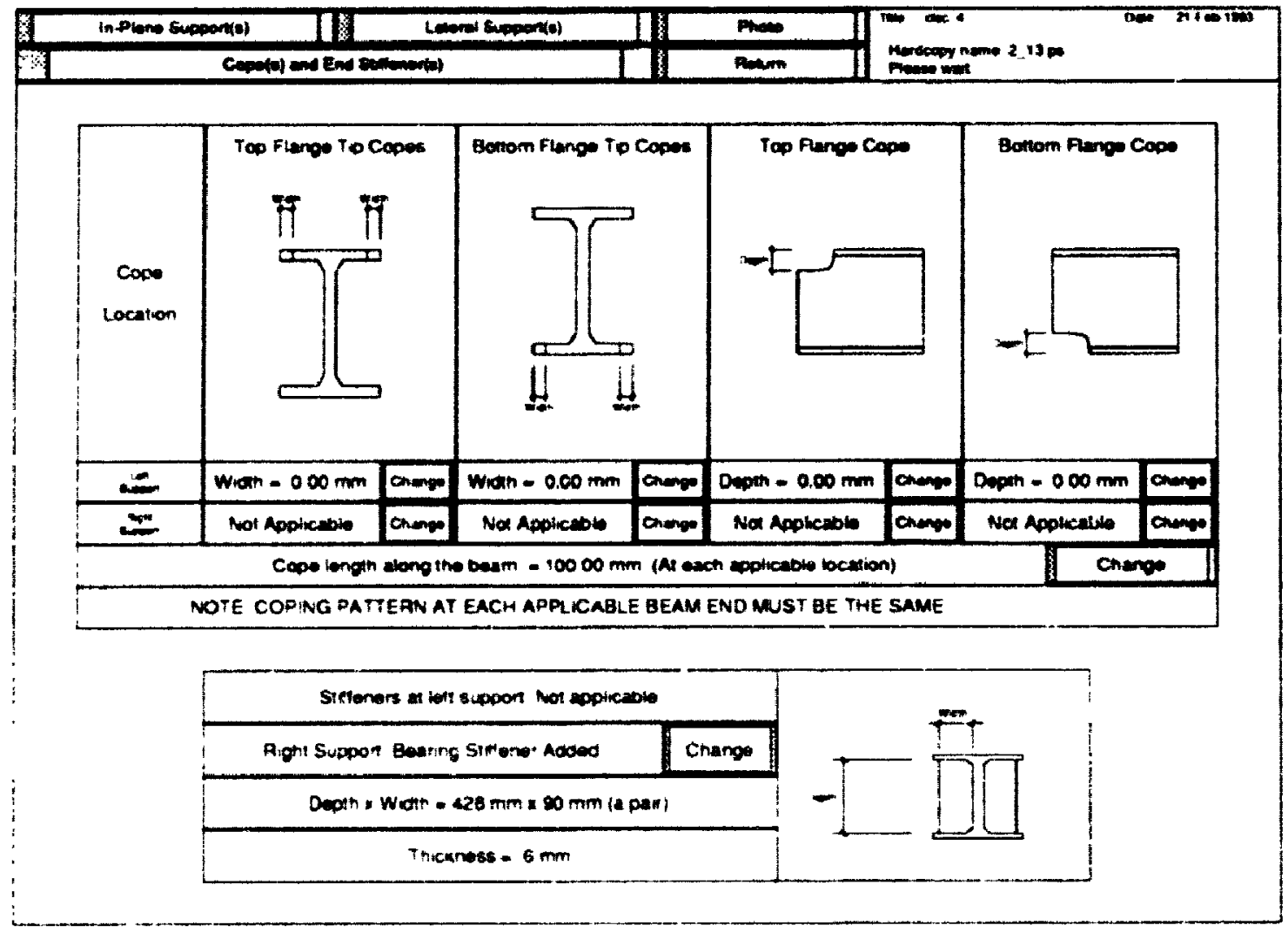

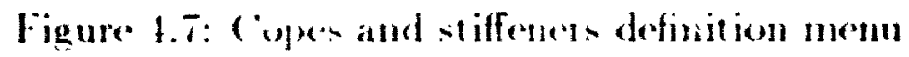

poproad by ( long (1992). Two interaction formula band on theoretical paramotric studien and experimental enidence. Were developerl: Fquation 4.20 for beams with ceper at bethend of the unbared longth and Equation 1.2 for beams coped at one end of the nibrared length.

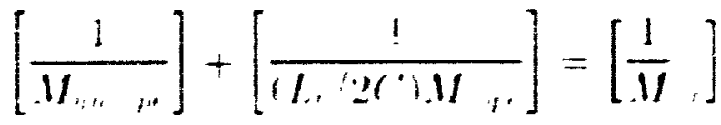

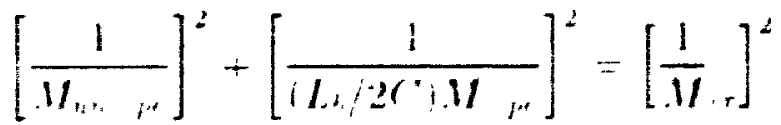

where.

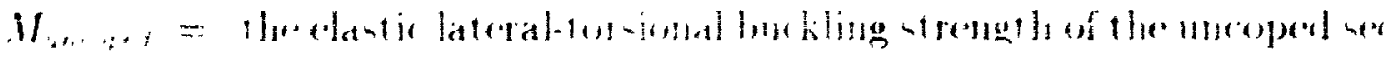

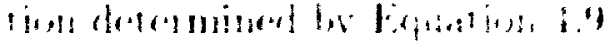




$$
\begin{aligned}
& M_{\text {copd }}=\text { the elastir lateral-torsional buckling strength of the coped sec- } \\
& \text { tion (calculated for a reduced I-shaped for flange tip copes or } \\
& \text { for a T-shaped sertion using Fquation } 1.9 \\
& M_{c r}=\text { the elastic lateral-torsional buckling st rength for the beam which } \\
& \text { sccounts for the interartion between coped and uncoped regions } \\
& l_{1,}=\text { the unbraced length } \\
& r^{\circ}=\text { the coper length }
\end{aligned}
$$

These equations are applieable only to cases wirere the rope length is less than twice the beam depth and the cope depth in low tians une-fifth the beam depth. The same restrictions are applied within IDPS.ll. For T-ihaped sections t Singly symmet-

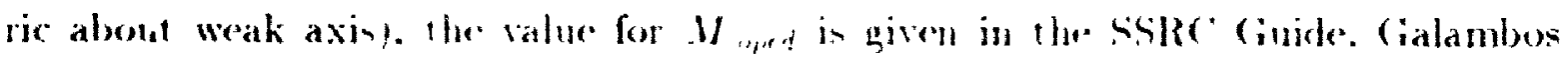
$(19 \times 8)$ as.

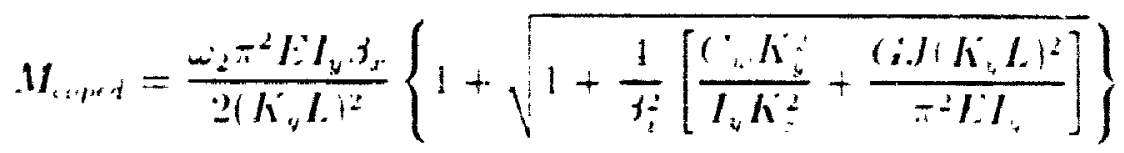

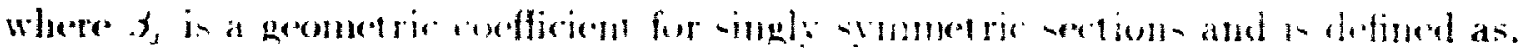

$$
x_{x}=0.9 d^{\prime}\left(\frac{2 I_{y}}{I_{y}}-1\right)\left[1-\left(\frac{I_{4}}{I_{y}}\right)^{2}\right]
$$

where.

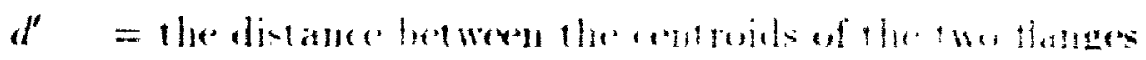

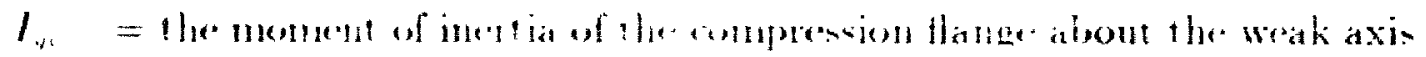

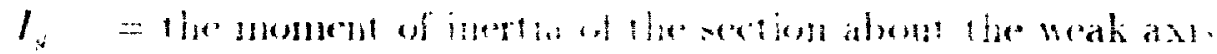

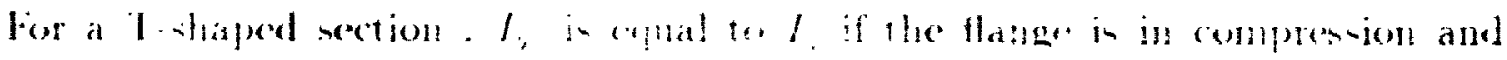

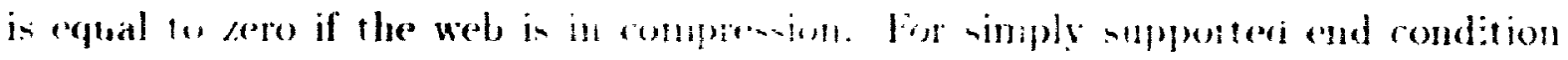
the effection lesgth factor $h$, and $h$ is set to one. In applying Funation 4.23 .

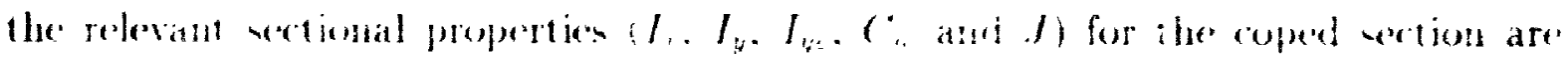

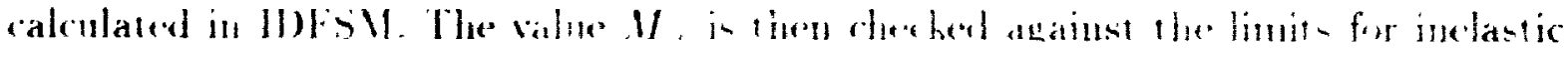




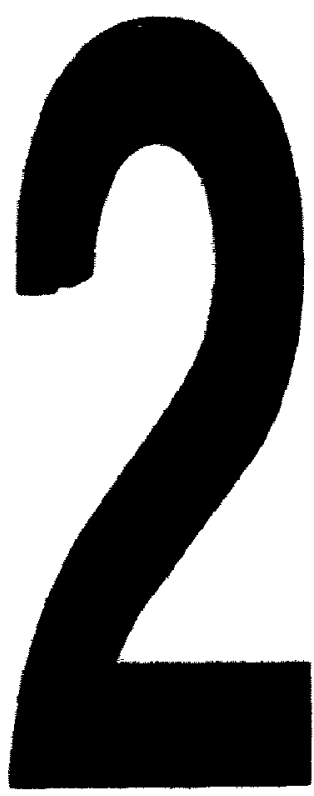

PM-1 31/2 "X4" PHOTOGRAPHIC MICROCOPY TARGET NBS 1010A ANSI/ISO \#2 EOUIVALENT

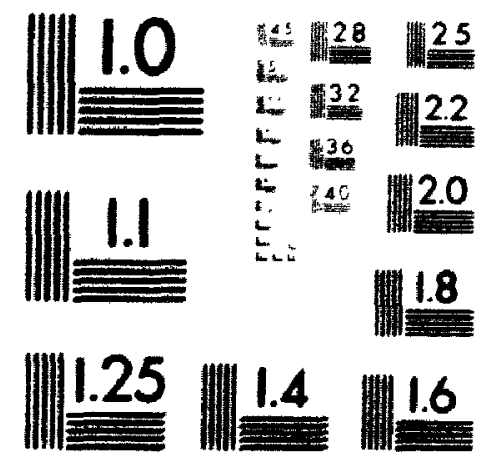


lateral-torsional buckling given in CAN/CSA-S16.1-M89 and the appropriate moment resistance is calculated.

The in-plane bending and shear strengths are calculated as for uncoped beams. The program IDFSM does not calculate the reduced torsional stiffness of the beam due to copes. Consequentiy, torsional loads cannot be placed with the coped regions of a laterallv unsupported bean.

\subsubsection{Applications of different solution strategies}

The descriptions of the different design solutions and solution st rategies available in the program IDFSM are given in Table 4.4 and 4.5 respectively:

Many design problems are well defined and the solutions produced by CAN/CSAS16.1-1189 are satisfactory. However. there are classes of buckling problems that lie outside the limitations of the design rules given in CAN/CSA-S16.1-M89, which require a more sophisticated solution. The program IDFSM provides this option. Each solution produced is valid, some are more conservative than ot hers. The solution using CAN/CSA-S16.1-M89 is always produced in conjunction with the user specified solution. The system is informative and educational. 


\begin{tabular}{|c|c|c|}
\hline Solution & Button names & Descriptions \\
\hline 1 & CAN/C'SA-S16.1-M89 & $\begin{array}{l}\text { Minimum design requirement; end coping effects; } \\
\text { may automaticaly invoke SSRC rules as they are } \\
\text { referenced within the standard; design for } \\
\text { bending and torsion, (lause } 15.11 \text {. D) iver and } \\
\text { kennedy (1989): always applied }\end{array}$ \\
\hline 2 & $\begin{array}{l}\text { Modified } \\
\text { SSRC Guide' } \\
(1: 388)\end{array}$ & $\begin{array}{l}\text { Alternative } u_{2} \text { values for different load patterns; } \\
M_{r r} \text { for tension flange support; effective length } \\
\text { factor } K \text { concept for cantilever beam segments }\end{array}$ \\
\hline 3 & $\begin{array}{l}\text { Schnitke de Kennedy } \\
\qquad(1989)\end{array}$ & $\begin{array}{l}\text { Interactive buckling of laterally unsupported } \\
\text { segments of continuous beams }\end{array}$ \\
\hline 4 & $\begin{array}{l}\text { Alhert and Kemuedy } \\
\qquad(1991)\end{array}$ & $\begin{array}{l}\text { Finite element analysis of bean: includes web } \\
\text { distortion. general loading and boundary } \\
\text { conditions; and residual stress patterns }\end{array}$ \\
\hline
\end{tabular}

Table 1.1: Design options 


\begin{tabular}{|c|l|}
\hline Solution Strategies & \multicolumn{1}{|c|}{ Scope and Limitations } \\
\hline 1 & beam without cantilever segment(s) \\
\hline $1+2$ & $\begin{array}{l}\text { build-in cantilever and beam with } \\
\text { cantilever segment(s) }\end{array}$ \\
\hline $1+2$ & beam without cantilever segment(s) \\
\hline $1+2+3$ & same as $1+2$. interactive buckling considered \\
\hline $1+3$ & same as 1 , interactive buckling considered \\
\hline $2+3$ & same as 2 , interactive buckling considered \\
\hline $1+4$ & Yet to be implemented \\
\hline \hline
\end{tabular}

Table 4.5: Solution strategies available in the program IDFSM 


\subsection{Limit States Design for Beams Subjected to Combined Bending and Torsion}

Flexural members may be subjected to combined bending and torsion if the section is not loaded through its shear centre. Examples are spandrel beams and girders that support cladding. Clause 15.11.1 of CAN/CSA-S16.1-M89 gives a general statement that instructs the structural engineer to provide a beam or girder with sufficient strength and rigidity to resist the torsional moment and forces in addition to bending moments and forces. The rational approach sclected for design and inclusion into IDFS.M was developed by Driver and Kennedy (1989). Based on test results and esearch conducted by others, Driver and kennedy developed moment-torque ultimate strength interaction diagrams for 1-shaped. Class 1,2 and 3 sections, for flexural members with different torsional and bending boundary conditions and for different bending and torsional load cases. Servireability limit states have also been developed and generally govern the design.

\subsubsection{Description of moment-torque interaction diagrams -ultimate limit state}

The proposed moment-trorque interaction diagram for Class 1,2 and Class 3 sections are shown in Figures 4.8 and 4.9 respectively. The bases for determining the limiting values of moments and torques, which are used in constructing the interaction diagrams are given in Table 4.6 , Driver and Kennedy (1989). 


\begin{tabular}{|c|c|c|c|c|c|}
\hline $\begin{array}{l}\text { Clave } \\
\text { of } \\
\text { section }\end{array}$ & $\begin{array}{l}\text { Maxinum } \\
\text { bendiat } \\
\text { momen }\end{array}$ & $\begin{array}{l}\text { bending } \\
\text { moment on } \\
\text { web. M. }\end{array}$ & $\begin{array}{c}\text { Maximum } \\
\text { total } \\
\text { tarque }\end{array}$ & Wisping torque. & $\begin{array}{l}\text { Si. Venant } \\
\text { torque, } T_{s=}\end{array}$ \\
\hline 1 & $\begin{aligned} M_{-} & =M_{p} \\
& =u_{r} z\end{aligned}$ & $\begin{aligned} M_{0} & =M_{r} \\
& =\pi, 2\end{aligned}$ & $\begin{array}{l}T_{m}=T_{*} \\
=T_{\text {wu }}+T_{w 4}\end{array}$ & $\begin{array}{l}\text { Rectangular stress } \\
\text { bloct. } \sigma_{m}=\sigma_{\nu}{ }^{*}\end{array}$ & $\begin{array}{l}\text { Sand heap. } T_{m u} \\
T_{m}=T_{1}=\sigma_{w} / \sqrt{3}\end{array}$ \\
\hline 2 & $\begin{aligned} M_{m} & =M_{p} \\
& =\pi_{y} 2\end{aligned}$ & $\begin{aligned} M_{*} & =M_{0} \\
& =0,2\end{aligned}$ & & $\begin{array}{l}\text { Rectangular stress } \\
\text { blocl:. } \sigma_{m}=\sigma,\end{array}$ & $\begin{array}{l}\text { Sand heap. } T_{\text {m, }}{ }^{1} \sqrt{3} \\
T_{m}=T_{1}=\sigma_{0} / V_{3}\end{array}$ \\
\hline $\mathbf{3}$ & $\begin{aligned} M_{m} & =M_{y} \\
& =0,5\end{aligned}$ & $M_{*}=M_{y,}$ & $\begin{array}{l}T_{m} \leqslant T_{y} \\
=T_{w+y}+T\end{array}$ & $\begin{array}{l}\text { Luncat stress } \\
\text { distribution. } \\
\sigma_{m}=\sigma \text {, }\end{array}$ & $\begin{array}{l}\text { Sowp film. } T_{\text {arrot }}^{\ddagger} \\
T_{m}=T_{1}=\sigma, / \sqrt{3}\end{array}$ \\
\hline
\end{tabular}

- See Trale 3.

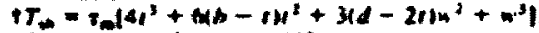

isec bieins and seabure (1963)

Table 4.6: Bases for determining limiting values of moments and torques, Table 4, Driver and Kennedy (1989)

The steps for determining the limiting values for drawing the interaction diagrams are:

1. Calculate of the maximum resistance moment $\mathbf{M}_{\mathrm{m}}$

- For class 1 and 2 sections, the maximum resistance bending moment $\mathbf{M}_{\mathbf{m}}$, with zero torque is the plastic moment capacity indicated by point $E$ in Figure 4.8 and is given by

$$
M_{m}=M_{p}=\sigma_{y} Z
$$

- For class 3 sections the maximum resistance bending moment $\mathbf{M}_{m}$, is the yield moment (point $\mathrm{E}$ in Figure 4.9), and is given by

$$
\boldsymbol{M}_{m}=M_{p}=\sigma_{y} S
$$

If the flexural capacity is limited by lateral-torsional buckling, as was the case in the tests conducted by Razzaq and Galambos (1979), then the maximum 


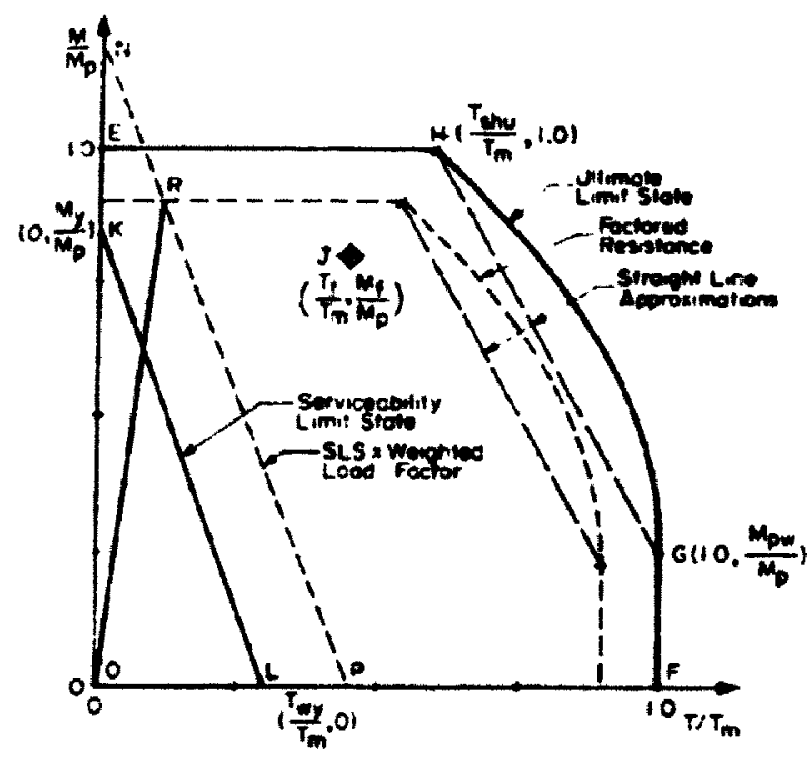

Figure 4.8: Moment-torque interaction diagram for Class 1, 2 sections. Fig. 17. Driver and Kenned! (1989)

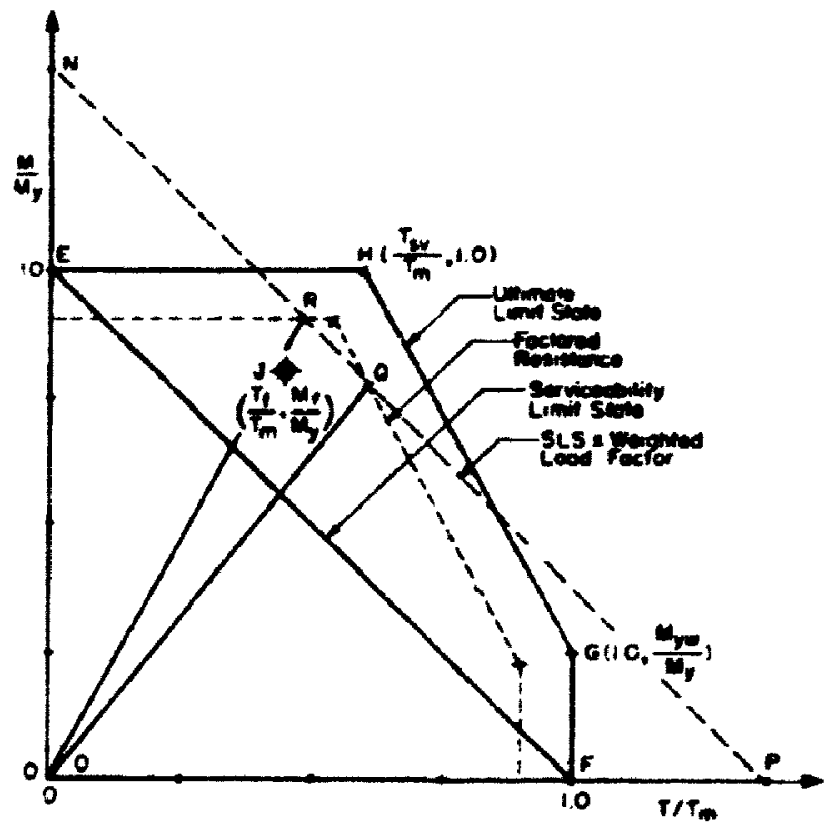

Figure 1.9: Moment-1orque interaction diagram for Class 3 sections, Fig. 18. Driver and Kennedy (1989) 
moment would correspond to lateral-torsional buckling capacity (elastic or inelastic).

2. Calculate the maximum torque $T_{m}$, with zero moment (point $F$ in Figures 4.8 and 4.9).

- For class 1 sections, maximum torque $T_{m}$, is taken to be the sand heap torque plus the plastic warping torque with both quantities based on the ultimate tensile strength of the material.

The sand heap torque $T_{\text {shu }}$, is a function of the ultimate shear stress $\tau_{u}$ $\left(\sigma_{\mathrm{u}} \sqrt{3}\right)$ and is given by Driver and Kennedy (1987) as.

$$
T_{s h u}=\frac{1}{6}\left[4 t^{3}+6(b-t) t^{2}+3(d-2 t) u^{2}+u^{3}\right] \frac{\sigma_{u}}{\sqrt{s}}
$$

The plastic warping torque $\mathrm{T}_{\text {wu }}$ at ultimate is based on a warping normal stress distribution consisting of opposite rectangular stress blocks in the flanges of intensity equal to the ultimate tensile strength and is given by Driver and Kennedy (1987) as.

$$
T_{u^{\prime} u}=\left[K b^{2} t(d-t) / L\right] \sigma_{u}
$$

where $K$ is a factor based on torsional end and loading conditions taken from Table 4.7 .

- For class 2 sections, the limiting torques are based on fully inelastic stress distributions, but with maximum stresses taken at the yield level instead of ultimate level. Hence,

$$
\begin{aligned}
& T_{s h_{y} y}=\frac{1}{6}\left[4 t^{3}+6(b-t) t^{2}+3(d-2 t) u^{2}+u^{3}\right] \frac{\sigma_{y}}{\sqrt{3}} \\
& T_{w p}=\left[K b^{2} t(d-t) / L\right] \sigma_{y}
\end{aligned}
$$




\begin{tabular}{|c|c|c|c|c|}
\hline \multirow{2}{*}{$\begin{array}{l}\text { Lowd } \\
\text { condition }\end{array}$} & \multicolumn{4}{|c|}{ Torsional end conditions } \\
\hline & Pinned-pinned" & Fixed-fixed* & Fined-freet & Fixed-pinnedt \\
\hline $\begin{array}{l}\text { Uniformily } \\
\text { distributed } \\
\text { torque }\end{array}$ & 1 & $3 / 2$ & $1 / 2$ & $5 / 4$ \\
\hline $\begin{array}{l}\text { Concentiated } \\
\text { torque at } \\
\text { midspan }\end{array}$ & $1 / 2$ & 1 & - & $11 / 12$ \\
\hline $\begin{array}{l}\text { Concentrited } \\
\text { torque at } \\
\text { free end }\end{array}$ & - & - & $1 / 4$ & - \\
\hline \multirow[t]{5}{*}{$\begin{array}{l}\text { Concentrated } \\
\text { torque at : }\end{array}$} & $\frac{1}{4(: / L)}$ & $\frac{2(z / L)+1}{4(z / L)}$ & $\frac{1}{4(z / L)}$ & $\begin{array}{c}\frac{2+2(z / L)-(z / L)^{2}}{4(z / L)(2-z / L)} \\
\text { for } z / L<0.586\end{array}$ \\
\hline & & & & $2+2(z / L)-(z / L)^{2}$ \\
\hline & & & & $\begin{array}{l}4(z / L)(3-z / L) \\
\text { for } 0.586<z / L<0.653\end{array}$ \\
\hline & & & & 1 \\
\hline & & & & $\overline{41-s / L)}$ \\
\hline
\end{tabular}

- 2 measured from the closer end

t $t$ menured from the fixed end

Table 4.7: Warping factor. K. Table 3. Driver and Kennedy (1989)

where.

$$
\begin{aligned}
& T_{s h y} \text { send heap torsional moment evaluated using } \tau_{u}=\sigma_{u} \sqrt{3} \\
& T_{u p} \quad \text { - plastic warping torsional moment evaluated using } \sigma_{y}
\end{aligned}
$$

- For class 3 section. limiting torques are based on linear elastic analyses. The total yield torque. $T_{y}$, is calculated as the sum of the St. Venant torque, $T_{s y y}$, and the warping torque, $T_{w y}$, based on an elastic analysis with the maximum stress taken as the yicld stress. The maximum torque, 
$T_{m}$, is likely to be less than the yield torque, $T_{y}$, as normal yield stresses due to warping and shear yield stresses due to St. Venant torsion are unlikely to be reached simultaneously.

3. Because the web does not contribute to the warping torque, point $G$ is established directly above point $\mathrm{F}$ at a moment corresponding to the fully plastic moment of the web ( $M_{p w}$, for bending moment and $T_{m}$ for torsional moment), for Class 1 and 2 sections; and to the yield moment of the web $\left(M_{y w}\right.$. for bending moment and $\mathrm{T}_{\mathrm{m}}$ for torsional moment), for a Class 3 section.

4. Point H. as shown in Figures 4.8 and 4.9 can be established from the corresponding values of $T_{s h u}, T_{s v}$ and $T_{m}$.

The curve EHGF as snown in Figures 4.8 and 4.9 forms a moment torque interaction diagram that defin's the ultimate limit state for a given load combination. The factored moment resistance can be obtained by multiplying the curve EIGF by the resistance factor $\phi=0.90$. The beam is considered satisfactory for strength if a series of points represented on these figures by a point $J$ (ratio of the factored moment to factored torque at any location along the beam) lie within the factored resistance curve.

\subsubsection{Serviceability limit state}

The serviceability criteria applicable for beams subject to combined bending and torsion are:

- A vertical deflection limit may be imposed as for beams in flexure.

- A similar limit may be placed on the maximum angle of rotation so that the nonstructural elements are not damaged. (see Section 4.8.2) 
- In addition, Driver and Kennedy (1989) propose that a serviceability limit state based on first yield of the cross section due to normal stresses, with the analysis carricd out on the undeformed shape. This guards against inelastic deformations at specified loads. The interaction diagrams for this serviceability limit state are plot ted in Figure 4.8 by connecting points $K\left(0, M_{y} / M_{p}\right)$ and $L\left(T_{w y} / T_{m}, 0\right)$ and in Figure 4.9 by connecting points $E\left(0, M_{y} / M_{y}\right)$ and $F\left(T_{m} / T_{m}, 0\right)$. The beam is considered satisfactory for serviceability if the series of points represented by point $J$ lie within the curve.

\subsubsection{Application of the Driver and Kennedy approach}

The Driver and Kennedy (1989) limit state design approach has been incorporated in the program IDFSM with some interpretation and modifications as required to apply it to common load cases and structural framing systems.

\section{- Warping torque factor, $\mathrm{K}$}

The $K$ values in Table 1.7. used to obtain the ordinate $T_{w u}$ for moment-torque diagrams of Class 1 and 2 sections, are given for two unique load cases.

- uniformly distributed torque and.

- a concentrated torque at any location along length of the beam.

Practical design rases include members that are subjected to load combinations in which the $K$ value has not been explicitly derived as for those cases given in Table 4.7. The program IDFSM uses the smallest $\mathrm{K}$ value possible. For the main span, the $K$ value corresponds to a concentrated load acting at midspan, and for cantilever beams or the overhanging segment of a continuous beam a concentrated load acting at the free end. This in turn gives a smaller value of $T_{\text {wu }}$, slightly shrinking the 
moment-torque interaction diagram, providing a lower bound ultimate limit state. Although this interpretation is conservative, it will not likely govern the design, as serviceability limitations generally control the design.

\section{Calculation of $T_{m}$}

For Class 3 sections the maximum torque, $T_{m}$, is likely to be less than the yield torque, $T_{y}$, given in Table 4.6, as the maximum normal yield stresses due to warping and the maximum shear yicld stresses due to St. Venant torsion are unlikely to be reached simultaneously. The value of $T_{m}$ is given as,

$$
T_{m}=T_{s u y}+T_{u \cdot y} \leq T_{y}
$$

which can be expressed in terns of $\phi^{\prime}$ and $\phi^{\prime \prime \prime}$ as.

$$
T_{m}=G J \phi^{\prime}+E C_{w}{ }^{\prime \prime \prime}
$$

The limiting value of $T_{m}$ may be reached when either the normal stress due to warping reached $F_{y}$, Case 1 , or the $S t$. Venant shear st ress reached $\tau_{u}=F_{y} \sqrt{3}$, Case 2. The relationship for $\phi, \phi^{\prime}, \phi^{\prime \prime}, \phi^{\prime \prime \prime}$ and the torsional loads and the relationships between the normal warping stress. $\sigma_{u \cdot s}$. and functions of $o$ must be determined.

The relationship between the angle of twist $\theta$ and the warping normal stresses $\sigma_{w s}$ as determined from the governing differential equation, Equation 3.2. is

$$
\sigma_{u \cdot s}=E W_{n s} \phi^{\prime \prime}
$$

where, $W_{n s}$ is the normalized warping function at any point on the cross section.

The relationship between the angle of twist $\phi$ and the uniform torsional stresses, St. Venant torsional stresses. $T_{t}$ as detc. mined from the governing differential equation. Equation 3.1. is

$$
\tau_{t}=G i \phi^{\prime}
$$


where $\mathrm{t}$ represents the flange or web thickness as appropriate.

a. Determination of $\mathrm{T}_{\mathrm{m}}$ for Case 1

1. set $\sigma_{u^{\prime} s}=F_{y}$ in Equation 4.32 and rearrange the expression to determine the corresponding $\phi^{\prime \prime}$ value.

$$
\phi_{\operatorname{mas}}^{\prime \prime}=\frac{F_{y}}{E W_{n s}}
$$

where.

$$
\begin{aligned}
& W_{n s}=h b / 1 \text { for } 1 \text {-shaped sections, AISC (1983) } \\
& h \quad=\text { depth of the beam } \\
& b \quad=\text { flange width }
\end{aligned}
$$

2. substitute $O_{m a x}^{\prime \prime}$ into the function $O^{\prime \prime}$ to determine the maximum value for the torsional load.

3. given the function for $o^{\prime}$ and $o^{\prime \prime}$ for the torsional loading and corresponding maximum load. calculate the values of $o^{\prime}$ and $o^{\prime \prime \prime}$ at the same location, along the beam where $\phi_{m, a x}^{\prime \prime}$ occurs.

1. substitute these values into Equation 4.31 to determine $T_{m l}$.

b. Determination of $T_{m}$ for Case 2

1. set $\tau_{t}=\tau_{y}=F_{y} \sqrt{3}$ in Equation 4.33 and rearrange the expression to determine the corresponding $o^{\prime}$ value.

$$
o_{\text {InIS }}^{\prime}=\frac{F_{y} / \sqrt{3}}{G i}
$$

2. substitute $\phi_{m u x}^{\prime}$ into the function $\sigma^{\prime}$ to determine the maximum value for the torsional load. 
3. calculate the corresponding value of $\phi^{\prime \prime}$ at the same location along the beam.

4. substitute these values into Equation 4.31 to determine $T_{m 2}$.

The value for $T_{m}$ is the lesser of $T_{m 1}$ and $T_{m 2}$ and cannot be greater than $T_{y}$. The value of $T_{y}$ can be obtained from Equation 4.31 by using corresponding $\phi^{\prime \prime \prime}$ value for $\phi_{\max }^{\prime \prime}$, as given in Equation 4.34, and $\phi_{\max }^{\prime}$ as obtained from Equation 4.35.

\section{Torsional restraints at in-plane and lateral supports}

Currently, only 12 cases of different torsional load and boundary conditions (torsional restraints) have been progranmed into IDFSM, see Section 3.2. Complete sets of solutions are given for uniformly distributed load. linearly varying distributed load and concentrated load for torsionally fixed-fixed. pmned-pinned, and fixed-free boundary conditions at the ends of a beam segment.

The fixed-fixed torsional boundary conditions are applied to cantilever beams and to overhangings of contimuous beams. Fixed-fixed and pinned-pinned torsional boundary conditions are applied directly to beams where the corresponding fexural boundary conditions have been specified. For continuous beams over supports or for fixed-pinned or for pinned-fixed flexural boundary conditions. the pinned-pinned torsional boundary conditions are applied. This leads to slightly ronservative results as some warping restraint does occur in a continuous member over the support or at the fixed end.

\section{Design of lateral unsupported segments subjected to bending and torsion}

The design of laterally unsupported segments subjected to bending and torsion is a relatively complex design problem and requires answers to the following questions.

1. What is the distribution and the magnitude of torsional loads introduced into a beam from the loars acting on member framing into it? 
2. What is the torsional restraint provided to the ends of a laterally unsupported segment by the lateral support and the continuity of the beam?

3. What is a rational design approach for laterally unsupported segments subjected to bending and torsion? Are there any assumptions and/or limitations?

The first question can be answered by comparing the torsional stiffness of the bearı (I-shaped) with the flexural stiffness of the members framing into the beam (also lateral support) which contributes to the torsional stiffness of system at the lateral support location. The following comparisons were made for two typical lateral support members (beams. OWSJ's) to illustrate the proportioning of the torsional loads.

\section{Beam to Beam:}

The structural layout is shown in Figure 4.10 .

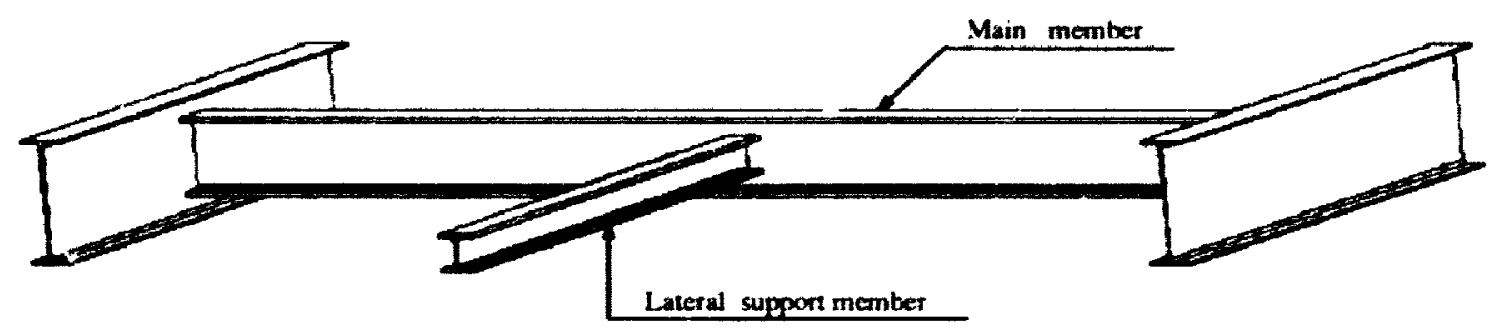

Figure 4.10: Beam to bean configuration

Lateral support member:

The lateral support member frames inte the main member from one side and connected through shear type connection at hoth ends

Section size: $11250 \times 33$

$I_{r}=18.9 \times 10^{6} \mathrm{mr}^{4}$ 


$$
L=4000 \mathrm{~mm}
$$

Assume that rotational stiffness of the shear connection is as low as $2 \%$ of that for a rigid connection, then the torsional stiffness provided the the beam is,

$$
\frac{T}{\phi}=\frac{3 E I}{L} \cdot 2 \%=\frac{3 \times 200000 \times 48.9 \times 10^{6}}{4000} \cdot 2 \%=146.7 \times 10^{6} \mathrm{Nmm} / \mathrm{radian}
$$

where, $T$ is the internal torque at corresponding braced point.

Main member:

Section size: $W 460 \times 71$

$$
\begin{aligned}
& J=0.517 \times 10^{6} \mathrm{~mm}^{3} \\
& G=77000 \mathrm{MPa} \\
& L=6000 \mathrm{~mm}
\end{aligned}
$$

The torsional stiffness of the beam for a concentrated torque at midspan (assuming simply supported boundary conditions for bending and torsion), can be obtained from the corresponding solution to this torsion problem. Case 3, $a=0.5$. AISC (1983), where

$$
\frac{\partial G . J}{T} \cdot \frac{1}{L}=0.105
$$

and,

$$
\frac{T}{\phi}=\frac{G J}{L}=\frac{77000 \times 0.517 \times 10^{i}}{6000}=6.6 \times 10^{6} \mathrm{Nmm} / \mathrm{radian}
$$

The portion of the total torque resisted by the lateral support is

$$
\frac{146 . \overline{7}}{146.7+6.6}=96 \%
$$

and the corresponding portion of the twal torque resisted by the main member (beam) is

$$
\frac{6.6}{146.7+6.6}=4 \%
$$


OWSJ's to beam:

The structural layout is shown in Figure 4.11

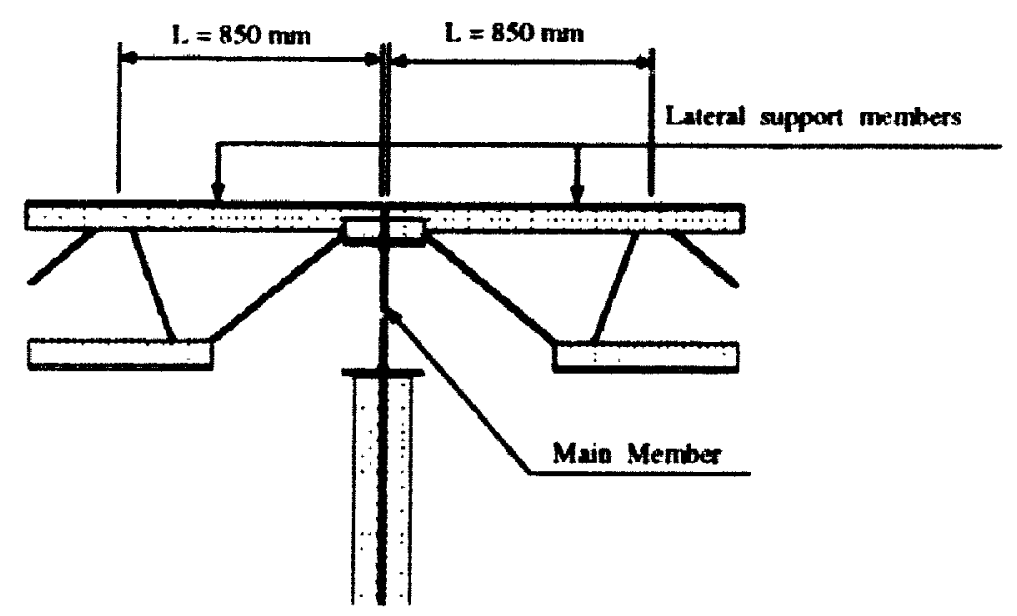

Figure 4.11: OWSJ's to beam configuration

Lateral support members:

2 back-to-back angles, $L 40 \times 40 \times 4$

$$
\begin{aligned}
& I_{x}=0.091 \times 10^{6} \mathrm{~mm}^{4} \quad(\text { each }) \\
& L=8,50 \mathrm{~mm}
\end{aligned}
$$

The flexural bending stiffness of the top chord of the OWSJ's at laterally braced point is

$$
\frac{T}{C}=\frac{3 E I}{L} \times 2=\left(\frac{3 \times 200000 \times 2 \times 0.091 \times 10^{6}}{850}\right)=183.0 \times 10^{6} \mathrm{Nmm} / \mathrm{radian}
$$

where, $T$ is the internal torque at corresponding braced point. 
Main member:

The section is a $W 460 \times 74$ and the rest of the parameters are the same as the previous example. The portion of the total torque resisted by the lateral support is

$$
\frac{183}{183+6.6}=96.5 \%
$$

The portion of the total torque resisted by main member (beam) is

$$
\frac{6.6}{183+6.6}=3.5 \%
$$

Based on these and other examples it was concluded that if a torsional load was introduced at the lateral support point that the torsional load on the main member could be neglected.

The answers to the second and third question are coupled. The Driver and Kennedy (1989) design approach can be used for laterally unsupported segments subjected to bending and torsion by limiting the moment resistance to its lateral torsional-buckling capacity. The torsional restraints at the ends are assumed to be simply supported. The resulting design would be slightly conservative as it neglects the effects of warping rest raint due to continuity and any possible increase in capacity. To eliminate any negative impact that might result from warping distortions from one segment on another, the program restricts the user from applying torsional loads on adjacent laterally unsupported segments for any given load combinations.

\section{Examples}

Examples illustrating the design limitations and torsional boundary conditions for beams with laterally unsupported segments are given in Figure 4.12. The torsional boundary conditions that have been applied are limited to the solutions currently provided in IDFSM. These approximations must be verified when the analytical tools have been developed. 


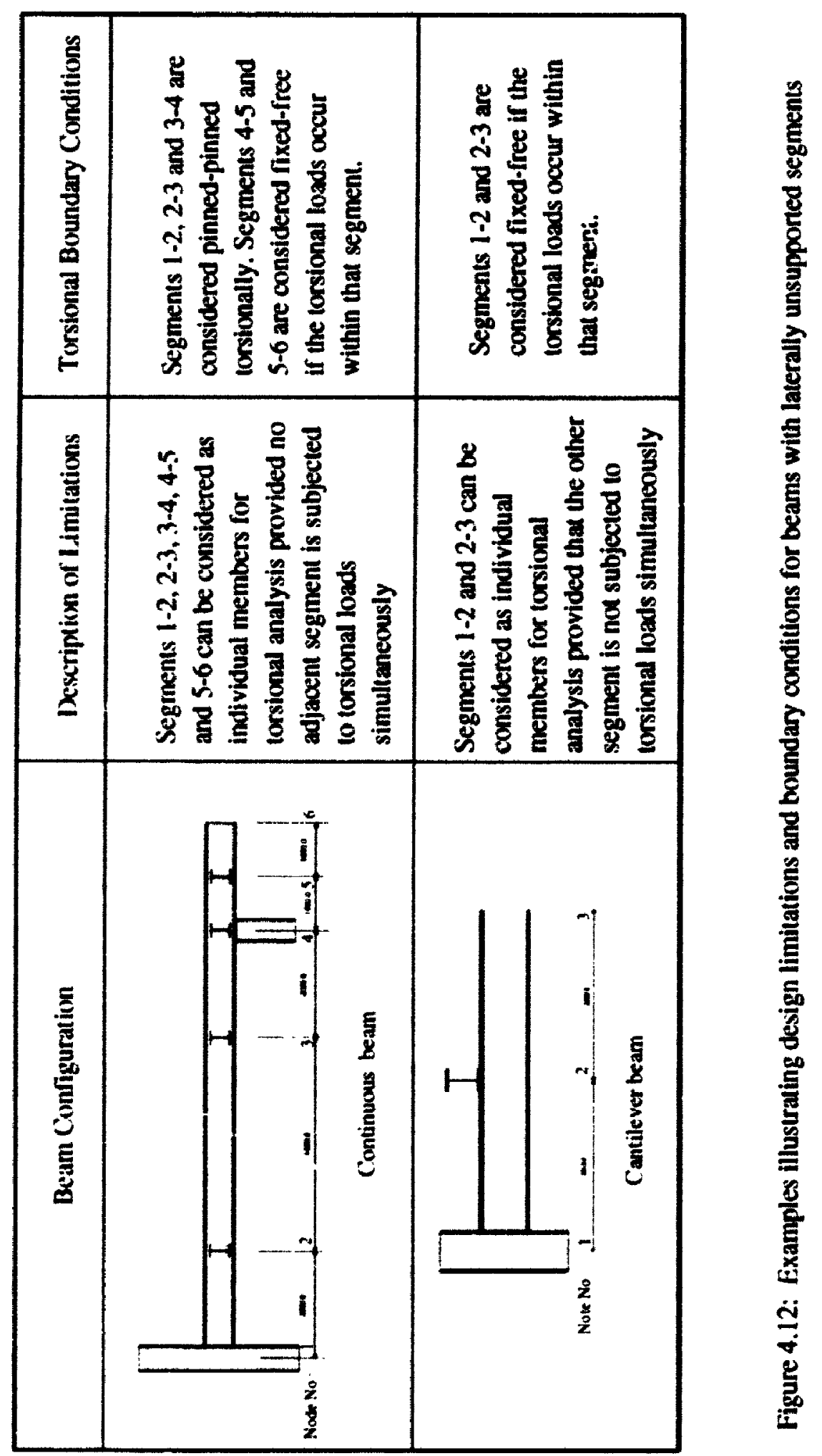




\subsubsection{Implementation of torsion evaluation into IDFSM}

The program block diagram for the design of beams subjected to combined bending and torsion is shown in Figure 4.13.

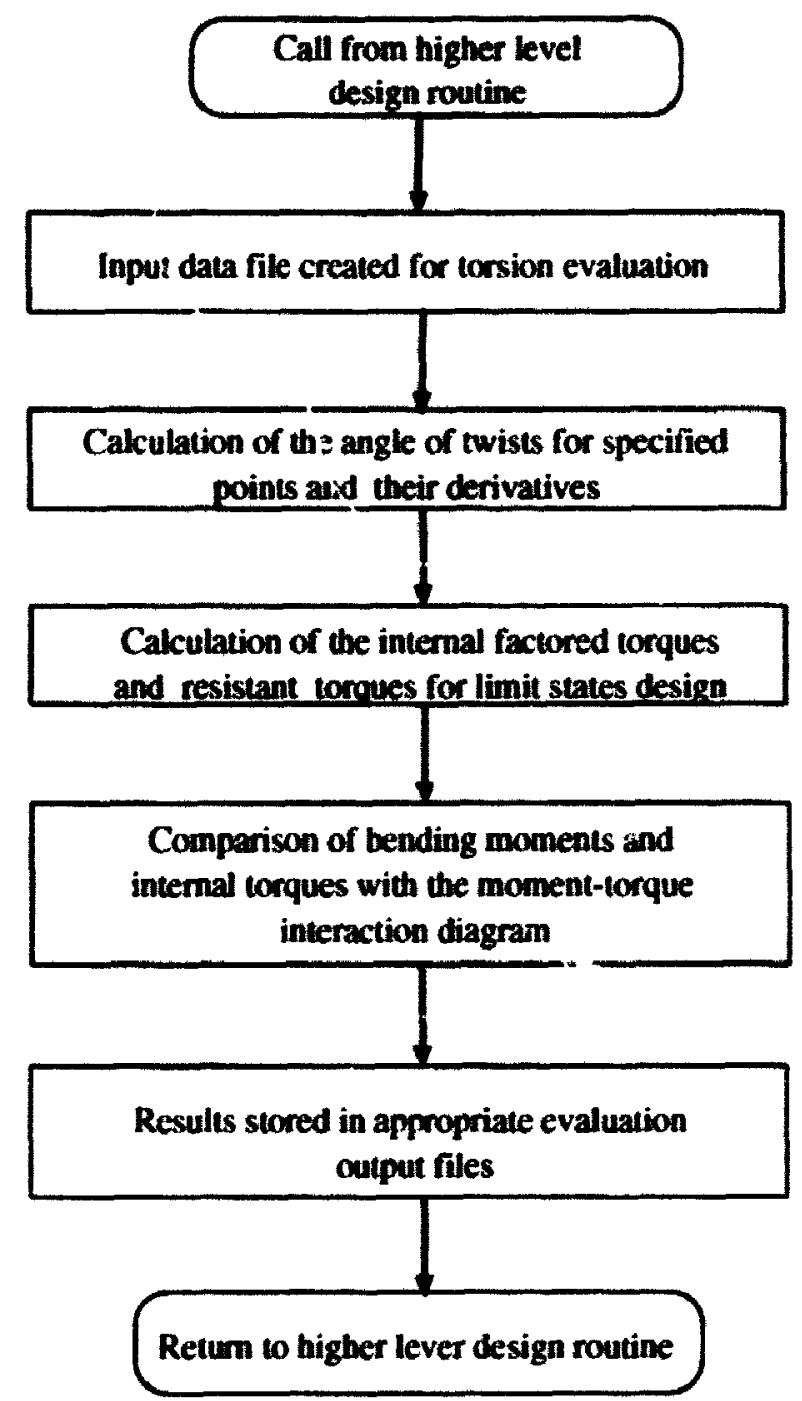

Figure 4.13: Program block diagram for design of beams subjected to combined bending and torsion 


\subsection{Bearing Stiffeners}

Bearing stiffeners are automatically designed in the program IDFSM to ensure local web stability and to enhance the overall stability of the member by preventing web distortions of continuous beams over supports. If effective lateral support is not provided to both flanges of overhanging beams at the locations of vertical support (beam on column or beam on girder) in the definition of the flexural design problem, then IDFSM will automatically insert and design a pair of bearing stiffeners at these locations. The minimum thickness will be $5 \mathrm{~mm}$.

\subsubsection{Local web stability}

In program IDFSM, four types of in-plane support configurations are identified as shown in Figure 4.14. Under these situations, it is assumed that the reaction is distributed uniformly over the entire length of the bearing plate (column depth or width as shown in Figures 4.14(a), (b) respectively); and over the width of the supporting beam as indicated in Figures $4.14(\mathrm{c})$,(d). For end bearing, the end of the beam coincides with the edge of the supporting member.

Inder a concentrated load or reaction, the beam web may fail locally by yielding or by inelastic weo buckling (crippling). The corresponding resistances for interior loads or reaction and for end reactions are given in Clause 15.9 of CAN/CSA-S16.1-M89, sentences (a) and (b), respectively.

- For interior reactions as shown in Figures 4.14(b),(c)

$$
\begin{aligned}
& B_{r}=1.10 w(N+5 k) F_{y} \quad \text { (web yielding) } \\
& B_{r}=300 u^{2}\left[1+3\left(\frac{N}{d}\right)\left(\frac{w}{t}\right)^{1.5}\right] \sqrt{F_{y} t / w} \quad \text { (crippling) }
\end{aligned}
$$



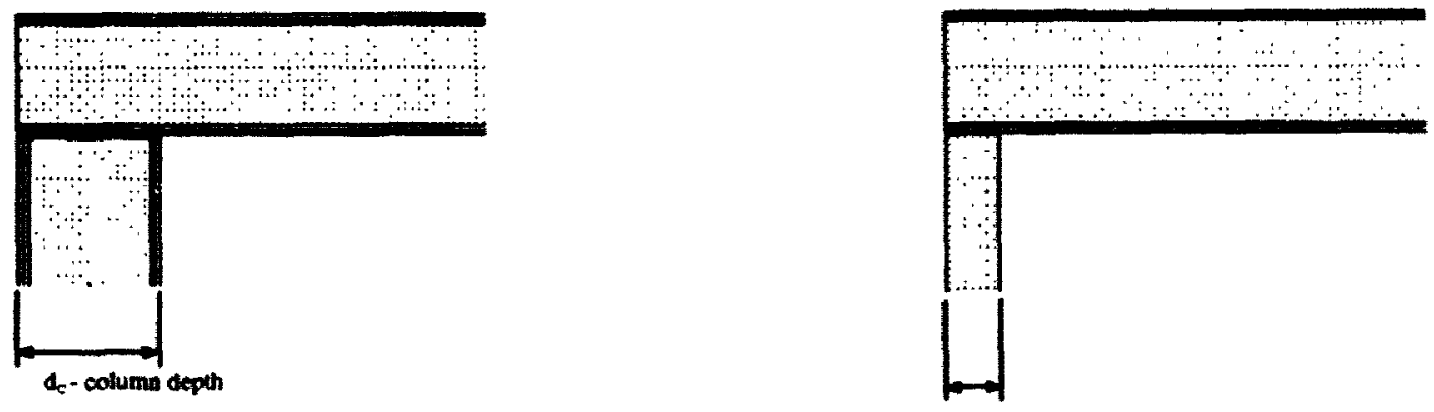

$b_{c}$ - columb hange with

(a) End bearing (Beam on Column)

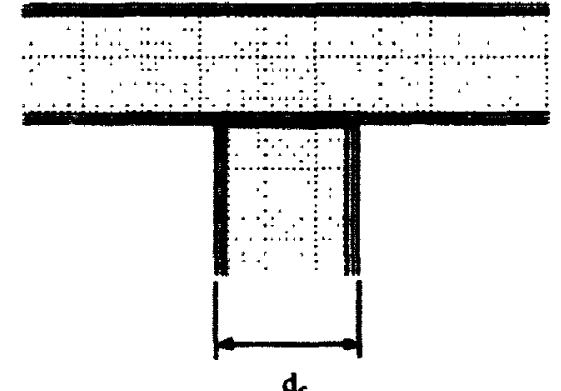

$\mathbf{d}_{\mathbf{c}}$

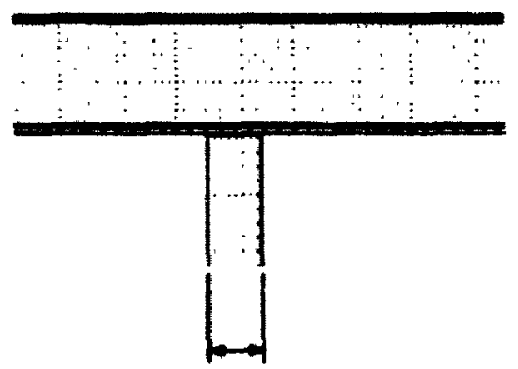

$b_{c}$

(b) Interior bearing (Beam on Column)

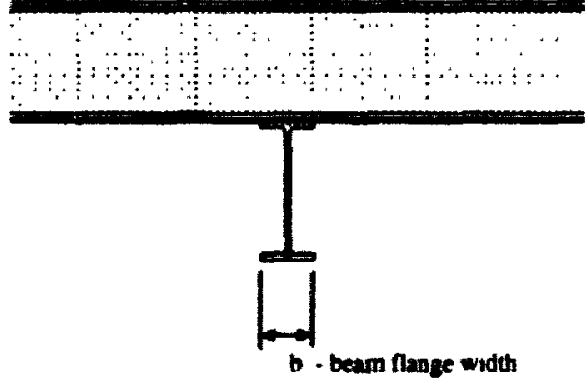

(c) Interior bearing (Beam on Beam)

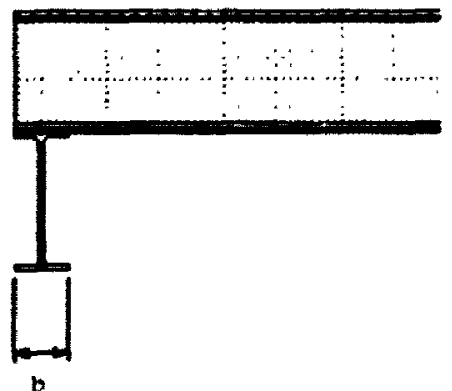

(d) End bearing (Beam on Beam)

Figure 4.14: Definitions of bearing lengths and types 
- For end reactions as shown in Figures 4.14(a),(d)

$$
\begin{aligned}
& B_{r}=1.10 w(N+2.5 k) F_{y} \quad \text { (web yielding) } \\
& B_{r}=150 u^{2}\left[1+3\left(\frac{N}{d}\right)\left(\frac{w}{t}\right)^{1.5}\right] \sqrt{F_{y} t / u} \quad \text { (crippling) }
\end{aligned}
$$

where,

$$
\begin{aligned}
w= & \text { web thickness } \\
N= & \text { length of bearing as defined in Figure } 4.14,(\mathrm{~N} \text { shall be not } \\
& \text { less than } k \text { for end reactions) } \\
k= & \text { distance from outer face of flange to the toe of flange-to-web } \\
& \text { fillet or the web } \\
t= & \text { flange thickness }
\end{aligned}
$$

Bearing stiffeners are also required at the unframed ends of beams (beam on a beam flange), with a web depth to thickness ratio greater than $1100 / \sqrt{F_{y}}$, to prevent overall instability.

\subsubsection{Automatic design for bearing stiffeners}

If bearing stiffeners are required, IDFSM will automatically design a pair of bearing stiffeners for the full height of the web. Plate thicknesses incorporated into a data base for stiffener design include thickness region from $5 \mathrm{~mm}$ through to $12 \mathrm{~mm}, 14$ $\mathrm{mm}$ through to $20 \mathrm{~mm}, 22 \mathrm{~mm}, 25 \mathrm{~mm}, 28 \mathrm{~mm}, 30 \mathrm{~mm}$ and $35 \mathrm{~mm}$ as listed in the table for flat metal products on page G-135 of the CISC Handbook, CISC (1990). The automatic design procedure for bearing stiffeners is as follows:

1. Determine the range of stiffener widths (geometric requirement): width $\geq 10 \mathrm{~mm}$ (mnimum width requirement) 
width $\leq 0.5[($ flange width of the beam)-(web thickness) $]$

width $\leq 200\left(t / \sqrt{F_{y}}\right)$ (Class 3 behaviour requirement)

where, $t=$ thickness of bearing stiffener

2. Select the smallest plate thickness, $t=5 \mathrm{~mm}$ and calculate the corresponding stiffener width.

3. The axial compressive resistance of the stiffeners and corresponding web is calculated in accordance with Clause 15.6.2 of CAN/CSA-S16.1-M89. The column section consists of the pair of stiffeners and a centrally located length of the web equal to not more than 25 !imes its thickness at interior stiffeners, or a length equal to not more than 12 times its thickness when the stiffeners are located at the end of the web. The effective column length, $K L$, is taken as three-fourths of the length of the stiffeners in calculating the ratio $k L / r$. The compressive resistance of column, $C_{r}$, with the cross-section and slenderness defined by Clause 15.6.2 is then calculated from Clause 13.3.1 of CAN/CSA-S16.1-M89.

4. The bearing resist ance of the cont act area of the stiffeners is calculated according to Clause 13.10.1(a) of CAN/CSA-S16.1-M89 standard.

$$
B r=1.50 \phi F_{y} A
$$

where, $A=$ the contact area of a pair of bearing stiffeners which is equal to $2($ width $+t / 2-k) t$

$$
\phi \quad=0.90
$$

5. If the capacity of the bearing stiffeners is less than the factored reaction, then the next larger thickness is selected and the process repeated until the largest plate thickness, $35 \mathrm{~mm}$, is exceeded. For this case (stiffener design is unrealistic). 
the program will print the following warning in the "Engineering report": Further reinforcement of support for bearing is required

\subsection{Deflection and Camber Requirements}

\subsubsection{Vertical deflections}

The program IDFSM automatically calculates the vertical deflections due to both the specified dead and live loads for each load combination.

The dead load deflection may be offset by cambering the beam and will be given in the engineering report if the camber option is activated in the main menu, refer to Figure 2.1. The structural engineering is required to enter the appropriate live load deflection limit for the given application, otherwise, the default option of $1 / 300$ of the beam span will be used. Recommended values are given in Appendix I of CAN/CSAS16.1-1189. The program IDFSM will either automatically select the appropriate section to satisfy the deflection limit specified for the automatic design option, or it will calculate and report the deflection as a function of the span and indicate whether or not it is satisfactory for the design check option.

\subsubsection{Lateral deflections}

The lateral deflections identificd by the program IDFSM are cause by both the specified dead and live torsional loads. Driver and Kennedy (1989), proposed as serviceability criteria that these deflections should be compared to the live load deflection limit specified for the gravity live loads. The lateral deflection at any location along the length of the member is given as

$$
s_{l}=\frac{o h}{2}
$$


where, $\quad \Delta_{l}=$ lateral deflection due to specified dead and live torsional loads

$\phi=$ the angle of rotation of the cross-section

$h=$ section depth, for I-shapes

\subsection{Determination of the Optimum Section Size}

The automatic design option of IDFSM will determine the optimum section size, minimum weight (hence minimum cost), that will satisfy all the design requirements (serviceability and strength) and geometric constraints specified; using a modified constraint direct search method.

The objeci:ce tunction for minimum weight is discrete and mathematically can be expressed as.

$$
W_{\min }=F n\left(x_{1}, x_{2}, \ldots \ldots, x_{n}\right)
$$

where,

$$
\begin{aligned}
W_{m i n}= & \text { minimum section weight }, \mathrm{kN} / \mathrm{m} \\
x_{1}, x_{2}, \ldots, x_{n}= & \text { design variables which are the geometric proper- } \\
& \text { ties of the section; } I_{x}, S_{x}, Z_{x}, I_{y}, S_{y}, Z_{y}, J, C_{w} . d . \\
& b, t, w \text { and } k
\end{aligned}
$$

The constraints imposed on the solution are related to ultimate and serviceability limit state criteria for flexural members, as well as two architectural constraints restricting the outer dimension sof the section. These are:

1. $M_{f} / M_{r} \leq 1.0$ and/or $T_{r} / T_{r} \leq 1.0$

(compared with the moment-torque interact:on diagram. when applicable) 
2. $v_{\mathrm{r}} / V_{\mathrm{r}} \leq 1.0$

3. $B_{r} / B_{r} \leq 1.0$

4. (maximum deflection due to live load)/(maximum deflection linit) $\leq 1.0$

5. (maximum depth) $/($ maximum specified depth $) \leq 1.0$

6. (member flange width $) /($ minimum specified flange width $) \geq 1.0$

Optimization by using a direct search method means that the objective function is evaluated and conclusions are drawn from the values of the function for various combinations of the independent design variables. The effectiveness of the optimization procedure is dependent on the search method which describes the logic behind those conclusions.

The CISC geometric data for W and WWF shapes are given as a function of the nominal depth and within that section group, i.e. W200's, the sections are listed in descending order by mass or weight. Examination of the geometric properties for the section with the largest mass with each section group indicates that there are two shape groups for W and WWF sections where the geometric properties increase with increasing mass. Large values for geometric properties is synonymous with increased capacity. These shape groups are:

- for W-shapes , shown in Figure 4.15

Shape group 1 -.. W100 through W300

Shape group 2 -W W10 through W1000 with the ex-

ceptions of sections W920 $\times 1072$,

$W 920 \times 1188$ and $W 920 \times 1262$

- for WWF-shapes.

Shape group 1 -- WWF350 through WWF650

Shape group 2 - WWF700 through WWF2000 


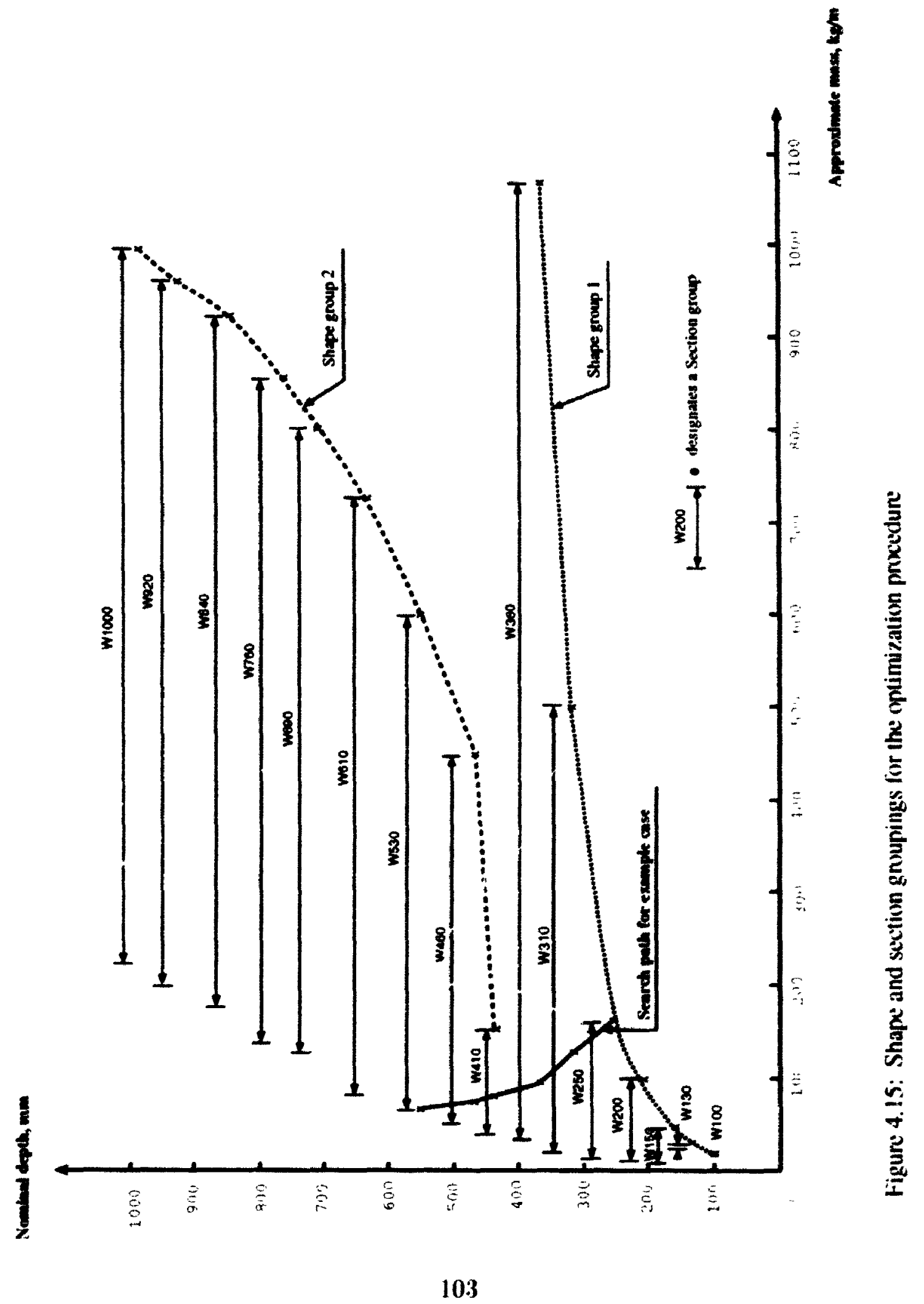


The first step of the automatic design procedure is to apply the direct search algorithm to determine the least weight section group within Shape group 1, which consists of the set of sections with the largest mass within each Section group and satisfies al the constraints. i.e. limit states design requirements. As illustrated in the example given in Figure $4.16,1250 \times 167$ were the least weight sections from Shape group 1 of W shape.

The second step is to apply the direct search algorithm to determine the least weight section within each Section group obtained by step one and to a subset of each Section group deeper than the least weight section group selected, which also satisfies all the constraints. As illustrated in Figure 4.16. the optimum section with the 11250 s was $11250 \times 167$. Only the subset of sections with weights less than 167 for the next deeper Section group, W310, needs to be searched. The opt imum section within that subset was a $1310 \times 129$. Similarly only the subset of sections with weights less than 129 for 11360 's needs to be searched. The optimum section within that subset was a $11360 \times 101$.

The process is repeated, as illustrated fo: the next shape group. section groups and all subsets (when applicable) to determine the optimum section. Each search within a list of sections determines the new maximum lightest weight section which satisfies all the design requirements. Any section with weights above this value need not be examined. For this particular example a $1 W 530 \times 66$ was found to be the optimum section. The search path showing the optimum sertion size for each section group is shown in Figure 4.15.

\section{Notes of the Application of the Direct Search Method}

A sertion check is performed on the section closest to the milse middle of any given group of sections. If the section satisfies all the constraints then the group of sections is reduced by half (n/2j to the smaller mass sertions only. Another section check is 
STEP I: DETERMINATION OF THE LEAST WEIGHT SFCTION GROUP WTTIIN SHAPE GROUP I

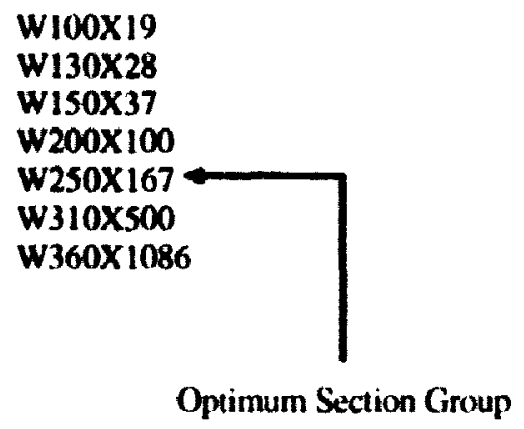

STTP 2: SECTION GROUP SFARCH WITIIN SHIAPE GROIP I
(a) $\mathrm{W} 250^{\circ} \mathrm{s}$
(b) W310\%s
(c) W360's
W250 $\times 18$
W310 21
W360x33
W250 $\times 22$
W $310 \times 24$
W $310 \times 28$
W360x39
W360x45
W250x 25
W310×31
W360x51
W $250 \times 28$
W310x33
W360x57
W310 39
W360x64

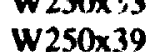
W $310 \times 45$
W360×72
W310x 52
W360x79
W250x49
W310 60
W360x91
W310 67
W360x 101
W360x 110
W310x74
W360x 122
W310 886
W360x
W $250 \times 80$
W $310 \times 97$
W $250 \times 101$
W310x 107
W250x 115
W310x 118
W250x 131
W250 $\times 149$
W310x 129
W310x 143
W250x 167
W310x 158

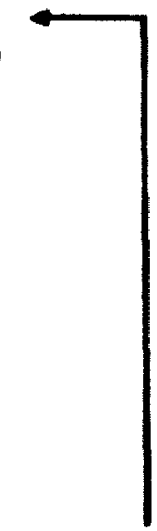
Optimum Section
Optimum Section
Within W250 Section Group
Within W310 Section Group
Optimum Section
Within W360 Section Group

Figure 4.16: Illustration of logic of direct search method 
STFP 3: DETERMINATION OF THE LEAST WEIGHT SECITON GROUP WIITIN SHAPE GROUP 2

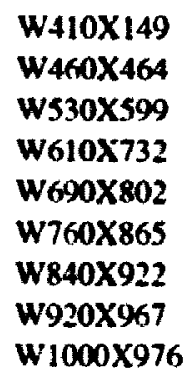

W410X149

W460X464

W530X599

W610X732

W690X802

W760X865

W920X967

W1000X976

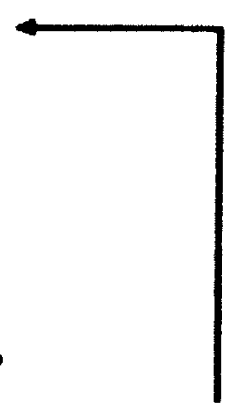

Optimum Section Group

STIP 4: SECIION GROUP SEARCH WITHIN SHAPE GROUP 2

(a) W410's

W410x39

$W 410 \times 46$

W410x54

W $410 \times 60$

W410x67

W410 $\times 74$

$W 410 \times 85$

$\mathrm{W} 410 \times 100$

Optimum Section

Within W410 Secton Group (b) $\mathrm{W} 460^{\circ} \mathrm{s}$

W460x52

$W 460 \times 60$

W460x61

W460x67

W460x68

W460x74

W460x82

\section{Optimum Section}

Within W460 Section Group (c) $\mathrm{W} 530^{\circ} \mathrm{s}$

W530x66

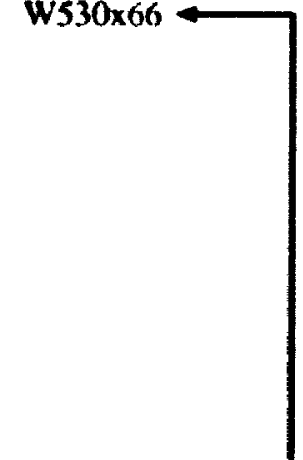

Optimum Section Within W530 Section Ciroup. and Overall

Figure 4.16: Illustration of logic of direct search method (Continued) 
performed on the section closest to the middle of this reduced group and one half of that will be eliminated. This reduces the total number of sections to be evaluated to $n / 4$. By performing $\log _{2}(n+1)$ section checks, the section of minimum weight within that section group will be determined. Practically however, this number is quite a bit less as the search starts with lightest section groups and reduces the data set with each optimum section found, and needn't proceed if the maximum lightest section found is smaller than the lightest section of next available Section group.

It is estimated that the maximum number of section checks that would need to be conducted for one automatic design with the above search constraints, including a search of all $W$ and WWF shapes, would be 30 .

\subsection{Design Module Structure}

The member design module BEAM_DESIGN has been designed so that it can be maintained and executed separately from the user-interface module. This facilitates the option of incorporating this flexural member design module into an integrated system for the analysis, design fabrication and erection of steel buildings. $A$ block diagram illustrating the basic is shown in Figure 4.18. The BEAM.DESIGN module is also an integrated program module consisting of multi-language (programming) subroutines and two individual programs TORSTEEL and PLFRAM. The block diagram for TORSTEEL is given in Figure 4.17 and for PLFRAM in Figure 3.1. 


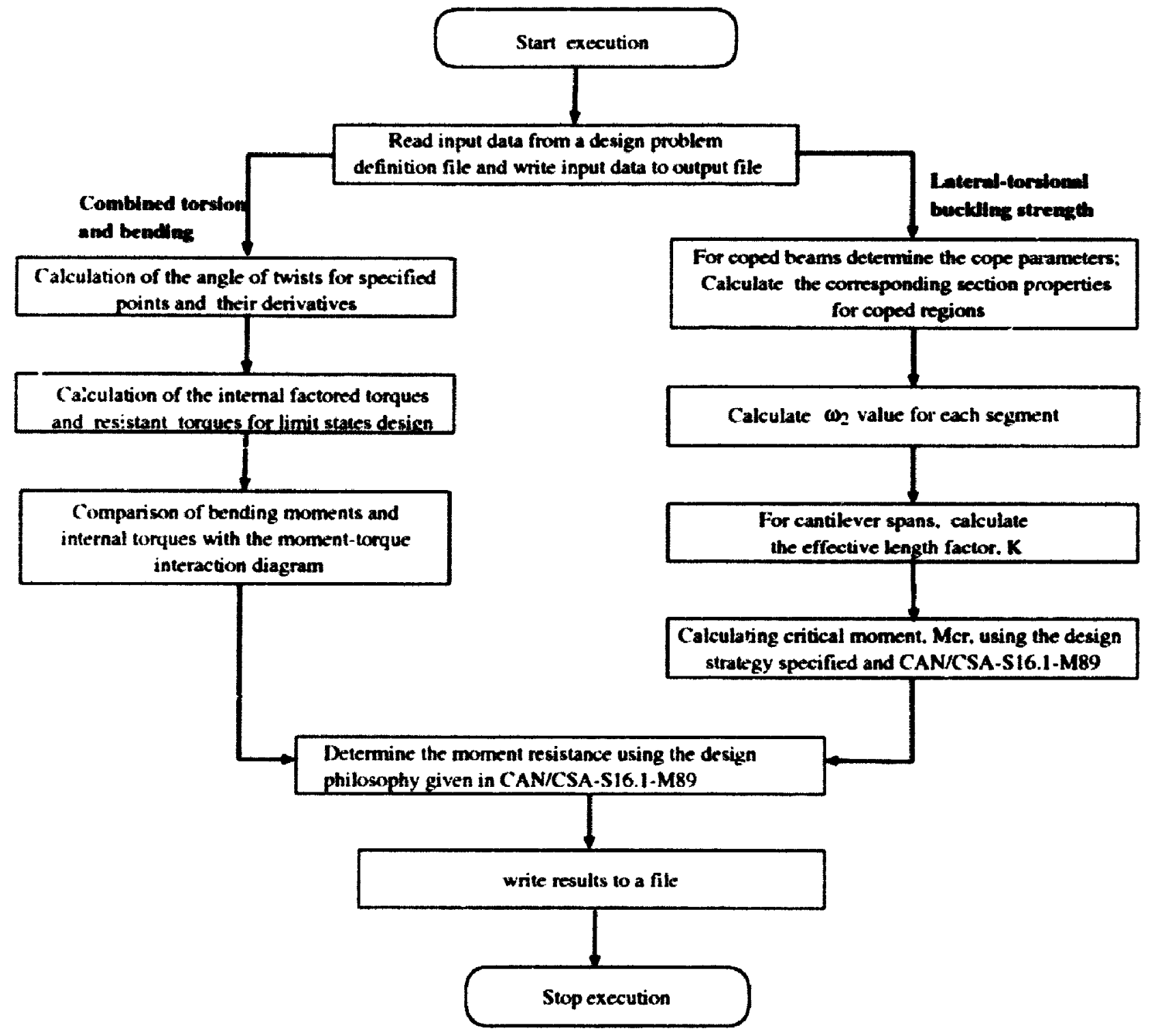

Figure 4.17: Block diagram for the module TORSTEEL 


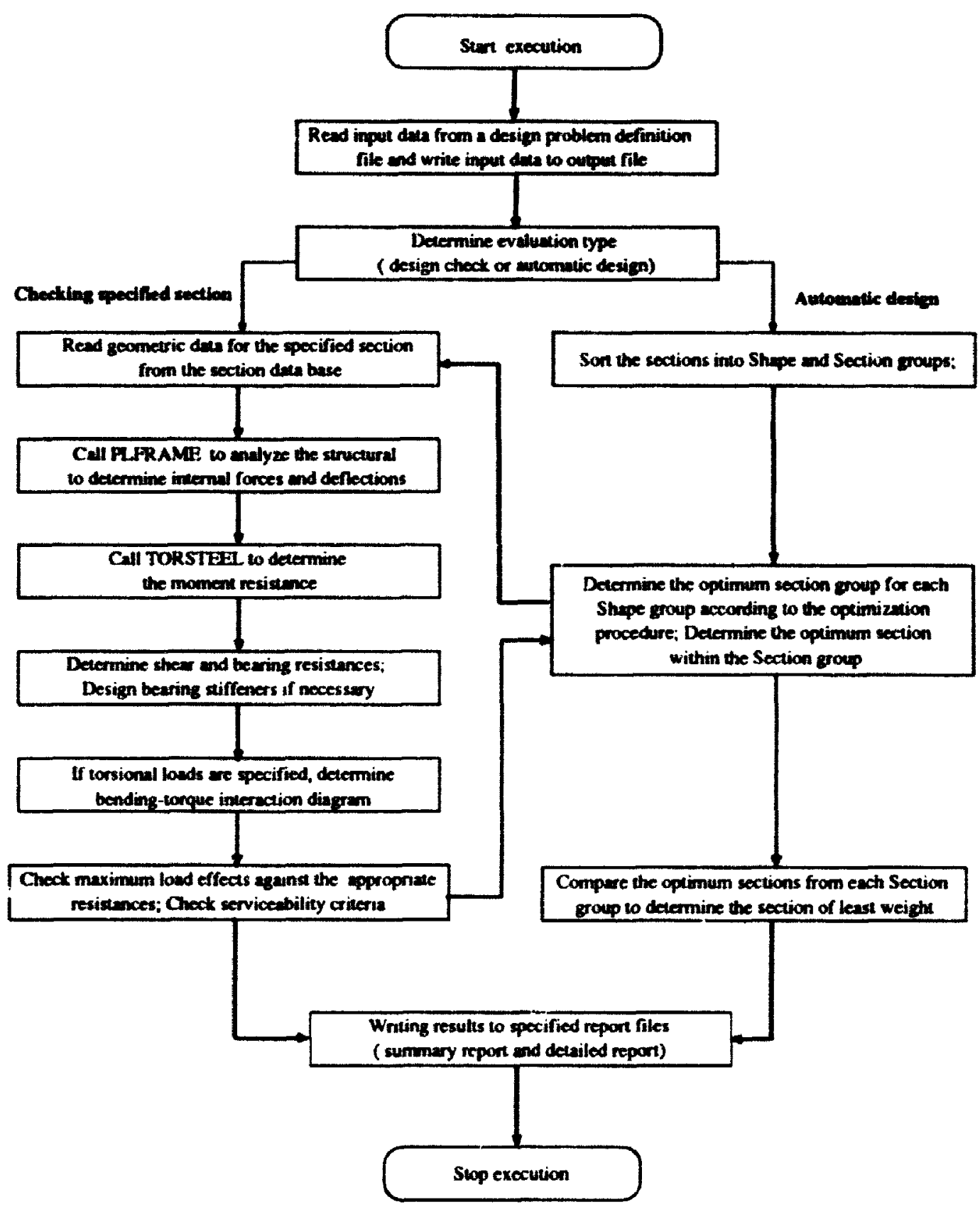

Figure 4.18: Block diagram for the module BEAM_DESIGN 


\section{Chapter 5}

\section{INTERACTIVE CAD SYSTEM FOR FLEXURAL MEMBER DESIGN}

A good member design program should:

1. determine the section size based on all possibla failure modes (according to the limit states design philosophy: and

2. provide a good user interface that is simple, comprehensive. easy to use. graphics oriented, and models the design process: and

3. be capable of being integrated with other programs: and

4. be capable of being ported to different operating systems.

The first of these has been discussed in detail in chapter 3 and 4 . The remainder will be discussed in the following seetions. 


\subsection{User Interface}

A good user interface should be simple, comprehensive, flexible, easy to use, provide as much information as requested, illustrate data through scaled images as well as numbers, and model the design process.

Unlike most other existing member design software, which at most provide a spreadsheet for input entries and limited structurat information displays, the program IDFSM has uniquely designed graphics-oriented user interface which has following features:

- Each structural geometrical or load data entry is illust rated by three-dimensional scaled structural image displays as shown in Figure 5.1. For example, the type of lateral support is specified by the highlighted button at the bottom of the screen and its location by the indicator shown.

- Each successful data entry is inst antly illustrated on an updated image as indicated in Figure 5.2, where an additional lateral support has been added.

With these features, and the implementation of grouped menus. arranged in accordance with design process, the designer should have no difficulty in using the program IDFSM, even without help facility menus. Errors resulting from incorrect data input are more casily detected through scaled images, hence the probability of any incorrect data being entered is diminished. This approach is a significant improvement on existing systems where the data structure is shielded or partially shielded from the designer.

Loads, scaled internal force and deflection diagrams are shown along with the structural system. This allows the structural engineer to clearly visualize whether or not the lateral supports are effective in supporting the compression flange. $A$ summary of member resistances and detailed engineering reports can be viewed on 


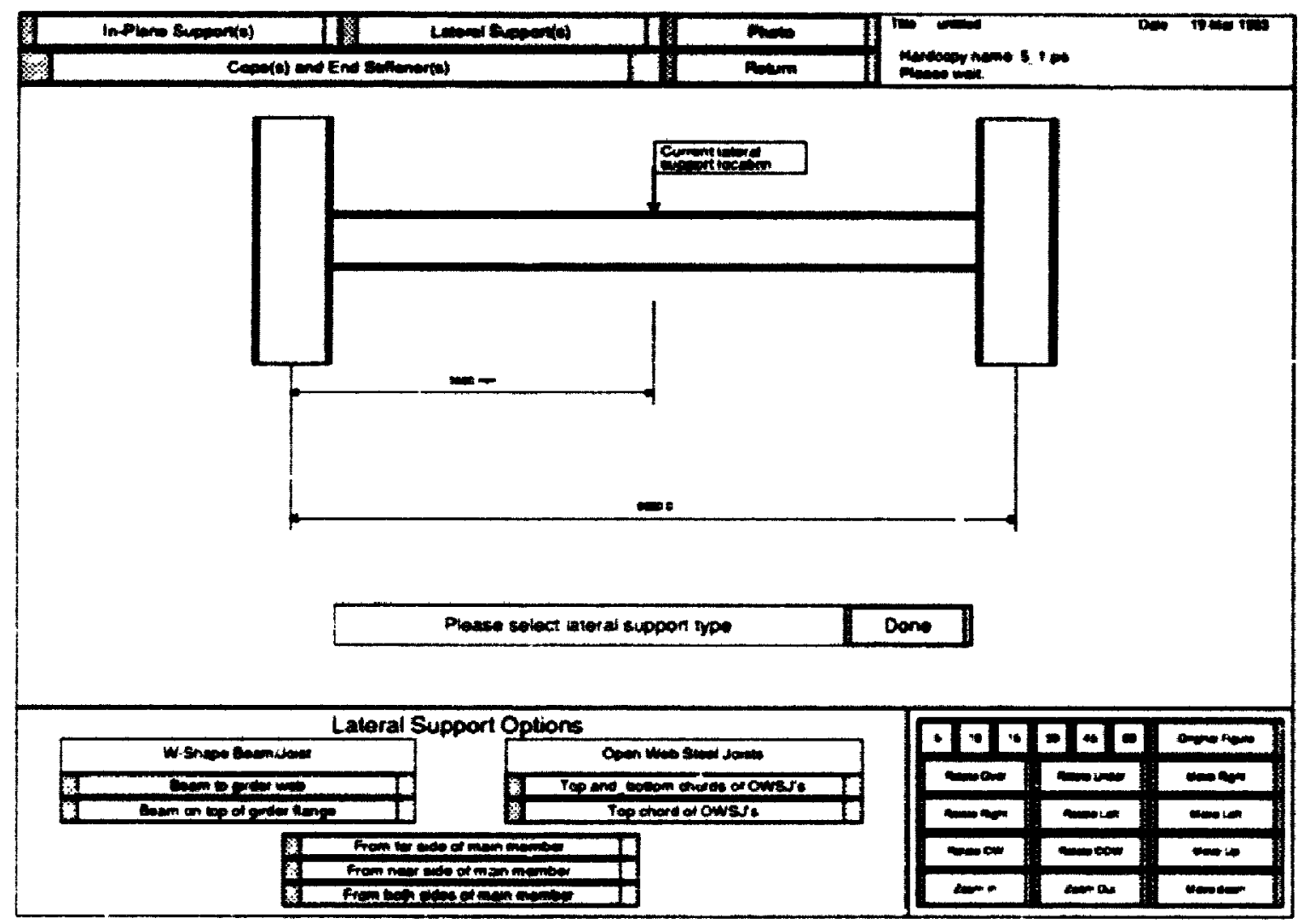

Figure 5.1: Graphics-assisted ent ry 


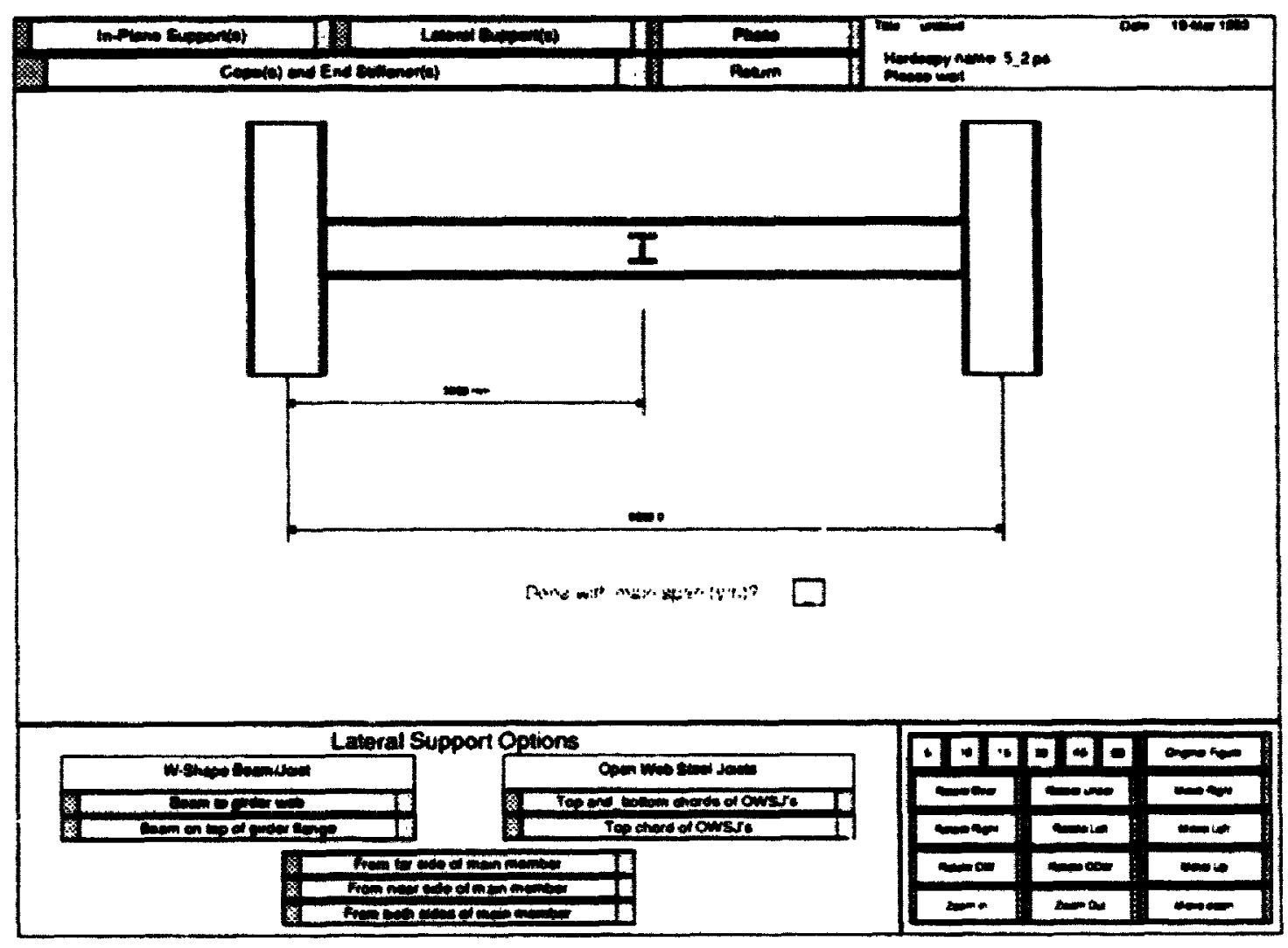

Figure 5.2: Instant response to the data entry 
the screen. Hardcopies of all images are easily ohtained by executing the photo option and printing the appropriate Post Script file.

A graphics-oriented user interface such as this leads to a better understanding of the structural system and the design process. The program IDFSM will serve as both a design tool and an educational tool.

\subsection{Integration}

There are basically two levels of integration related to the nember design step of the whole design process. The higher lever integrates the stand alone program like IDFSM. into an integrated system for the design of steel buildings. The lower lever integrates existing third party programs to perform one portion of IDFSM functions.

\subsubsection{Design of stand alone program for an integrated sys- tem}

The program IDFSM has been designed to be integrated into a complete design (integrated) system for steel buildings. which would include other member design modules. a load determination module. a geometric modeling module, analysis modules, and ronnection and fabrication modules.

In the int egrated module, member definition, boundary condit ions and loads would be determined by using general load determination and a geometric modeller module for the whole structure and data for each flexural member would be automatically generated. Current member definition screens would not be used. Within the integrated program. IDFSM would be a sub-program. and would be activated by a flexural member design button.

To make it possible to integrate the flexural member design module, the user 
interface code and member design code were designed and written to function independently. The flexural member design module is a stand alone sub-program and can be utilized in both IDFSM and for integrated steel building design program. The flexural member design module would simply be executed by system calls.

When implemented as a sub-program within the integrated program, add-on control routines will be written to execute the stand-alone design module multiple times. At this stage, the user interface module of IDFSM would be modified to act as a viewing tool for the design results of each individual member. The user would retrieve detailed graphical and non-graphical information about a member geometry. loads. internal forces, design constraints. design options. member resistance and deflections. Current member definition screens would be ased to allow changes in the design parameters for specific members and the redesign of those members. The corresponding results would be stored in the general database.

The general database is defined as a romprehensive database created for entire integrated system to facilitate communication between the modules (sub-programs. like IDFSM) of the system. All modules would be capable of reading from and writing to this database with the information required for or created by their process, Duchesse and Thomson (1992). The format of the flexural member design portion of this general database las been developed and is a communication file with extension in. Both user interface and design module are linked to .in files. The user interface module will be able to perform its viewing functions. given a in file for a specific job even if the design module was missing. 


\subsubsection{Flexural member design program as an integrated ap- plication}

The stand alone program IJ)FSM in itself is an integrated application. IDFSM is composed of two independent modules, one for user interface and one for flexural member design. which communicate through a common data base. Other third party or new modules could easily be incorporated into the system provided that proper communication routines ase written to read and write information to the database. This is exemplified : the BEAM_DESIGN module which integrates the program TORSTEEL and PLFEAM. This modular format allows:

1. the programmer to make use of existing programs. and

2. each program to be maint ained separately. which is desirable for fut ure updating: and

3. for the integration of programs written in FORTRAN. ( $. C^{+}++$and

1. for ponsible enhancement of the application enviromment (from FORTRAN to ('. and to $\left(C^{+}+\right)$.

When only a portion of an existing program is useful and the source code of the progran is a ailable, and multi-language corles in a single application are supported by the operating system. it is productive to simply copy reguired rontines to the module under development. Data will be transferred in and ont of these copied rontines by its arguments.

\subsection{Portability}

The program. IDFSM. has been fesigned so that it may be ported to other operating systeme. To ensure the portability of II)Fill to other operating systems: 
1. the primary program modules were written in $\mathrm{C}$ language using common (system independent) functions; and

2. the program was molularized making it convenient to be divided into several blocks to acrommodate memory management for PC. applications.

HOOPS, the graphirs tool system adopted in the program IDFSM. is rapable of producing advanced graphics applications across the entire spectrum of workstations and personal computers. Among these computer systems, which HOOPS provicies 100\% sourcecode compatibility are ST X, WAX, X Windows, DOS. Machintosh and OS/2.

Integrated FORTRAN programs or routine should be converted to $C^{\prime}$ or $C^{\circ}++$ using FORTRAN to ('or $(+++$ converter programs before they are ported to a new environment. The result is likely to be less hardware dependent. The original code should be retained for maintenance and translation when required.

With a small anount of sonrec code modifications, the program IDFSll could be ported to other workstations and personal romputers. 


\section{Chapter 6}

\section{PROGRAM STRUCTURE}

This chapter describes the program. file and database structures, and system requirements. and gives informaion on installing. executing and maintaining the program.

\subsection{General Information}

The program IDFSM. deseleped on the $\$ T Y$ workstation emironment. consists of the following four individual executable programs:

IDFSM is the main program. writhen primarily in the C programming language. has its main function written in $(++$ and cont ains seceral FORTR $A N$ rontines that have been extracterd from the progenn TORSTEEL. The program IDFSM can he divided into two major components according to their inction a user imterface program in which the complnter graphics soft ware parkage HOOPS is embedded and called extensively to produce graphics-oriented windows, buttons.

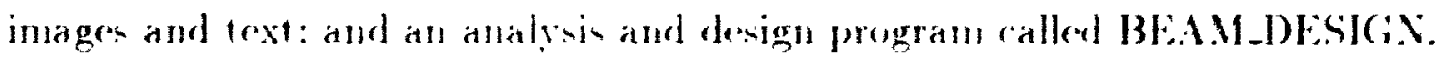

BEAM_DESIGN in a program for attalyoin atud design flexural steel members for bending and tornom. that an be executed on it own or from within the program 
IDFSM. It is written in both C and FORTRAN, and contains two individual programs called TORSTEEL and PLFRAM.

TORSTEEL is an executable program for calculating moment and torsion resistance for both laterally supported and unsupported beams. It is integrated with BEAM_DESIGN by file transmission and system calls from within BEAM_DESIGN. TORSTEEL is written in FORTRAN.

PLFRAM is an existing executable program for plane frame analysis, wi.ich was modified for IDFSM and is integrated with IDFSM by file transmission and system calls from within BEAM_DFSIGN. PLFRAM is written in FORTRAN.

\subsection{System Requirements}

Currently, the program IDFSA runs on SI $\mathrm{Y}$ workstat ions with SPARC microprocessor architecture (SPARC station SICC and better models), under the Sun Operating System (SunOS 1.0). and through net work support the screen display can be opened on all other workstation and personal computer environments running the $Y$ Window network-transparent system. The SunOS is the basic level of device indepenaice. and $\mathrm{X} 11$ and either Open Window or Sunliew/XView graphics libraries are required to open user interface display.

The source code of the program IDFSII package uses approximately 3008 tape blocks or 3.0 MBytes of static memory. The memory management of Sun Systems is handled at the operating spstem level under Sun virtual memory operating sustem. which ensures that for exen the minimum memory installation of low end SPARC. stations, the program IDFSM has sufficient memory available. 


\subsection{Program Installation and File Structure}

All source files and the executable version of the program II)FSM are stored in one single tar file archive, named idfsm.tar. These files (including sub-directories) can be extracted from idfsm.tar to user defined working directory by typing the following command from the system prompt in that directory:

tar xvf idfsm.tar

All executable files are kept in a top level directory (working directory) of directory trees. These files are: idfsm. beam_design. torsteel. and plfram. Along these are the four subdirectories - data2. cisc. design and window. and a README and a Makefile files.

The program reads and writes the data files other than sectional data-base files needed in the process of execution from and to the data2 directory. These data files have following extensions:

in files containing geomet ric. load data, design constraints and results for any given momber (individual design job)

sum files that contain the summary design report and have the same prefix job wame as the in files

.det files that contain the detailed report and have the same prefix job name as the in files

data files containing defanlt design data

-ps PostScript files created in the execution process by using the Photo option 
Other files that might be created in the execution process are:

$\begin{array}{ll}\text { torsteel.input } & \text { input file for TORSTEEL which is created } \\ & \text { automatically by the program when evalu- } \\ & \text { ating the moment capacity. } \\ \text { torsteel.output } & \text { output file of TORSTEEL } \\ \text { torsteel.idfsm_specified }- & \text { output file of TORSTEEL (user specified } \\ & \text { solution), to be read by IDFSM (internal } \\ & \text { use only) } \\ \text { output file of TORSTEEL(default solu- } & \text { tion). to be read by IDFSM (internal use } \\ \text { onsteel.idfsm_s16 } & \text { input file for PLFRAM which is created } \\ \text { automatically by the module IDFSM } & \text { output file of PLFRAM to be read by } \\ \text { IDFSM which contains the results from the } & \text { analysis }\end{array}$

The cisc directory houses the ('ISC sectional dat a files which have dat exteasions. The prefix of dat files represents the corresponding sectional shapes (W shapes. w.dat: WWV shapes. wwf.dat: WRF shapes, wrf.dat; HSS. hss.dat: C shapes, c.dat; angles, angles.dat; HP shapes, hp.dat: $\mathrm{M}$ shapes, m.dat; and S shapes. s.dat; ).

The design and window directories hous we source files for design and user interface module of the program IDFSM respectively: Files in these two directories have the following extensions:

$$
\begin{aligned}
& \text {.c C program text files } \\
& \text {.cc }(++ \text { program text files } \\
& \text {.f - FORTR } A N \text { program text files }
\end{aligned}
$$


.h - header text files for $C$ program text

.o - the object files for equivalent source files

\subsection{Program Execution}

The first step is to login to the host machine where the program is stored ( $\mathrm{X}$ terminal emulator is required, for remote connection to the host machine). Go to the working directory that houses IDFSM and type:

idf sm

The following will appear on the screen:

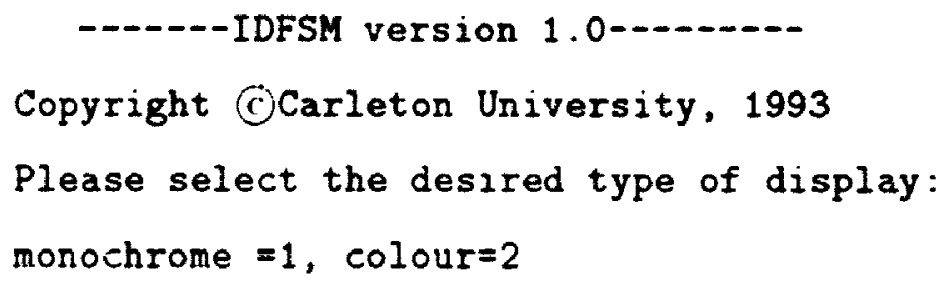

Select the desired type of display and press the Return key. the front page of the program will be displayed, as shown in figure 2.2. System environment variables will not be required to be set up for executing the program. regardless whether or not the program is run locally or remotely. The executable version has non-shared linkage with the $C \mathrm{C}++$ and FORTRAN run time libraries.

If the design job is completely defined (all the input requirements are met), either by using the user interface screns or even by modifying the input file using a text editing tool. then the member design can beexecuted directly from the system prompt by typing:

beam_design JotName 
where, JobName is the prefix of the file with the extension .in. The summary and detailed reports are created during the execution of the program BEAM-DESIGN. This feature has been developed for the future versions that will incorporate IDFSM into a comprehensive integrated system for the design of steel buildings.

\subsection{User Interface}

A typical IDFSM screen page, shown in Figure 6.1, consists of five regions:

1. Major imenu

2. Message display window

3. Structural image display window

4. Additional member definition nenu

5. View contiol menn

Each ment item within one of the window regions on the screen is called a -button". The selection of various buttons controls the flow of screens. Some button: generate sub-windows, sperific to the design task, that are either appear as a different screen or only a small window within the current screen. The user is prompted to type in a numeric value using the keyboard. Cenerally. type the number desired and press the Return or Enter key. The l'nits for the input data are indicated within the same window. The units are used throughout and are $\mathbf{m m}$ for distance. $\mathrm{kN}, \mathrm{kN} / \mathrm{m}$, or $\mathrm{kNm}$ for loads and/or internal forces.

For most of the screens, activating the Return button will either return the user to the main inenu, as shown in Figure 2.1, or when in the main menu. cause the display of first page of IDFSM as shown in Figure 2.2. New or existing jobs can be created or retrieved using the menu on the first page. 


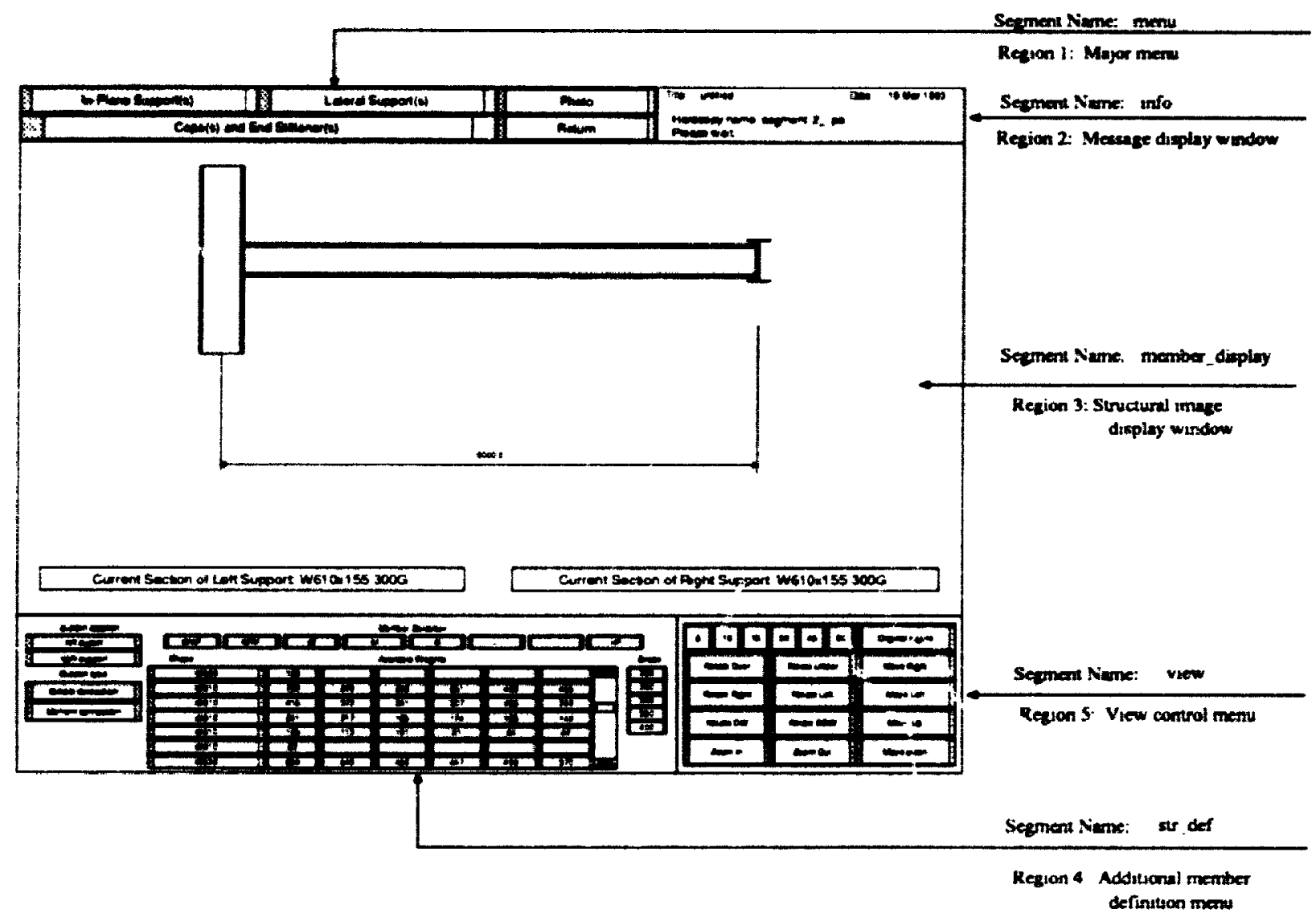

Figure 6.1: Typical IDFSII screen regions and the corresponding HOOPS segments 
When the Photo button is activated, a portion of or all of the image displayed on the screen will be written to a PostScript file with user specified name and will be stored in data2 directory.

\subsection{Updating IDFSM}

To make changes to the source code and to debug the program, SUN C, C++. FORTRAN compiler and corresponding run time libraries are required. and HOOPS graphics package (vession 2.20 or up) has to be installed on the host machine, in which the program is located. (.$(++$ or FORTRA $\mathrm{N}$ codes can be added to modify. revise and update the program. It is recommended that new code would be written in $\mathrm{C}$ or $\mathrm{C}++$

To compile and link the modified program. simply type the system command make in the top level directory: A corresponding Makefile is included with the program IIPFSM to perform all the compiling. updating and regeneration tasks. The make command will activate the make functions for the two subdirectories. design and window. where source files of the program IDFSM are being held. Makefiles in these sub-directories contain all the commands that are executed during the make process. The make command can be executed within either the design or window directory to update any changes to the source code within. If the additional source files are created during the program updating process, the file makefile in the corresponding directory has to be modified accordingly.

The (' function and FORTRAX subroutine source files ending with .c and .f suffixes, respectively. The associated prefix file name is representative of the task it performs. Any ( function being called, which is not declared in a local file. is global function and is declared in the header file id-gfun.h. 'The C language defines all FORTRAN subroutines as global functions. All global variables used in program are 
being declared in the header file id_var.h. These header files are included at the "head" (beginning) of each .c files.

\subsection{Program Modules}

\subsubsection{Major modules}

The program IDFSM is designed to house specific struct ural design and graphic interface functions within specific software nodules. The combinations of these modules form various levels of the integrated program modules. The flow of the program is controlled by the mem buttons which represent these modules. Figure 6.2 illustrates the higher level modules within the program IDFSM and their relationship to each other. Solid blocks represent individual modules while dashed blocks represent their parent module.

\subsubsection{Corresponding programming routines for modules}

Figure 6.3 lists the major routines within each modules illustrated in Figure 6.2. where "routines" are defined as "functions" in (" language or "subroutines" in FORTRAN language. In Figure 6.3. All routines are (' functions unless otherwise noted by the letter $(F)$ after the routine name. The files in which these routines reside are also lintod.

\subsubsection{Structure of graphic data}

The program IIDFSW utilizes the Hoops graphics packige for creating interactive graphic user interface. The Hoops graphics database (a series of graphics macros) is organized into a tres-shaped hierarchy. resembling a file directory tree. Graphics macros are given or have beren developed for geometrical primitives. cameras, lights, 
rendering and modeling attributes. and application-specific information. Related elements are grouped together in segments which are the units of organization within the database. Each segment can contain other segments, forming a tree structure.

In each stage of member design process, as described in Chapter 2, the input data will be interpreted into both executable design data and executable data for graphical display. The data for graphical displays will be stored in appropriate segments, in HOOPS, HOOPS Reference Manual (1992). The "segment tree" for IDFSM, shown in Figure 6.4 defines the relationship among the segments developed. The "?Picture" is the top level seginent, required by HOOPS and is used to open a display screen. The next level of segments define different regions on the screer. Lower level segments define the contents (in the form of text data and/or image data) of each region. The typical window regions corresponding to the highest level of segments are illustrated in Figure 6.1. Lower level of segments are defined in the program in routines as HC_Open_Segment. and can easily be traced through out the program (' functions. 


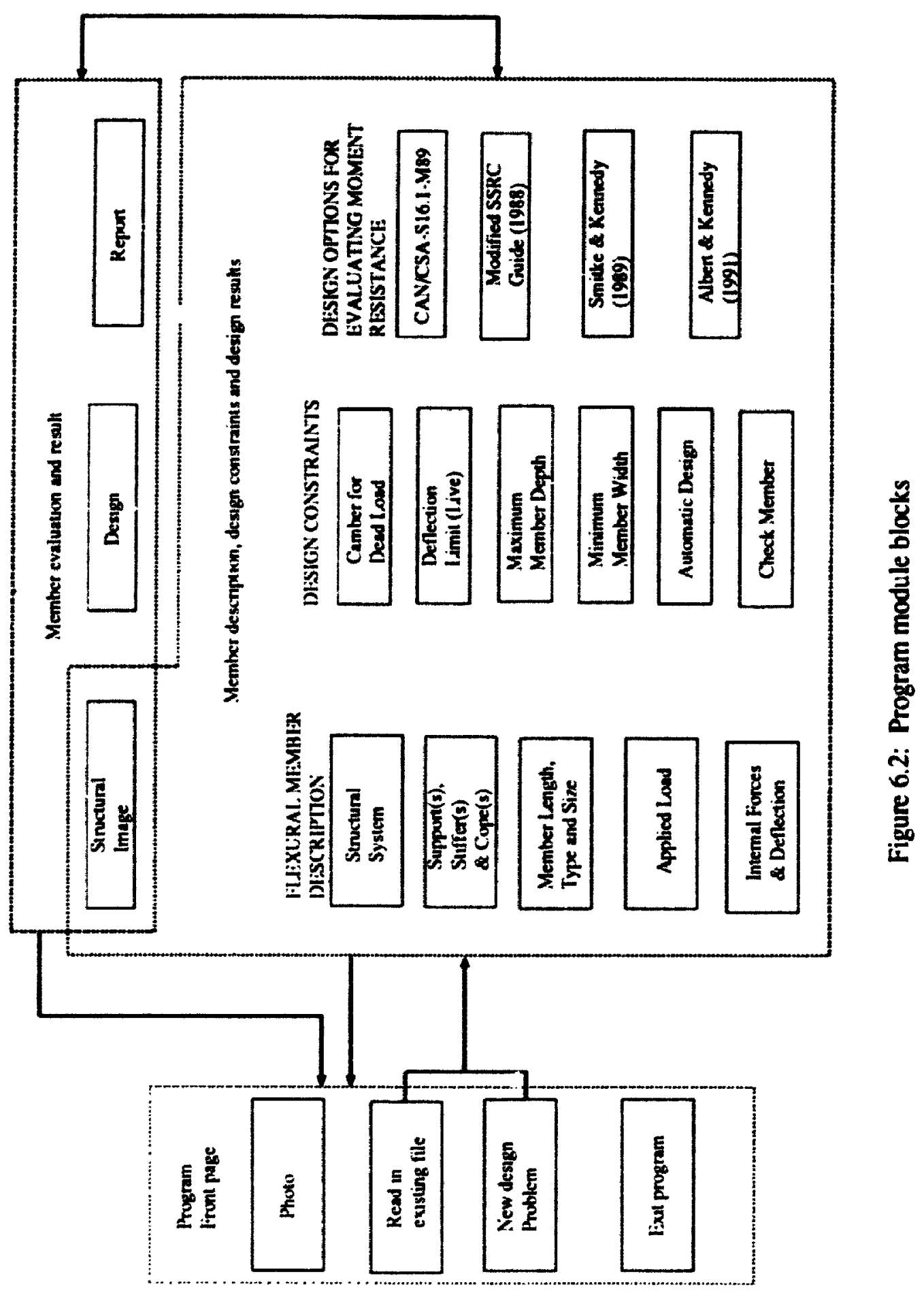




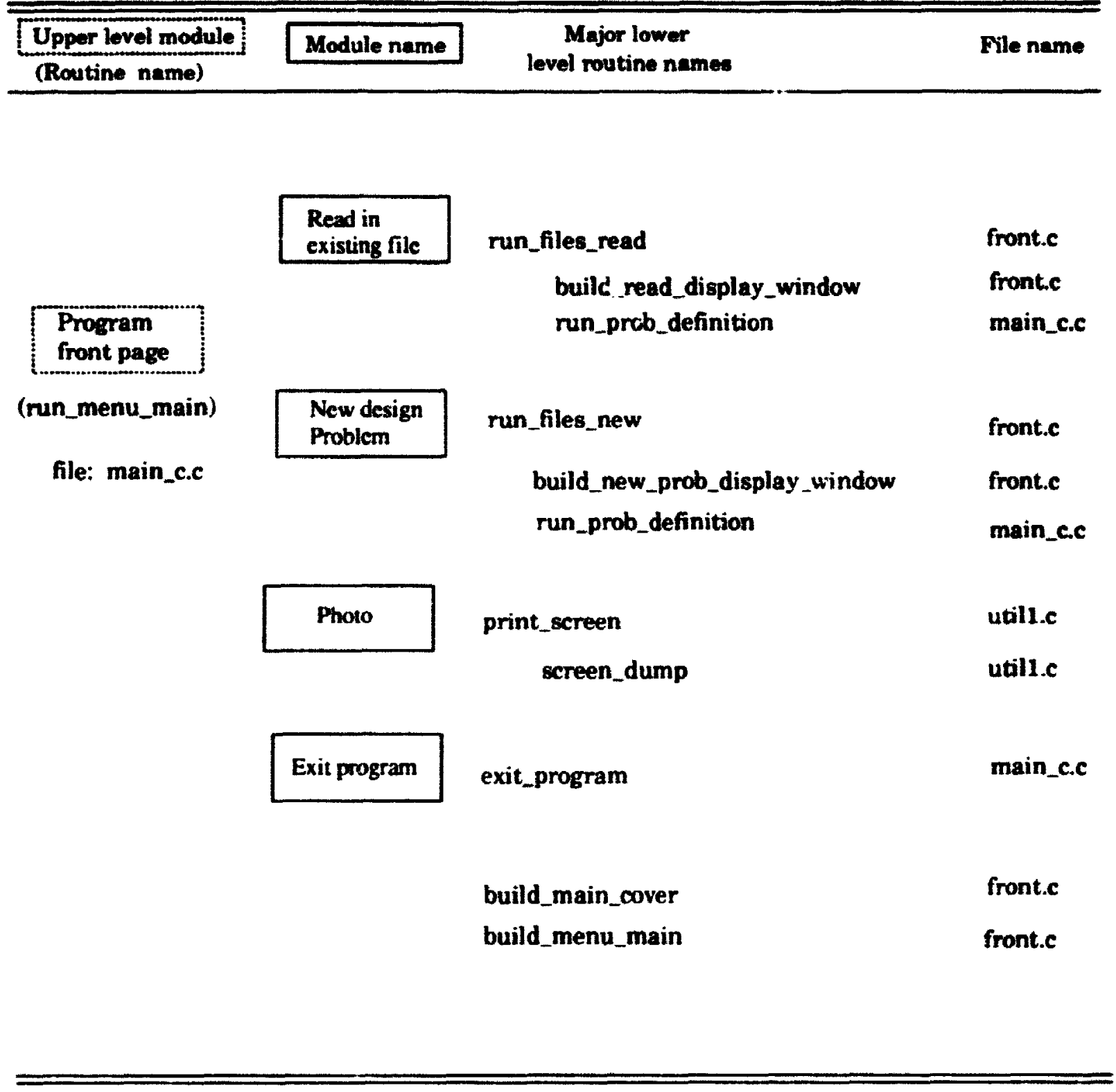

Figure 6.3: Module related routines 


\begin{tabular}{|c|c|c|c|}
\hline $\begin{array}{l}\text { Upper level module } \\
\text { (Routine name) }\end{array}$ & Module name & $\begin{array}{c}\text { Major lower } \\
\text { level routine Names }\end{array}$ & File name \\
\hline & $\begin{array}{l}\text { Camber for } \\
\text { Dead Load }\end{array}$ & change_camber_stalus & prob_defi.c \\
\hline & $\begin{array}{l}\text { Deflection } \\
\text { Limit (Live) } \\
\end{array}$ & change_deflaction_limit & prob_defi.c \\
\hline & $\begin{array}{l}\text { Maximum } \\
\text { Member Depth }\end{array}$ & change_depth_limit & prob_defi.c \\
\hline $\begin{array}{l}\text { Member description, } \\
\text { design constraints }\end{array}$ & $\begin{array}{l}\text { Minimum } \\
\text { Member Width }\end{array}$ & change_width_limit & prob_defi.c \\
\hline (run_prob_definition) & Automaric Design & change_to_auto_design & prob_defi.c \\
\hline file: main_c.c & Check Member & change_10_design_check & prob_defi.c \\
\hline & CAN/CSA-S16.1-M89 & default_s16 & prob_defi.c \\
\hline & $\begin{array}{l}\text { Modified SSRC } \\
\text { Guide (1988) }\end{array}$ & change_ssre & prob_defic \\
\hline & $\begin{array}{l}\text { Smitke \& Kennedy } \\
(1989)\end{array}$ & change_interactive_buckling & prob_deficc \\
\hline & $\begin{array}{l}\text { Alben \& Kennedy } \\
\text { (1991) }\end{array}$ & $\begin{array}{l}\text { change_finite_element } \\
\text { (to be implemented) }\end{array}$ & prob_deficc \\
\hline
\end{tabular}

Figure 6.3: Module related routines (continued; 


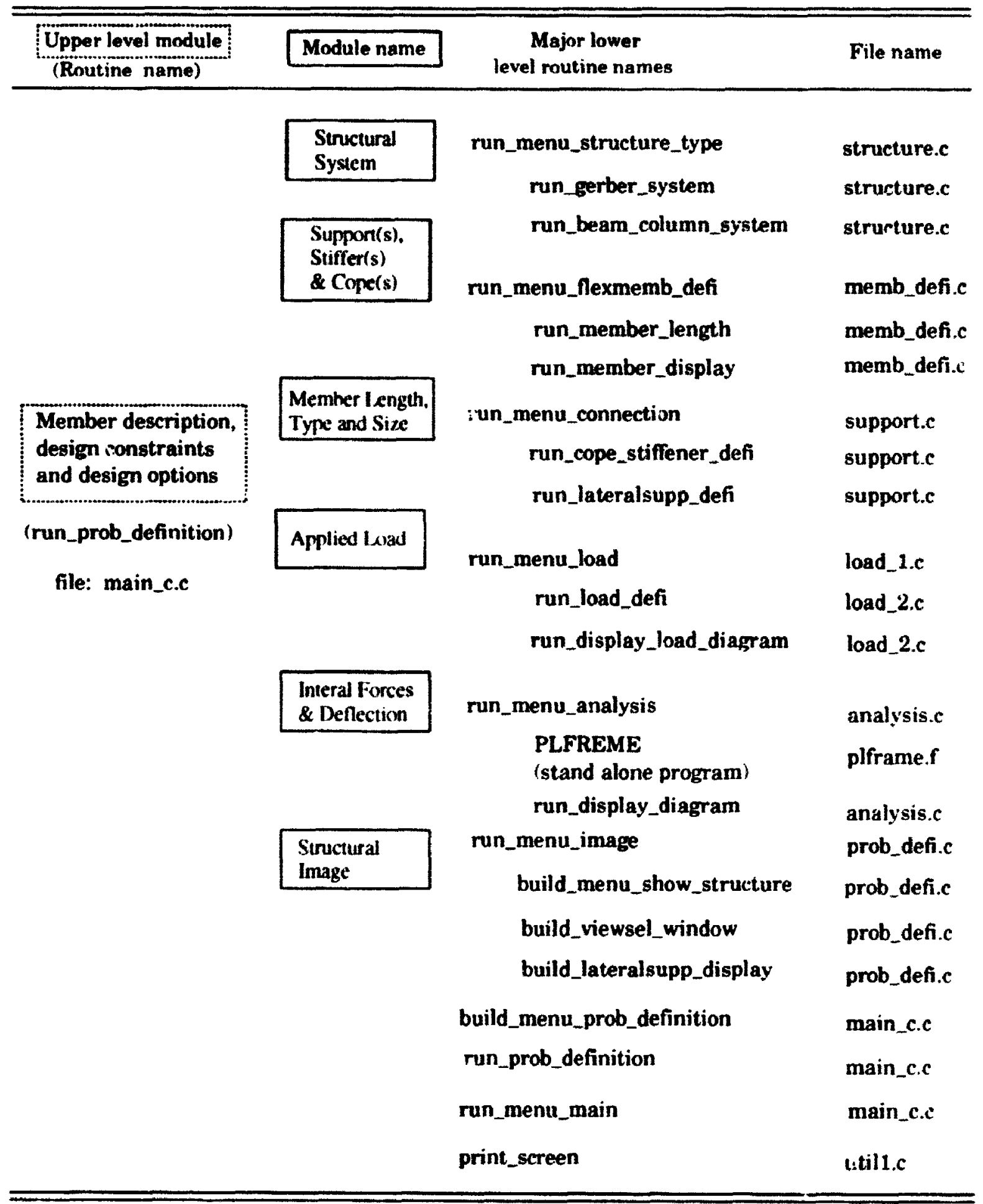

Figure 6.3: Module related routines (Continued) 


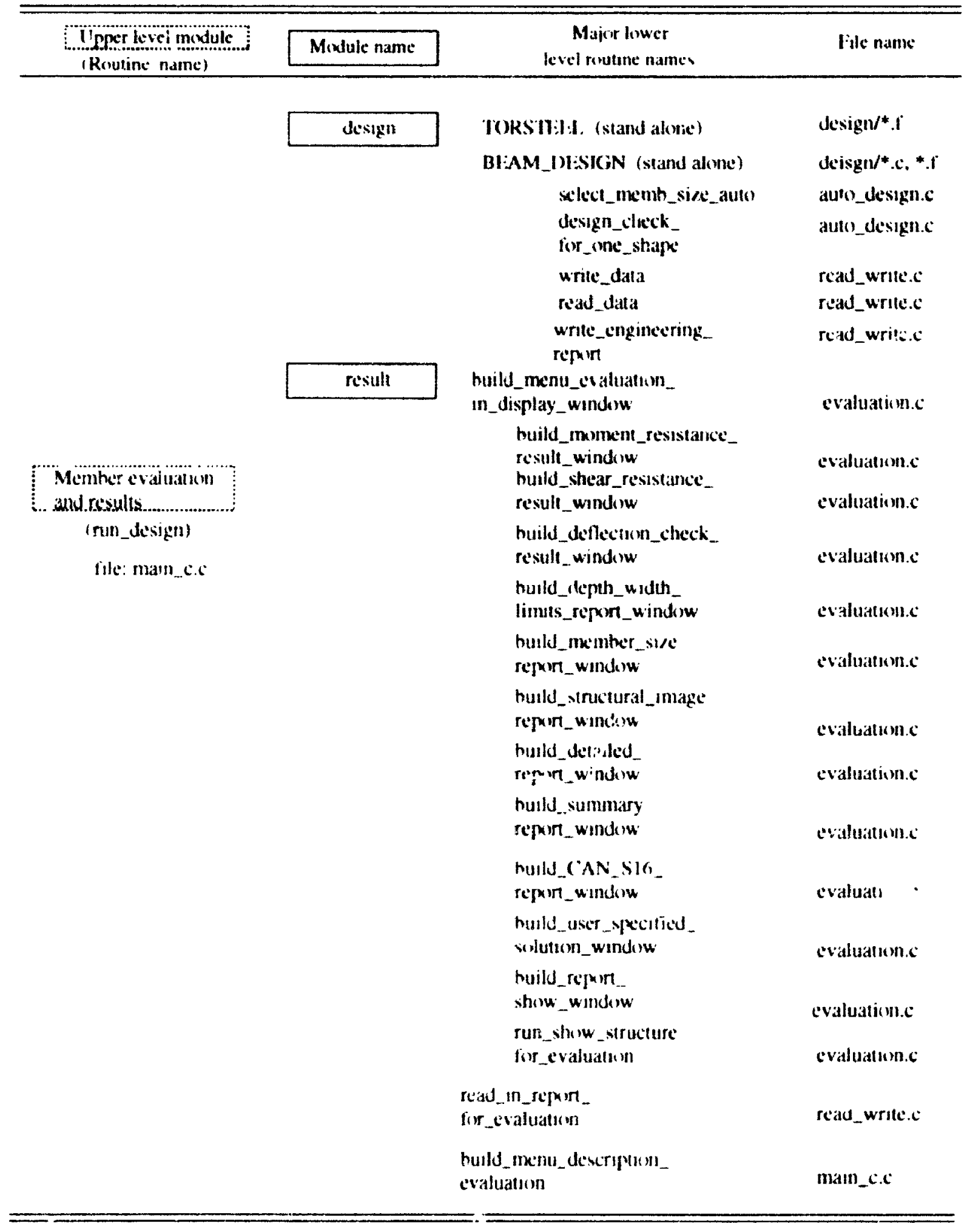

Figure 6.3: Liolule velated rontines (contimura) 


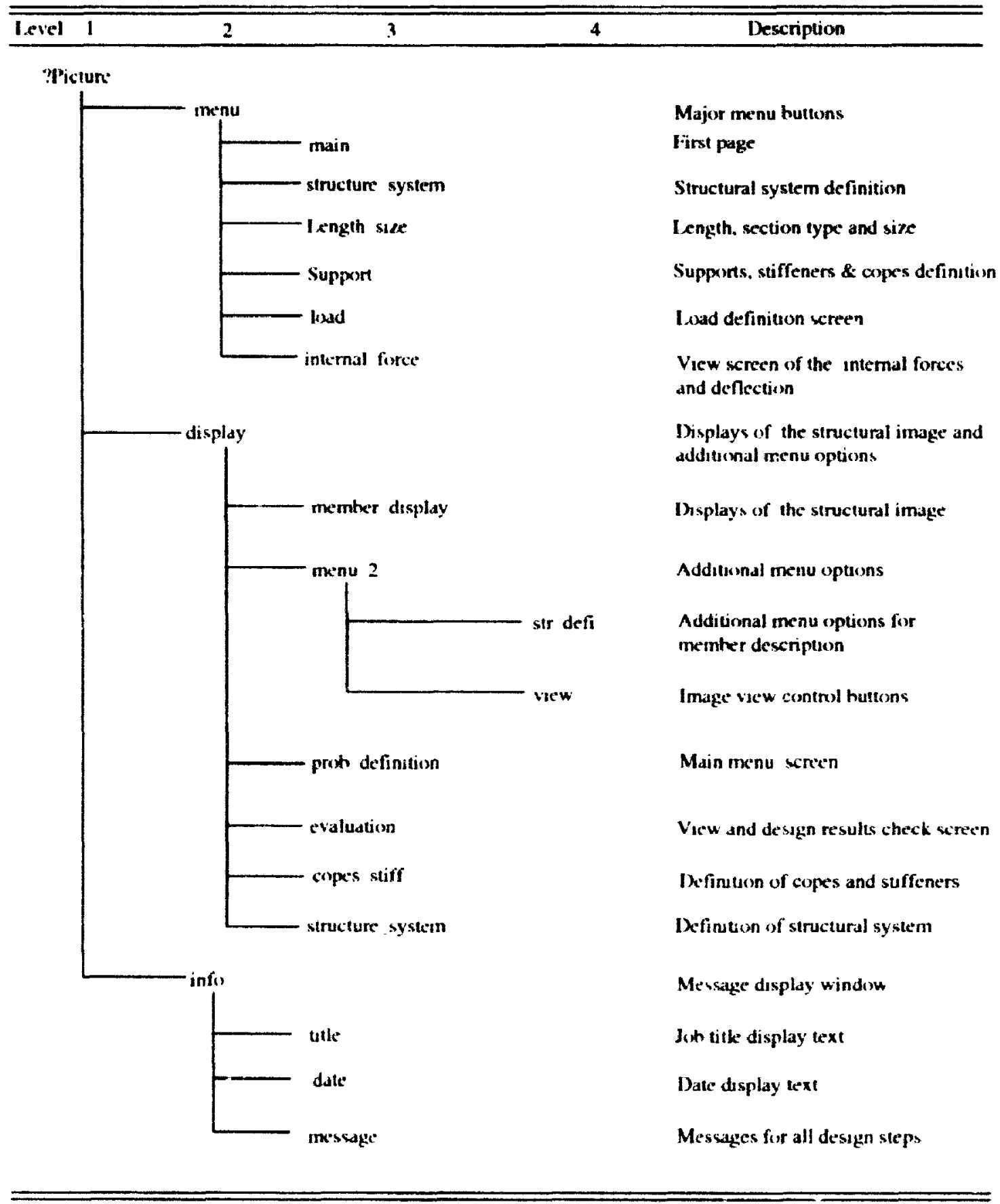

Figure 6.4: HOOPS segment tree within IDFSM 


\section{Chapter 7}

\section{ILLUSTRATED EXAMPLE PROBLEMS}

This ('hapter contains ten example problems which illustrate the features (user interiac $\therefore$ graphic displays and reports) ind versatility (the ability to handle a large number of different design problems) or the program IDFSM. As verification, these examples are compared to existing solutions whenever they exist.

\subsection{Moment Capacity for Laterally Supported Beam}

Structure Type: Simply supported beam (laterally supported)

Reference: Kulak (i.L.. Arams, P.F. and Gilmor M.I. 1990. Limit States Design in Structural Steed. CISC. p.122-124.

Problem Definition: Design check for a simply supported W3310x.52 bean, 7300 mm long. subjected to a uniformly distributed factored load of $33.9 \mathrm{kN} / \mathrm{m}$. The 
beam is comected to the flanges of columns at both ends by standard web angle connections (single or back-to-back angles, bolted and /or welded), as shown in Figure 7.1. The steel grade is specified as CAN/CSA G40.21-M87 Grade 300W.

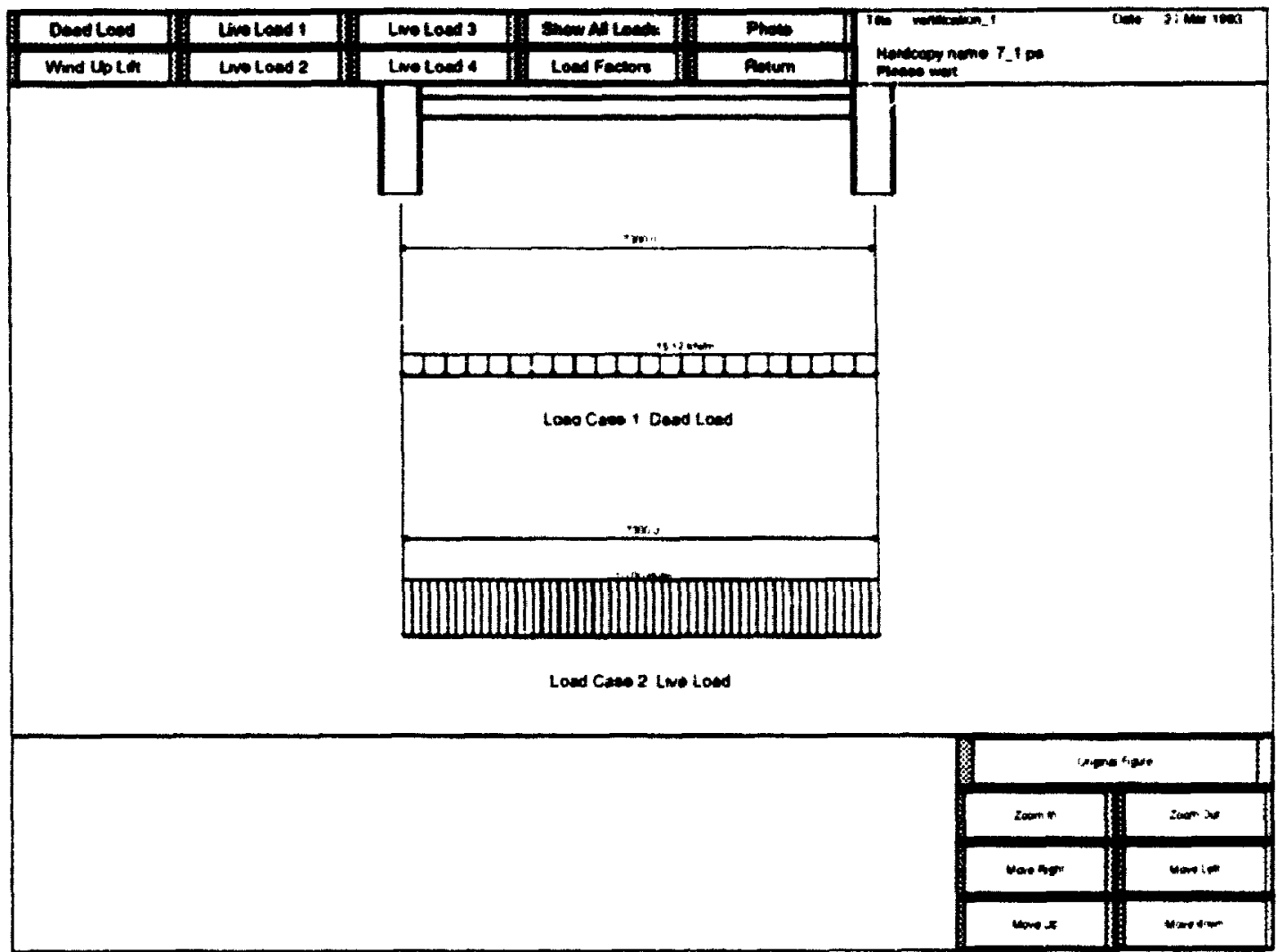

Figure 7.1 : Loads and geometry: Example problem 1

Solution: The solution screen corresponding to the design check is shown in Figure 7.2 . 


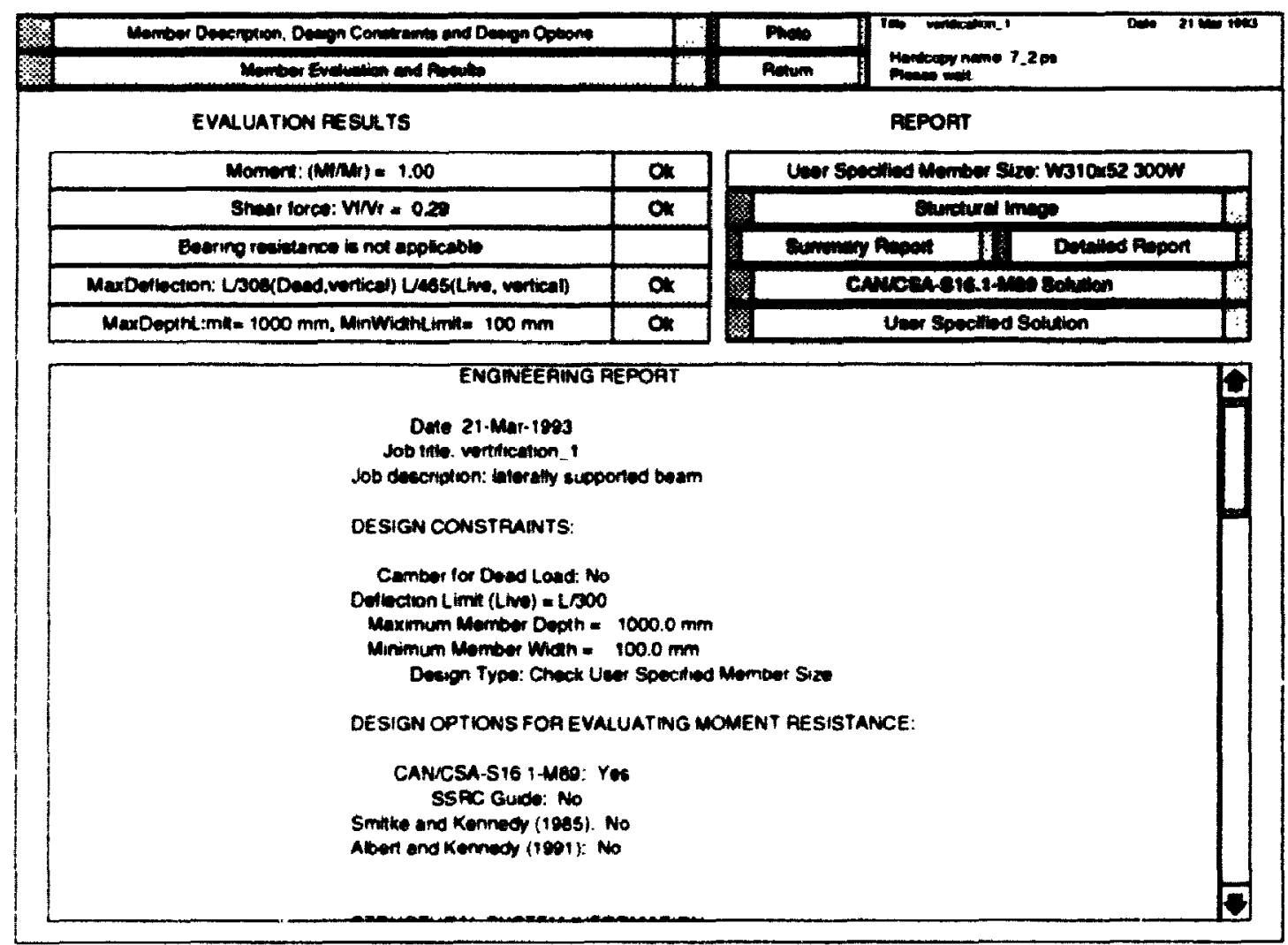

Figure i.2: Design result screen: Example problem 1

\section{Solution Comparison:}

\begin{tabular}{|c|c|c|}
\hline & $\begin{array}{c}\text { Factored Moment } \\
(\mathrm{kN}-\mathrm{m})\end{array}$ & $\begin{array}{c}\text { Factored Moment Resistance } \\
(\mathrm{kN}-\mathrm{m})\end{array}$ \\
\hline IDFSM & 226 & 226 \\
\hline hulak. Adams, and Gilinor (1990) & 226 & 226 \\
\hline Difference & None & None \\
\hline \hline
\end{tabular}

Table 7.1 : Solution comparison: Example problem 1 


\subsection{Moment Capacity for Laterally Unsupported Beam}

Structure Type: Simply supported beam (laterally unsupported)

Reference: Kulak G.L., Adams, P.F. and Gilmor M.I. 1990. Limit States Design in Structural Steel, CISC, p.139-141.

Problem Definition: Design check for a simply supported W310x.52 beam, $7300 \mathrm{~mm}$ long, subjected to an uniformly distributed factored dead load of $15.0 \mathrm{kN} / \mathrm{m}$. as shown in Figure 7.3. The beam is connected to the flanges of columns at both ends by standard web angle connections. The steel grade is specified as G40.21-M87 Grade 300W steel.

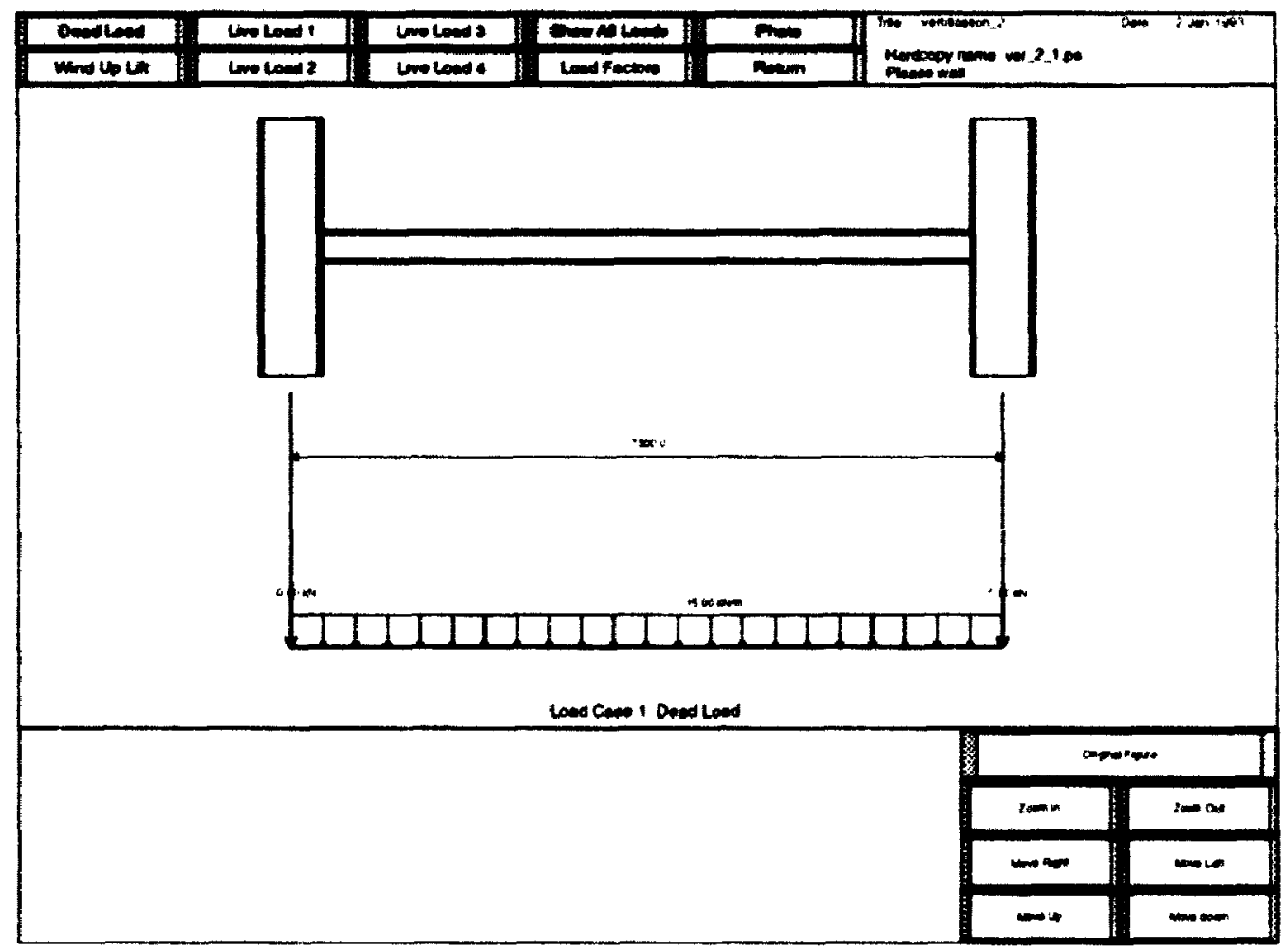

Figure 7.3: Loads and geometry: Example problem 2 
Solution: The solution screen corresponding to the design check is shown in

Figure 7.4

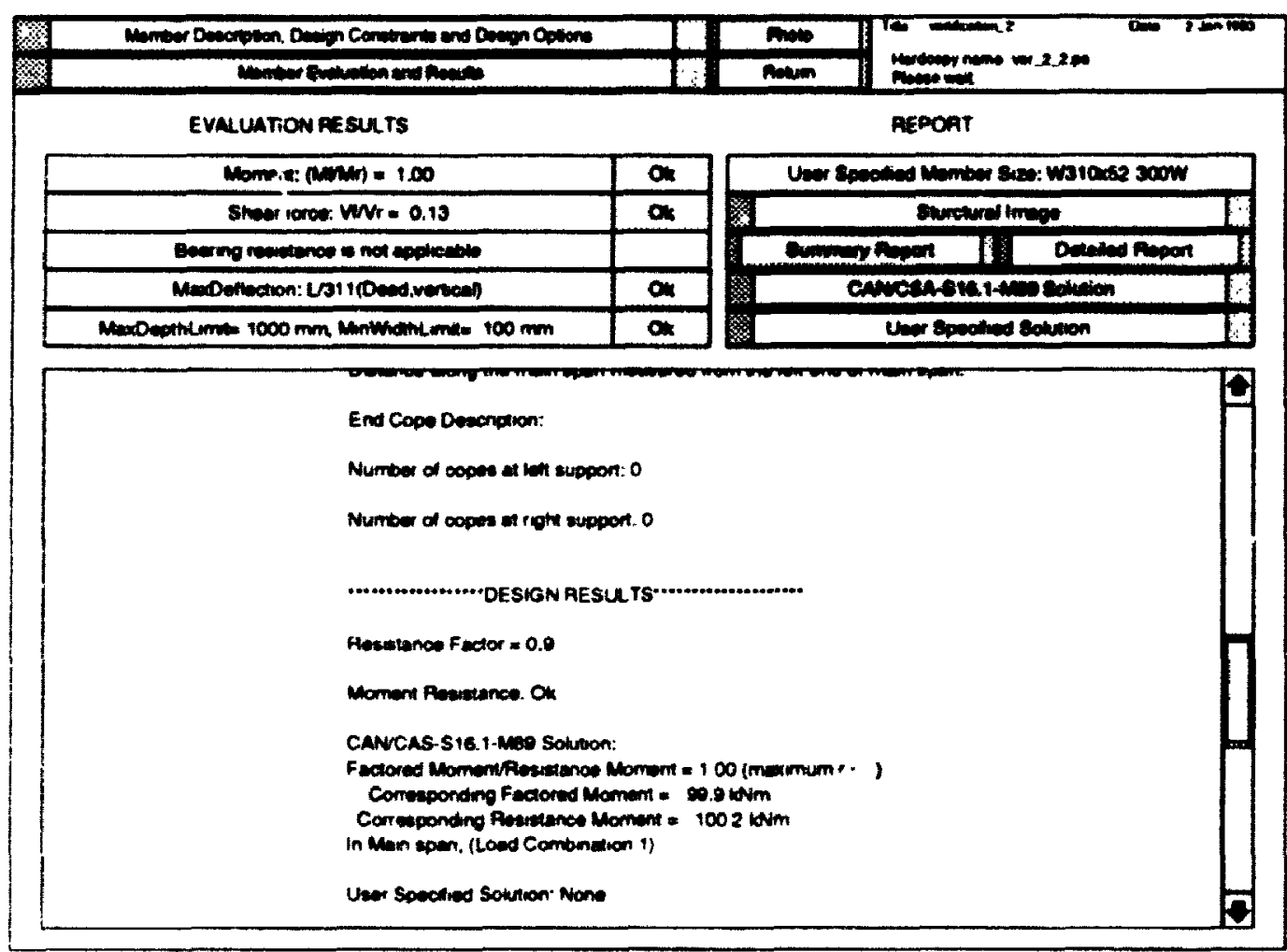

Figure 7.4: Design result screen: Example problem 2

\section{Solution Comparison:}

\begin{tabular}{|c|c|c|}
\hline & $\begin{array}{c}\text { Factored Moment } \\
(\mathrm{kN}-\mathrm{m})\end{array}$ & $\begin{array}{c}\text { Factored Moment Resistance } \\
(\mathrm{kN}-\mathrm{m})\end{array}$ \\
\hline IDFSM & 100 & 100 \\
\hline Kulak. Adams, and Gilmor (1990) & 100 & 100 \\
\hline Difference & None & None \\
\hline
\end{tabular}

Table i.2: Solution comparison: Example problem 2 


\subsection{Laterally Unsupported Beam Using Different Solution Strategies for Evaluation of Moment Resistance}

Structure Type: Simply supported beam (laterally unsupported)

Problem Definition: Design check for a simply supported W410x39 beam. $12000 \mathrm{~mm}$ long, subjected to the total factored concentrated loads as shown in Figure 7.5 . The beam is connected to the web of supporting girders at both ends by standard web angle connections. The stel grade is specified as G40.21-M87 Grade $300 \mathrm{~W} \mathrm{~s}^{+}$eel.

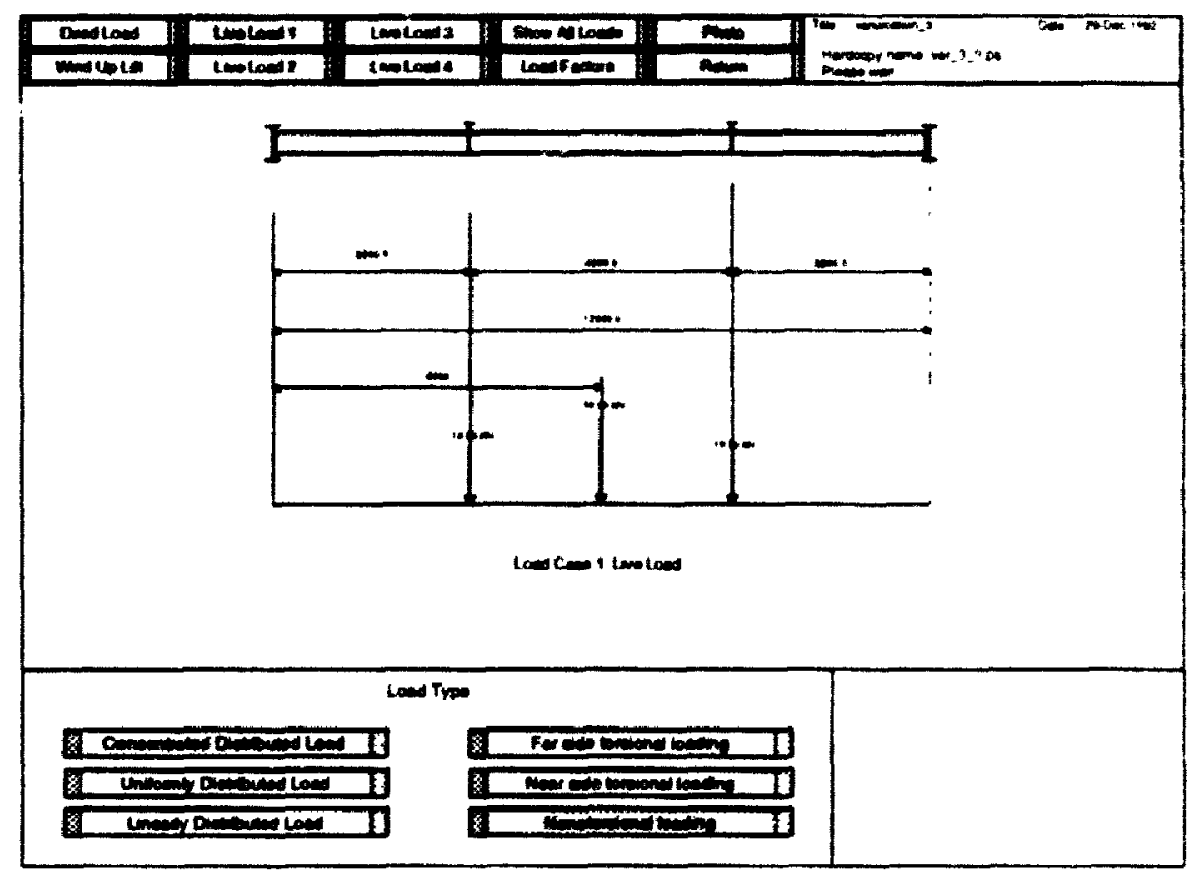

Figure 7.5: Loads and geometry: Example problem 3 - Illustration of different solution strategy options for evaluating the moment capacity 


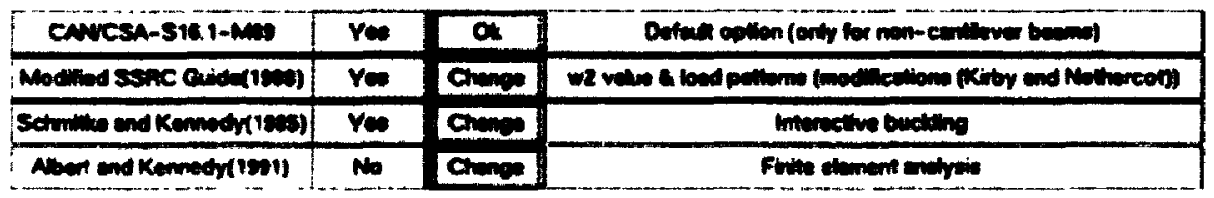

Figure 7.6: Different solution strategy options for evaluating moment capacity (extracted from the main menu screen)

Solution: The solution screen for the user specified solution is shown in Figure 7.7 .

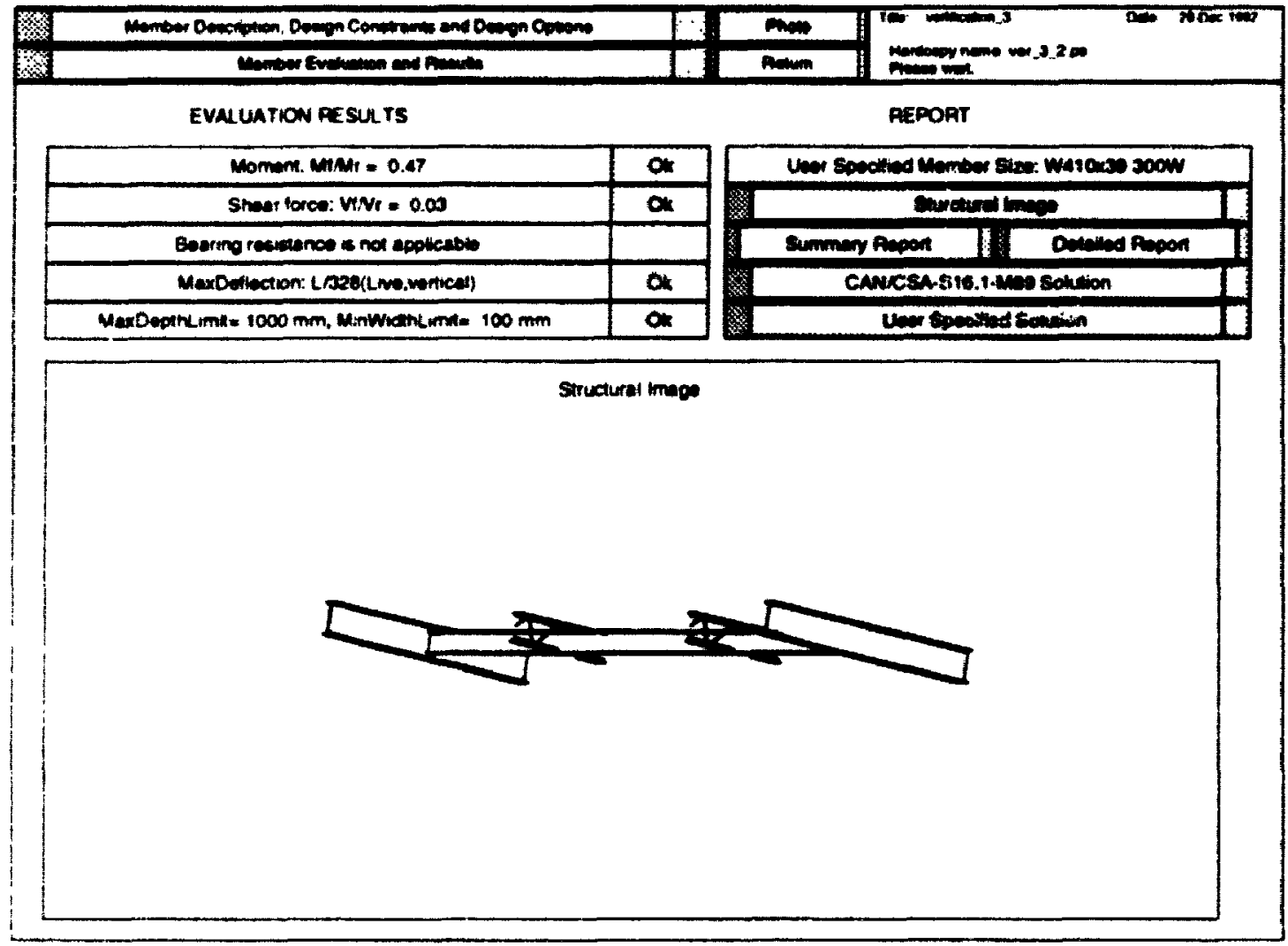

Figure Ћ.т: Design result: Lser specified solution

\section{Solution Comparison:}

The following is a portion of the detailed report produced, from which the evaluation results using three different solution strategies are shown. 'The text, data and strengths given for each span and solution strategy has the following format: 
- Span identification number relative to the left-hand end,

- Effective length or equivalent length for a beam with uniform moment, Schmitke and Kennedy (1985),

- Describing whether or not the span is satisfactory,

- Factored moment capacity, and

- Maximum factored moment occurring within the span

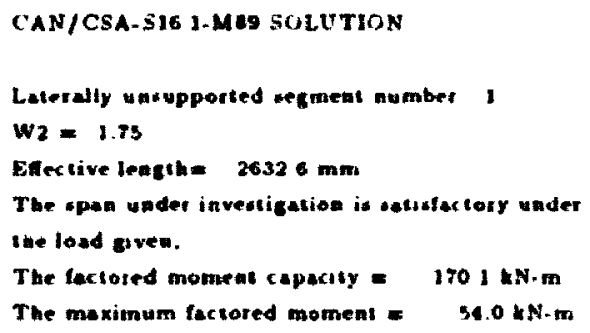




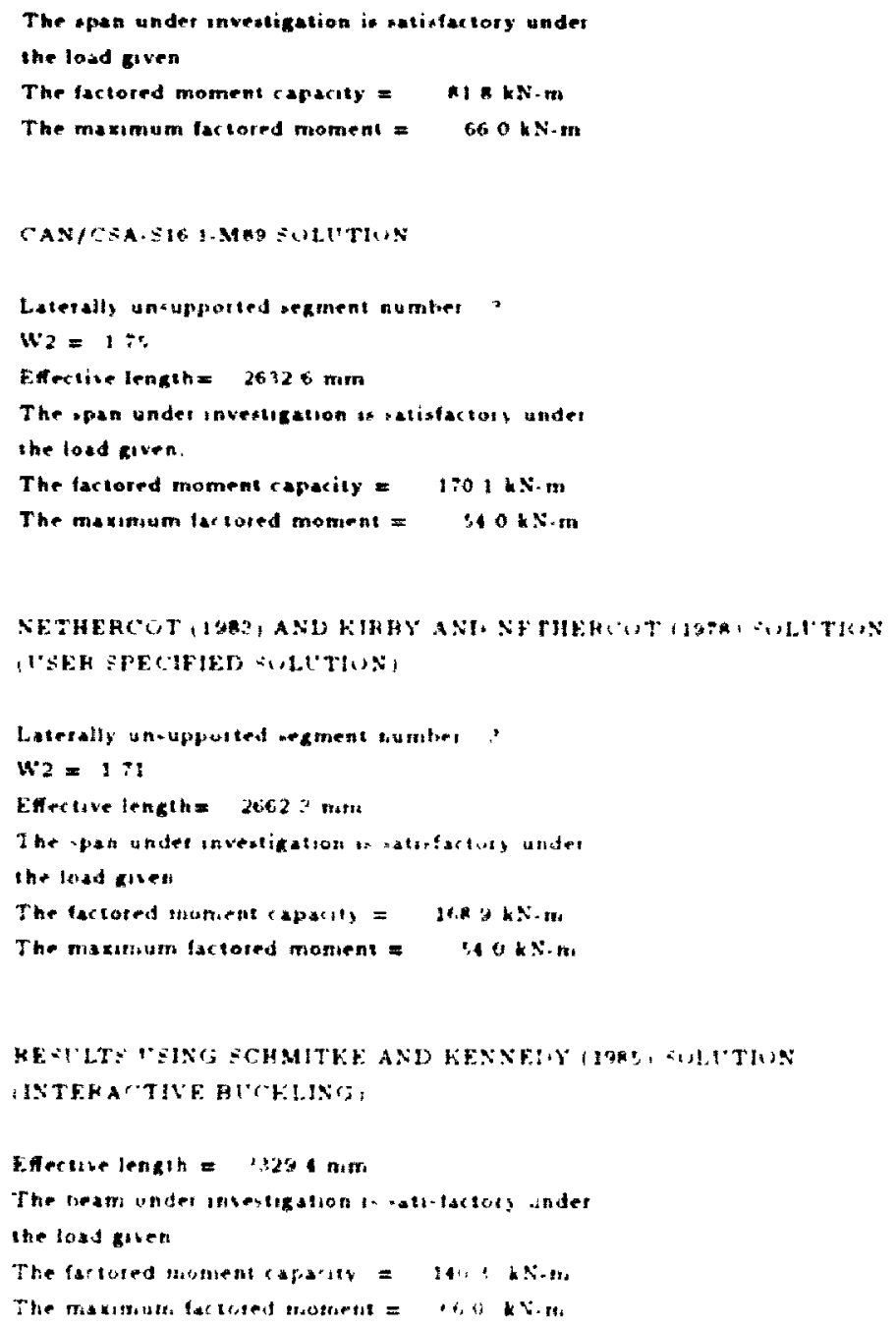

The results for using each of thres solution strategies is summarized in

\section{Table 7.3}

Discussion: The relative difference between the ('AN/CSA-S16.1-M89 solution and the modified SSRC' Guide (1988) solution is small for this particular case with the first being slightly more conservative. In both cases the capacity of the beam was governed by segment 2 and is limited to $81.8 \mathrm{k} . \mathrm{m}$. If the interactive buckling capacity of the beam is recognized, then the beam has approximately $72 \%$ mose moment apacity $1100.3 \mathrm{kNm}$. that can be utilized. 


\begin{tabular}{|c|c|c|c|c|}
\hline \multirow{2}{*}{$\begin{array}{c}\text { Solution } \\
\text { Option }\end{array}$} & \multicolumn{2}{|c|}{$\omega_{2}$ value } & \multicolumn{2}{c|}{ Ratio $M_{r} / M_{r}$} \\
\cline { 2 - 5 } & Left end span & Midspan & Left end segment & Midsegment \\
\hline CAN/CSA-S16.1-M89 & 1.75 & 1.0 & 0.32 & 0.85 \\
\hline Modified SSRC Guide(1988) & 1.64 & 1.05 & 0.33 & 0.81 \\
\hline Schmitke and Kennedy(1985) & N/A & N/A & \multicolumn{2}{|c|}{$0.4 \tau$} \\
\hline
\end{tabular}

Table 7.3: Solution comparison: Different solution strategy options

\subsection{Laterally Unsupported Coped Beam}

Structure Type: Simply supported beam (laterally unsupported)

Reference: Kulak (i.l... Adams. P.F. and (iilmor M.I. 1990. Limit Sates Design in Structural Sicel. CISC. p.139-141.

Problem Definition: Design for a simply supported $11: 310 \times 52$ beam. $7300 \mathrm{~mm}$ long. subjected to an uniformly distributed factored dead load of $15.0 \mathrm{kN} / \mathrm{m}$. The beam is connected to the web of supporting girders at both ends by standard web angle connections. The ends are coped to fit around the top flange of the girders and are defined (location and dimensions using the screen shown in Figure 7.9. The' steel i." "pecitied as (:10.21-.M187 Grade 300W.

Solution: A typical solution screen is shown in Figure 7.10 .

Solution Comparison: The effects of varions coping conditions for cope length of $150 \mathrm{~mm}$ and $300 \mathrm{~mm}$ on the the moment and shear resist ances have been investigated and are given in Table 7.4 and 7.5 . respectively. The relative capacities 


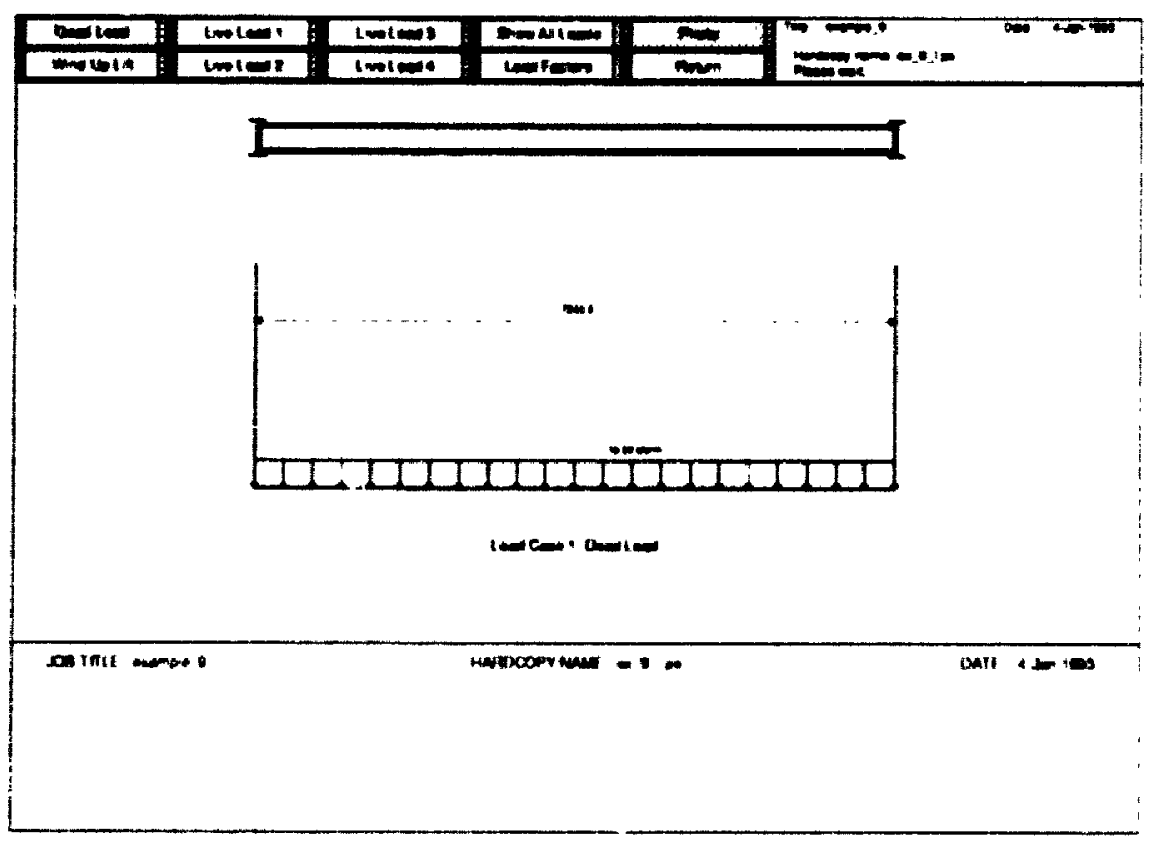

Figure 7 .s: Loads and geometry: Example problem 1

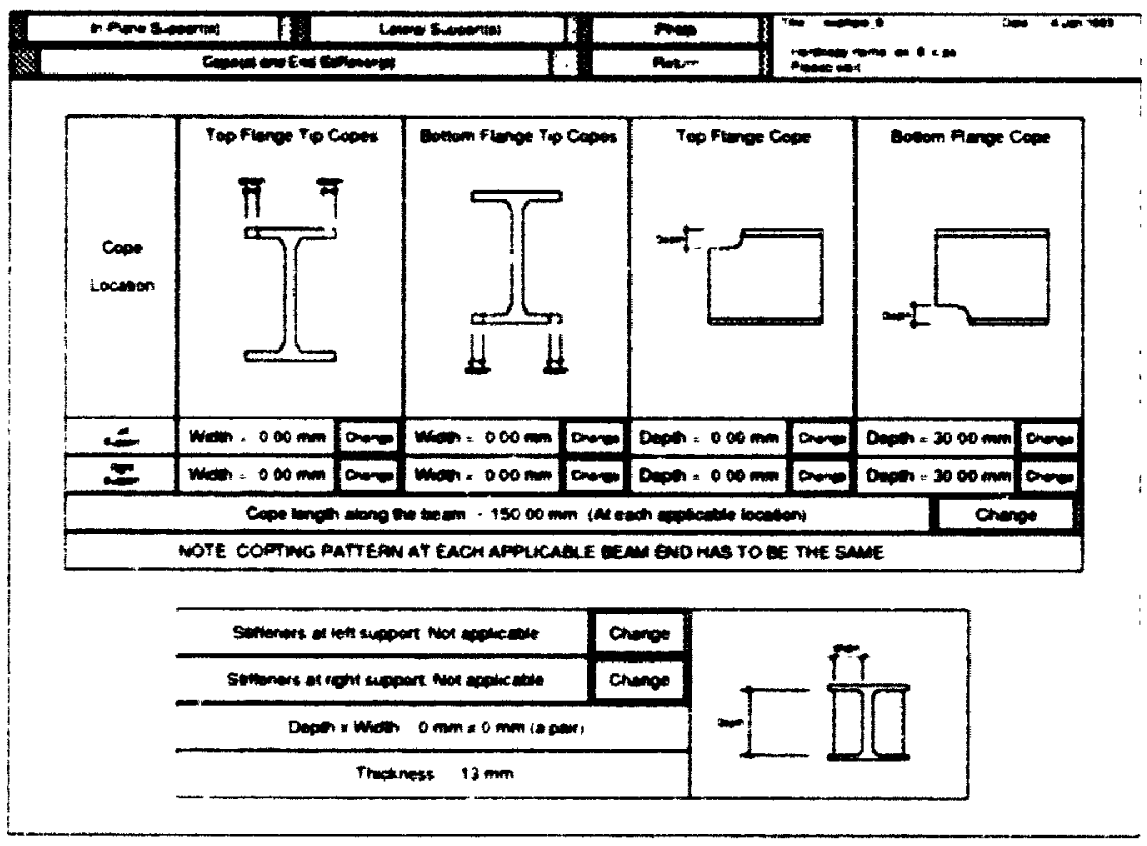

Fïgure 7.9: (oping definition screen 


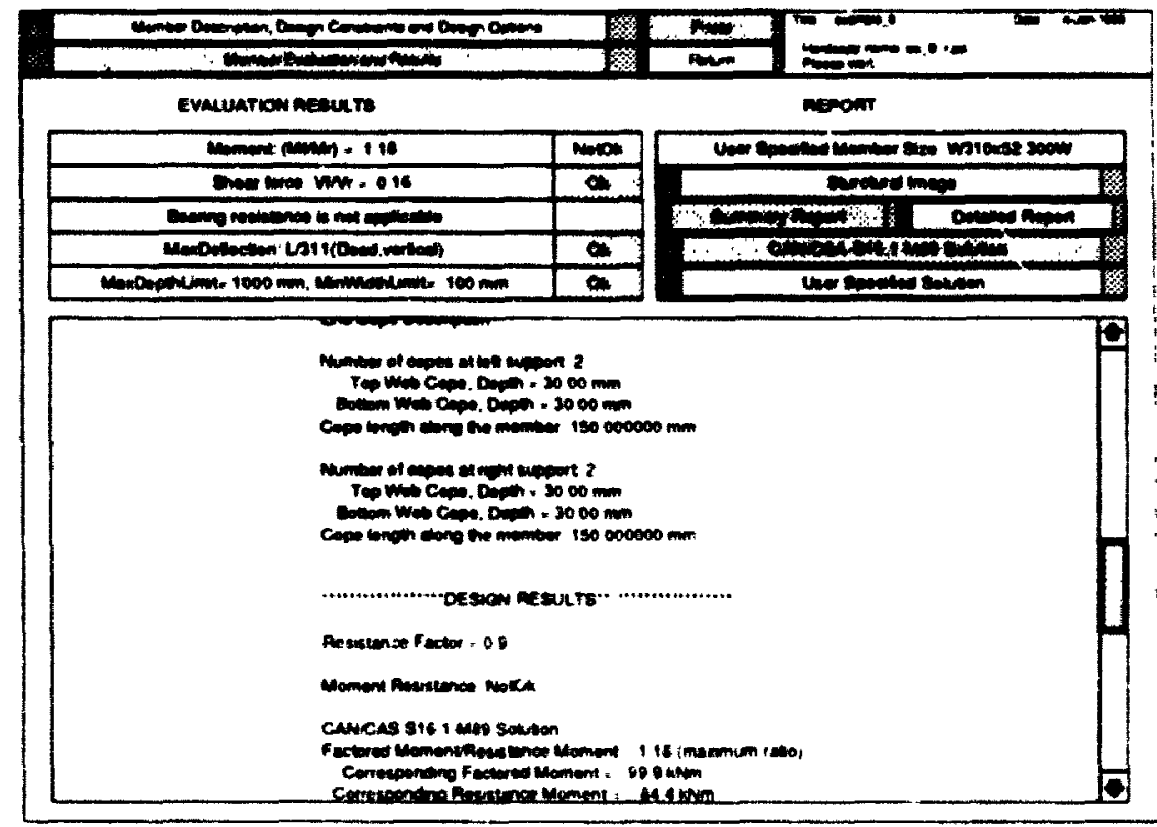

Figure 7.10: Desigi results: Laterally unsupported coped beam

are given as a function of the capacity of the beam without copes. The subscript $n c$ is a short form for no copes.

\section{Discussion:}

As indicated by the relative monernt capacities given in Table 7.4 and 7.5 . the lateral-torsional buckling st rength of the beams with coped compression flanges are reduced and significantly reduced if hoth flanges are coped. Coping of just the tension flange has no effect. Even though there is a relative decrease in the shear capacity for coped beams. the overall capacity being utilized is still quite small, less than $16 \%$ for the worst case.

It may be practical to reinforce the coped area with stiffeners to obtain the full moment capacity of the beam. For this case. the structural engineer should design the beam as though there are no copes. 


\begin{tabular}{|l|c|c|c|c|}
\hline \multicolumn{1}{|c|}{ ('oping Type } & Support Location & (ope Jepth & $\mathrm{Mr} / \mathrm{Mr}_{\mathrm{n}}$ & $\mathrm{Vr}_{\mathrm{r}} / \mathrm{Vr}_{\mathrm{nc}}$ \\
\hline Xo copes & $\mathrm{N} / \mathrm{A}$ & $\mathrm{N} / \mathrm{A}$ & 1.00 & 1.00 \\
\hline Bottom Flange Cope only & Left and Right & $30.0(\mathrm{~mm})$ & 1.00 & 0.93 \\
\hline Top Flange Cope only & Left and Right & $30.0(\mathrm{~mm})$ & 0.96 & 0.93 \\
\hline Top, and Bot tom Flange Copes & Left and Right & $30.0(\mathrm{~mm})$ & 0.85 & 0.81 \\
\hline \hline
\end{tabular}

Table 7.4: Solution comparison: fiffect of end coping conditions with a cope length of $150 \mathrm{~mm}$

\begin{tabular}{|c|c|c|c|c|}
\hline (opping Type & Support Lowation & $($ ope 1$)$ peth & $. M r / M r_{m c}$ & $V_{r} / V_{n}$ \\
\hline locopen & $x / A$ & $x / A$ & 1.00 & 1.00 \\
\hline Bottom Flange (ope only. & Left and Right & $30.0(\mathrm{~mm})$ & 1.00 & 0.93 \\
\hline Top Flange Cope only & Left and Right & $30.0(\mathrm{~mm})$ & 0.91 & 0.93 \\
\hline Top and liottom Flange (opees & Left and Right & $30.0(\mathrm{mmn})$ & 0.57 & 0.81 \\
\hline
\end{tabular}

[atser T.5: Solution comparison: Bifeed of end coping conditions with a cope length of $: 3(10) \mathrm{mm}$ 


\subsection{Cantilever Beam}

Problem Definition: Design of a cantilever beam, $3000 \mathrm{~mm}$ long. with and without lateral support, and subjected to factored concentrated loads. The steel grade is specified as G40.21-.1489 Grade 300W. The loads and basic geometry are shown in Figure 7.11.

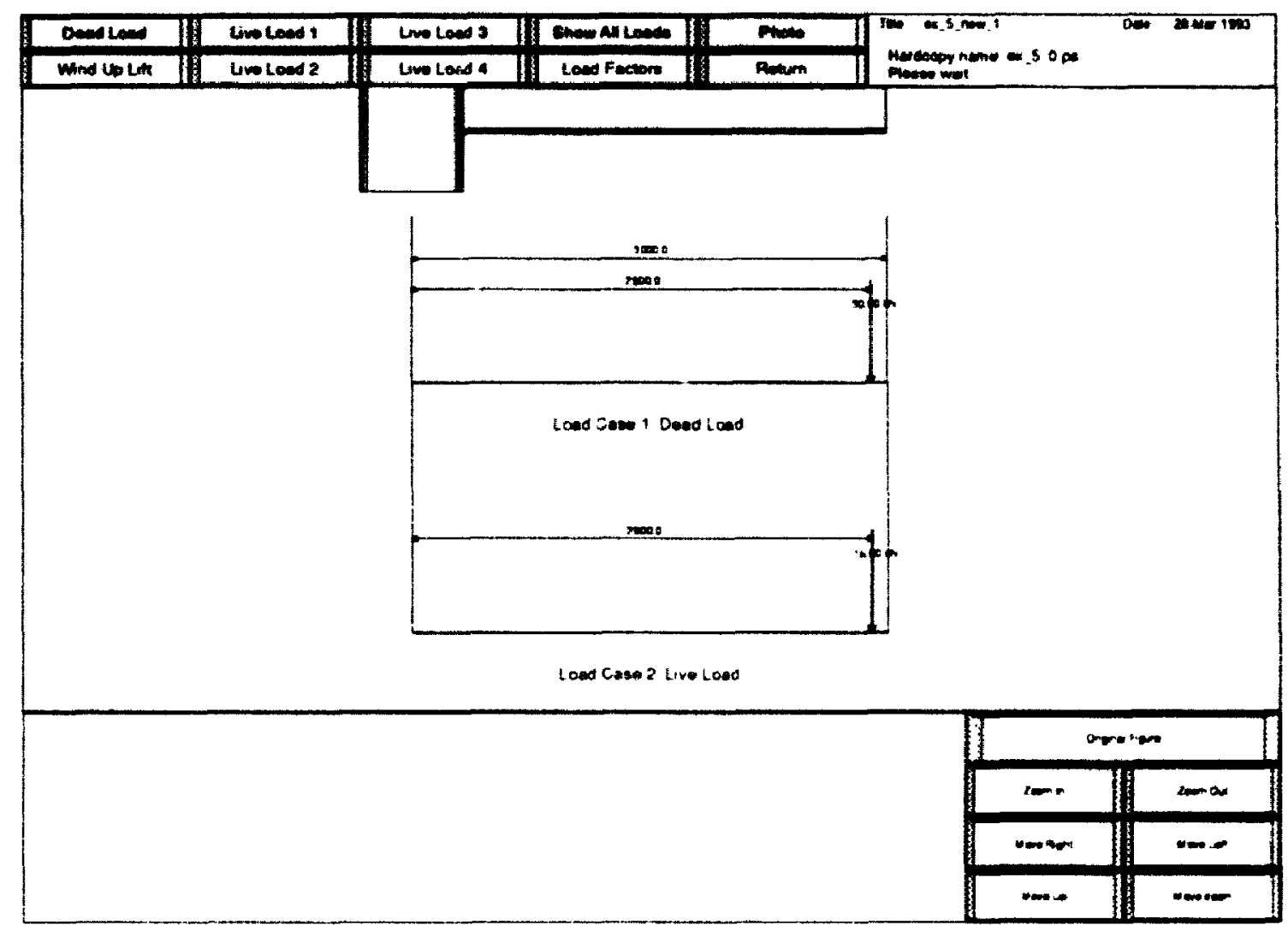

Figure 7.11 : loads and basic geometry: ('antilever beam

Solution: The solution screns for different hateral support conditions. nsing the (AN/('SA-S16.1-MS9 solut ton in conjunction with the Modified SSRC Guide(1988) solution are shown in Fignres 7.12 to 7.14 . 


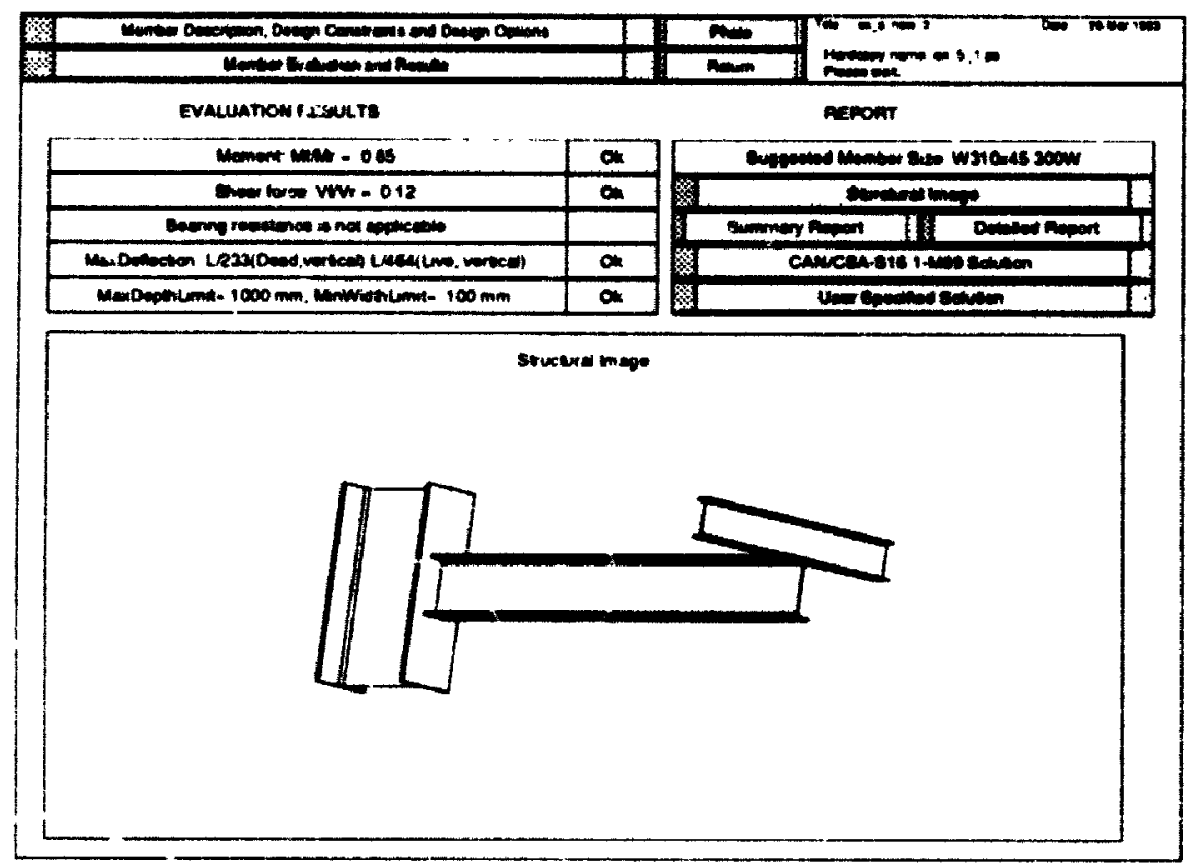

Figure 7.12: La teral suppont provided to the top flange at the load point

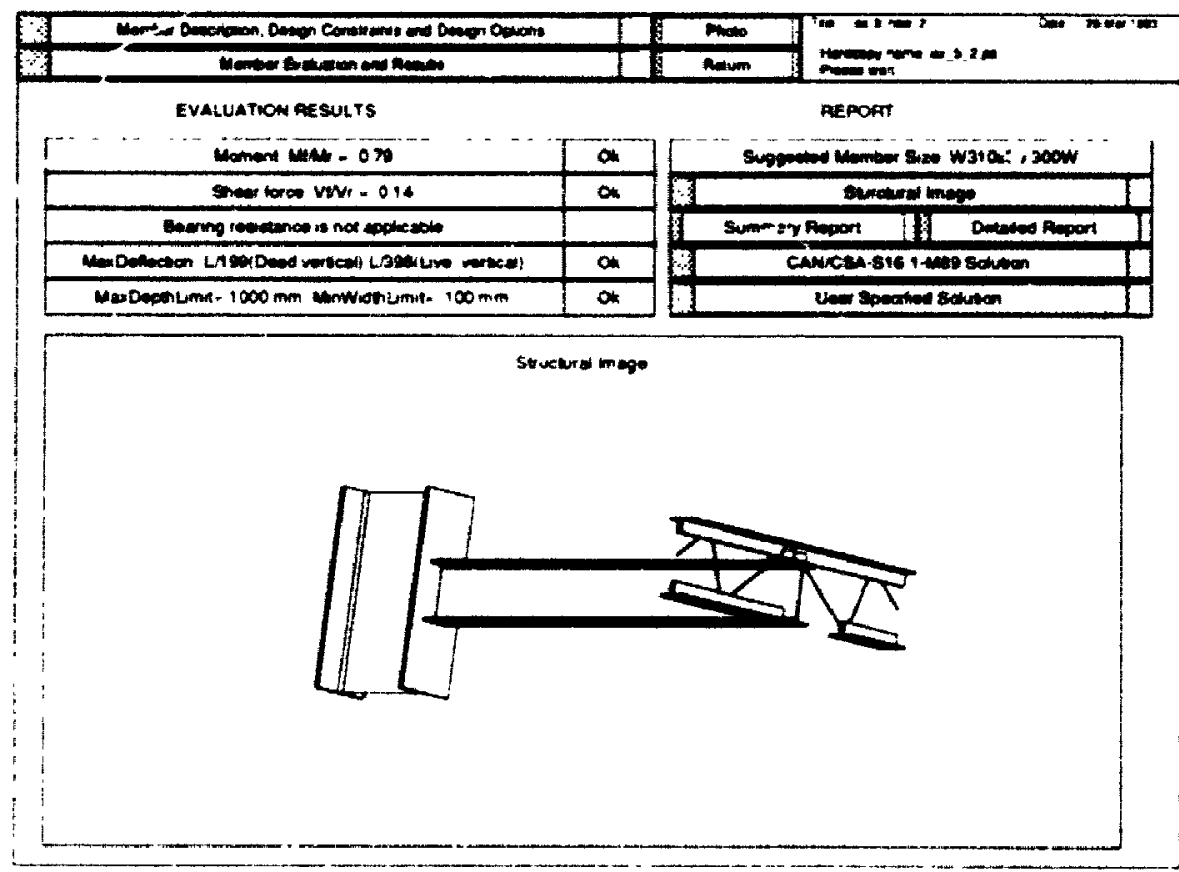

Figure 7.13: Lateral suppost powired to both the top and botwom flanges at the load point (O) 


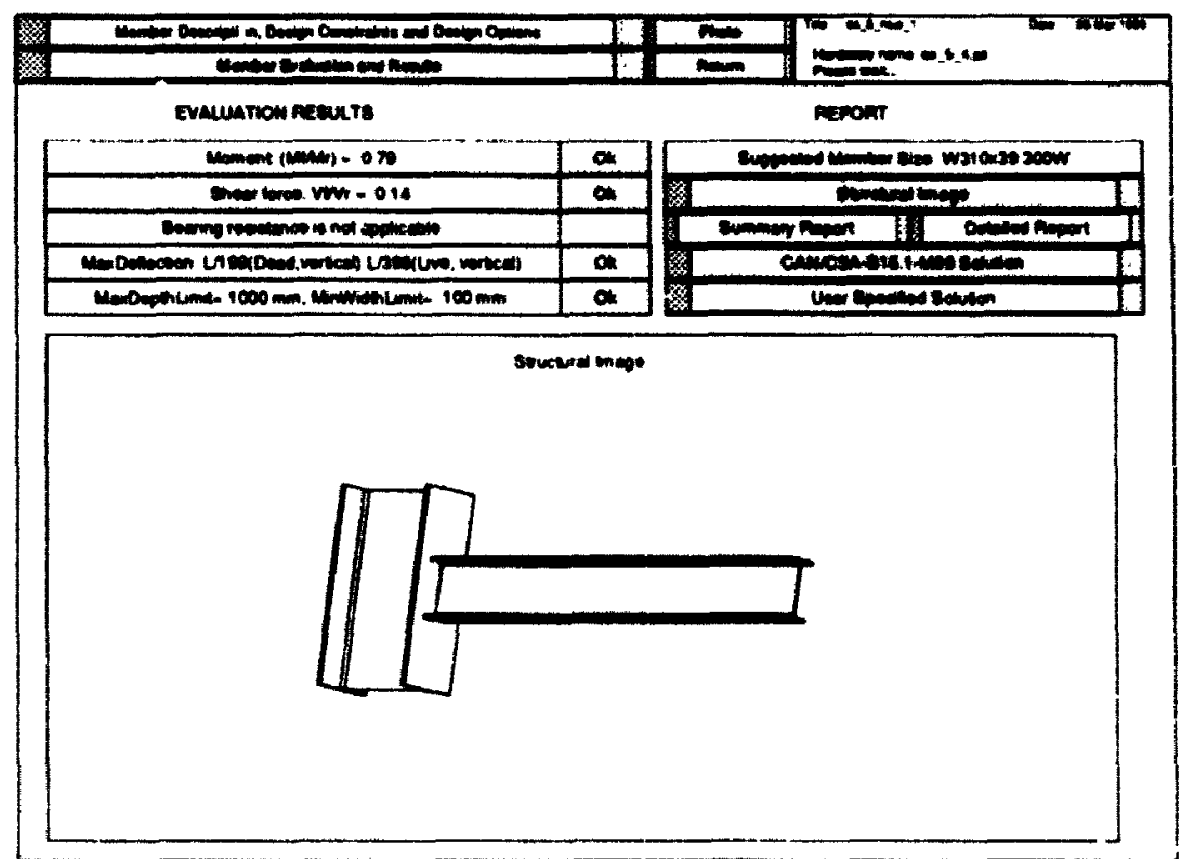

Figure 7.14: Lateral support provided along the beam length (both top and bottom flanges)

Solution Comparison: The design results for different lateral support conditions are summarized in Table 7.6

Discussion: The cantilever beam was automatically designed by IDFSM for each set of lateral support conditious. The corresponding sections given in Table 7.6 show a general increase in size as the relative effectiveness of the lateral support to compression flange dimunishes.

The moment capacity for continuous lateral support to both flanges was calculated to be $161.7 \mathrm{kNm}$ for $11310 \times 39$ as is denoted by the symbol $\mathbf{M}_{\mathrm{rls}}$. The corresponding moment capacity of the sane sertion but for other lateral support conditions is given by the ratio $\mathrm{Mr}_{\mathrm{r}} / \mathrm{M}_{\mathrm{l}}$ in Table 7 .6. The ratio $\mathbf{M r} / \mathrm{M}_{\mathrm{ris}}$ decreases as the relative effectiveness of the lateral support to compression flange diminishes. 


\begin{tabular}{|c|c|c|}
\hline $\begin{array}{l}\text { Lateral Support } \\
\text { Conditions }\end{array}$ & $\mathbf{M r} / \mathbf{M}_{\mathrm{rls}}$ & $\begin{array}{c}\text { Section Obtained } \\
\text { from Automatic design }\end{array}$ \\
\hline Top flange at braced point & 0.78 & $W 310 \times 45$ \\
\hline Top and bottom flanges at braced point & 1.0 & $W 310 \times 39$ \\
\hline Top and bottom fanges along the length & 1.0 & W310x39 \\
\hline
\end{tabular}

Table 7.6: Solution comparison: Different lateral support conditions

\subsection{Beam Laterally Supported Along Entire length of the Top Flange}

Problem Definition: Desigu check for a $11: 360 \times 39$ overhanging beam, $12000 \mathrm{~mm}$ long for main span with two overliang segments of $2000 \mathrm{~mm}$ each, laterally supported along entire length of the top flange. subjected to the in-plane factored load shown in Figure 7.15. The steel grade is specified as (i40.21-1187 grade $300 \mathrm{Wl}$ sterl.

Solution: The solution screen for the user specified whlution in shown in Figure 7.16 .

\section{Engineering Report:}

The following is a portion of the summaty repon produced: 


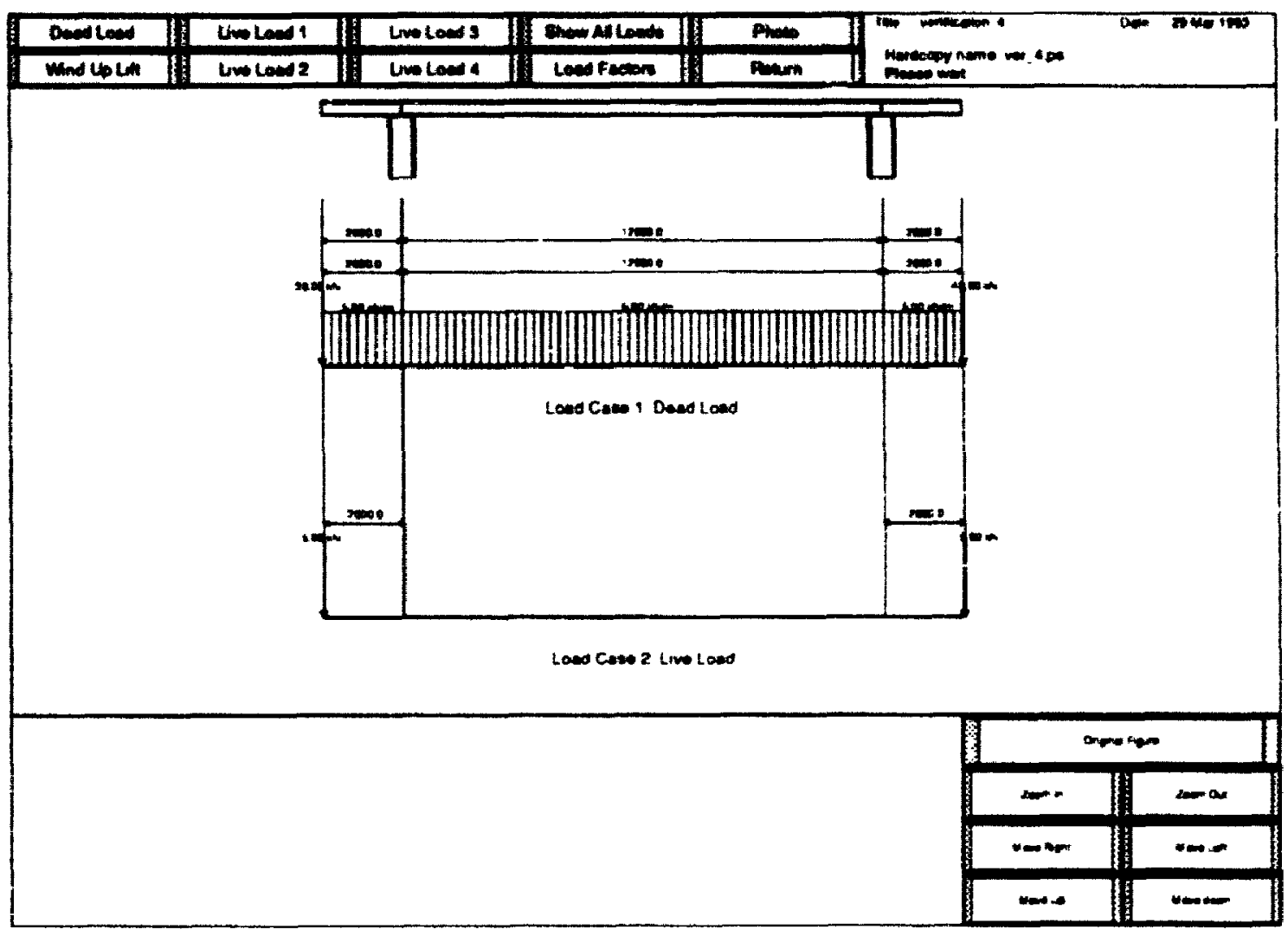

Figure 7.15; Load and geometry: Beam laterally supported along top flange only: 


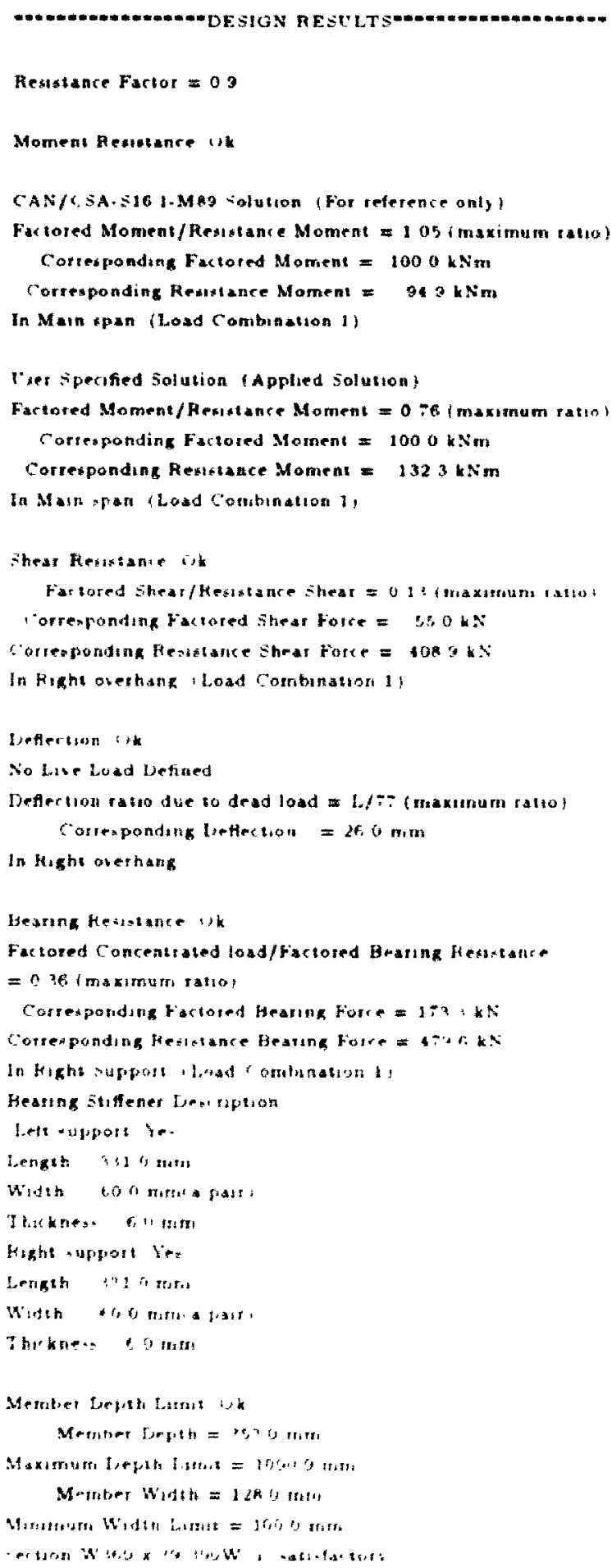




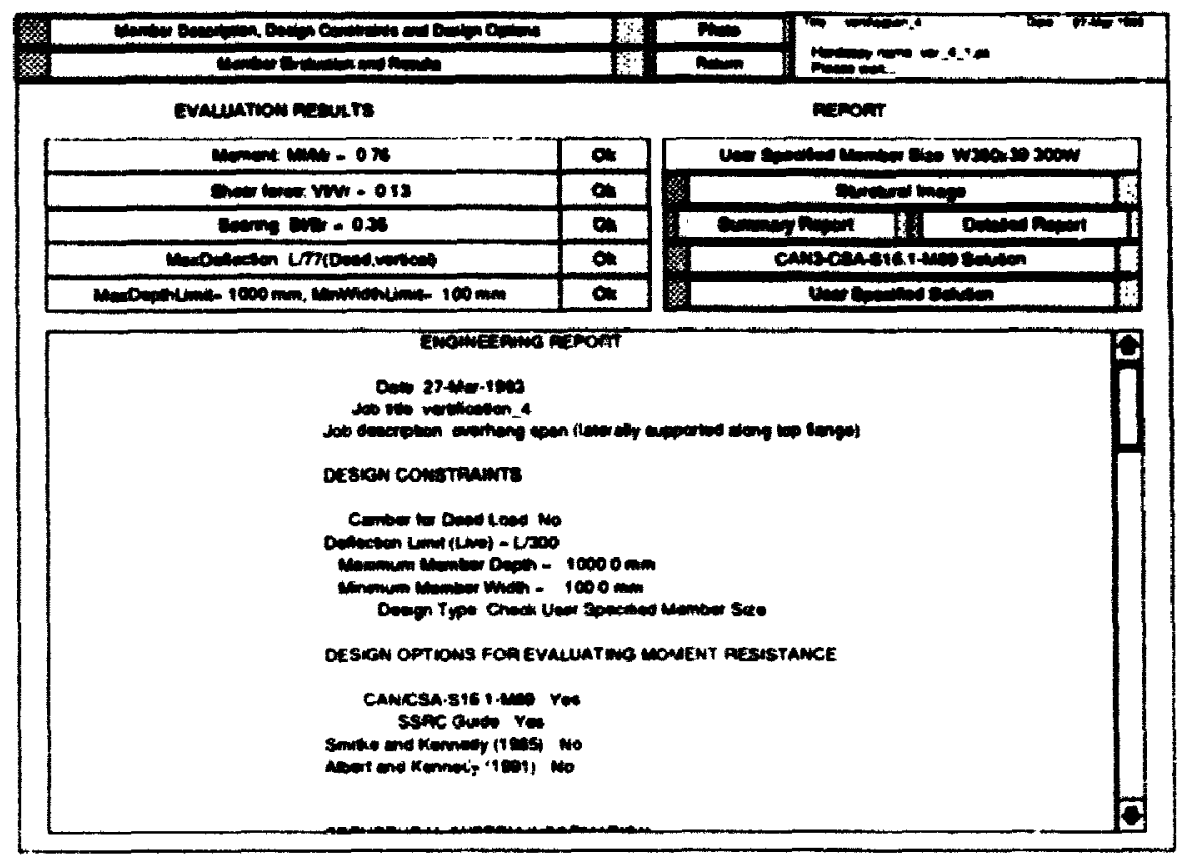

Figure 7.16 : Design result: Iser specified solution

\section{Discussion:}

The beam shown in Figure 7.17 , can be divided into five lateral braced segments according to the locations of points of inflections and the in-plane supports. Each end of these segments is marked by node number 1 through 6 . In evaluating the moment capacity. segment $3-4$ is considered to be laterally supported; segment $2-3$ and $4-5$ are identified to be laterally supported only at ends: and segmonts 1-2 and 5-6 are evaluated as individual cantilevers with continuous lateral support provided to the top flange only. The corresponding laterally unsupported lengths. factored moments. moment resistances and applicable solution aro listed in Table 7.7 


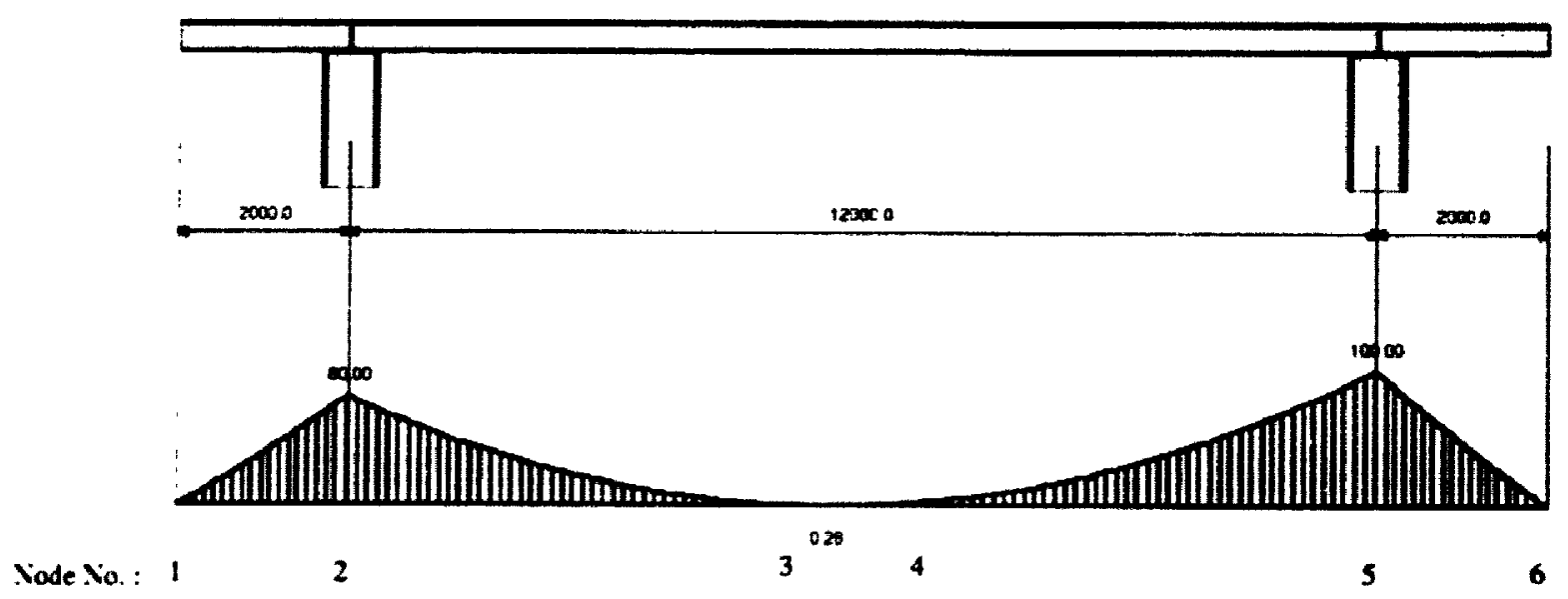

Moment Dagram (hN-m) iload combinution is

Figure 7.17: Moment diagram showing points of moment inflections

\begin{tabular}{|c|c|c|c|c|c|}
\hline Segment & $\begin{array}{c}M_{f} \\
(k \times m)\end{array}$ & $\begin{array}{c}\mathrm{Mr}_{\mathrm{r}} \\
(\mathrm{kNm})\end{array}$ & $M_{r} / M_{r}$ & $\begin{array}{l}\text { Laterally linsupported } \\
\text { Langth (mm) }\end{array}$ & $\begin{array}{l}\text { Applicable } \\
\text { Solution }\end{array}$ \\
\hline $1 \cdot 2$ & $\times 0.0$ & 178.7 & 0.45 & 2000 & $\operatorname{ssR}(19 \times 8)$ \\
\hline $2 \cdot 3$ & 80.0 & 112.2 & 0.56 & 5400.0 & SSRC and S16.1 \\
\hline $3-4$ & 0.28 & 178.7 & 0.01 & 600.0 & SSRC and S16.1 \\
\hline $4-5$ & 70.0 & 132.3 & 0.53 & 6000.0 & SSRC and S16.1 \\
\hline $5-6$ & 100.0 & $17 \pi .7$ & 0.53 & 2000.0 & SSSR \\
\hline
\end{tabular}

Table $T . \bar{T}$ : Design results and applicable solution st rategies 


\subsection{Laterally Unsupported Overhang Beam with Various Load Combinations}

Structure Type: Cantilever Girder

Reference: Roof Framing with Cantilever (Gerber) Girders \& Open Web Steel Joists, CISC (1989)

Problem Definition: Design cleck W460X74 section for the Gerber System and loads defined in example 6 -. CISC (1989), as shown in Figure 7.18 ; and if necessary, a redesign using the automatic design procedure in IDFSM. The steel grade is specified as G:0.21-M8T Grade 300W steel.

Load conditions: The load combinations are defined in Table 7.8 and the corresponding load factors are given in Figure 7.19. Detailed load values and locations as given in IDFSM are shown in Figures 7.20 to 7.22 .

\begin{tabular}{|c|c|c|}
\hline \hline Load Combinati: & Cantilevers and Drop Span & Main Span \\
\hline 1 & Dead plus Full Snow & Dead plus Full Snow \\
\hline 2 & Dead plus Full Snow & Dead plus Half Snow \\
\hline 3 & Dead plus Half Snow & Dead plus Full Snow \\
\hline 4 & Dead Plus wind uplift & Dead plus wind uplift \\
\hline
\end{tabular}

Table 7.8: Load combinations and the corresponding Load conditions 

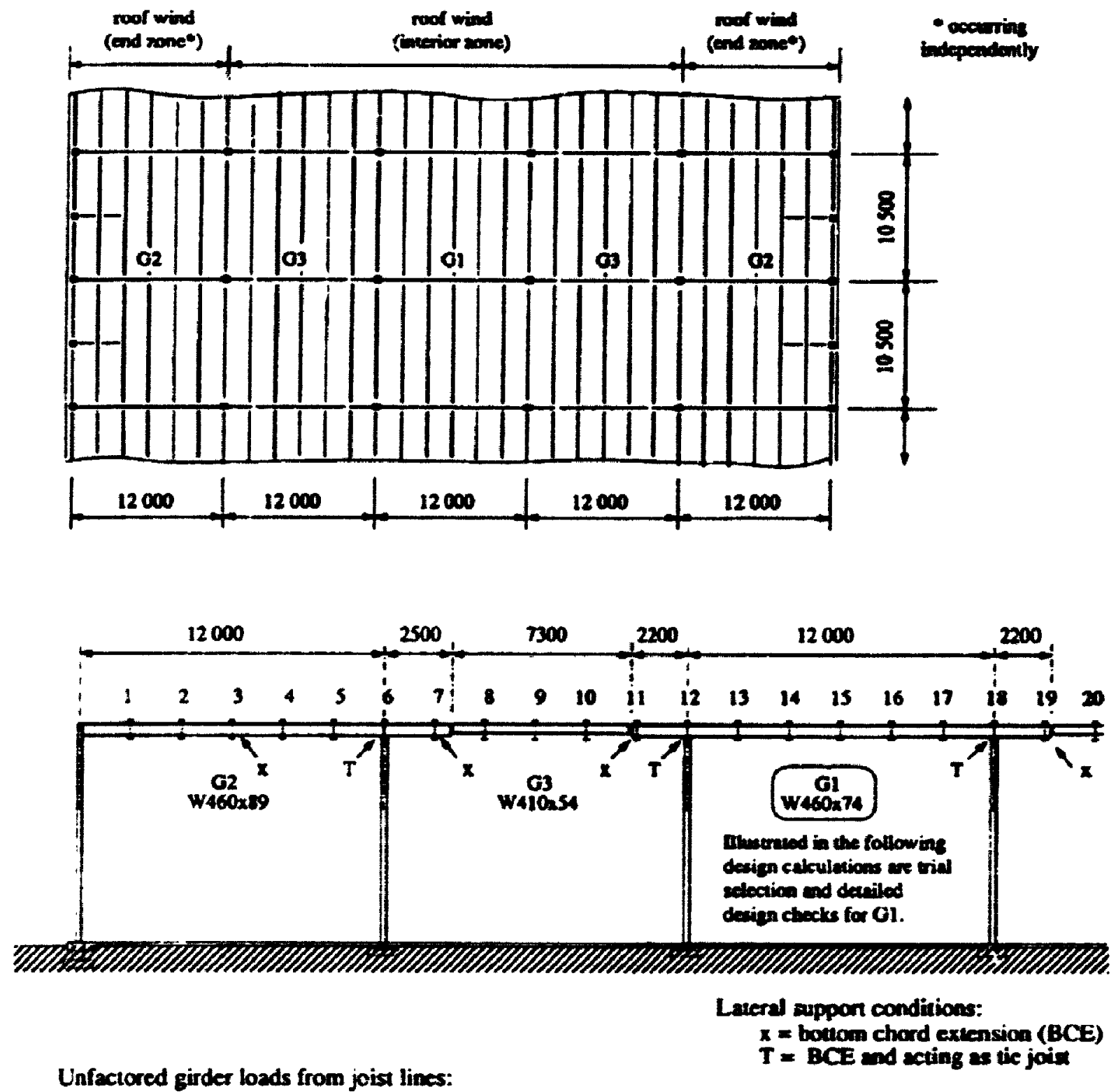

\begin{tabular}{|c|c|c|c|}
\hline $\begin{array}{c}\text { Joist tinc } \\
\text { location }\end{array}$ & $\begin{array}{c}\text { Dead lowd } \\
\text { kN }\end{array}$ & $\begin{array}{c}100 \% \text { snow } \\
\text { kN }\end{array}$ & $\begin{array}{c}\text { Wiad uplifa } \\
\text { kN }\end{array}$ \\
\hline $1.5 .25-29$ & 18.1 & 33.6 & 27.6 \\
$8-10$ & 18.1 & 33.6 & 22.4 \\
6.24 & 18.1 & 33.6 & 23.9 \\
$7.11-23$ & 18.1 & 33.6 & 20.3 \\
\hline
\end{tabular}

Notes:

1. including ated weight

2. roof snow

3. wind loads for strength design are computed uring Commentary B. Supplement to the Nationd Bulding Code of Canada. 1985.

Fignre 7.15: (iencral design conditions, (ISC (19s9), p.8 


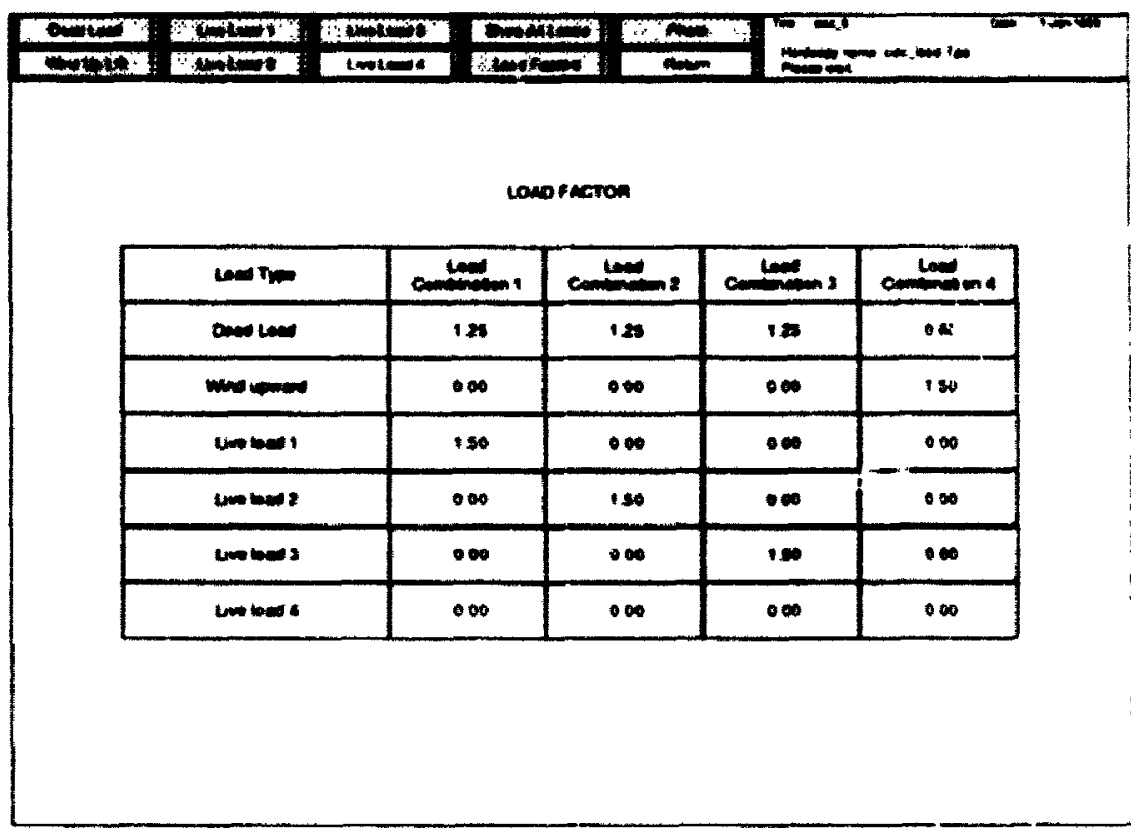

Figure 7.19: Load combinations

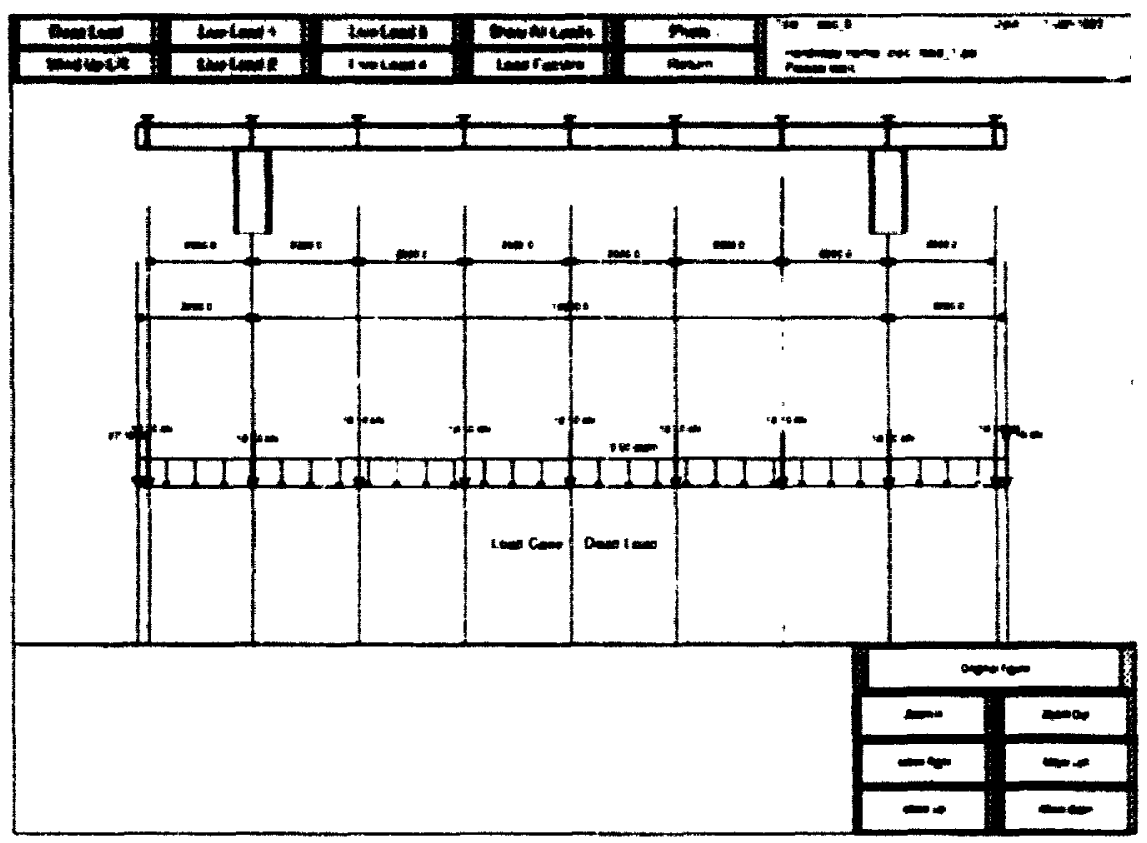

Figure 7.20: Specilied dead loads (Load (ase 1) 


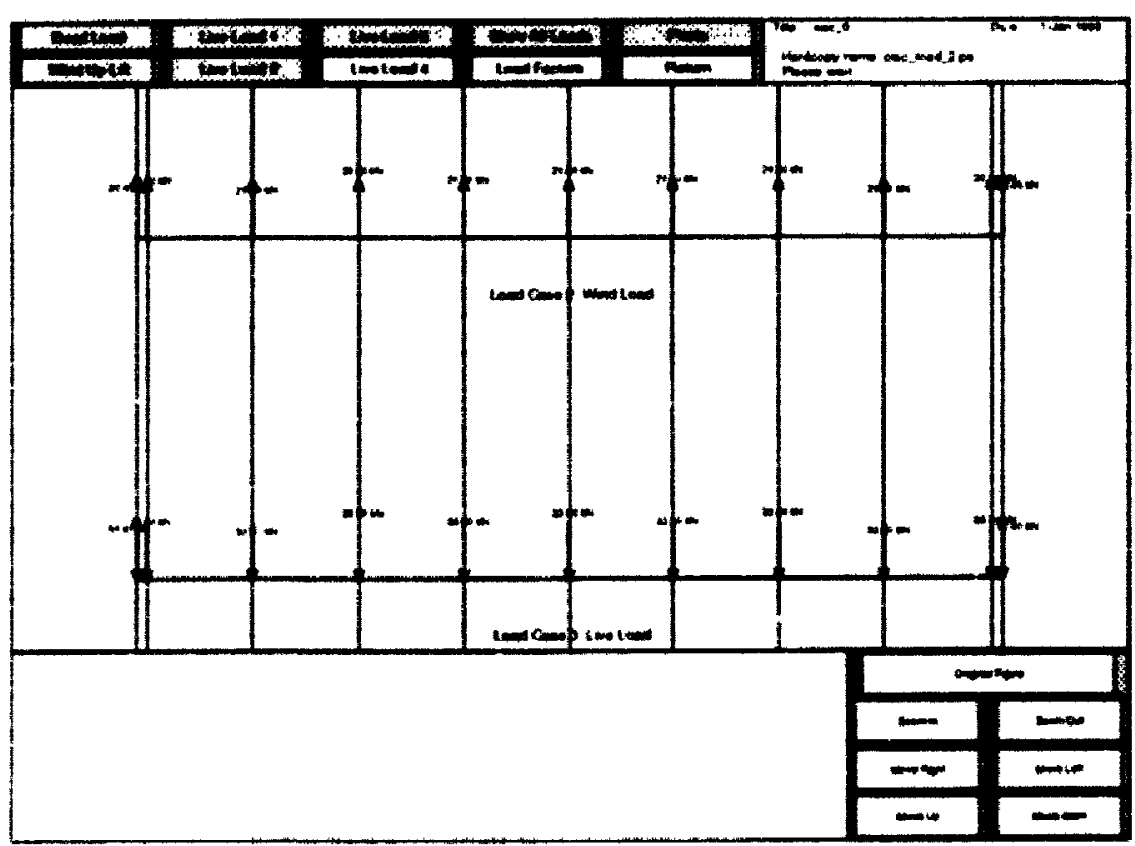

Figure 7.21 : Specified wind and snow load (Load Case 2 and 3 )

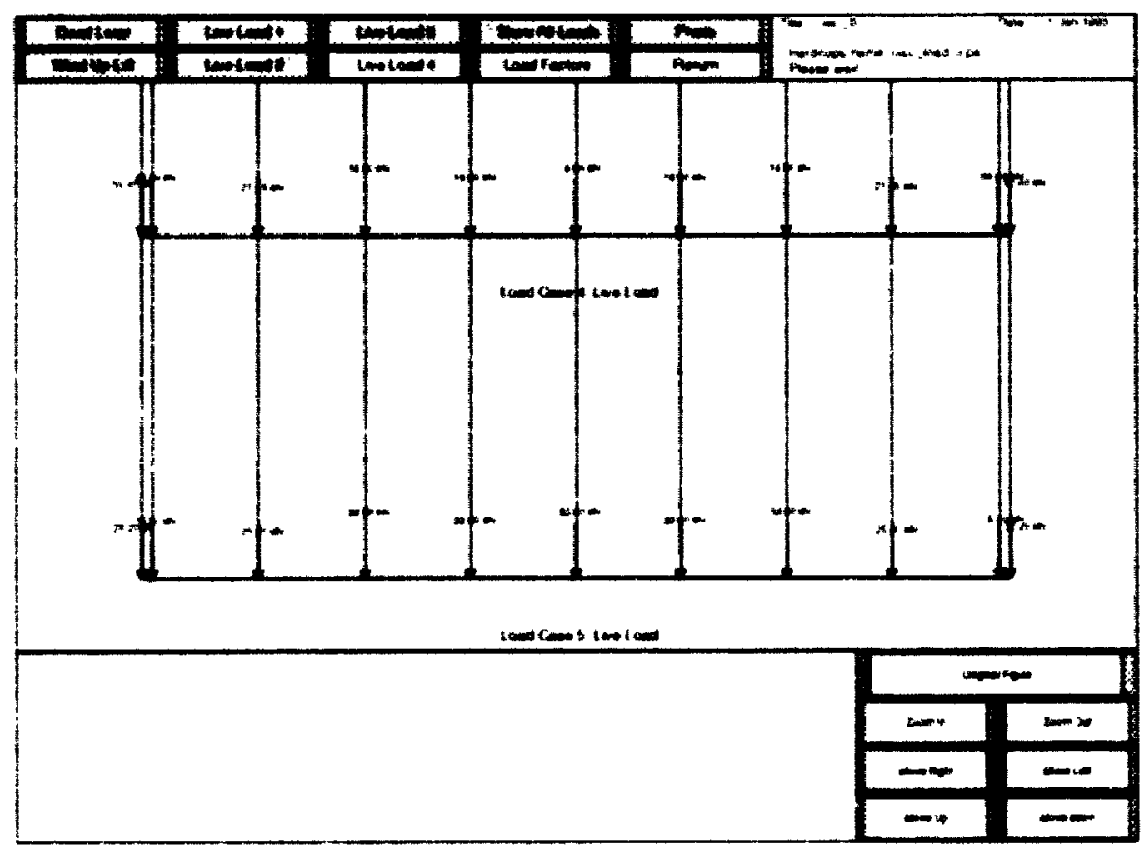

Figure 7.22 : Load ('ase 1: Full snow load on cantilevers and half load on main span Load ('ase 5: Half snow load on cantilevers and full load on main span 
Solution: The design option screen for this problem is illustrated in Figure T.23. The internal bending moment, shear forces and deflections for all load combinations are shown in Figures 7.24 and 7.25, Figures 7.26 and 7.27, Figures 7.28 to 7.30, respectively. The results from the design check of the $W 460 \times 74$ section are shown in Figure 7.31. As indicated, the section is unsatisfactory as the live load deflection limit is excreded and a redesign is necessary. The results from the automatic design shown in Figure 7.32 is followed by corresponding enginering report.

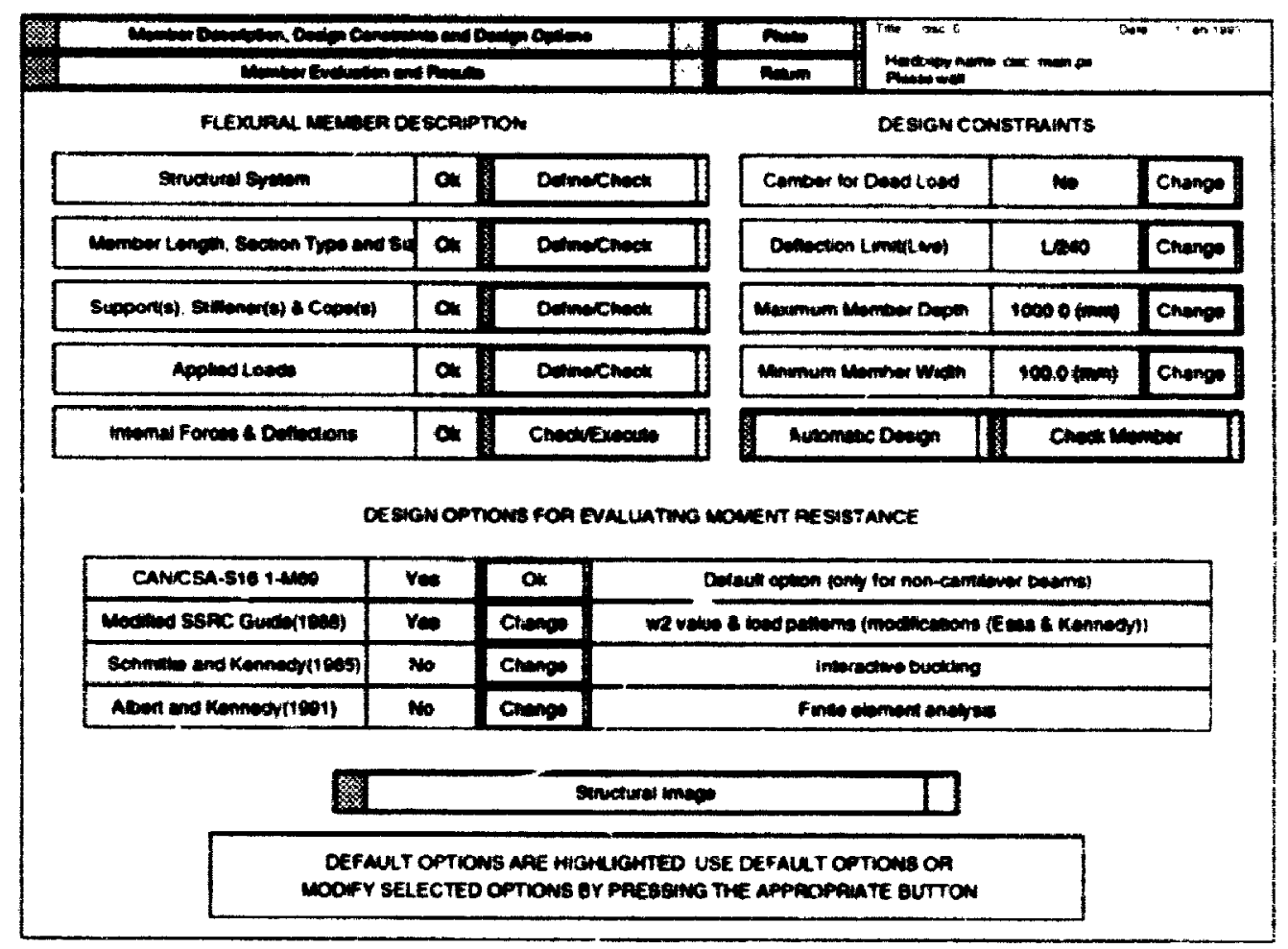

Figure 7.23: Design option screen 


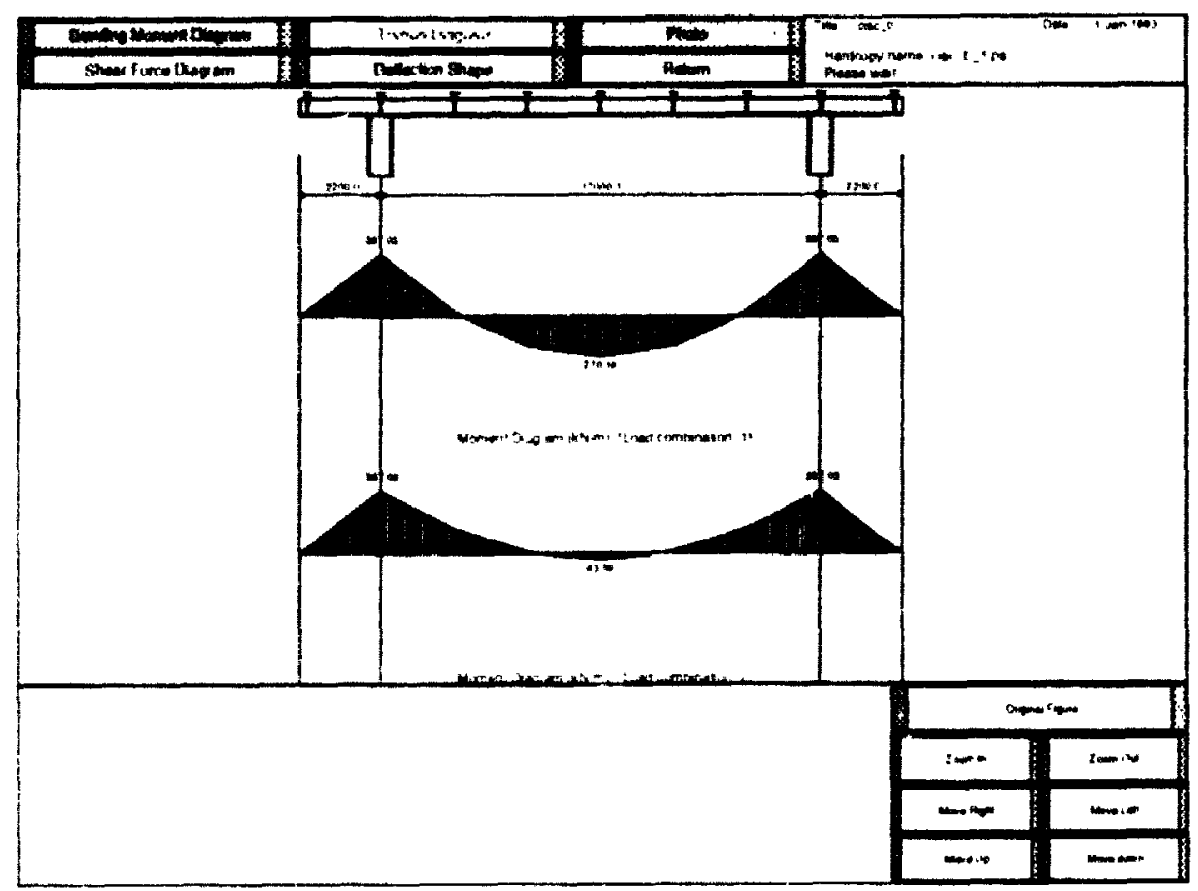

Figure 7.24: Bending moment diagrams, for load combinations 1 and 2

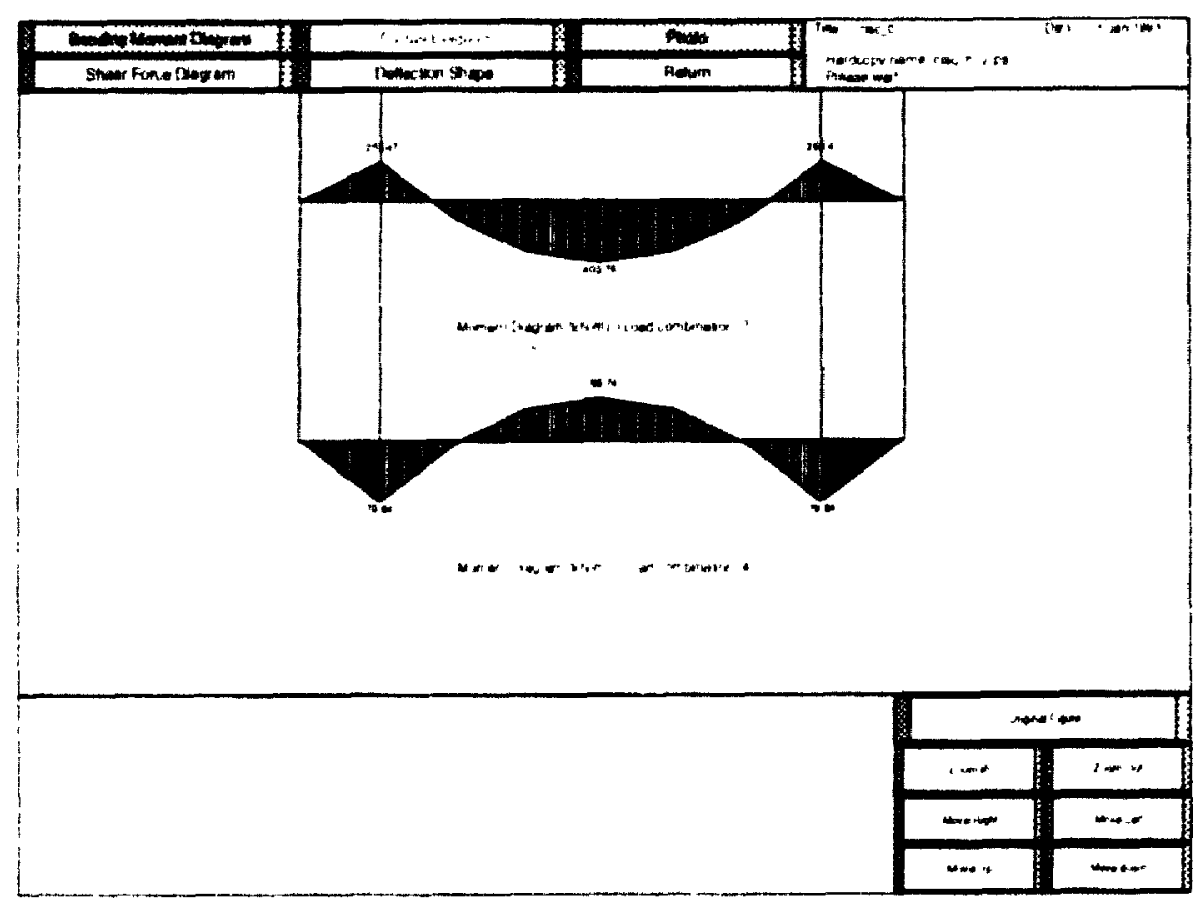

1 igure 7.25 : Bending moment diagrams. for load combinations 3 and 4 


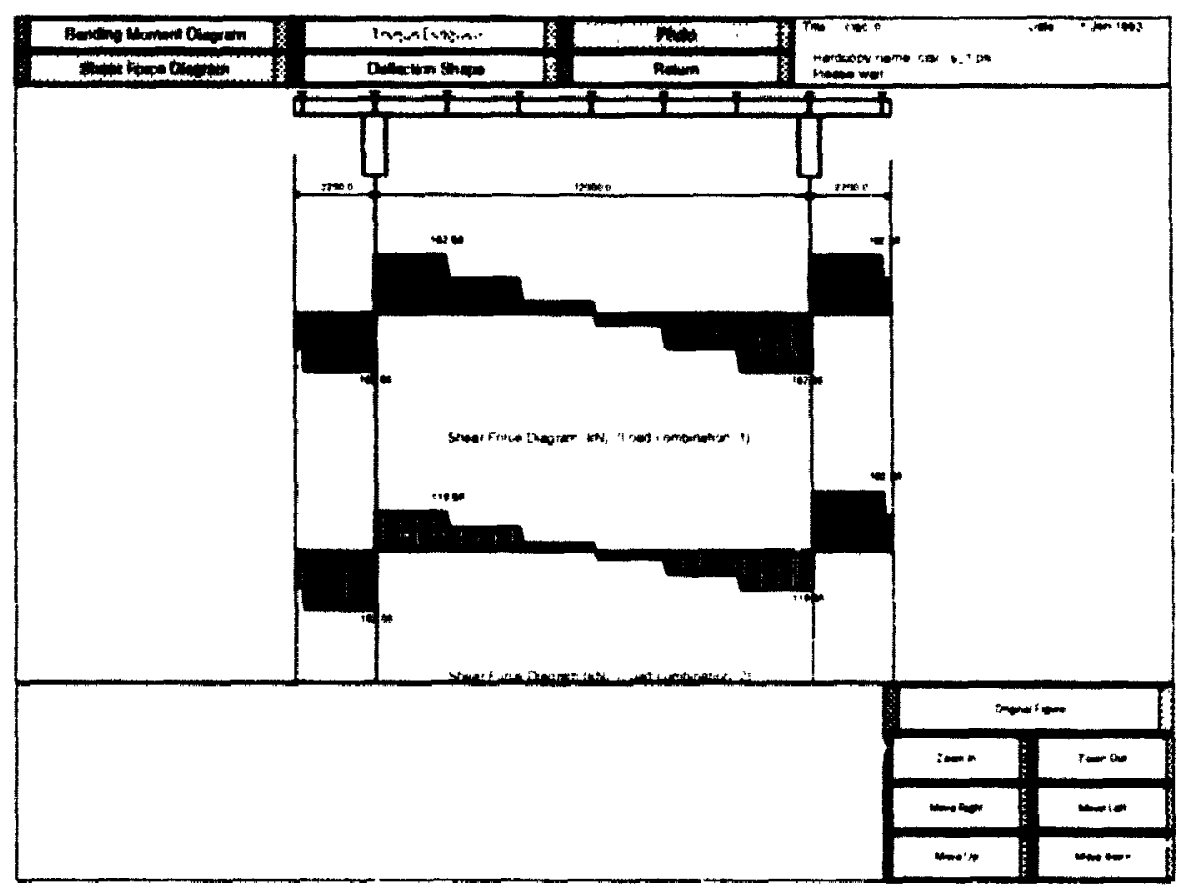

Figuse 7.26: Sïnear force diagrams, for load combinations 1 and 2

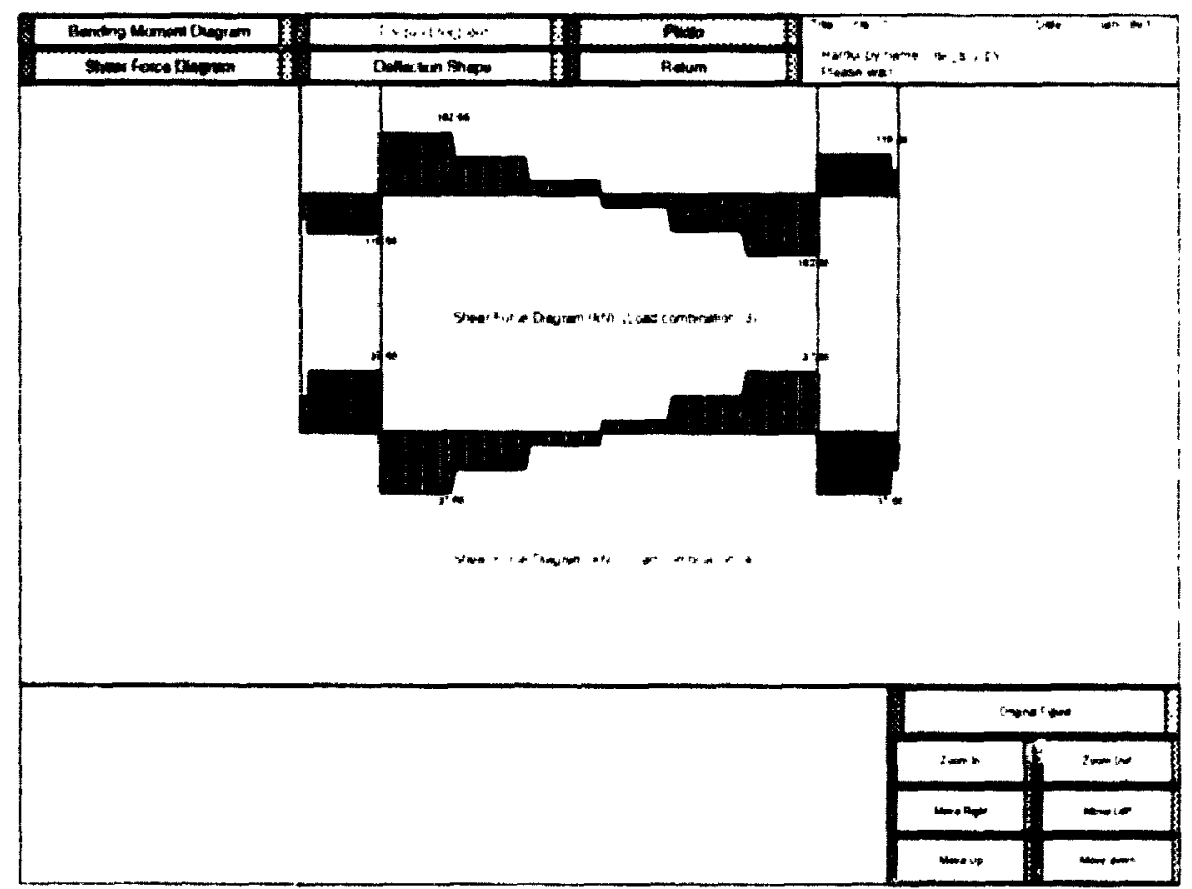

Figure 7.27 : Shear force diagrams. for load combinations 3 and 1 


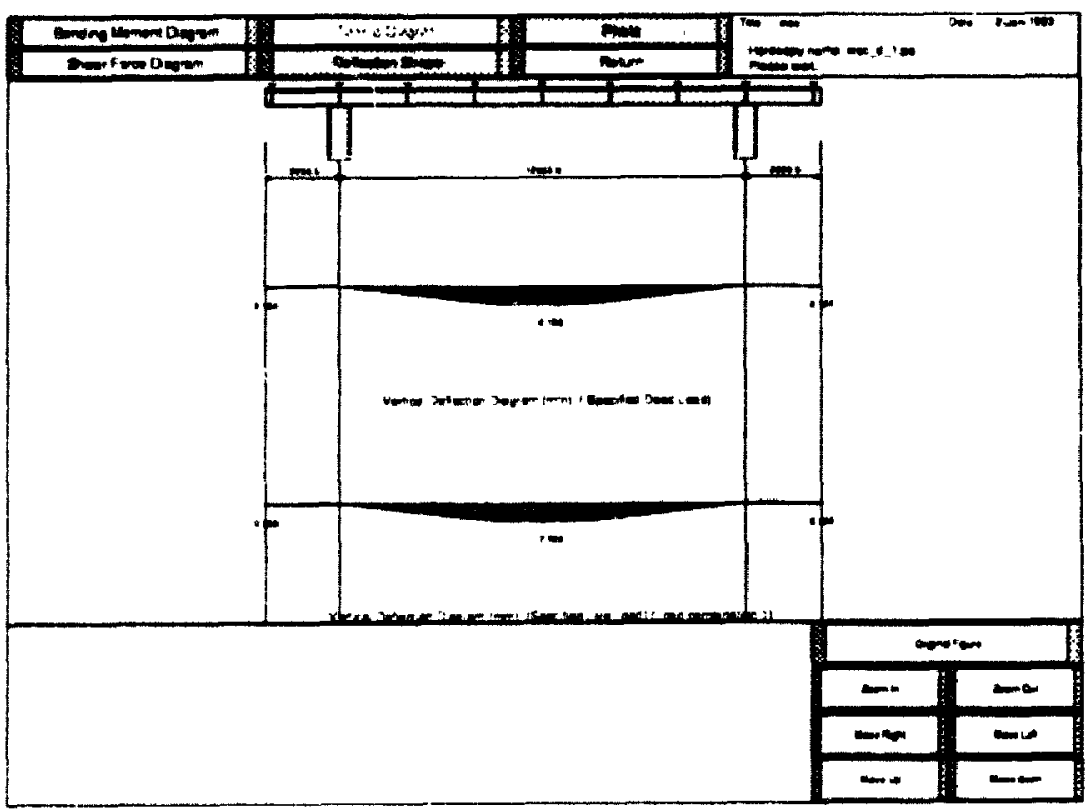

Figure 7.28: Deflecter shapes. for the sperified dead and live loads from load combination 1

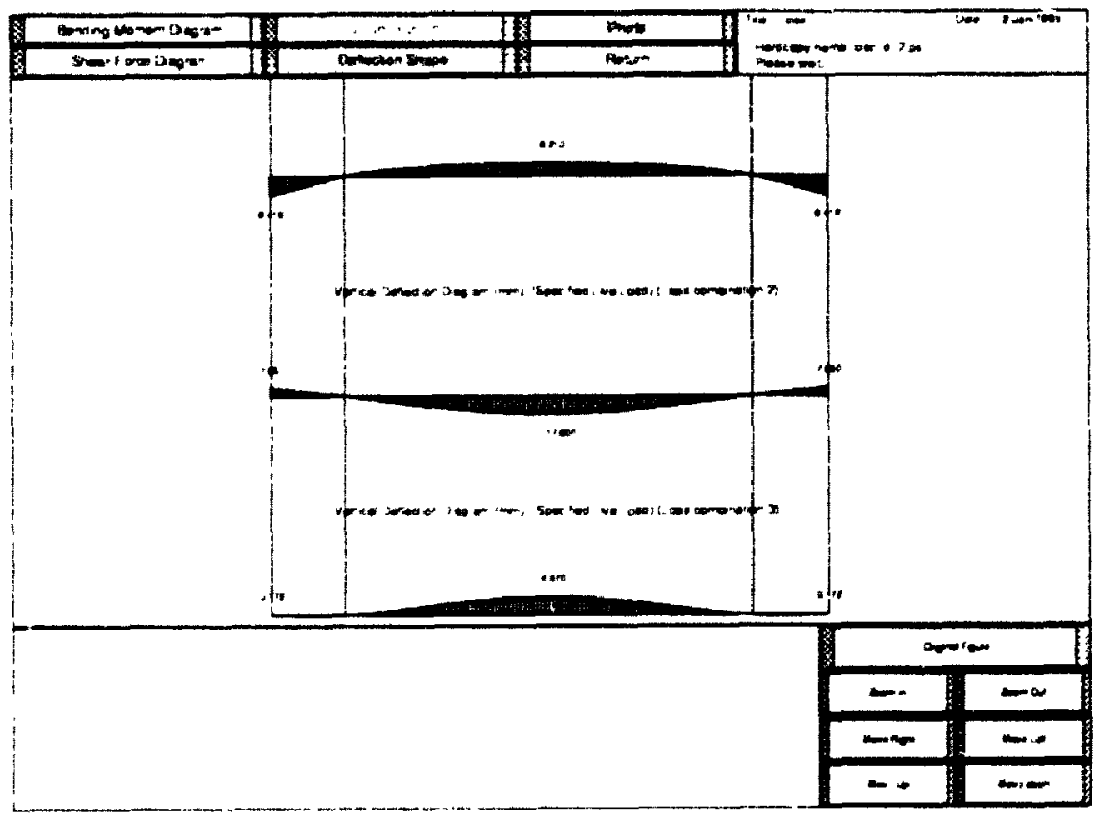

Figure T.29: Beflected shapes. for the percified live loads from load combinations 2 and 3 


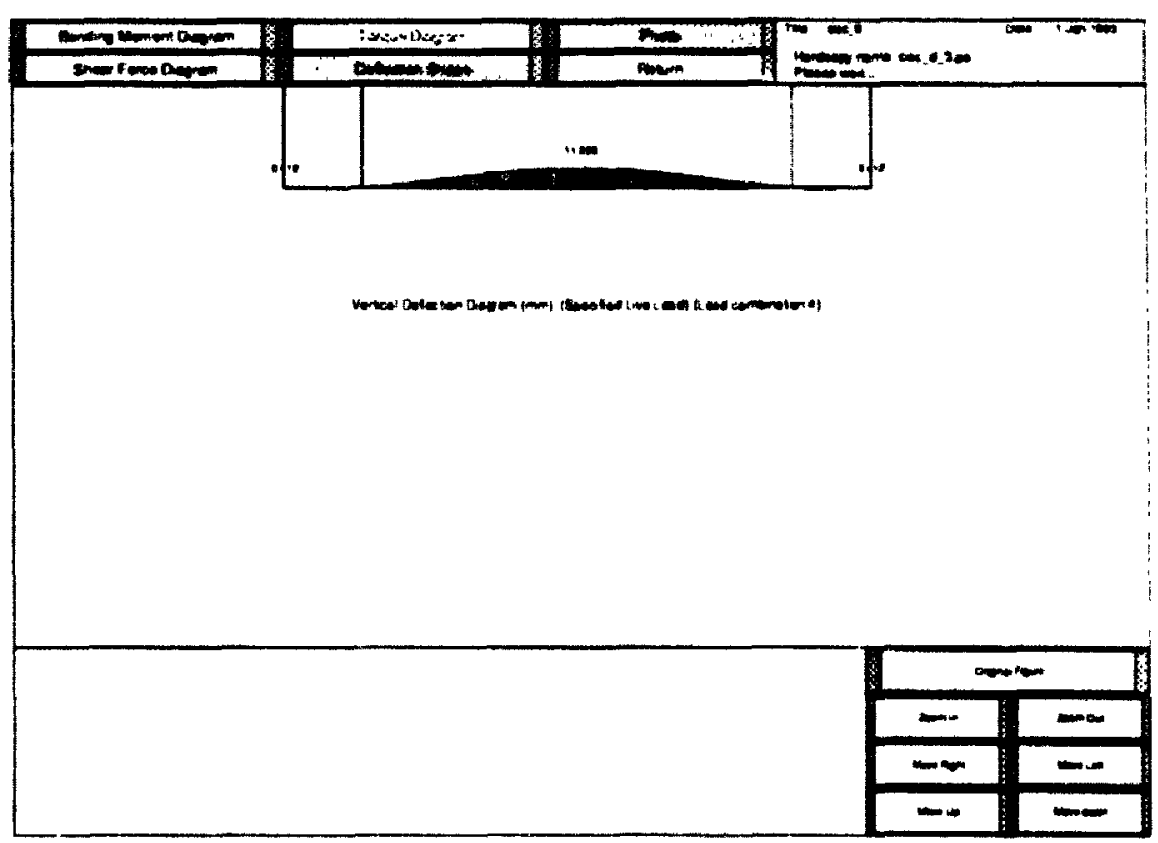

Figure 7.30: Deffected shapes, for the specified live loads from load combination 4

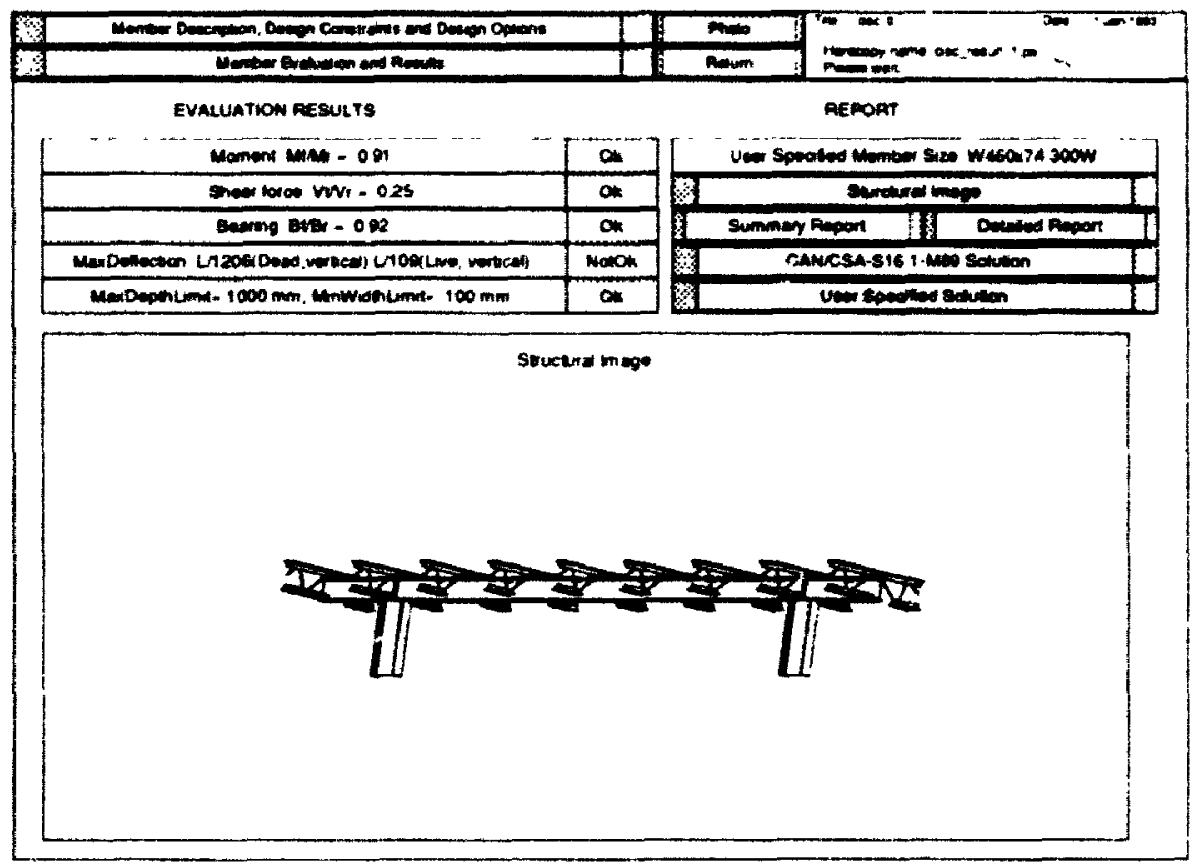

Figure 7.31: Design check: W110xia section 


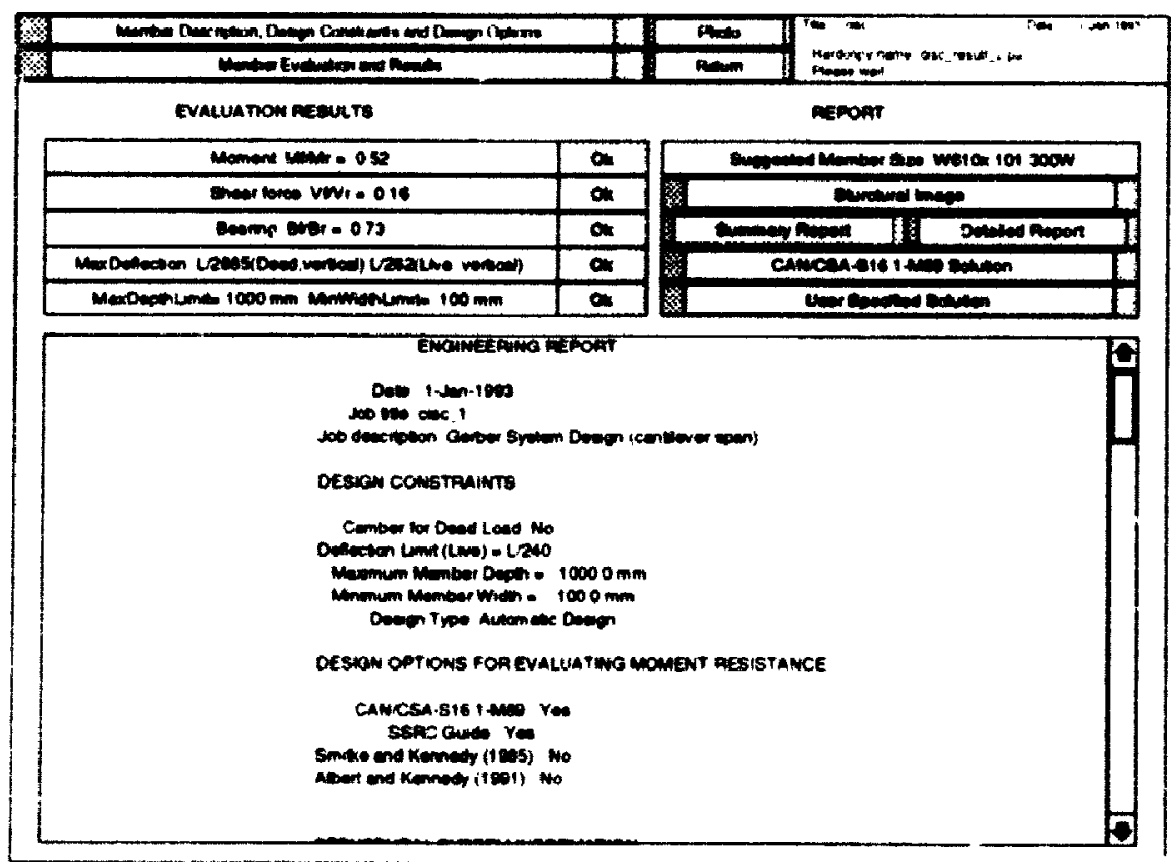

Figure 7.32 : Automatic redesign

\section{Engineering Report: (stmmary report)}

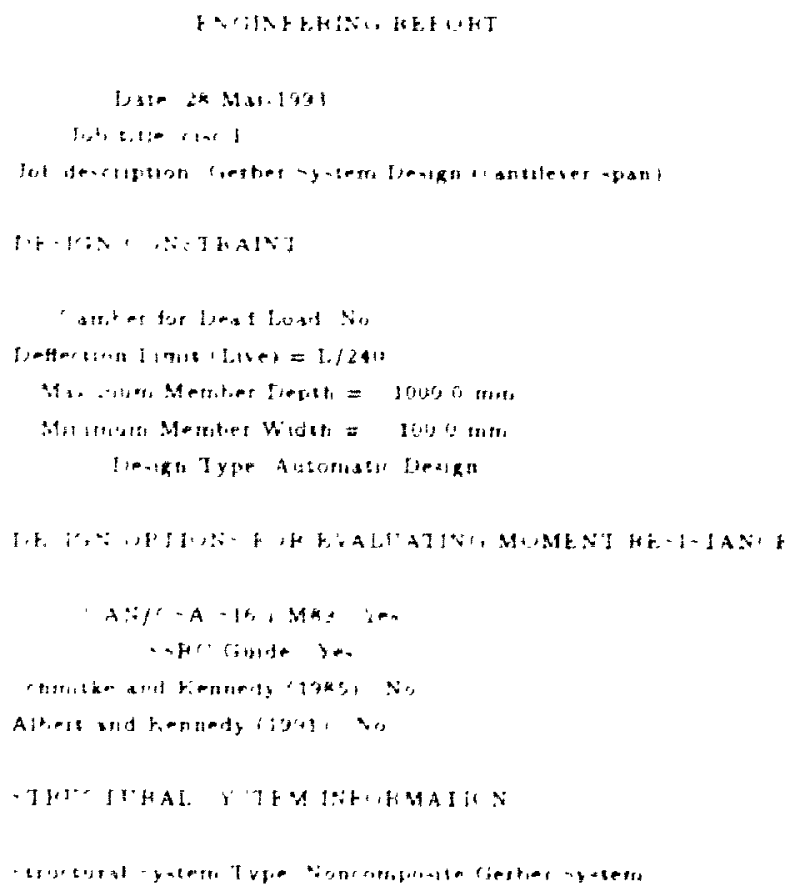




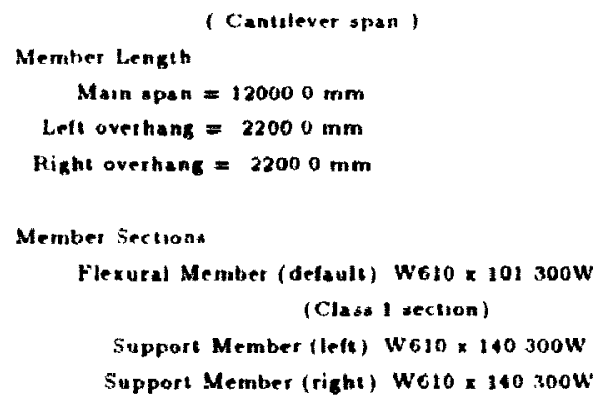

Lateral tupport Letcription

Number of baterally supported point(n) in main span?

Distance along the man span mesured tiom the lefi end of main apan $200000(\mathrm{~m})$ ( Top chosd of WWSJ's, Fram both sdes of man mesniber)

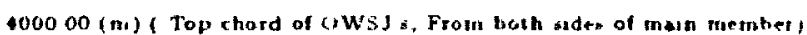
600000 (m) (Top chord of OWSJ's. From both sides of man member)

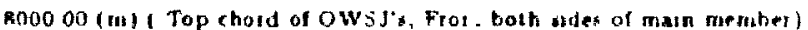
$1000000(\mathrm{~m})$ ( Top chord of OWSJ's, ficm both sides of main member)

$000(\mathrm{~m})$ ( Top and tottom shords of $6 \mathrm{~W}^{*} \mathrm{~s}$ : fhom botit sidex of man memher,

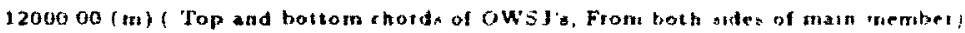
Number of Latesally at pported pointl il an Left overhank,

Distance along the left ovethang measured fiom the left end of main -piat

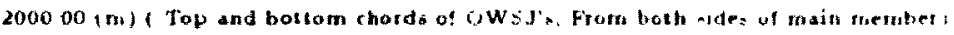
Number of Lacetally suppotted pointlstin right overhang 1 Diatance along the right overhallg mestured fiogu the raht end of matn epan

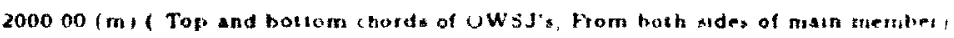

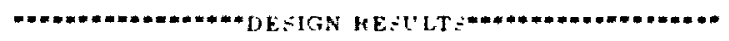

Hesustuc Fartor $=09$

Montent Feastance id

CAN/CSA.S161.M49 Solution (Fot teieience onth)

Fartoled Moment/Hesintance Mowent $=0: 2$ :maximutu a ano

Corseponding Factored Mom-nt $=105 \mathrm{kNm}$

Corretponding Rentetance Motrent $=78.0 \mathrm{kNm}$

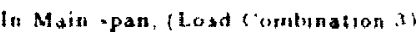

liner specified sollition (Applied solusion)

Factored Moment/Heststance Moment $=052$ (maximum iatio)

Corresponding Fatcoted $\mathrm{Moment}=403 \mathrm{k} \mathrm{km}$

Cor-ajondug Mesubance Moment $=78,10 \mathrm{kNm}$

In Masa -pan. (Load Combination 3)

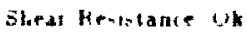

Futored sheat / Heriatance ihear $=0$ lit (maxinum tatwi

colle ponding Factored shear Forre $=1 \mathrm{k} 2 \mathrm{t} . \mathrm{k}$

Colirgouding Hexstancr Steat Force $=112 \mathrm{k} \mathrm{kN}$

In Maln tpan, (Lodd combuation is

beftertion on 


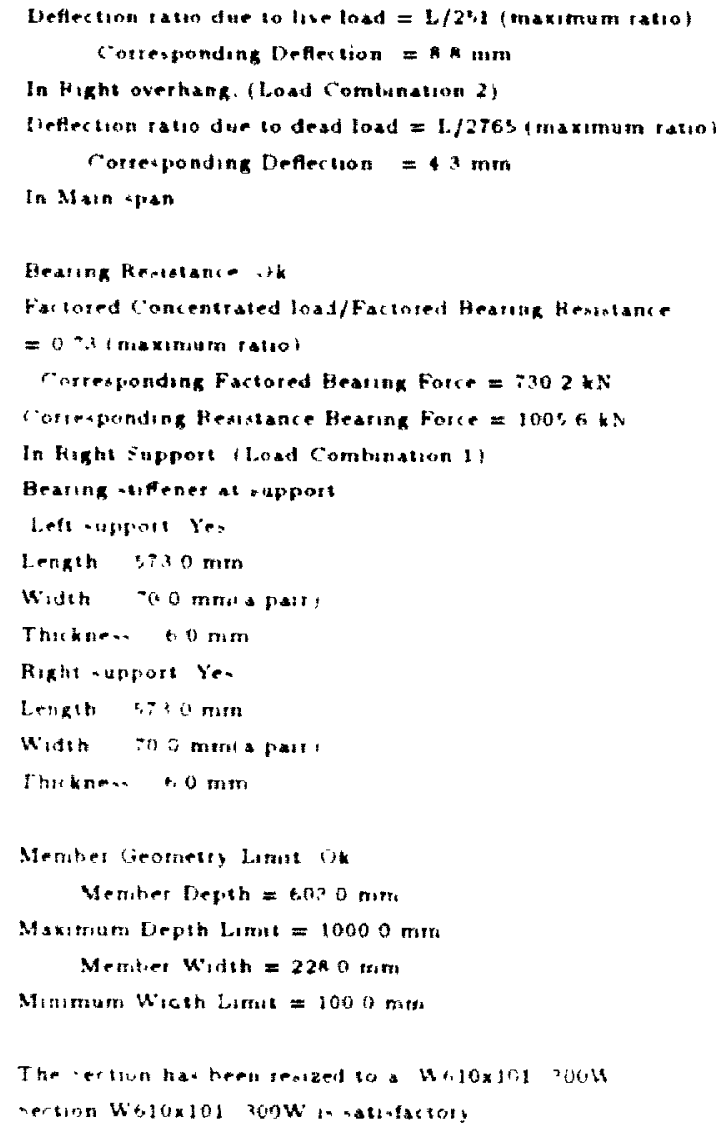

Discussion: The moment capacity determined by the design check using IDFSM was consistent with thene guven in (ISC (1989). The sertion was found to be insatisfactory with respect to serviceability limit states. The deflection at the tip of the cantilever for load combination 2 exceded the specified limit of 1./240. The reflection at the tip of cantilever span also governed the automatic denign, where the optinum section was found to be W610x101. Information on the mumber of effective lateral supports, the length of laterally braced segments and the corresponding monent capacities for each load combination can be traced in the detailed engineering report homend in det filc. A summaty is given in Iable 7.9 


\begin{tabular}{|c|c|c|c|c|c|}
\hline & Load Combination & 1 & 2 & $\mathbf{3}$ & 4 \\
\hline \multirow{3}{*}{ Segment 1} & Length (mm) & 2000 & 4000 & 2000 & 2000 \\
\hline & Location & Main Span & Main Span & Main Span & Main Span \\
\hline & $M_{1}(\mathrm{kN}-\mathrm{m})$ & 783.0 & 7830 & 783.0 & $7 \times 3.0$ \\
\hline \multirow{3}{*}{ Segment 2} & Length (mm) & 2000 & 2000 & 2000 & 8000 \\
\hline & Location & Main Span & Main Span & Main Span & Main Span \\
\hline & $M_{1}(k N-m)$ & 783.0 & 783.0 & 883.0 & 370.3 \\
\hline \multirow{3}{*}{ Segment 3} & Length (mm) & 2000 & 2000 & 2000 & 2000 \\
\hline & Location & Main Span & Main Span & Main Span & Main Span \\
\hline & $M_{r}(k N-m)$ & isso & IB3.0 & $7 \times 3.0$ & $7 \times 3.0$ \\
\hline \multirow{3}{*}{ Segment 4} & Length (mm) & 2000 & 4060 & 2000 & 2000 \\
\hline & Location & Man Span & Main Span & Majn Span & Left Overh. \\
\hline & $M_{r}(\mathrm{kN}-\mathrm{m})$ & 78.3 .0 & 783.0 & 783.0 & 783.0 \\
\hline \multirow{3}{*}{ Siggment 5} & Length (mm) & 2000 & 2000 & 2000 & 2000 \\
\hline & Location & Main Span & Left Overh. & Main Span & Right Overh. \\
\hline & $M_{r}(\mathrm{kN}-\mathrm{m})$ & 783.0 & $7 \times 3.0$ & 783.0 & 783.0 \\
\hline \multirow{3}{*}{ Segnemt 6} & Length (mm) & 2000 & 2000 & 2000 & 200 \\
\hline & Location & Main Span & Might Overh. & Main Span & Left Overh. \\
\hline & $M_{i}(k, N-m)$ & 783.0 & 783.0 & $7 \times 3.0$ & 783.0 \\
\hline \multirow{3}{*}{ Segment $T$} & Length (mm) & 2000 & 200 & 2000 & 200 \\
\hline & Location & Left Overh. & Left Overh. & Left Owh. & Right Onerh. \\
\hline & $M_{r}(k N-m)$ & 783.0 & 783.0 & 783.0 & .83 .0 \\
\hline \multirow{3}{*}{ Segment 8} & Length (num) & 2000 & 200 & 2000 & \\
\hline & Location & Right Overh. & Right Overh. & Right Overh. & \\
\hline & $M_{r}(k N-m)$ & 783.0 & 783.0 & 783.0 & \\
\hline \multirow{3}{*}{ Segmrnt 9} & Length (mm) & 200 & & 200 & \\
\hline & Location & Left ()verh. & & Left Overh. & \\
\hline & $M_{r}(k N \cdot m)$ & 783.0 & & 783.0 & \\
\hline \multirow{3}{*}{ Segment 10} & Length (mm) & 200 & & 200 & \\
\hline & Location & Right Overh. & & Right Overh & \\
\hline & $M_{1}(\mathrm{kN}-\mathrm{m})$ & 783.0 & & 783.0 & \\
\hline
\end{tabular}

Table 7.9: Summary of design results 


\subsection{Laterally Unsupported Beam with Combined Bending and Torsional Loads}

Structure Type: Simply supported beam (laterally unsupported)

Reference: AISC 1983. Torsional Aualysis of Steel Members. American Institute of Sterl Construction.

Problem Definition: Design check for a W250X80 (W10X54) beam. $4572 \mathrm{~mm}$ (15 ft) long. connected to the columns at either end by standard web angle comertions. and subjected to a factored concent rated load of $40.04 \mathrm{kN}$ (9 kips). with an eccentricity of $152.1 \mathrm{~mm}(6 \mathrm{in})$ at midspan, as shown in Figure 7.33 . Tho steel grade was specified as G40.21-M87 Grade 300W steel ( Fy=43.51 ksi).

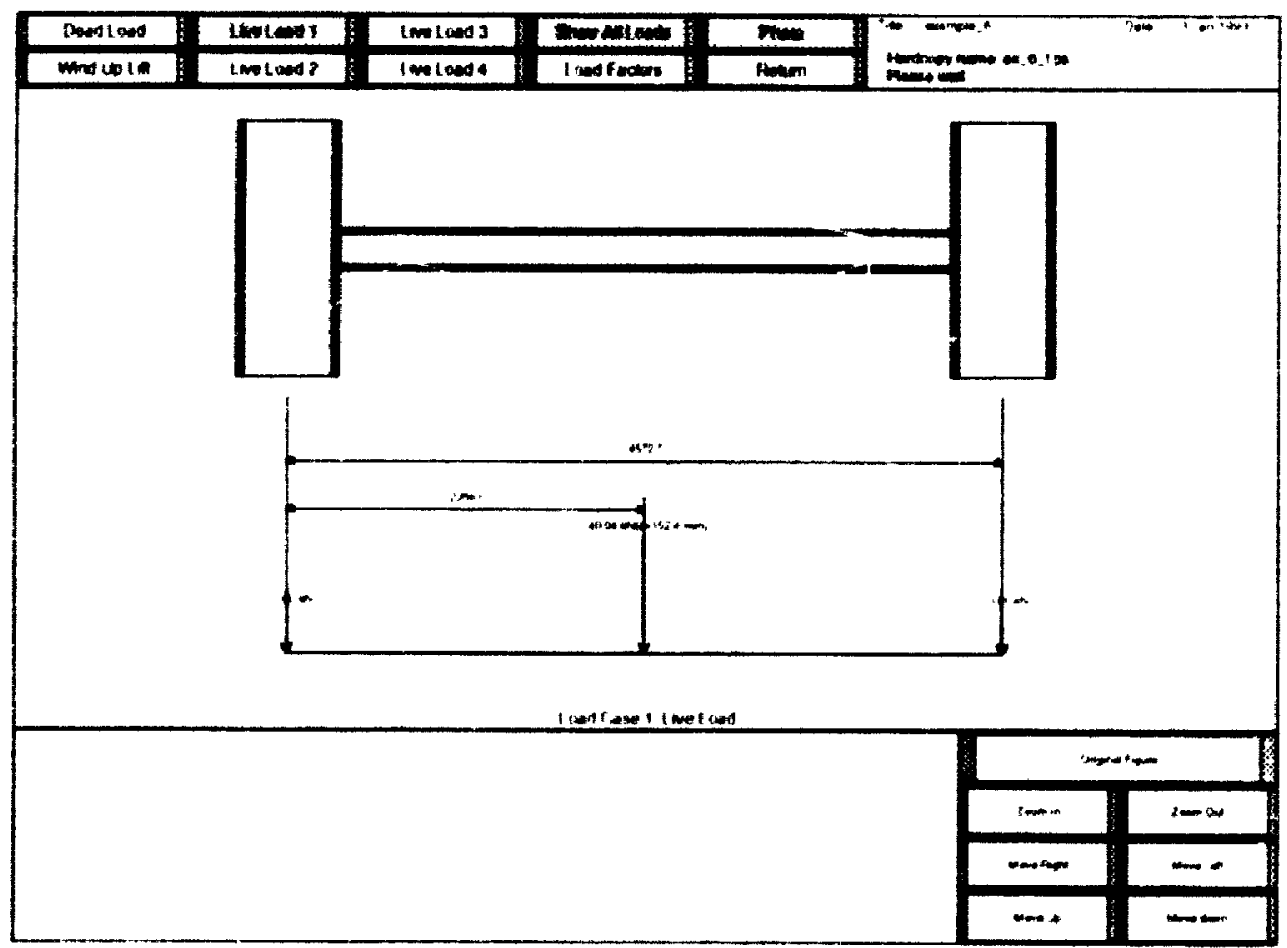

Figure 7.33 : Loads and geometry: ('ombined bending and torsion 
Solution: The torque diagram and the corresponding design results are shown in Figure 7.34 and 7.35 , respectively.

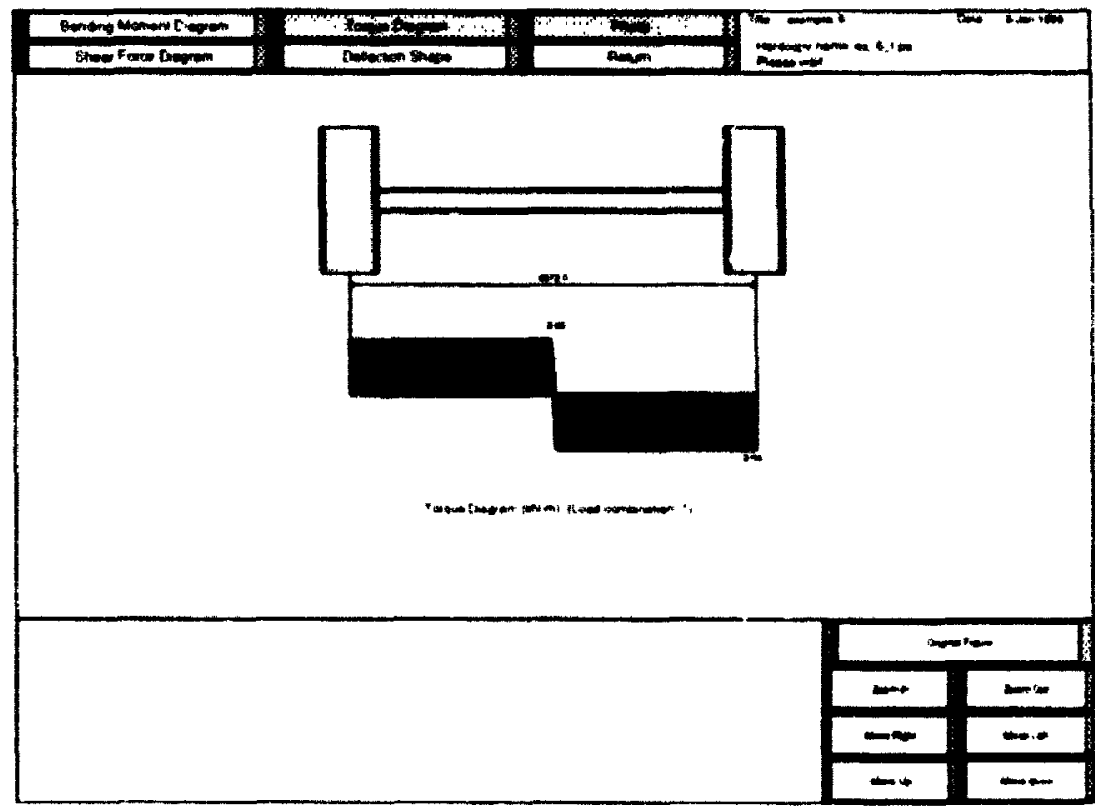

Figure 7.34: Torque diagram

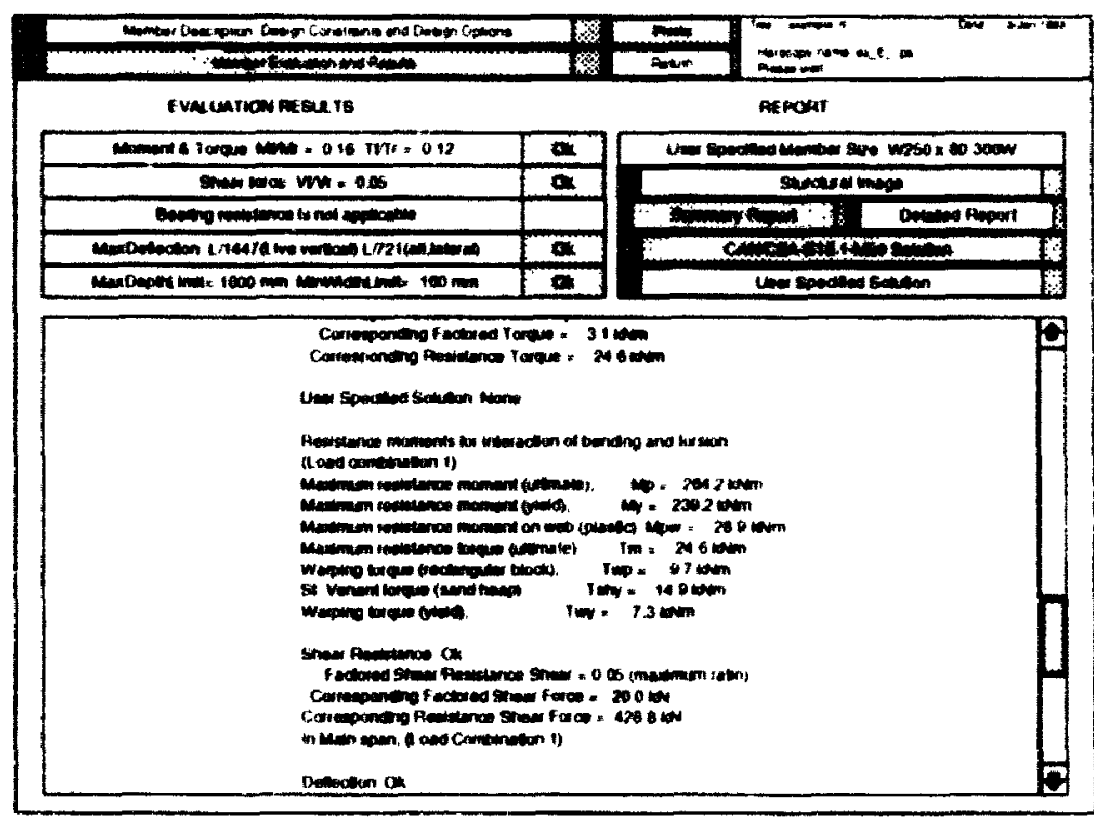

Figure 7.35: Design results: Combined bending and torsion 


\section{Discussion:}

The indices for moment torque diagram, calculated by IDFSM and given in Figure 7.35 , are sisown non-dimensionally in Figure 7.36 . The ultimate limit st ate and serviceability limit state curves are given by curves EHCF and KL, respectively. Point $P$ represents the maximum combination of torque and bending moment which occurs at midspan. The torque is directly proportional to the bending moment. The intersection of the line through $P$ and the origin, and the serviceability limit state curve Kl, represents the maximum combination of torque and moment that cam be applied to the beam (58\% of the beams capacity is being utilized). This corresponding to the AISC (1983) evaluation where the maximum combined normal stress due to bending and warping is limited to $F_{y}$. For this case, the rombined normal st ress was calculated to be $21.4 \mathrm{ksi}$. approximately $19 \%$ of the yield st ress.

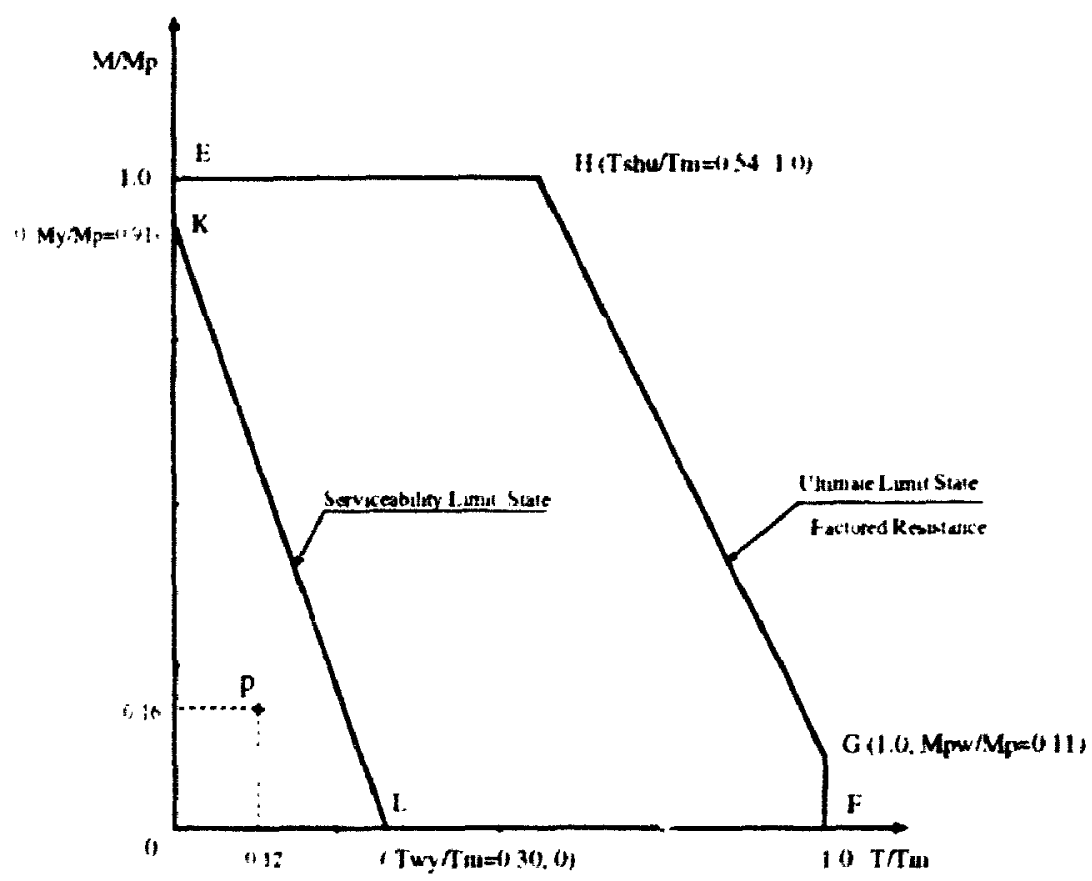

Higne 7.36: Moment-torque diagram for class I sextions 


\subsection{Laterally Unsupported Beam with Combined Bending and Torsional Load of Different Pat- terns}

Structure Type: Simply supported beam (laterally unsupported)

Problem Definition: Automatic design of a beam. $4000 \mathrm{~mm}$ long, connected to columns at either end by standard web angle connections. and subjected to a factored concentrated load and an uniformly distributed load. as shown in Figure 7.37 . The steel grade was specified as G40.21-M87 Grade $300 \mathrm{~W}$ steel.

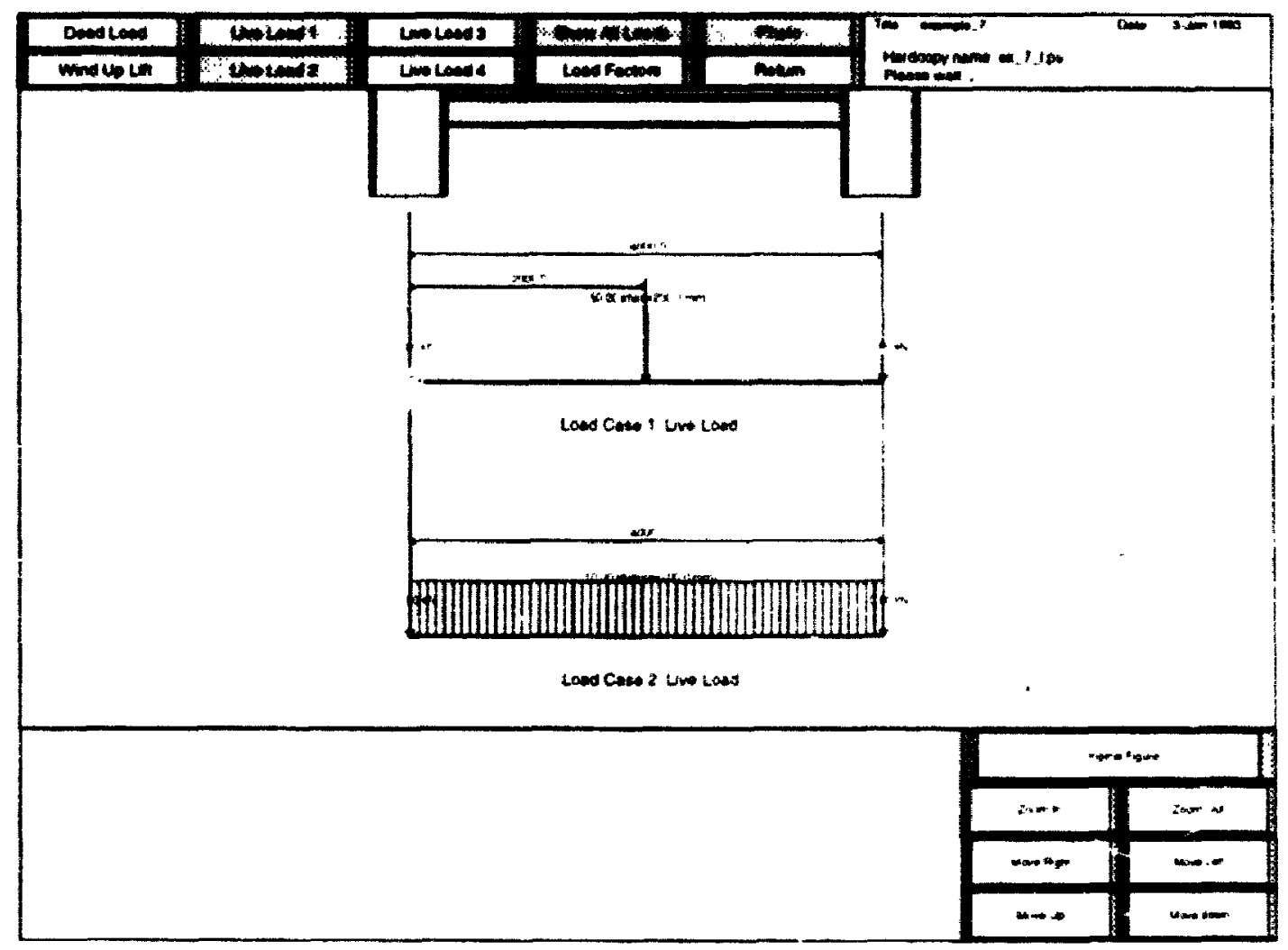

Figure 7.37 : Load and geometry: Combined bending and torsion with different load patterns 
Solution: The torque diagrams for each load case and the combination (superimposed) are shown in Figure 7.38 . The corresponding design results are shown in Figure 7.39.

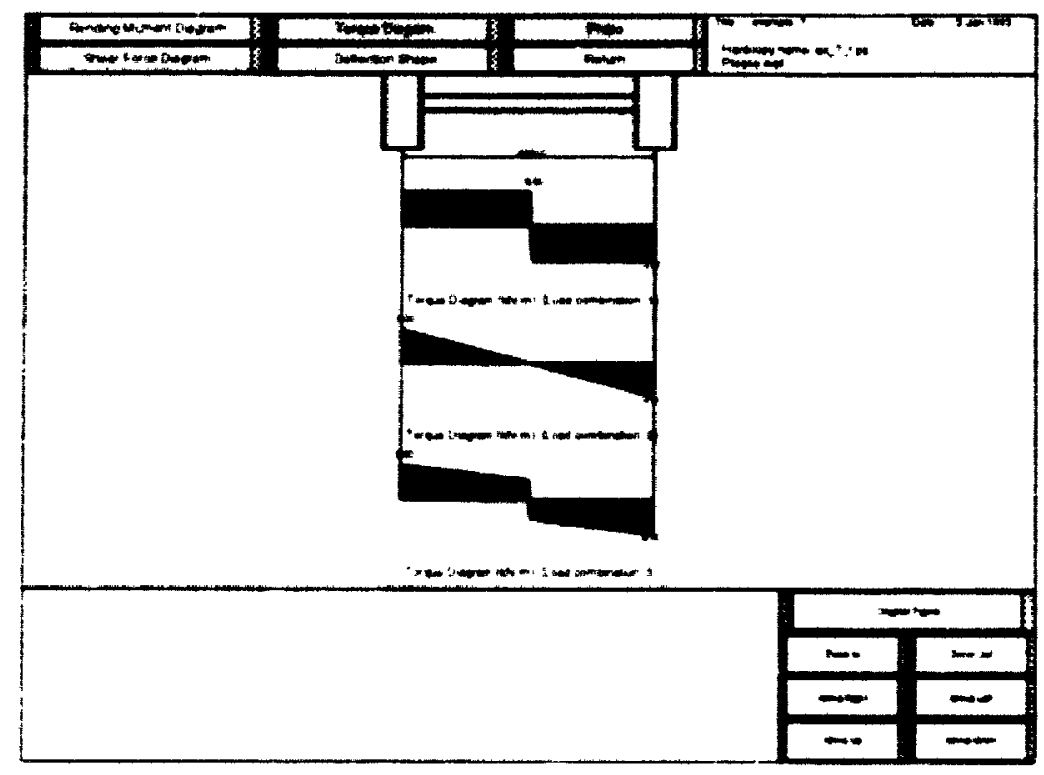

Figure 7.38: Torque diagrams

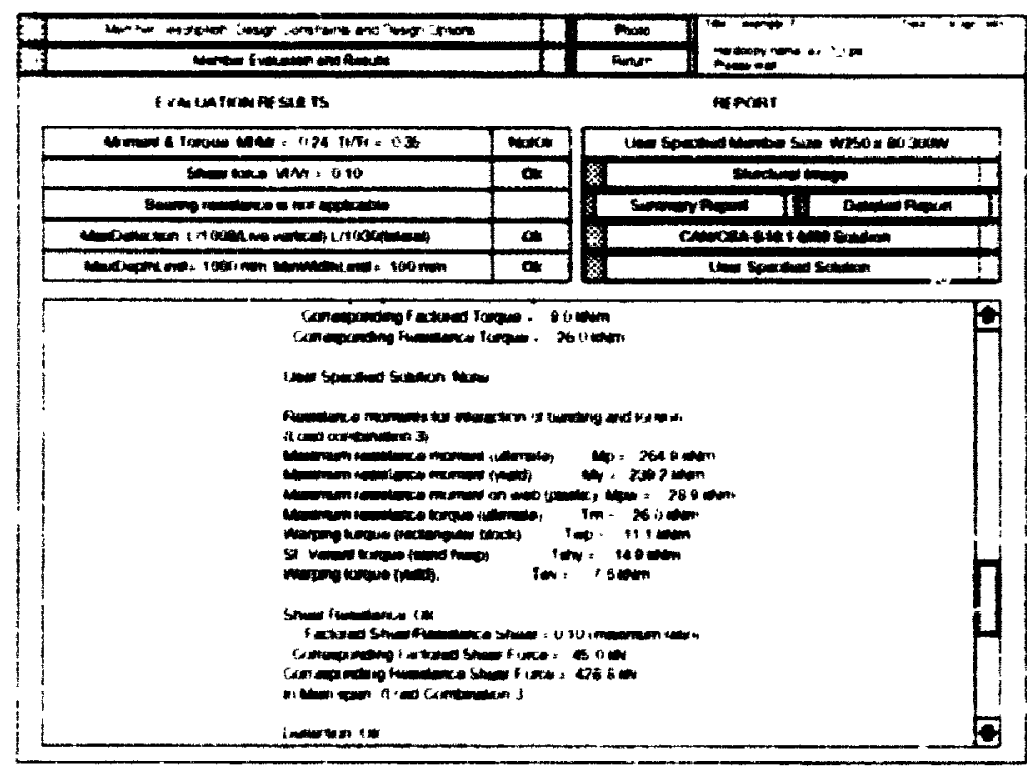

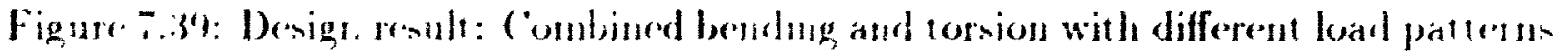




\section{Discussion:}

The modified strategy for constructing the moment-torque diagram described in Chapter 4 for beams subjected to more than one torsional load pattern was userd to determine the indices (critical moments and torques) given in Figure 7.39 . As indicated for the W250x80 section specified, the moment/torque capacity was "Not $\mathrm{Ok}$ " even thrugh the ratio"s of $\mathrm{M}_{\mathrm{f}} / \mathrm{M}_{\mathrm{r}}$ and $\mathrm{T}_{\mathrm{r}} / \mathrm{T}_{\mathrm{r}} \mathrm{of} 0.21$ and 0.35 are less than one. An examination of the torcion part of the detailed report. reproduced below. shows that the serviceability imit state (S.L.S) has been exceeded at either end of the member. Note. comparisors of moment and torque values with limit state design criteria were made at 100 rqually spaced locations along

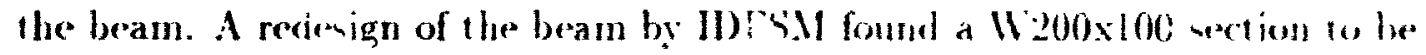
satisfactory.

\begin{tabular}{|c|c|c|c|}
\hline Fontet & $\begin{array}{l}\text { Bending Morreni } \\
\text { q } \mathrm{kN}-\mathrm{m} \text { t }\end{array}$ & $\begin{array}{c}\text { Ela-u Tofque } \\
\text { (kN-n!) }\end{array}$ & Limut -tate Exrecten \\
\hline 1 & 000 & son & $\cdot \mathbf{L} s$ \\
\hline 2 & 179 & R: & -1.5 \\
\hline 3 & $7 \%$ & nat & SL \\
\hline 1 & 5.4 & e it & $\therefore L:$ \\
\hline s & $70 \%$ & a $E R$ & $\therefore \mathbf{L}=$ \\
\hline 6 & 10 & A. 2.0 & $\pm:$ \\
\hline- & $10: 1$ & 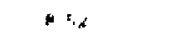 & $-:$ \\
\hline 8 & 1221 & 14 & -1 \\
\hline 3 & $13 \mathrm{~kg}$ & p is & $\because:$ \\
\hline 10 & $10: 5$ & $N=$ & $+;$ \\
\hline 11 & 1520 & 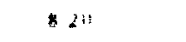 & 1 \\
\hline $1 \%$ & $\ln x$ & 12 & $=1$ \\
\hline $2:$ & 104 & B.4 & $\cdot i=$ \\
\hline 14 & 220 & $=\because+6$ & $i$ \\
\hline 15 & $2+1$. & $=2 \pi$ & $\cdot 6 x^{2}$ \\
\hline $1 t$ & 2520 & $-m$ & $=1$. \\
\hline 17 & $2 t=s_{2}$ & $\cdots$ & -1 \\
\hline $1 n$ & 2024 & i 64 & $=1-$ \\
\hline 19 & 2981 & $: 26$ & $\because 1:$ \\
\hline 40 & 31 & $\$ 4 k$ & $-:$ \\
\hline 21 & $22 n 0$ & $=10$ & \\
\hline $2 z$ & $4 z^{4}$ & -12 & . \\
\hline$s$ & as - & $\therefore$ & \\
\hline 24 & 1717 & $: 11$ &.- \\
\hline$\therefore$ & $18 \cdot t$ & $-n g$ & - \\
\hline 26 & 400 & $=i$ & \\
\hline 27 & $113 x_{0}$ & (. 32 & . \\
\hline
\end{tabular}



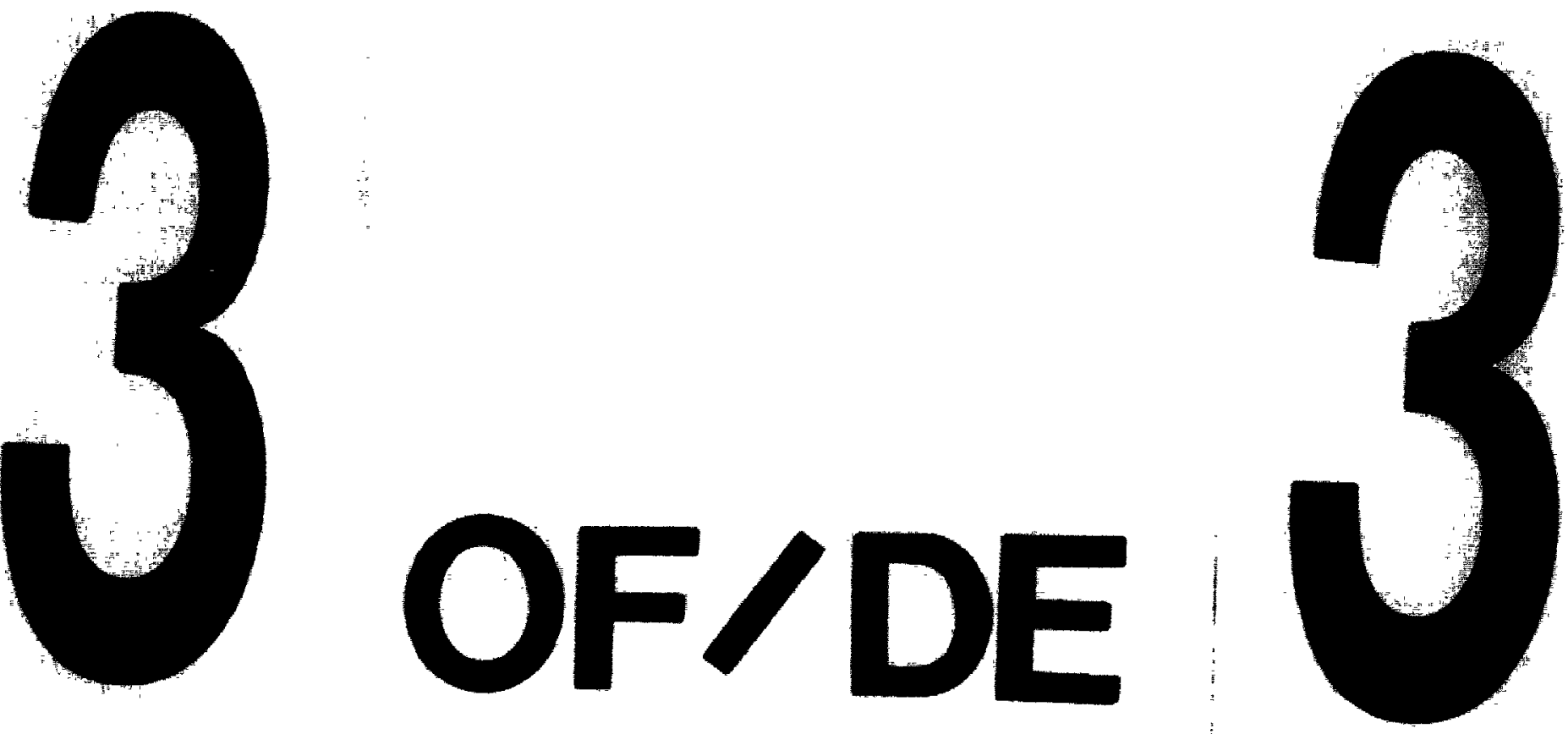

PM-1 3'2" 64 " PHOTOGAAPIC MICROCOPY TARGET NES 10t0a AWSIISO 2 EOUNALENT

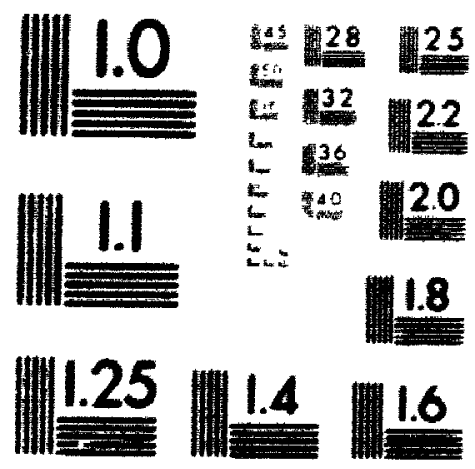




\begin{tabular}{|c|c|c|c|}
\hline 28 & 1277 & 684 & - \\
\hline 20 & 44.13 & 6.76 & $\cdots$ \\
\hline 30 & 45.47 & 668 & - \\
\hline 31 & 1680 & 6.60 & - \\
\hline 32 & 48.11 & 6.32 & - \\
\hline 33 & 1911 & 641 & - \\
\hline 34 & 30.69 & 6.36 & $\cdots$ \\
\hline 3s & 31.90 & $6.2 \%$ & - \\
\hline 36 & 33.20 & 620 & 一. \\
\hline 37 & 56.43 & 6.12 & $\cdots$ \\
\hline 38 & 5565 & 604 & - \\
\hline 39 & 36.85 & 596 & - \\
\hline 40 & 5003 & 5.58 & - \\
\hline 41 & 5920 & 5.80 & - \\
\hline 12 & 60.3 & 3.72 & - \\
\hline 43 & 61.49 & 561 & - \\
\hline 44 & 6261 & 536 & $\cdots$ \\
\hline 4 & 63.71 & 5.46 & $\cdots$ \\
\hline 4 & $6+80$ & 540 & $\ldots$ \\
\hline 47 & CS E⿱ & 532 & $\cdots$ \\
\hline 48 & 66.93 & 3.28 & - \\
\hline 9 & 6797 & 516 & - \\
\hline 30 & 68.59 & 500 & $\rightarrow$ \\
\hline 31 & 7000 & $=00$ & $\cdots$ \\
\hline 32 & 609 & 300 & $\ldots$ \\
\hline$\$ 3$ & 67.97 & 316 & - \\
\hline 34 & 6693 & 524 & - \\
\hline 53 & 65,67 & 3.32 & $\cdots$ \\
\hline 56 & 64.80 & 540 & - \\
\hline 37 & 6371 & 548 & $\cdots$ \\
\hline 38 & 0263 & 5.36 & $-\cdots$ \\
\hline$\therefore 3$ & 6149 & $3 \in 4$ & - \\
\hline so & $60.3 \pm$ & 572 & $\cdots$ \\
\hline 61 & 59.20 & 5,80 & 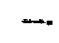 \\
\hline 62 & sk.OA & 5.88 & $\cdots$ \\
\hline 43 & 36.85 & 596 & - \\
\hline 64 & 5565 & 6.04 & - \\
\hline 63 & 540 & 612 & $\cdots$ \\
\hline 66 & 5320 & 6.20 & $\cdots$ \\
\hline 67 & 3195 & 638 & - \\
\hline 68 & 5069 & 6.36 & - \\
\hline 62 & 1941 & 6.44 & $\cdots$ \\
\hline 70 & 1811 & 652 & - \\
\hline 71 & $16 \mathrm{no}^{\circ}$ & 6.00 &.- \\
\hline 72 & 4547 & 665 & $\cdots$ \\
\hline 73 & 1413 & $C 7 t$ & - \\
\hline 74 & 6277 & 684 & $\cdots$ \\
\hline is & 6139 & 692 & - \\
\hline 76 & 40.00 & 700 & - \\
\hline 73 & $38: 9$ & 70 & $\cdots$ \\
\hline 78 & 3717 & 736 & $\cdots$ \\
\hline 78 & 36.73 & 724 & $\cdots$ \\
\hline 80 & 3427 & 732 & $\cdots$ \\
\hline (1) & 32.00 & 700 & - \\
\hline ह2 & 3131 & 74 & SL S \\
\hline
\end{tabular}




\begin{tabular}{|c|c|c|c|}
\hline$* 3$ & $29 \mathrm{Al}$ & 7.56 & $\$ \mathrm{LS}$ \\
\hline 84 & 26.29 & 764 & 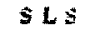 \\
\hline $5 s$ & 26.75 & 772 & S.L.S \\
\hline 66 & 2520 & 760 & $3 L S$ \\
\hline 87 & 23.63 & 7.86 & S L $\mathbf{s}$. \\
\hline A & 2205 & 796 & 3.L 3 \\
\hline 69 & 2045 & 04 & S.LS \\
\hline 90 & 1083 & 12 & $\mathbf{S L S}$ \\
\hline 91 & 1720 & $* 20$ & s.z.s \\
\hline 92 & $185 s$ & 628 & SLS. \\
\hline 93 & 1349 & 636 & si. \\
\hline 94 & 1221 & et4 & 35 \\
\hline 95 & 10.31 & 132 & $\mathbf{P L S}$ \\
\hline 26 & 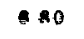 & 860 & $\$ \mathrm{Ls}$ \\
\hline 97 & 707 & ete & $\$ \mathbf{L} 、$ \\
\hline 9 & 53 & $A 76$ & $S L S$ \\
\hline 92 & .57 & 194 & $3<5$ \\
\hline 104 & 179 & 02 & $5 L \mathbf{s}$ \\
\hline 101 & 000 & 900 & 515 \\
\hline
\end{tabular}

\subsection{Combined Bending and Torsional Loading within a Laterally Unsupported Segment}

Structure Type: Simply supported beam (three laterally unsupported segments)

Problem Definition: Automatic design of a beam with discrete lateral supports (same geometry and in-plane loads as the example given in section 7.3) and with a torsional loads of $10.0 \mathrm{kNm}$ applied within one of the laterally unsupported segments as shown in Figure 7.40. The steel grade was specified as G40.21-M87 Grade $300 \mathrm{~W}$ steel.

Solution: The torque diagram and the corresponding design results are shown in Figures 7.41 and 7.42 , respectively. 


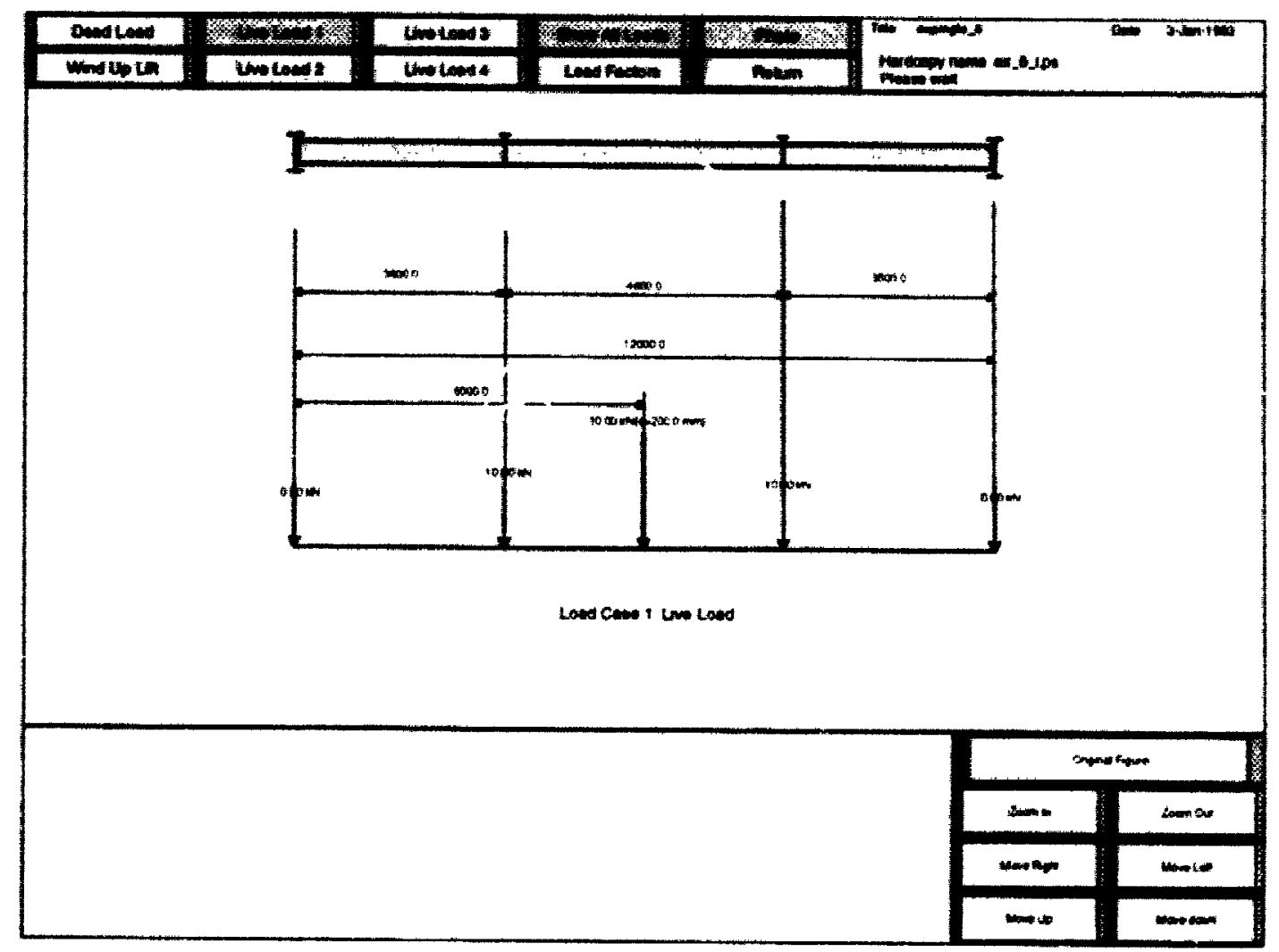

Figure 7.40: Loads and geometry: Combined bending and torsion on a laterally unsupported segments 


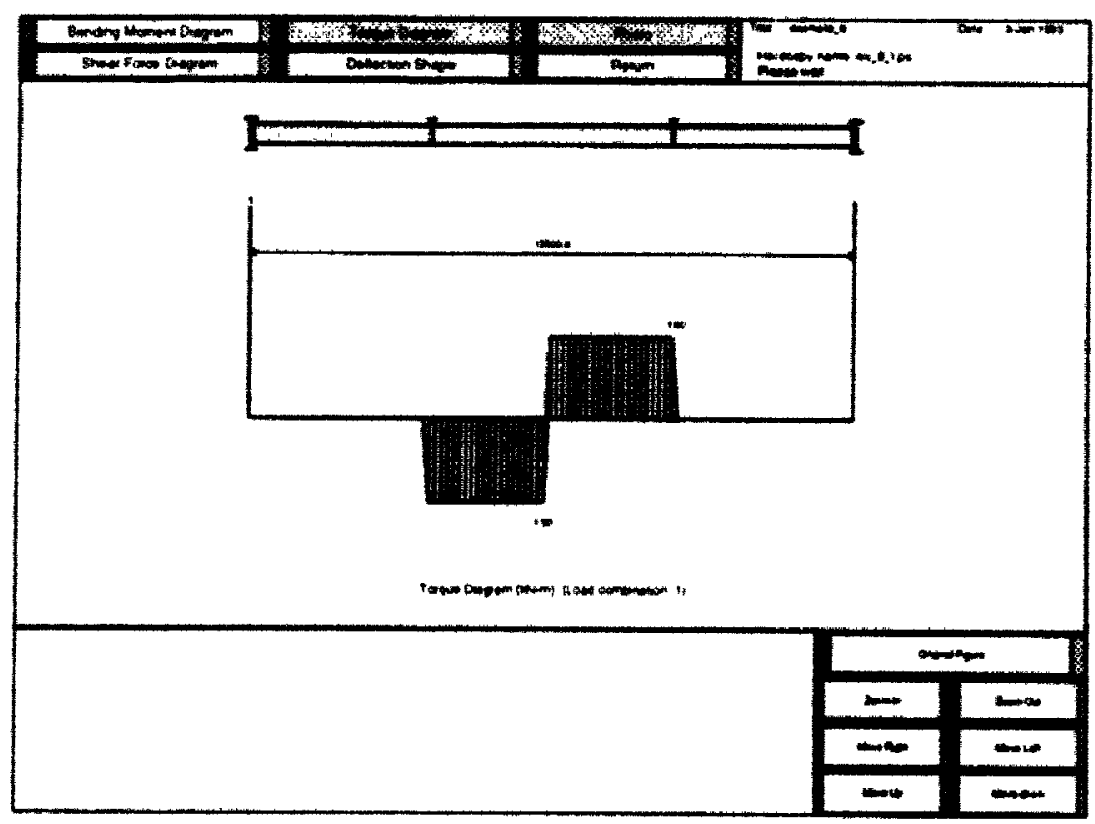

Figure 7.41: 'Torque diagram

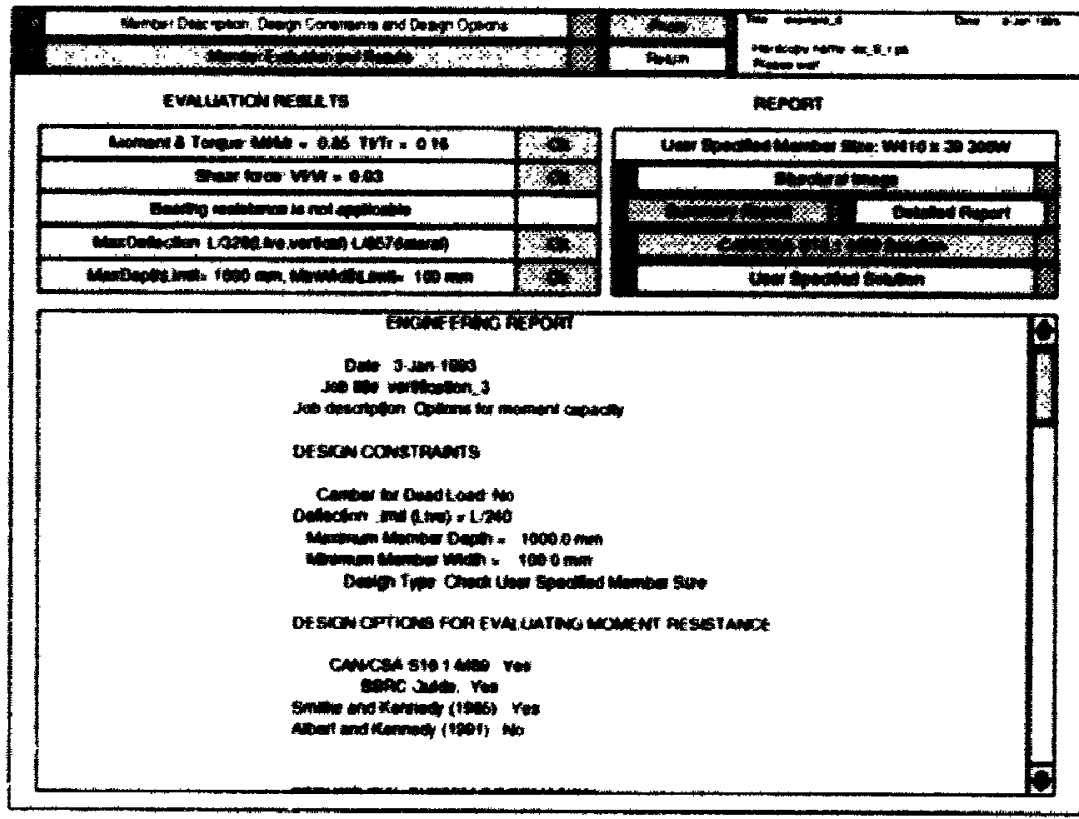

Figure 7.42: Design result: Combined bending and torsion on a laterally unsupported segment 


\section{Discussion:}

The program IDFSM assumes that the reaction to the applied torque is taken out by the flexural capacity of the lateral supports. This is illustrated in Figure 7.41 by the zero torque values in the segments adjacent to the torsionally loaded segment. The maximum moment for the moment torque interaction diagram is defined by the interactive buckling capacity of the beam. All other applicable limit states design checks are made and are given in the engineering reports. 


\section{Chapter 8}

\section{CONCLUSIONS, \\ RECOMMENDATIONS AND FUTURE WORK}

\subsection{Conclusions}

The program IDFSM - "Interactive Design of Flexural Steel Members for Bending and Torsion", provides engineers with a comprehensive and practical tool for designing and evaluating the capacity of beams subjected to bending and/or torsion. It provides for comprehensive descriptions of the structural system and loads without labourious cryptic input. The graphics-oriented user interface has been designed for the anaiysis/design process and does not require a manual for use. Positive visual responses are given for any action.

As an engineering design software which handles a large variety of problems ranging from the trivial to complex, IDFSM makes extensive use of current and ongoing 
research for problems that are not handled by CAN/CSA-S16.1-M89 directly, but a reference to as rational methods of analysis and design.

\subsection{Recommendations and Future Work}

The modular format and separation of program code for the engineering analysis/design and user interface modules make the adaptation, expansion, revision and integration of IDFSM relatively easy. Generally, the following recommendations refer to expansion of the capabilities of the program, some of which are in progress.

- Extend the program to include shapes other than W and WWF shapes, like Angles, Channels, Tee's, S-shapes and Z-shapes. The primary reasons why these singly symmetric and non-symmetric shapes have not been included are:

1. The latcral-torsional buckling behaviour is not well understood and,

2. There is not a limit states design approach for combined bending and torsion. This could be addressed using the same approach as described in AISC (1983), where the combined maximum stresses due to bending and torsion is limited to the yield stresses. These routines already exist for Channels and Z-shapes in TORSTEEL.

- Add continuous beams (i.e. crane girders) as another flexural system. The additional work would involve some modifications to the user interface and minor changes with respect to the organization of design routines to evaluate multispans.

- Add modules for the analysis/design of decks, composite decks and beams, stub girder systems, plate girders and OWSJ's. With each flexural member 
type additional specialized user interface and design modules would have to be developed.

- Implement the Albert \& Kennedy (1991) finite element module for evaluation of the lateral-torsional buckling capacity of beams. This method is considered to give the best possible solutions to beam stability problems and has already been incorporated into the user interface portion of IDFSM.

- Porting the program IDFSM to PC applications.

- Integration of IDFSM with other member and connection design modules for the integrated design program for steel buildings. The complete integrated program will evolve over a period of time as more modules are developed. Currently, the program would be integrated with an existing module SCADD, "Steel Connection, Analysis. Design and Detailing”, to design the connection from the beam to the supporting members. This would eliminate the need to define the soping dimensions as they are determined within SCADD and end reactions as they are determined with IDFSM. The integration of these two modules would be relatively simple as both programs have similar data structures.

The next evolutionary step in the integration process would be the integration of IDFSM with a good 3D frame analysis program such as CU-STAND, Cornell University (1989). This would allow for the development of file structures and user interfaces for the design of a large number of beams. Additional algorithm would be developed to determine the optimum number of beam sections selected and their sizes for a building. 


\section{Chapter 9}

\section{REFERENCES}

- AISC 1983. Torsional Analysis of Steel Members. Chicago, IL, U.S.A. American Institute of Steel Construction.

- Albert C., Essa H.S. and Kennedy D.J.L. 1991. Stability of Steel Beams in Cantilever-Suspended Span Construction. Department of Civil Engineering, University of Alberta, Edmonton, Alberta.

- Albert C. and Kennedy D.J.L. 1991. Inelastic Distortional Buckling of Beams, Finite Element Program. Department of Civil Engineering. University of Alberta, Edmonton, Alberta.

- Anumba, C.J. and A.S. Watson A.S. 1992. An innovative appproach towards designer-oriented CAD systems. The Structural Engineer, 70(9): 165-168.

- Brohn D.M. 1992. A new paradigm for structural engineering. The Structural Engineer, 70(13): 239-240.

- Cheng, J.J.R. 1992. Design of Steel beams With End Copes. Department of Civil Engineering, University of Alberta, Edmonton, Alberta. 
- Cheng, J.J.R., Yura, J.A., and Johnson, C.P. 1984. Design and Behaviour of Coped Beams. Department of Civil Engineering, The University of Texas at Austin, PMFSEL Report No. 84-1.

- Chu, K., and Johnson, R.B. 1974. Torsion in beams with open sections. ASCE Journal of the Structural Division, 100(ST7): 1397-1419.

- CISC. 1989. Roof framing with cantilever (Gerber) girders \& open web steel joists. Canadian Institute of Steel Construction, Willowdale, Ont.

- CISC. 1991. Handbook of Steel Construction (5th ed.). Canadian Institute of Steel Construction, Willowdale, Ont.

- Cornell University, 1989. Programmer's manual for CU-PREPF, CU-STAND, and CU-QUAND. Cornell University, Ithaca, New York, U.S.A.

- CSA. 1989. Steel Structures for Buildings (Limit States Design), National Standard of Canada, CAN/CSA-S16.1-M89. Canadian Standards Association, Rexdale, Ont.

- CSA. 1987. Structural Quality Steels. National Standard of Canada, CAS/CAN G40.21-M87. Canadian Standards Association, Rexdale, Ont.

- Driver, R.J., and Kennedy, D.J.L. 1987. Combined flexure and torsion of Ishaped steel beams. Structural Engineering Report 144, Department of Civil Engineering, University of Alberta, Edmonton, Alberta.

- Driver, R.J., and Kennedy, D.J.L. 1989. Combined flexure and torsion of Ishaped steel beams. Canadian Journal of Civil Engineering, 16(2): 124-139.

- Duchesne D.P.J. and Thomson S. 1992. State of the art in Civil Engineering program integration. Proceedings of the Second Canadian Conference on 
Computing in Civil Engineering.

- Duchesne, D.P.J. and Humar, J.L. 1991. Engineering Software - A Sturctural Consultant's Perspective. Canadian Journal of Civil Engineering. 18: 303-311.

- ECOM Associates, 1991. SD4C Steel Beam/Column Design. ECOM Associates, Milwaukee, Wisconsin, U.S.A.

- Essa H.S.and Kennedy, D.J.L. 1992. Design of cantilever beams against lateraltorsional buckling. Department of Civil Engineering, University of Alberta, Edmonton, Alberta.

- Galambos, T.V. 1988. Guide to Stability Design Criteria for Metal Structures (4th ed.). Structural Stability Research Council, John Wiley \& Sons, Inc., New York, NY.

- CISC 1992. Gravity Frame Design 3, User's Guide and Technical Reference Manual. Canadian Institute of Steel Construction, Willowdale, Ontario.

- Johnston, B.F. 1976. Guide to Stability Design Criteria for Metal Structures (3rd ed.). Structural Stability Research Council,John Wiley \& Sons, Inc., New York, NY.

- Kollbrunner, C.F., and Basler, K. 1969. Torsion in Structures (2nd ed.). SpringerVerlang, Berlin.

- Kollbrunner, C.F., Hajdin, N., and Obradović, P. 1979. Elastic-plastic fixed ended beam of I-section subjected to bending and warping torsion. Institut iür Bauwissenschaftliche Forschung Publikations, No. 46, May, p. 1-40.

- Kulak, G.L., Adams, P.F., and Gilmor, M. I. 1990. Limit States Design in Structural Steel. Canadian Institute of Steel Construction, Willowdale, Ont. 
- McGuire W. 1992. Computers and Steel Design. Modern Steel Cosntruction. July, 1992. p.39-42.

- Murray D.W. 1988. Program for Plane Frame Analysis. University of Alberta.

- NRC, 1988. National Building Code of Canada. National Research Council of Canada, Ottawa, Ontario.

- Nethercot D.A., and Trahair, N.S. 1983. Design of laterally unsupported beams. Chapter 3, Ed. Narayanan, R. Beams and Beam-Columns-Stability and Strength. Applied Science Publishers, Barking, Essex, England,

- Nethercot, D.A. 1983. Elastic lateral buckling of beams. Chapter 1, Ed. Narayanan, R. Beams and Beam-Columns-Stability and Strength. Applied Science Publishers, Barking, Essex, England,

- Nethercot, D.A. 1979. Design for Structural Stability. Constrado Nomographs, Granada Publishing, London.

- Nethercot, D.A. 1973. The Effective Lengths of Cantilevers as Governed by Lateral Buckling. The Structural Engineer. 515:161-168.

- Ojalvo, M. 1975. Warping and Distortion at I-Section Joints Discussion. ASCE Journal of Structural Division. 103(ST1).

- Pastor, T.P., and DeWolf, J.T. 1979. Beams with torsional and flexural loads. RSCE Journal of the Structural Division. 105(ST3): 527-538.

- Razzaq, Z., and Galambos, T.V. 1979. Biaxial bending tests with or without torsion. ASCE Journal of the Structural Division, 105(ST11): 2163-2185.

- Rahimian, A. 1992. Engineering Software Company's Advanced Integrated Beam Design Program. Modern Steel Construction. May, 1992. p. 12-13. 
- Schmitke C.D. and Kennedy, D.J.L. 1985. Effective lengths of laterally continuous, laterally unsupported steel beams. Canadian Journal of Civil Engineering. 12:603-616.

- W.E.S.1992. Stuctural Optimization Design \&. Analysis (SODA), User Manual (Release 3.1). Waterloo Engineering Software, Waterloo, Ontario.

- Sourochnikoff, B. 1951. Strength of I-beams in combined bending and torsion. ASCE Transactions, 116: 1319-1342.

- Sun. 1991(a). Sun C++ Programmers Guide. Sun. Microsystems, Inc.

- Sun. 1991(b). Sun FORTRAN User's Guide. 1991. Sun. Microsystems, Inc.

- Timoshenko S.P., and Gere, J.M. 1961. Theory of elastic Stability. McGrawHill, New York.

- Trahair, N.S. 1983. Inelastic lateral buckling of beams. Chapter 3, Ed. Narayanan R. Beams and Beam-Columns-Stability and Strength. Applied Science Publishers, Barking, Essex, England.

- Yong, L.P., and Trahair, N.S. 1992. Prebuckling deflection and lateral buckling I, theory. Journal of Structural Engineering, 118(11):124-139. 

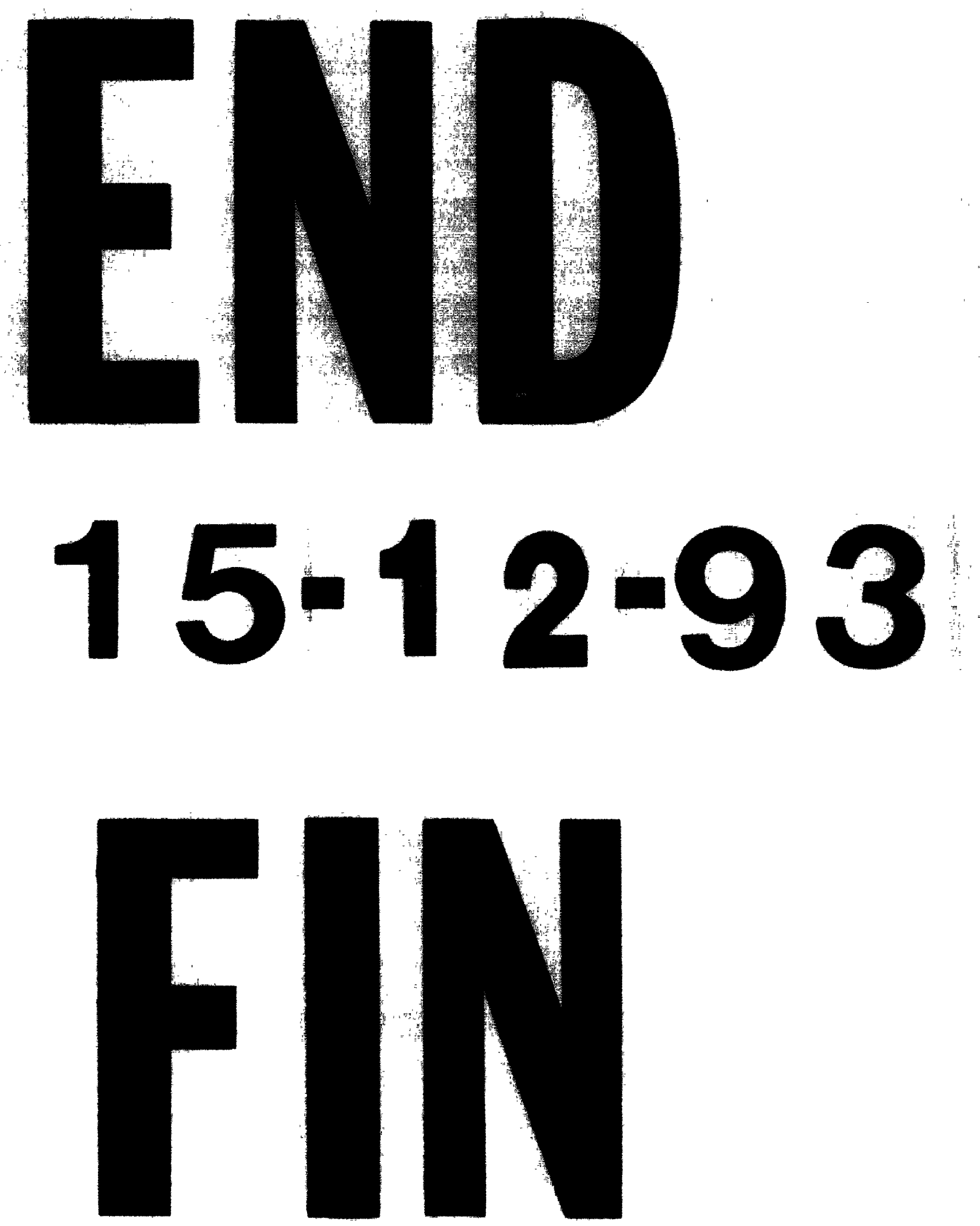